\title{
Development of a vehicle road load model for ECU broadcast power verification in on-road emissions testing
}

Nathan A. Moynahan

West Virginia University

Follow this and additional works at: https://researchrepository.wvu.edu/etd

\section{Recommended Citation}

Moynahan, Nathan A., "Development of a vehicle road load model for ECU broadcast power verification in on-road emissions testing" (2005). Graduate Theses, Dissertations, and Problem Reports. 1675.

https://researchrepository.wvu.edu/etd/1675

This Thesis is protected by copyright and/or related rights. It has been brought to you by the The Research Repository @ WVU with permission from the rights-holder(s). You are free to use this Thesis in any way that is permitted by the copyright and related rights legislation that applies to your use. For other uses you must obtain permission from the rights-holder(s) directly, unless additional rights are indicated by a Creative Commons license in the record and/ or on the work itself. This Thesis has been accepted for inclusion in WVU Graduate Theses, Dissertations, and Problem Reports collection by an authorized administrator of The Research Repository @ WVU. For more information, please contact researchrepository@mail.wvu.edu. 
Development of a Vehicle Road Load Model for ECU Broadcast Power Verification in On-Road Emissions Testing

\author{
Nathan A. Moynahan
}

Thesis submitted to

The College of Engineering and Mineral Resources

at West Virginia University

in partial fulfillment of the requirements

for the degree of

\author{
Master of Science \\ In \\ Mechanical Engineering \\ Gregory J. Thompson, Ph.D., Chair \\ Nigel Clark, Ph.D \\ Mridul Gautam, Ph.D
}

Department of Mechanical and Aerospace Engineering

Morgantown, West Virginia

2005

Keywords: Diesel Emissions, In-Use Emissions Testing, Mobile Measurement Techniques, Road Load, Vehicle Resistance 


\title{
Development of a Vehicle Road Load Model for ECU Broadcast Power Verification in On-Road Emissions Testing Nathan A. Moynahan
}

\begin{abstract}
West Virginia University (WVU) has become an industry leader in heavy-duty emissions testing and is continuously improving and updating their testing goals, procedures, and quality. As emissions testing is conducted at WVU in a real-world, onroad environment, engine parameter values are read through the test vehicle's electronic control unit (ECU) and recorded for use in data reductions. One significant value that is recorded by the WVU emissions measurement system is the ECU engine power output. Theses values are recorded and used to report vehicle's brake specific emissions values over a prescribed open-road test route. Because of the fact that the engine power output values reported by the vehicle's ECU are difficult to accurately measure elsewhere, they are assumed to be accurate and used in the data reduction process. This presented the need for a study to develop a model to validate the ECU power output data. The objective of this work was to develop such a model that accurately produces values for the test vehicle's road load while in use. By developing this model, the quality of the results of the on-road emissions testing performed by WVU could be monitored and confirmed.
\end{abstract}

By measuring three parameters of a vehicle test, this model was developed and produced accurate results. The three primary variables required by this study to verify the ECU power were the ECU vehicle speed, the ambient pressure, and the test time. These three values were measured and recorded using the WVU Mobile Emissions Measurement System (MEMS) and were used in determining the four main components that describe a vehicle's road load under real-world driving conditions. Although parameters such as driveline efficiency and interactions by the driver, such as brake applications, could not be accounted for in this study, the results that were determined matched the vehicle's ECU outputted power values accurately and were repeatable. Furthermore, the differences between the two different data sets considered provided an estimate for the test vehicles driveline efficiency and were found to be averaged at approximately $82 \%$. 


\section{Table of Contents}

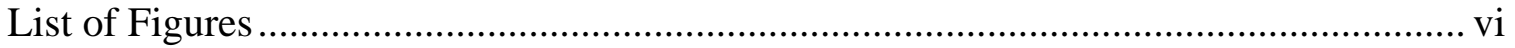

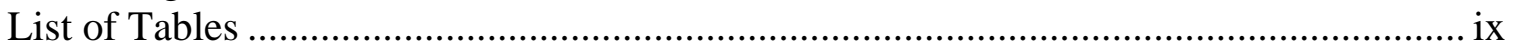

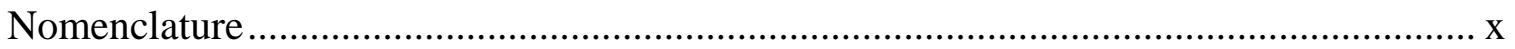

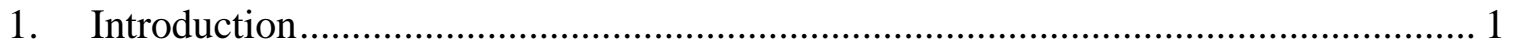

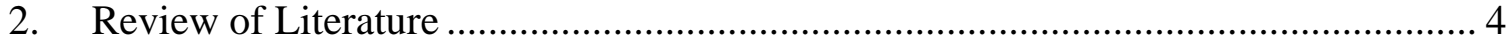

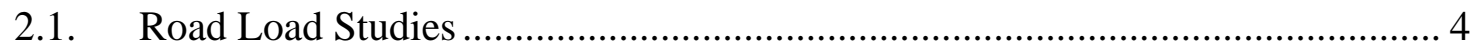

2.1.1. United States Environmental Protection Agency, 1977 ............................ 4

2.1.2. General Motors Corporation, 1978 ....................................................... 5

2.1.3. Toyota Motor Co., 1982 ................................................................... 5

2.1.4. Northrop Services Inc., U.S. Environmental Protection Agency, 1983 ..... 6

2.1.5. University of Saskatchewan, 1989............................................................. 7

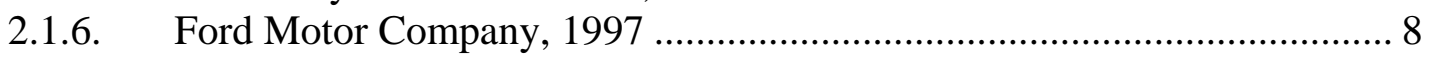

2.1.7. IVK/FKFS - University of Stuttgart, 2003............................................ 8

2.1.8. SAE J1708/1587 and J1939 Protocols ................................................. 8

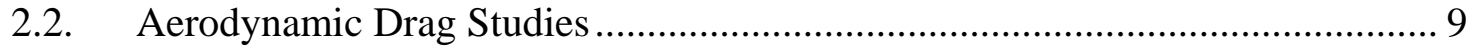

2.2.1. The Motor Industry Research Association, 1969 ...................................... 9

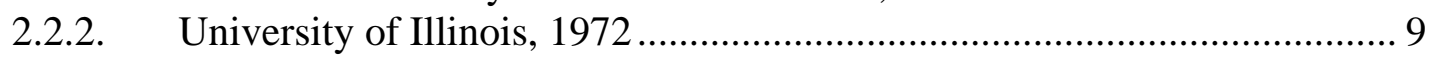

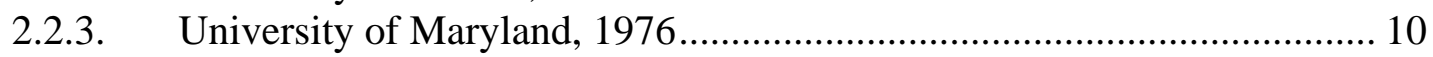

2.2.4. $\quad$ Rover Group Ltd. and Loughborough University, 1994.......................... 11

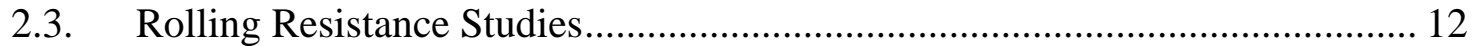

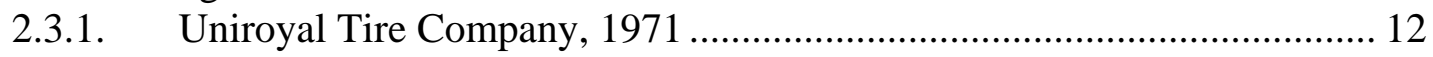

2.3.2. Goodyear Tire and Rubber Company, 1977 ........................................ 12

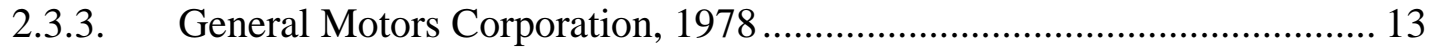

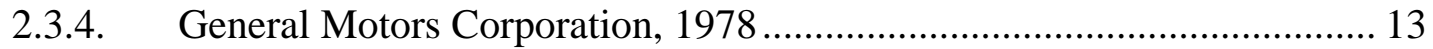

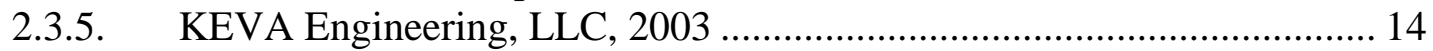

2.4. Climbing Resistance and Vehicle Speed Studies.......................................... 15

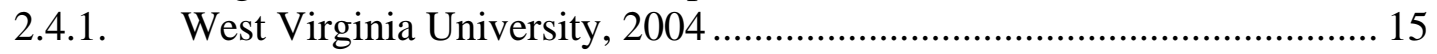

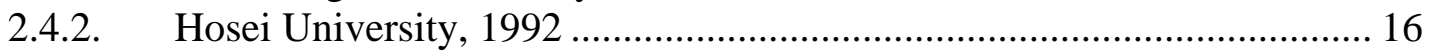

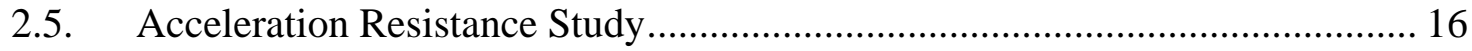

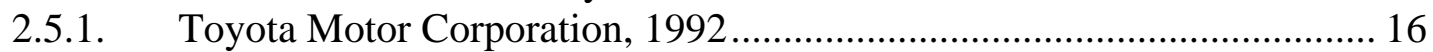

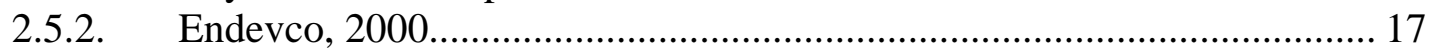

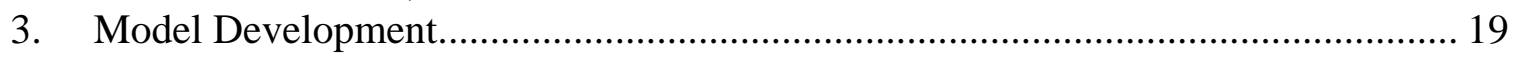

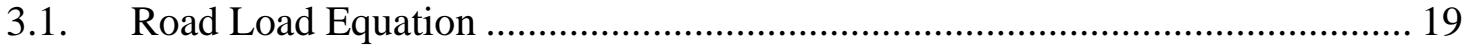

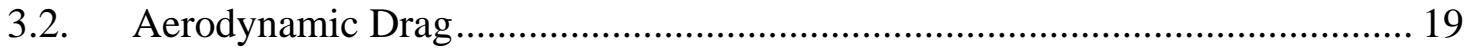

3.3. Rolling Resistance ................................................................................ 21

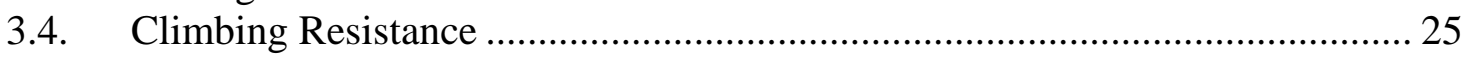

3.5. Acceleration Resistance .............................................................................. 26

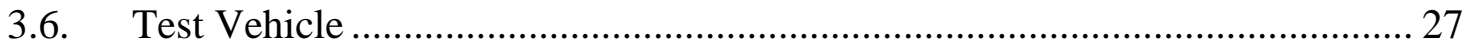

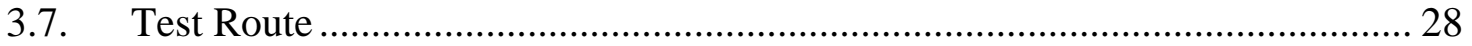

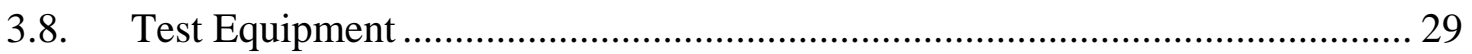

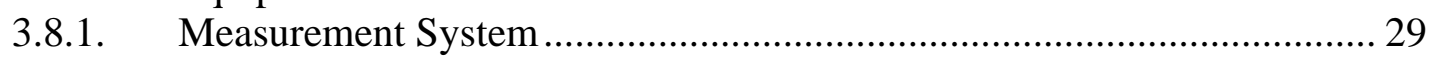

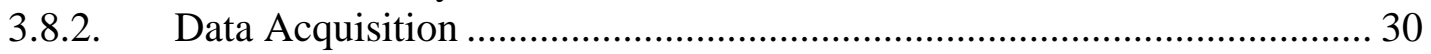

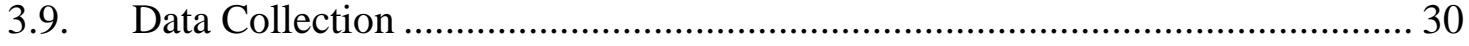

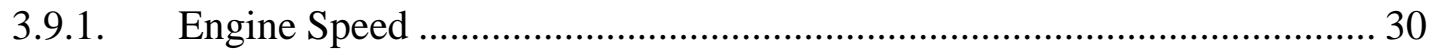


3.9.2. Ambient Pressure ................................................................................. 31

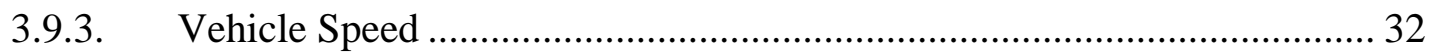

3.9.4. Inferred Torque and Power .................................................................... 33

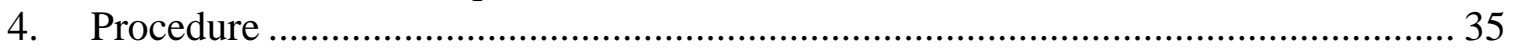

4.1. Ambient Pressure ..................................................................................... 35

4.2. ECU Vehicle Speed .............................................................................. 36

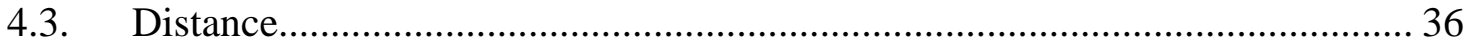

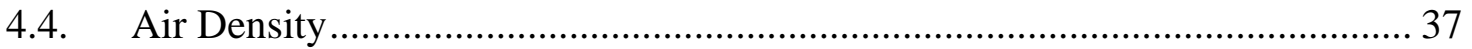

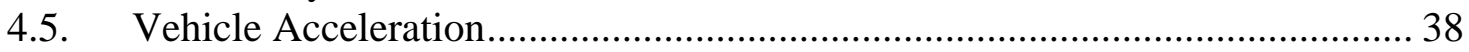

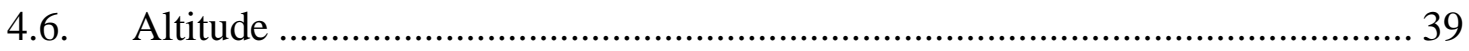

4.7. Road Inclination Angle .................................................................................... 40

4.7.1. Individual Test Inclination Angle Calculations ........................................... 40

4.7.2. Overall Test Inclination Angle Calculations................................................ 41

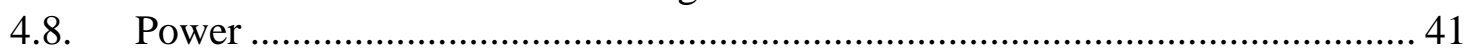

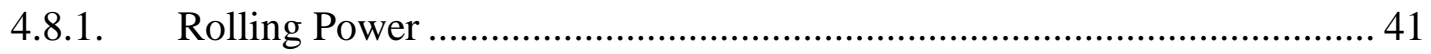

4.8.2. Climbing Power ............................................................................. 42

4.8.3. Acceleration Power................................................................................. 42

4.8.4. Aerodynamic Power............................................................................ 42

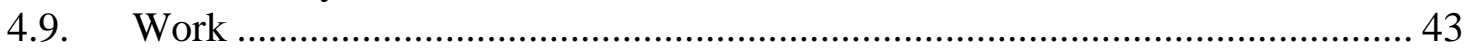

4.10. Uncertainty Analysis................................................................................ 43

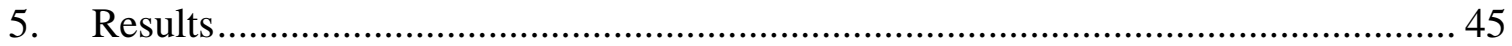

5.1. Ambient Pressure ........................................................................................... 45

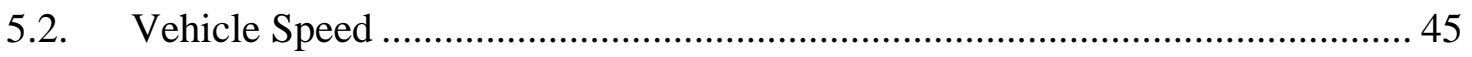

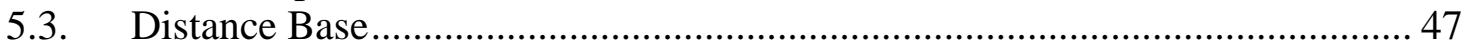

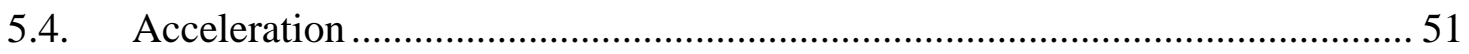

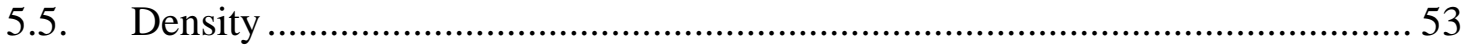

5.6. Altitude and Inclination Angles ..................................................................... 54

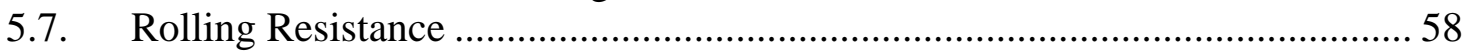

5.8. Climbing Resistance ....................................................................................... 59

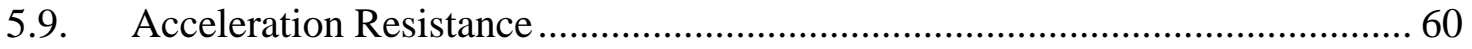

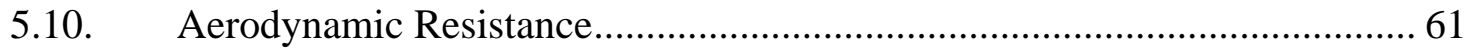

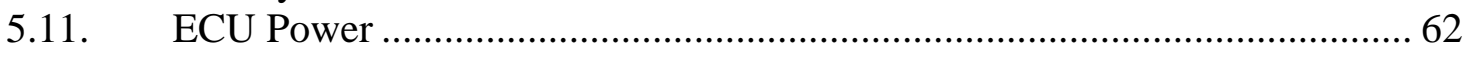

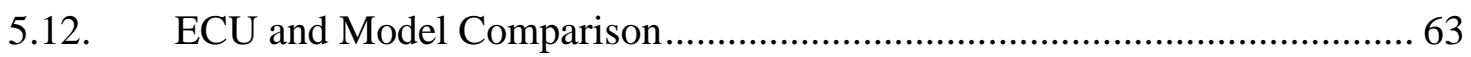

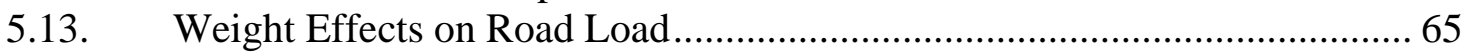

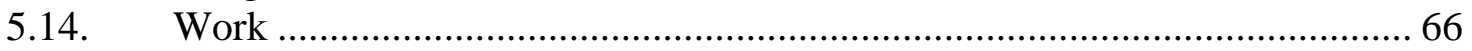

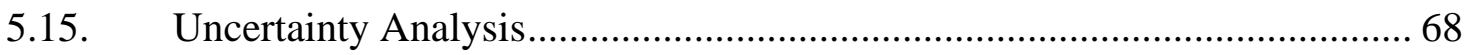

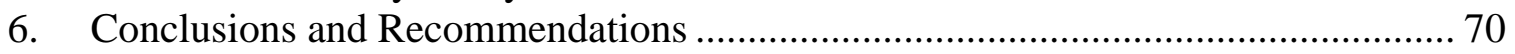

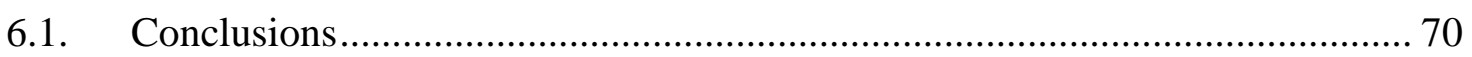

6.1.1. Integrated Work ................................................................................. 70

6.1.2. Efficiency ………………………………………………………..... 71

6.2. $\quad$ Future Studies and Experiments ……………................................................. 72

6.2.1. Ambient Pressure .................................................................................... 72

6.2.2. Inclination Angles ............................................................................... 72

6.2.3. Acceleration ...................................................................................... 72

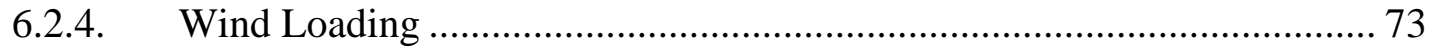

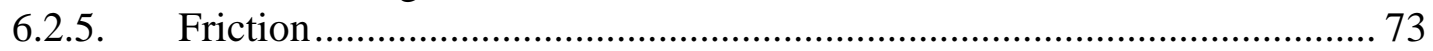




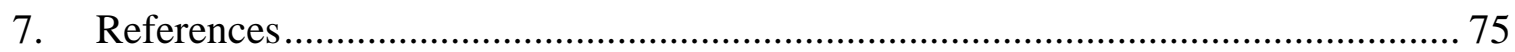

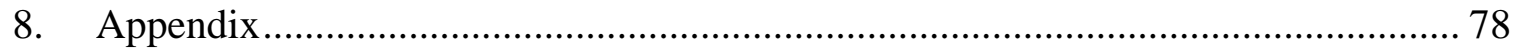

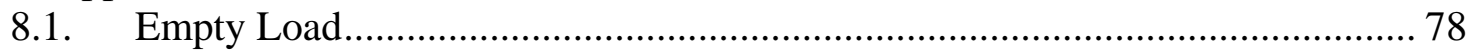

8.1.1. Test 1 / Empty Load.............................................................................. 78

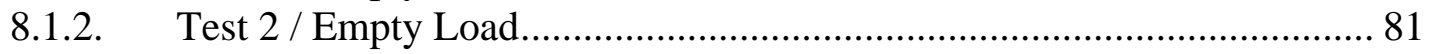

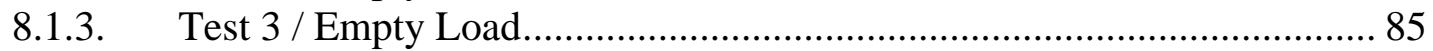

8.1.4. Test 4 / Empty Load............................................................................... 88

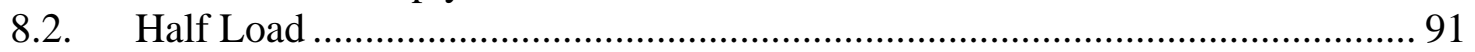

8.2.1. Test 1 / Half Load ................................................................................. 91

8.2.2. Test 2 / Half Load ............................................................................. 94

8.2.3. Test 3 / Half Load ................................................................................. 97

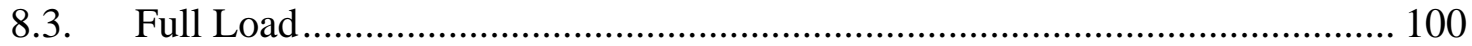

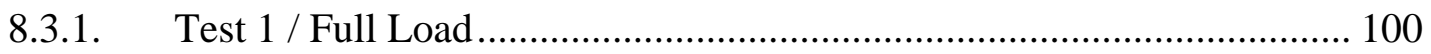

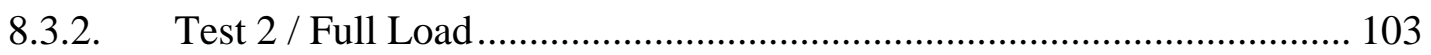

8.3.3. Test 3 / Full Load................................................................................... 106

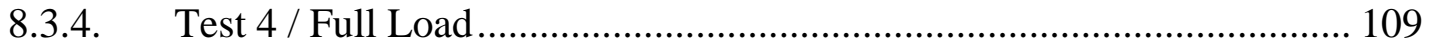

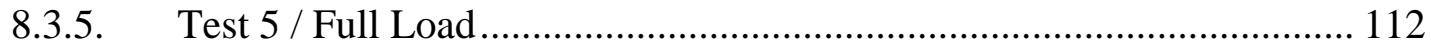

8.3.6. Test 6 / Full Load................................................................................. 115 


\section{List of Figures}

Figure 1: Tire Hysteresis and Adhesion Components of Tire Traction.......................... 24

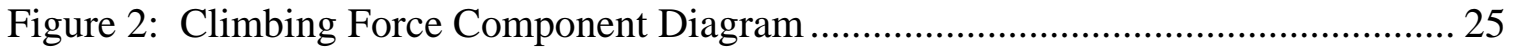

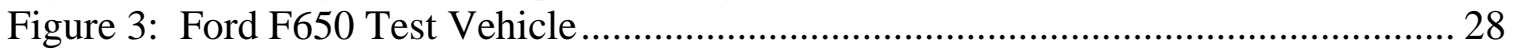

Figure 4: Vehicle Test Route Around Morgantown, WV ............................................ 29

Figure 5: Omega Model PX176 Pressure Transducer ................................................. 32

Figure 6: Heise Model PTE-1 Pressure Calibrator and Pressure Unit............................ 32

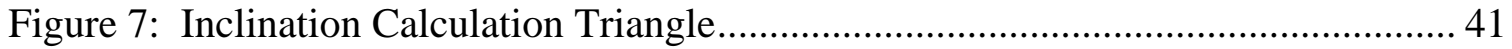

Figure 8: Ambient Pressure Readings During One Empty Load Test Run .................... 45

Figure 9: ECU Vehicle Speed During One Empty Load Test Run ............................... 46

Figure 10: ECU and GPS Vehicle Speed Comparison ............................................... 47

Figure 11: Test Distance Determined From ECU Vehicle Speed and Test Time .......... 48

Figure 12: Total Distance Traveled During Each Test Run .......................................... 49

Figure 13: Vehicle Acceleration Over The Test Period.................................................. 52

Figure 14: Vehicle Acceleration Layered With ECU Vehicle Speed............................. 53

Figure 15: Ambient Air Density Determined From Raw Ambient Pressure Readings ... 54

Figure 16: Altitude Values During Test Run Calculated From Smoothed Ambient

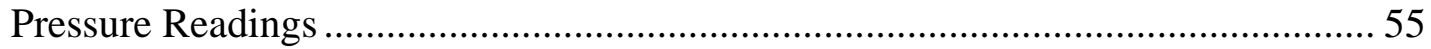

Figure 17: Primary Inclination Angle’s Determined From Smoothed Ambient Pressure

Readings................................................................................................. 56

Figure 18: Primary and Final Test Rout Inclination Angles After Averaging All Test

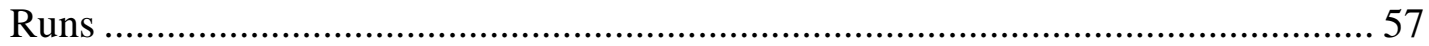

Figure 19: Inclination Angles Between 15,000ft and 35,000ft of Test ........................ 58

Figure 20: Vehicle Rolling Resistance Over Test Route ............................................ 59

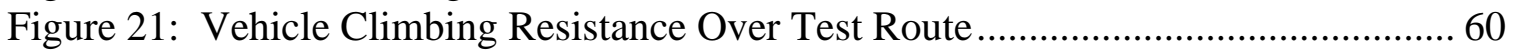

Figure 22: Vehicle Acceleration Resistance Over Test Route.......................................61 61

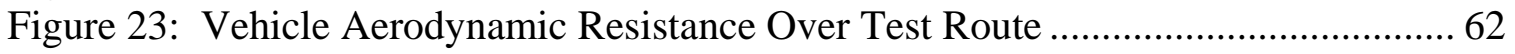

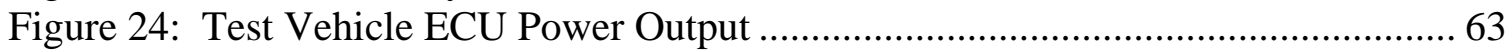

Figure 25: Vehicle Road Load From Vehicle ECU Values and Developed Model ........ 64

Figure 26: Calculated Road Load Power Averaged for Three Test Weights .................. 65

Figure 27: Averaged ECU Vehicle Speeds for Each Test Weight ................................. 66

Figure 28: Positive, Negative, and Total Work Due To Acceleration and Inclination

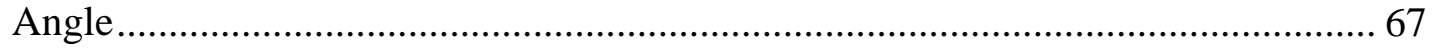

Figure 29: Work Comparison Over One Test at 17,140lb Test Weight ......................... 68

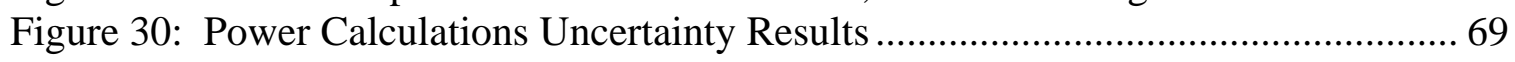

Figure 31: Integrated Work for All Tests Conducted ................................................ 71

Figure 32: Test 1 / Empty Load ECU Vehicle Speed..................................................... 78

Figure 33: Test 1 / Empty Load Altitude ................................................................... 78

Figure 34: Test 1 / Empty Load Rolling Power........................................................... 79

Figure 35: Test 1 / Empty Load Climbing Power.......................................................... 79

Figure 36: Test 1 / Empty Load Acceleration Power ................................................... 80

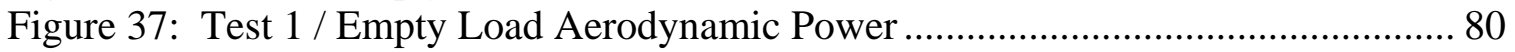

Figure 38: Test 1 / Load Weight Power Comparison ................................................... 81

Figure 39: Test 2 / Empty Load ECU Vehicle Speed ................................................. 81

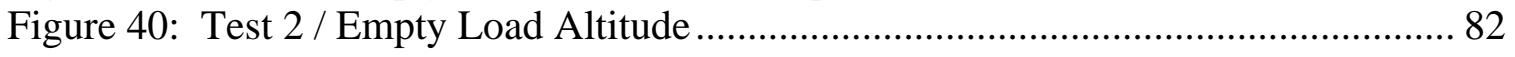

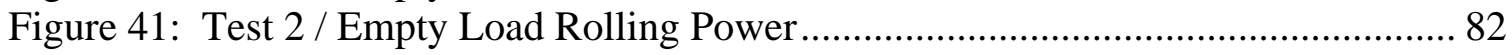




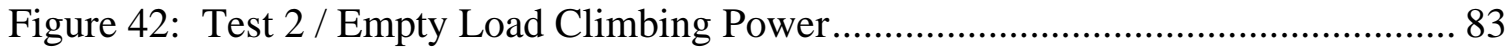

Figure 43: Test 2 / Empty Load Acceleration Power ................................................... 83

Figure 44: Test 2 / Empty Load Aerodynamic Power ...................................................... 84

Figure 45: Test 2 / Empty Load Power Comparison Showing Problem in ECU Power

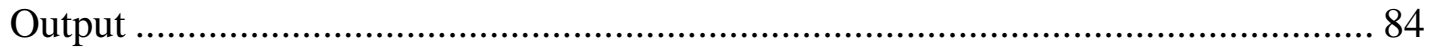

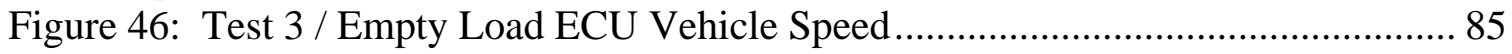

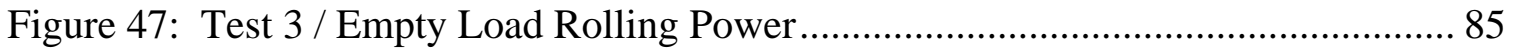

Figure 48: Test 3 / Empty Load Climbing Power............................................................ 86

Figure 49: Test 3 / Empty Load Acceleration Power ..................................................... 86

Figure 50: Test 3 / Empty Load Aerodynamic Power ................................................... 87

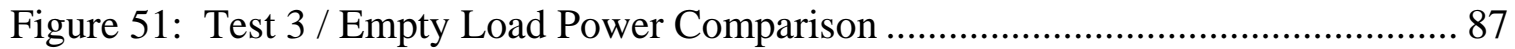

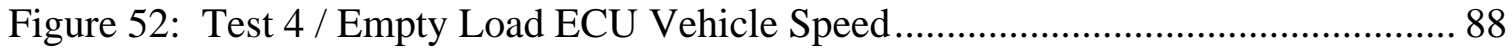

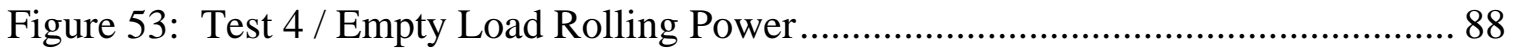

Figure 54: Test 4 / Empty Load Climbing Power........................................................... 89

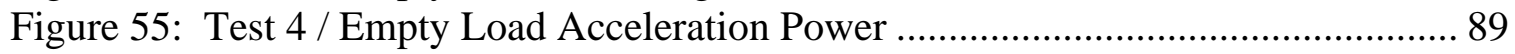

Figure 56: Test 4 / Empty Load Aerodynamic Power .................................................... 90

Figure 57: Test 4 / Load Weight Power Comparison .................................................... 90

Figure 58: Test 1 / Half Load ECU Vehicle Speed ...................................................... 91

Figure 59: Test 1 / Half Load Rolling Power .............................................................. 91

Figure 60: Test 1 / Half Load Climbing Power ............................................................. 92

Figure 61: Test 1 / Half Load Acceleration Power ...................................................... 92

Figure 62: Test 1 / Half Load Aerodynamic Power...................................................... 93

Figure 63: Test 1 / Half Load Power Comparison .......................................................... 93

Figure 64: Test 2 / Half Load ECU Vehicle Speed ....................................................... 94

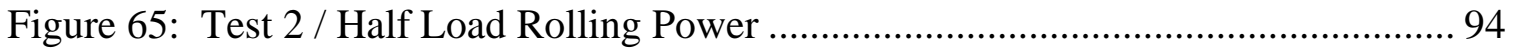

Figure 66: Test 2 / Half Load Climbing Power ........................................................... 95

Figure 67: Test 2 / Half Load Acceleration Power ........................................................ 95

Figure 68: Test 2 / Half Load Aerodynamic Power....................................................... 96

Figure 69: Test 2 / Half Load Power Comparison.......................................................... 96

Figure 70: Test 3 / Half Load ECU Vehicle Speed ..................................................... 97

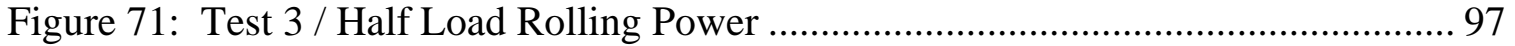

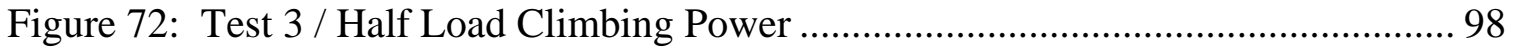

Figure 73: Test 3 / Half Load Acceleration Power ......................................................... 98

Figure 74: Test 3 / Half Load Aerodynamic Power..................................................... 99

Figure 75: Test 3 / Half Load Power Comparison ........................................................... 99

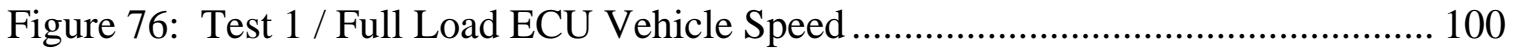

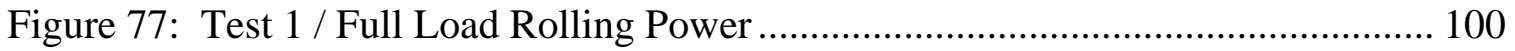

Figure 78: Test 1 / Full Load Climbing Power............................................................. 101

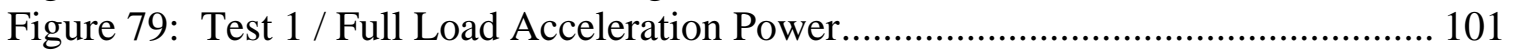

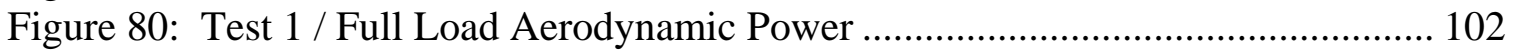

Figure 81: Test 1 / Full Load Power Comparison........................................................ 102

Figure 82: Test 2 / Full Load ECU Vehicle Speed ..................................................... 103

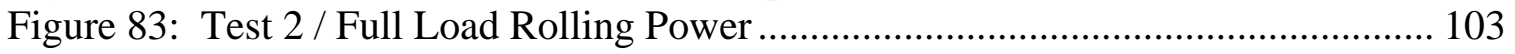

Figure 84: Test 2 / Full Load Climbing Power ............................................................. 104

Figure 85: Test 2 / Full Load Acceleration Power....................................................... 104

Figure 86: Test 2 / Full Load Aerodynamic Power .................................................... 105 
Figure 87: Test 2 / Full Load Power Comparison......................................................... 105

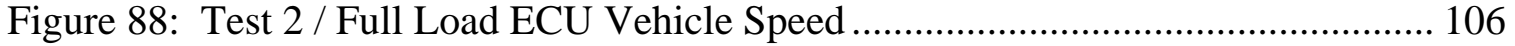

Figure 89: Test 3 / Full Load Rolling Power ............................................................... 106

Figure 90: Test 3 / Full Load Climbing Power ............................................................. 107

Figure 91: Test 3 / Full Load Acceleration Power....................................................... 107

Figure 92: Test 3 / Full Load Aerodynamic Power ..................................................... 108

Figure 93: Test 3 / Full Load Power Comparison........................................................ 108

Figure 94: Test 4 / Full Load ECU Vehicle Speed ......................................................... 109

Figure 95: Test 4 / Full Load Rolling Power ................................................................ 109

Figure 96: Test 4 / Full Load Climbing Power ............................................................ 110

Figure 97: Test 4 / Full Load Acceleration Power....................................................... 110

Figure 98: Test 4 / Full Load Aerodynamic Power ....................................................... 111

Figure 99: Test 4 / Full Load Power Comparison.......................................................... 111

Figure 100: Test 5 / Full Load ECU Vehicle Speed ..................................................... 112

Figure 101: Test 5 / Full Load Rolling Power .......................................................... 112

Figure 102: Test 5 / Full Load Climbing Power ........................................................... 113

Figure 103: Test 5 / Full Load Acceleration Power..................................................... 113

Figure 104: Test 5 / Full Load Aerodynamic Power ................................................... 114

Figure 105: Test 5 / Full Load Power Comparison...................................................... 114

Figure 106: Test 6 / Full Load ECU Vehicle Speed .................................................... 115

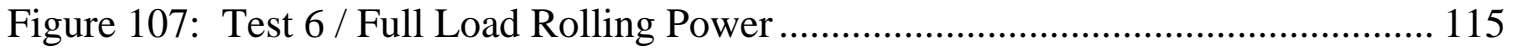

Figure 108: Test 6 / Full Load Climbing Power .......................................................... 116

Figure 109: Test 6 / Full Load Acceleration Power....................................................... 116

Figure 110: Test 6 / Full Load Aerodynamic Power .................................................. 117

Figure 111: Test 6 / Full Load Power Comparison....................................................... 117 


\section{List of Tables}

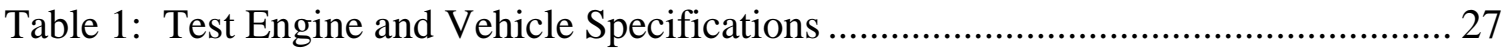

Table 2: Testing Weights and Number of Experiments............................................... 28

Table 3: Final Testing Weights and Number of Experiments ...................................... 37

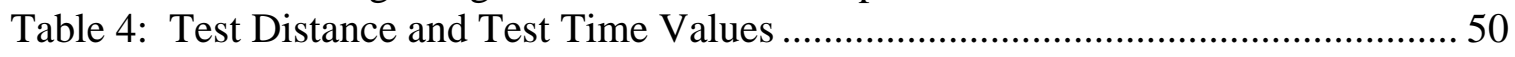

Table 5: Pre and Post Weather Conditions During Testing ........................................... 51 


\section{Nomenclature}

\section{Symbol Description}

A

a

$\mathrm{C}_{\mathrm{D}}$

$\mathrm{d}_{\mathrm{i}}$

$\mathrm{f}_{\mathrm{R}}$

G

$\mathrm{G}_{\mathrm{N}}$

$\mathrm{h}$

M

$\mathrm{N}$

$\mathrm{y}_{\mathrm{i}}$

$\mathrm{p}$

$P$

$\mathrm{P}_{\mathrm{A}}$

$\mathrm{P}_{\mathrm{C}}$

$P_{D}$

$P_{R}$

$\mathrm{q}_{\infty}$

$\mathrm{R}$

$\mathrm{t}$

$\mathrm{T}_{\text {Inferred }}$

$\mathrm{T}_{\mathrm{o}}$

$\mathrm{V}$

$\mathrm{W}_{\mathrm{A}}$

$\mathrm{W}_{\mathrm{C}}$

$\mathrm{W}_{\mathrm{D}}$

$\mathrm{W}_{\mathrm{R}}$

$\mathrm{X}_{\mathrm{i}}$

$\mathrm{Z}$

\section{Greek}

$\mu$

$\eta_{\mathrm{A}}$

$\eta_{G}$

$\rho$

$\theta$

$\varepsilon$

$\Delta$

Area

Acceleration

Vehicle Weight

Step Size

Mass

Engine Speed

Pressure

Power

Rolling Power

Time

Inferred Torque

Velocity

Climbing Force

Rolling Force

Total Force

Micro

Axle Efficiency

Density

Change
Drag Coefficient

Instantaneous Distance

Rolling Resistance Coefficient

Vehicle Weight Perpendicular to Incline Surface

General Instantaneous Point

Acceleration Power

Climbing Power

Aerodynamic Drag Power

Dynamic Pressure

Relative Ambient Temperature

Acceleration Force

Aerodynamic Drag Force

Parameter in an Equation
Universal Gas Constant

Units

$\mathrm{ft}^{2}$

$\mathrm{ft} / \mathrm{sec}^{2}$

miles

$\mathrm{lb}_{\mathrm{f}}$

$\mathrm{lb}_{\mathrm{f}}$

$\mathrm{lb}_{\mathrm{m}}$

$\mathrm{rev} / \mathrm{min}$

inHg

Hp

Hp

Hp

Hp

Hp

$\mathrm{lb}_{\mathrm{m}} / \mathrm{ftsec}^{2}$

$\mathrm{ftlb}_{\mathrm{f}} / \mathrm{lb}_{\mathrm{m}} \mathrm{R}$

sec

ft-lbs

$\mathrm{R}$

$\mathrm{ft} / \mathrm{sec}$

$\mathrm{lb}_{\mathrm{f}}$

$\mathrm{lb}_{\mathrm{f}}$

$\mathrm{lb}_{\mathrm{f}}$

$\mathrm{lb}_{\mathrm{f}}$

$\mathrm{lb}_{\mathrm{f}}$

$10^{-6}$
$\%$
$\%$
$\mathrm{lb}_{\mathrm{m}} / \mathrm{ft}^{3}$
Degrees
$\%$

$10^{-6}$

Gearbox Efficiency

Road Inclination Angle

Rotating Mass Contribution

\section{Abbreviation}

AC

DC

Alternating Current

Direct Current 


$\begin{array}{ll}\text { ECU } & \text { Electronic Control Unit } \\ \text { EPA } & \text { Environmental Protection Agency } \\ \text { GMC } & \text { General Motors Corporation } \\ \text { GPS } & \text { Global Positioning System } \\ \text { GVWR } & \text { Gross Vehicle Weight Rating } \\ \text { HDDE } & \text { Heavy Duty Diesel Engines } \\ \text { LCD } & \text { Liquid Crystal Display } \\ \text { MEMS } & \text { Mobile Emissions Measurement System } \\ \text { MIRA } & \text { Motor Industry Research Association } \\ \text { NTE } & \text { Not To Exceed } \\ \text { PEMS } & \text { Portable Emission Measurement System } \\ \text { QA/QC } & \text { Quality Assurance / Quality Control } \\ \text { SPOT } & \text { Simple Portable On-Vehicle Testing } \\ \text { US } & \text { United States } \\ \text { WVU } & \text { West Virginia University } \\ & \\ \text { Units } & \\ { }^{\circ} \mathrm{C} & \text { Degrees Celsius } \\ \mathrm{ft} & \text { Feet } \\ \mathrm{Hz} & \text { Hertz } \\ \mathrm{inHg} & \text { Inches of Mercury } \\ \mathrm{km} / \mathrm{hr} & \text { Kilometers Per Hour } \\ \mathrm{lbs} & \text { Pounds } \\ \mathrm{lb} & \text { Pounds Force } \\ \mathrm{lb} & \text { Pounds Mass } \\ \mathrm{m} & \text { Meters } \\ \mathrm{m} / \mathrm{s} & \text { Meters Per Second } \\ \mathrm{mm} & \text { Millimeters } \\ \mathrm{mph} & \text { Miles Per Hour } \\ \mathrm{mV} & \text { Millivolts } \\ \mathrm{mph} / \mathrm{sec} & \text { Miles Per Hour Per Second } \\ \mathrm{psi} & \text { Pounds Per Square Inch } \\ \mathrm{psia} & \text { Pounds Per Square Inch Absolute } \\ \mathrm{sec} & \text { Seconds } \\ & \end{array}$




\section{Introduction}

With a large portion of exhaust emissions being created through the use of heavyduty diesel engines, substantial restrictions have been placed on manufacturers to produce low emission engines within the past two decades, and will continue to do so into the future. Heavy duty diesel engines are large contributors to particulate matter and oxides of nitrogen pollution into the ambient air and are of much concern to the general public health. Along with restrictions being placed upon heavy-duty diesel engine manufacturers to reduce brake-specific mass exhaust emissions in the design and manufacturing process, on-road emissions testing research is currently being conducted and required for engine manufacturers.

In conventional diesel engine dynamometer certification and testing, emissions are measured within a dilution tunnel where concentrations of diesel exhaust emissions are collected. In order to create emissions levels from the engine that are comparable to on-road driving conditions, the engine in testing is supplied a load with a test cycle consisting of a preformed speed-load profile as a function of time. This load is usually supplied to the flywheel of the test engine by an AC or DC dynamometer. To obtain the highest accuracy and precision, the measuring equipment is of laboratory grade and very accurate. Instruments used to supply a load to the test engine are precise and minimize uncertainty within testing and measurements. Chassis dynamometer testing is also conducted to certify engines by supplying a simulated road load to the drive wheels of a test vehicle to record engine exhaust emissions. Similar to engine dynamometer testing, laboratory grade instruments are present and measured values are accurate. Chassis dynamometer emissions levels are usually reported on a distance specific basis, but fail to completely simulate real-world driving conditions as on-road testing provides. During on-road testing, it is difficult to measure engine torque and power directly, with a high level of accuracy. Engine torque must be inferred based upon fueling measurements. For that reason, engine power output data from the vehicle's electronic control unit (ECU) is collected and used to report emissions level on a brake specific basis.

West Virginia University (WVU) is a leader in on-road emissions testing, and is in contract with the six heavy-duty diesel engine manufacturing companies (Settling- 
HDDE) to conduct on-road diesel emissions testing on certain model year engines (6). Requirements set forth for testing procedures to be conducted were defined by the Consent Decrees into four phases with West Virginia University currently operating in phase IV. Phases I and II consisted of an evaluation of current and available technologies and an assessment and proposition for the design and development of an on-road measurement diesel engine emissions measurement system. Phases III and IV consisted of the development and commencement of on-road testing of the system.

Previously developed in-use measurement systems include, but are certainly not limited to, ROVER, SPOT, and the Semtech-D model system. In the early 1990's, an onroad measurement system development began by the US Environmental Protection Agency (EPA) initially designed for emissions measurements of light-duty gasoline vehicles but has grown into a heavy-duty measurement system as well (10). This system measured the mass emissions on a distance basis and is considered one of the first generations of Portable Emission Measurement Systems (PEMS). In 2001 the EPA continued their PEMS development program and began their simple portable on-vehicle testing system (SPOT). SPOT was established onto the ROVER system and was primarily established for off-road emissions testing on large scale heavy-duty diesel engines. The Semtech-D system, developed by Sensors Inc., is another available system. With ECU connections, an exhaust flow meter, gaseous emissions analyzers, and supporting transducers attached to a test vehicle, emissions can be recorded on a distance specific basis or brake-specific basis.

Heavy-duty engine manufacturers broadcast engine power, speed, and torque through the vehicle's electronic control unit (ECU). These broadcast values are developed through algorithms that account for instantaneous engine parameters such as fueling, and engine speed. To report brake-specific emissions, engine power values are recorded from the vehicle's ECU and applied to the mass emissions measurements taken. The issue here is that the broadcast torque is taken to be true without an alternative for comparison.

For quality control and assurance (QA/QC) purposes, it is desired to develop a model to verify and compare vehicle road load and engine power for on-road emissions 
testing being conducted at West Virginia University and elsewhere. The objective of this study is to develop and test the accuracy of this model. In order to accurately capture the vehicle's road load power an analysis of the contribution and uncertainty in the rolling, climbing (or inclination), acceleration, and aerodynamic resistance was performed. By developing a model that describes the vehicle's road load, the output of the manufacturer's ECU can be justified and verified. 


\section{Review of Literature}

Multiple studies have been conducted in the past that are relevant to this work. Within this section, these studies will be discussed and summarized. This study is dependent upon road loads and dynamic parameters of on-road driving conditions. Because of this, this discussion was focused on past studies containing information on such things as, but not limited to, vehicle speed measurement devices, aerodynamic drag measurements, and rolling resistance measurements. The studies introduced within this section played a key importance role in the development of this work by providing guidance into procedure assumptions and test methods.

\subsection{Road Load Studies}

\subsubsection{United States Environmental Protection Agency, 1977}

A study was conducted by the EPA in 1977 in order to predict the vehicle load settings a chassis dynamometer would have to be set at in order to provide an accurate simulation of realistic light-duty road load values (23). Using fifteen different light duty trucks and twenty track tests, or vehicle coastdown tests, experiments were conducted for each vehicle at each test weight in order to determine accurate road load values from a vehicle speed verses time relation. These values were then compared to chassis dynamometer test results for the same vehicles. The study considered the two road load constituents of rolling resistance and aerodynamic drag for the basis of the chassis dynamometer load settings that were being predicted. After testing was complete, it was found that the aerodynamic drag was the preferred method of predicting the chassis dynamometer settings. Furthermore, the vehicles' frontal areas were found to be the best technique of determining or predicting the vehicles’ aerodynamic drag values. The study determined that by using the vehicles’ aerodynamic drag values as a basis for the chassis dynamometer power absorption settings, as apposed to the vehicles' weights, the prediction was accurate. 


\subsubsection{General Motors Corporation, 1978}

A study was conducted in 1978 by the General Motors Company (GMC) that described a more accurate method of relating real-world road loads to chassis dynamometer testing by determining more precise correction coefficients for the different road load constituents (32). When conducting coastdown tests, a correction was needed to convert measured road loads to standard conditions for an analysis of the forces acting on a vehicle in a coastdown test for the purpose of determining road load forces for a dynamometer absorber level setting. Such factors as aerodynamic lift on a vehicle while traveling were considered in the planning of this study. However, while lift was shown to have an affect on a vehicle's road load by a few percent decrease, at the speeds that coastdown testing takes place, equations used to determine the lift, chassis, and tire drag was simplified dramatically by neglecting vehicle lift contributions. For their testing, twenty-two cars and light-duty trucks were used to conduct 157 coastdown tests in Arizona and Michigan at the GMC Proving grounds. Through these tests, GMC was able to form a set of corrections for wind, air density, and track surface temperatures. Their methods for determining the road loads and correction factors are described in more detail in the SAE paper, but it was found that the effects of ambient temperature and wind speed were the most significant factors affecting the rolling resistance of the test vehicles. Furthermore, the wind direction was found to have significant effects on the dynamic pressure, and the surface temperature of the track was found to correlate to the ambient temperature and could not be considered an individual factor.

\subsubsection{Toyota Motor Co., 1982}

A study was done by Toyota Motor Company in 1982 with intentions of determining two correction factors or coefficients to relate road load on a vehicle during real driving conditions to road load measurements determined from chassis dynamometer tests (14). The two correction coefficients were needed to verify the relationship between the rolling resistance of a vehicle's tires and aerodynamic drag measured during chassis dynamometer testing and realistic driving conditions. By knowing the two correction coefficients, vehicle road load could be determined during laboratory testing on a chassis dynamometer as apposed to on-road vehicle coastdown tests being performed. The study testing began by varying the tire loss to four levels while maintaining aerodynamic drag, 
brake drag, and drive train losses at a constant level. At each of the four levels, coastdown tests along with chassis dynamometer tests were performed and using a least squares method, a straight line was fit to the data. From this, the correction coefficient could be determined for the tire loss. Similarly, the tire loss was maintained at a constant level, and the vehicles aerodynamic drag was varied to four levels and chassis dynamometer and vehicle coastdown tests were performed to determine the correction coefficient for the aerodynamic drag.

\subsubsection{Northrop Services Inc., U.S. Environmental Protection Agency, 1983}

In conjunction with the United States EPA, Northrop Services Inc. conducted a study in 1983 that determined average road load values for class six trucks (5). The factors being focused on in this study included aerodynamic drag, vehicle rolling resistance, and drive train drag. Effects due to variations in road grade were considered negligible with the assumption that the testing surface maintained a constant zero grade value, but contributions to aerodynamic drag due to nonzero yaw angles and driving resistance changes due to ambient air conditions were corrected for in the data analysis. Using vehicle coast down tests, speed versus time data was collected for each of the vehicles tested, which consisted of two heavy-duty vans, and one medium-duty stake bed truck. During the testing, speed data was colleted at a frequency of ten hertz with the use of a fifth wheel containing a minicomputer attached to the rear of the vehicles. To account for nonzero yaw angles of wind, the speed and direction of the wind was measured using a three-cup anemometer and vane three times during each test. These three values were averaged and used to establish an overall wind direction and speed for each test run. Four different analytical models were developed with increasing complexity to determine the road load for each vehicle and test. Variations of up to $14 \%$ were found for the estimated driving resistance between the four different models and it was concluded that complicating the analysis models was not the best method of determining more accurate results. Instead, the use of simpler models is more favorable if vehicles' types are considered and categorized to account for differences in body styles, frontal areas, and drive train efficiencies. 


\subsubsection{University of Saskatchewan, 1989}

A study was conducted by the University of Saskatchewan in 1989 which intended to conduct vehicle coastdown tests and determine vehicle road load due to aerodynamic drag and rolling resistance under various weather conditions (20). The coastdown tests were to be conducted under windy conditions, along with the testing being performed on a testing track of variable grade. In this study, certain parameters contributing to the vehicle's road load were considered negligible including centripetal force due to road curvature, lift force, velocity dependencies of rolling circumference and rolling resistance. To perform this study, the University of Saskatchewan used the Nexus computer car to test, which was a prototype, fuel efficient, safety oriented, single passenger vehicle. The Nexus car was shown to have much lower drag and road load than conventional cars and was chosen under the assumption that if repeatable results could be acquired with it, results could be found for any conventional vehicle using the same model developed. For the coastdown tests, a free wheel was attached to the Nexus vehicle with intentions of measuring resistance due to the pavement/tire interaction, the driveline bearings, the aerodynamic drag, and the free wheel itself. Effects of brake drag were eliminated during testing by removing the vehicle's rear brake, and backing off the vehicle's front brake before each test. Approximately half of the tests were conducted during windy conditions and the other have were conducted during calm conditions where wind speed did not exceed eight $\mathrm{km} / \mathrm{hr}$. In analyzing the data recorded during testing, the calm conditions could be evaluated as an entire data set with the assumption that the yaw angle was assumed to be equal to zero. However, the windy conditions had to be analyzed differently due to the fact that the aerodynamic drag factor is a function of the yaw angle, and therefore the data was analyzed in a moving window with an interval size of sixteen seconds which moved laterally in five second steps until the end of the data points was reached. The analysis method that was developed for this study produced accurate results for the calm condition tests. However, for the windy conditions, results were significantly different from those expected. For the Nexus vehicle, results showed that the aerodynamic force along the traveling direction decreased with yaw angle, which was the opposite for most road vehicles where the aerodynamic force increases with yaw angle. 


\subsubsection{Ford Motor Company, 1997}

In 1997, the Ford Motor Company conducted a study which presented a concept of using an effective road profile to predict and determine vehicle road loads with an emphasis on surface loading (33). This study, using the effective road profile, focused on the tire dynamics and developing a model that simulates and determines the load found at a vehicle's tires. The tire model formed within this study incorporated complicated road profiles acting on the vehicle's tires in the vertical as well as the longitudinal and lateral directions. By the use of a tire test stand, loads were applied statically and dynamically to passenger vehicles to determine frequency response times of the tires in order to relate the measured times to the road load mathematically.

\subsubsection{IVK/FKFS - University of Stuttgart, 2003}

A study was conducted by the University of Stuttgart in 2003 with intentions of validating a new method of determining vehicle road load (16). Their method of measuring road load was done with the use of a driving torque measurement and an additional vehicle rolling resistance measurement to increase accuracy. The torque measurement was taken with the use of special measuring wheels contributed by the Kistler Instrument Corporation. These wheels measured the driving torque specifically and avoided introducing measurements of wheel bearing friction and brake drag that are found when driveshaft torque measurements are taken. The Kistler torque measuring wheels used were based on the principle of piezoelectric quartz force sensors. The additional rolling resistance measurements were taken with a trailer fabricated with instruments to measure rolling drag specifically and avoid interference from wind and drive train components. With road load measurements being taken on a small part of the Autobahn, accurate results were found to show the new system developed was an alternative to vehicle coastdown tests.

\subsubsection{SAE J1708/1587 and J1939 Protocols}

Vehicle parameters such as engine speed and power are broadcast by the vehicle's ECU within accordance of the SAE J1708/1587 and J1939 protocols (6). These protocols are defined to govern or establish standards on the methods used by heavy-duty engine manufacturers to broadcast vehicle information. The protocols prescribe such factors as 
the rate at which the data must be broadcast, the data range, and the data resolution. However, the accuracy of the signals broadcasted by the vehicle's ECU is not defined by the protocols and therefore introduces possibilities of inexactness.

\subsection{Aerodynamic Drag Studies}

\subsubsection{The Motor Industry Research Association, 1969}

A study was done in 1969 by the Motor Industry Research Association with intent of determining a simple method to estimate vehicle drag coefficients (30). The study's broad nature was to be simply used as a guideline in early stages of vehicle design to prevent undesirable vehicle features and was not intended to replace wind tunnel testing. This study considered many passenger and light-duty vehicle types and shapes and categorized them into different classes depending on their physical attributes. After the classes were constructed, vehicle drag contributions due to each attribute could be summed to determine an overall drag coefficient estimate. Classes included such features as front end shape, ground clearance or elevation, cowl and fender cross section, windshield plan and peak, roof plan, rear roof/trunk, lower rear end, and the underbody. Drag coefficients determined using the estimation method developed in this study were found to be within seven percent of actual wind tunnel testing values which shows that the method can be of some help at early design stages which was the intent of the study to begin with.

\subsubsection{University of Illinois, 1972}

In 1972, a study was conducted by the department of mechanical and industrial engineering at the University of Illinois with intentions of deriving an improved method for determining vehicles' aerodynamic drag coefficients (29). At the time of the study, primary methods for determining drag coefficients were determined from wind tunnel testing of scaled models and full-sized vehicles, and vehicle coast down testing. Limitations with these two methods include boundary layer inconsistency and separation due to the ground plane simulation in wind tunnel testing, and with vehicle coast down tests, test results accuracy was decreased due to the combination of aerodynamic drag and rolling resistance. This study, using a mathematical analysis, developed two dimensionless parameters to determine any vehicle’s aerodynamic drag coefficient. The 
mathematical model developed by imitating the energy of the coast down process produced statistical results to predict aerodynamic drag coefficients for vehicles of any size or weight including medium-duty and heavy-duty applications.

\subsubsection{University of Maryland, 1976}

The mechanical engineering department at the University of Maryland conducted a study in 1976 to compare coastdown data, with emphasis on aerodynamic drag, for multiple roof mounted drag and vortex reducers on full scale heavy-duty tractor trailers (4). One important aspect of this study was the fact that the coastdown tests were conducted in windy conditions and not restricted to conditions of approximately wind velocity yaw angles of zero degrees. The justification of this study was the fact that under high speed travel, the aerodynamic drag becomes responsible for approximately one-half of the truck's fuel consumption and with dramatic reductions in aerodynamic drag, efficiency would increase similarly and operating costs for tractor-trailer combinations could be decreased. Certain aspects, or discontinuities, of wind tunnel testing that are inaccurate of on-road testing were discussed in the paper such as the fact that ground effects cause an increase in wind speed with an increase in vertical height, and that large wind eddies exist in nature commonly the size of a tractor-trailer and are independent of wind speed, neither of which are accurately simulated in wind tunnel testing. The University's testing was conducted on an 8,750ft runway specifically designed for research by NASA in Wallops, Virginia. An International Harvester cabinover engine tractor with a sleeper was used as the test vehicle. It was noted that the tractor-trailer combination was not loaded and fluctuations in weight were due only to fuel consumption and different aerodynamic devices installed, and that airflow was prevented through the grill of the tractor as it was covered during testing. Four different aerodynamic devices were used in testing consisting of a wind deflector that was commercially available, a commercial wind deflector and vortex stabilizer combination, a roof mounted fairing specifically designed and built by the University for the testing, and a gap seal and fairing combination. Due to the fact that testing was conducted in windy conditions, air speed and direction was measured using an anemometer mounted to the front of the truck at a height of approximately half of the maximum truck height for the 68 tests conducted on the runway. The study found that there was an inconsistency 
between wind tunnel testing and the coastdown tests. Results showed that the addition of aerodynamic devices in some cases showed no significant improvement in aerodynamic drag in the wind tunnel but showed dramatic reductions in the coastdown tests and suggested that the real world flow field was almost impossible to recreate in a wind tunnel setting.

\subsubsection{Rover Group Ltd. and Loughborough University, 1994}

A study was conducted in 1994 by Loughborough University in conjunction with Rover Group Ltd. with intent to develop a coastdown method or test procedure that was repeatable and produced high accuracy (19). In the study developed, multiple components of vehicle loading were calculated such as rolling resistance and driveline losses, and aerodynamic resistance. For the test vehicle, a 1990 model year Rover 820Si Saloon was used and instrumented with an anemometer located approximately 1.3 meters ahead of the vehicle's front bumper. The anemometer was used to develop a time history of relative wind direction and velocity. Before conducting coastdown tests, the vehicle was tested in a full scale wind tunnel owned and maintained by the Motor Industry Research Association (MIRA) at standard test speeds of $27 \mathrm{~m} / \mathrm{s}$. During wind tunnel testing, instruments were installed and removed for a comparison between the aerodynamic drag coefficients determined and was shown to increase the vehicle's drag coefficient about 0.006 with the anemometer instrumented onto the vehicle. During the study's coastdown testing, such parameters as tire pressures were maintained at 28psi and $68^{\circ} \mathrm{F}$, vehicle weight was measured pre and post testing with a linear reduction of weight assumed, and the static trim heights of the vehicle were measured pre and post testing as well to ensure accuracy and repeatability. Twenty coastdown tests were conducted as a whole with data being collected at a sampling rate of $10 \mathrm{~Hz}$. Vehicle speed was measured by the use of a Leitz Correvit optical speed measuring device while the wind velocity and traveling direction was determined with the vane anemometer attached to the vehicle. With coastdown testing completed a relationship was found that showed an average aerodynamic drag coefficient from the coastdown testing that was $7.5 \%$ above values determined within the wind tunnel and was primarily accounted for on the bases that wind flow in the tunnel is an inadequate simulation. One final important factor that was 
determined throughout this study that when using this model, accuracy results determining drag coefficients to within $1 \%$ can only be reached with a minimum of forty pairs of coastdown tests.

\subsection{Rolling Resistance Studies}

\subsubsection{Uniroyal Tire Company, 1971}

In 1971, the Uniroyal Tire Company conducted a study to try to compute power consumption of passenger tires (9). Uniroyal's intent of describing tire power consumption was because its effects on gasoline mileage, acceleration performance, and high speed durability. Eighty tires were analyzed in this study and the rolling resistance was divided into two components. One of which was due to the general distortion of the tire at very low speeds and was considered extremely speed dependent, and the other component was due to additional distortions of the tires at high speeds and was shown to be negligible at low speeds (less than 50mph). At higher speeds, the high speed component was show to account for around two-thirds of the entire rolling resistance of the tire being tested. One problem that was discussed and considered in this study was the fact that the general rolling resistance of a tire can vary depending on the type of testing being conducted. Factors such as tire pressure, temperature, alignment, surface condition, and so on contribute to the rolling resistance and must be accounted for. Studies conducted in the past on power consumption have contradicting results which is intended to be accounted for in this study by acknowledging the different testing procedures and variables. Relationships were created by this study that showed correlations of velocity, temperature, tire size, pressure, belt angle, tread design, and materials with the rolling resistance.

\subsubsection{Goodyear Tire and Rubber Company, 1977}

A study was conducted by the Goodyear Tire and Rubber Company in 1977 that considered the effects of the reinforcing material of passenger tires on a vehicle's rolling resistance and also fuel consumption or economy (21). This study considered the effect of both the tire's belt and carcass when taking into consideration the entire fabric reinforcing material. Twenty tires in all were created for their testing with varying carcass material and belt construction combinations. Testing was done using a 
conventional coast down test to determine rolling resistance and fuel economy for each tire type. All tires tested were broken in for 100 miles at $55 \mathrm{mph}$ and a tire pressure of 28psi was maintained. Results of the test showed that aramid provided the best overall fuel efficiency and rolling resistance while nylon provided the worst. The study did, as expected, find that rolling resistance did increase due to tire or carcass weight increases, and at the same time, fuel economy decreased. It was found that a change in rolling resistance of no more than five percent could be reached using certain tire designs and fuel economy values could be increased around that same five percent by using a high tenacity, light cord in a single ply carcass.

\subsubsection{General Motors Corporation, 1978}

In 1978 a study was done by General Motors Corporation to develop a relationship between the elasticity of vehicle tire and rolling resistance (22). Their basis was that due to misshapen tires, a torque is created due to the weight of the vehicle on the road. Because of the vehicle's weight, the symmetry of the tire is distorted and undergoes a non-radial acceleration, even at constant speeds, which implies a torque that must be countered and a resistance and energy loss is produced if the tire is not perfectly elastic. In their analysis, a simplified case was considered where a perfectly circular tire was distorted by the road in a fashion where the tire was deformed into a truncated circle, with the width of it being undisturbed. Further analysis introduced non-uniform distortions where a lack of symmetry was allowed as the tire became introduced to a surface. To describe the rolling resistance of a tire, the force was divided into two components and included the resistance of the tire due to inelastic impact effects and resistance due to flexing of the tire. Results of the study showed that tires with a smaller effective elastic inefficiency, as speed is varied, could be produced under the conditions that temperature and tire inflation pressure were held constant. By increasing the elasticity of the tire, or decreasing the inefficiency of it, would decrease the overall vehicle rolling resistance created by the tire.

\subsubsection{General Motors Corporation, 1978}

In 1978 a study was conducted to consider and determine the major effects that road surface texture has on a vehicles rolling resistance (7). This study was conducted 
and overseen by the General Motors Corporation. Four categories were used to separate rolling resistance into its major contributing factors and they were tire design, tire operating parameters, ambient conditions, and highway design. Both indoor and outdoor testing was completed with the indoor tests focusing on the differences between two surfaces on a tire dynamometer. The two surfaces considered were the smooth steel surface, and a 3-M safety walk surface which had the texture comparable to 80-grit sandpaper. The outdoor tests were conducted on multiple roadway surfaces with asphalt and concrete constructions. The laboratory tests, or indoor tests, were comprised of two tires being tested in ten different radial constructions with a test speed of 50mph. The tests showed that rolling resistance was much higher, as anticipated, on the 3-M surface as compared to the smooth steel surface with average differences being about 5.3\% higher for the 3-M surface. In order to measure the rolling resistance in the outdoor tests, a single wheel test fixture was mounted to the rear of a vehicle and load and tire inflation pressure were controlled from inside the vehicle's cabin and could be modified at any time if desired. Again ten passenger tire constructions were tested but at a speed of $30 \mathrm{mph}$ as apposed to $50 \mathrm{mph}$. The outdoor test results were similar to the laboratory testing results with a significant effect shown between the road surface texture and tire rolling resistance, and an increase of up to $30 \%$ for different road surfaces and a difference of approximately $8 \%$ on primary type highway surfaces alone.

\subsubsection{KEVA Engineering, LLC, 2003}

With intent of developing accurate frictional drag coefficients, a study was done in 2003 by KEVA Engineering (28). Factors that have significant impacts on a roadway's friction were discussed in the study and include the age of the pavement, the amount of excess tar, and the amount of excess oils and binders. KEVA Engineering's testing involved instrumentation of a passenger vehicle with an optical speed sensor, triaxial accelerometer, and pitch and yaw angular rate sensors. Twenty-five locked-wheel braking tests were conducted on freshly pave roads at three different locations. The method used in the experiments to determine vehicle velocity involved using the DLS sensor and numerical integration of the accelerometer data and comparing the two. Similarly, values for the braking distance were determined and compared using an AAA brake gun and double integration of the accelerometer data. Three averaging methods 
were used to calculate the friction drag and insignificant differences were found between them. After analyzing the data, it was recommended that a sampling frequency of at least $100 \mathrm{~Hz}$ be used in any future testing to establish accurate results. It was found from the study that asphalt's friction drag, or coefficient, increases as it ages as the density of the asphalt is increased from vehicles' weights and traffic flow. However, there comes a time when the drag reaches a peak and begins to decrease, and at this point fresh asphalt needs to be considered.

\subsection{Climbing Resistance and Vehicle Speed Studies}

\subsubsection{West Virginia University, 2004}

A study was conducted by West Virginia University in 2004 to account for road grade variations in heavy-duty chassis dynamometer testing (24). In traditional methods of chassis dynamometer testing, a driver has the responsibility of following a trace provided on a computer screen in the cabin of the truck being tested. The trace shown was a graphical representation of the desired vehicle speed, and a second line was overlaid onto the first to display the vehicles actual speed. The driver was required to match the desired speed to his or her ability and the ability of the vehicle to provide the required power. By developing a virtual reality interface, road grade or inclination was introduced into the testing. Unlike the two dimensional line trace method used, virtual reality allowed the driver to anticipate speed and inclination changes more clearly as opposed to adding additional lines to the trace method which would become increasingly more confusing for the driver. The virtual reality system was created by WVU using Microsoft Visual C++ and OpenGL for the system's graphics. To test the developed system, two tests were conducted. The first test introduced road grade into the line trace method by displaying an inclination value on the bottom of the screen, while the second test used the virtual reality configuration. It was found that the numerical display of the grade did not significantly improve the driver's load response. It was in most cases ignored by the driver, because of its difficulty to see while watching the trace, and the driver's focus was maintained on matching the trace. The use of the virtual reality system was found not to interfere with the driving cycle and introduced a great way of 
displaying the multiple test parameters, such as speed and inclination, to the driver at the same time without creating difficulties in test matching.

\subsubsection{Hosei University, 1992}

In 1992 a study was conducted in Tokyo, Japan to develop a new method of determining a vehicle's traveling speed (15). This study was based upon intensity and spatial periodic patterns noticed in UHF/VHF radio waves. For this study, two antennas were mounted to a test vehicle, and through the use of a phenomenon described as multipass fading, the vehicle's velocity could be determined. Multi-pass fading is a noise present in radio waves which can best be described as a propagation of wave intensity due to large reflections from such large objects such as mountain ranges or buildings. By measuring the time delay between the two antennas as they received the propagations, the vehicle speed was calculated. On-road testing was performed on highways, urban city areas, and very rural areas where it was found the intensity of the radio waves diminished significantly away from the presence of large skyscrapers, buildings, and large geological objects. When speeds calculated using the developed radio wave method was compared with vehicle speedometer readings, an average error between the two was found to be approximately $\pm 6.2 \mathrm{~km} / \mathrm{hr}$.

\subsection{Acceleration Resistance Study}

\subsubsection{Toyota Motor Corporation, 1992}

A study was conducted in 1992 by engineers at Toyota Motor Corporation in which a sensor was developed and tested for determining the acceleration values for an object such as a motor vehicle (13). With vehicle accelerations taking place in three different directions, lateral, longitudinal, and vertical, the sensor developed focused on the first two and was not designed to calculate the vertical accelerations. The configuration of their sensor that was developed consisted of an aluminum housing with an outer shell made of iron which acted as a magnetic shielding. The aluminum casing was filled with a magnetic fluid consisting of ultra fine particles of a ferrite substance with particle sizes on the order of $0.01 \mu \mathrm{m}$. Placed within this fluid was a magnet which was suspended by the magnetic field created around itself. A pair of Gallium-Arsenide Hall elements were fixed to each end of the housing with the purpose of detecting 
translational displacements of the internal magnet due to changes in the magnetic field's flux density and a relative voltage was induced. The electrical signals produced could then be amplified and recorded by a data acquisition system and the acceleration of the object could be determined. Note that with an acceleration value of zero, the internal magnet would be fixed within the center of the aluminum housing and equal voltage outputs would be created by each of the Hall elements on each end of the housing. Testing of the sensor included mounting it onto a small disc connected to a DC motor and recording voltage outputs and comparing them to the known acceleration of the motor, and an installation on a test vehicle. Vehicle testing consisted of sudden accelerations, decelerations, and slalom tests where the sensor showed accurate results when the axis of the sensor was mounted in the longitudinal direction. However, when mounted with the axis of the sensor in the lateral direction, sudden accelerations and decelerations were relatively unnoticed by the sensor except for the slalom tests performed where it responded accurately and produced precise results.

\subsubsection{Endevco, 2000}

Endevco conducted a study in 2000 to develop an accelerometer on a very small scale (12). Basis for this development came from the fact that accelerometers were desired to measure values of accelerations during vehicle crashes, specifically in race car applications. A problem that was faced was that previously designed accelerometers were only small enough to be mounted securely to a driver's protective helmet. At this mounting location, accelerations are significant due to any rotation of the driver's head during crashes or normal driving conditions. Because of this, accurate measurements could not be made to describe decelerations felt by drivers during vehicle accidents. The accelerometer developed was based upon a previously designed sensor frame and had dimensions of $1 \mathrm{~mm}$ high by $3.8 \mathrm{~mm}$ long by $1.4 \mathrm{~mm}$ wide which allowed the design to be configured to fit within an ear piece of the driver. The sensor developed was composed of silicone and had an inner core with a mass fixed to a hinge which allowed it to move during accelerations and decelerations. Strain gages measured the translational movement of the inner mass and produced an electrical output that could be correlated to acceleration values. The developed sensor had a range of approximately $4.9 \mathrm{~km} / \mathrm{sec}^{2}$ which is equal to 500 times the pull of gravity. At the same time, it has a sensitivity of 
$81.6 \mathrm{mV} / \mathrm{km} / \mathrm{sec}^{2}$ which allows it to be accurate at very low accelerations. To develop these results, and the others presented in this study, testing was conducted in the fields of frequency response, shock testing, transverse sensitivity testing, and temperature response testing. 


\section{Model Development}

This chapter discusses the methods used to develop this study and model. Discussions on background fundamentals of different measured parameters and vehicle road loading are presented as well as equipment used for taking measurements during testing. One test vehicle was used for the model development and is discussed within this chapter along with a description of the route chosen for testing to take place.

\subsection{Road Load Equation}

The road load model that was developed uses the fundamental road load equation for vehicles presented below in Equation 1, where $\mathrm{Z}$ is the force needed for the vehicle to be in motion and is defined by four terms (1).

Equation 1

$$
Z=W_{D}+W_{R}+W_{C}+W_{A}
$$

The four terms that develop the total force applied to the drive wheels are defined as the aerodynamic drag, the vehicle's rolling resistance, the climbing force due to variations in road grade, and the inertial or acceleration resistance. With the driving force determined, the engine's power can be calculated using the relationship shown below in Equation 2.

Equation 2

$$
P=\frac{Z V}{\eta_{G} \eta_{A}}
$$

In this relationship, the power required is determined by multiplying the force determined previously, by the vehicle's speed. The two coefficients shown in the denominator of Equation 2 are the terms that correspond to a vehicle's driveline efficiency comprised of the gearbox or transmission, and axle efficiency. Vehicles with lower driveline efficiency require more engine power to overcome losses in the gearbox and axle such as friction between gears and heat.

\subsection{Aerodynamic Drag}

A vehicle's aerodynamic drag is created when the ambient air is forced to change directions as it is displaced by the volume of the vehicle as it is in motion. As the vehicle travels through ambient air, high pressure and low pressure regions are created and the drag due to aerodynamic effects is created. The magnitude of the pressure distribution 
about the vehicle is dramatically affected by the curvature of the vehicle's body. A more blunt faced object, or sharp bends in a vehicle's body, causes a more severe change in direction for the ambient air to maneuver and will induce a larger aerodynamic drag. With smoothed lines and curvatures, the ambient air is allowed to follow the body of the vehicle much easier and the overall drag is reduced.

A small portion of aerodynamic drag can also be contributed to a vehicle's skin friction. Small imperfections in a vehicle's surface area, or skin, will cause friction to occur as the ambient air travels across it. The viscosity of the fluid, or ambient air, fills these imperfections, which are tiny bumps due to the body material's surface finish and paint, and a shear stress is created. This shear stress acts tangential to the surface of the vehicle's body and contributes to the overall aerodynamic drag. A third contribution to overall aerodynamic drag is due to wave effects. However, when dealing with on-road vehicle dynamics, transonic or supersonic speeds, where wave drag is present, are not reached and can be considered zero below the drag-divergence Mach number (2). It has been shown by Buckley how different combinations of drag reducing attachments, such as gap seals and roof fairings, can greatly reduce the overall aerodynamic drag effects specifically in heavy-duty truck applications (4).

A vehicle's motion resistance due to aerodynamic friction can become timely and expensive to measure when wind tunnel testing and extensive measurement systems are involved. It has been shown that an estimation of a vehicle's aerodynamic drag coefficient based on the vehicle's frontal area, can be comparatively similar to full scale aerodynamic wind tunnel testing. For this study, the test vehicle's drag was determined using the following equation.

Equation 3

$$
W_{D}=\frac{1}{2} \rho V^{2} C_{D} A
$$

In Equation 3 above, the aerodynamic drag coefficient is found by combining the ambient air density, the square of the vehicle's velocity, the total drag coefficient, and the frontal area of the vehicle. The value of the vehicle's frontal area was determined by the use of a planimeter. With a picture of the test vehicle taken, and a reference measurement taken of the frontal area of one of the vehicle's headlights, the planimeter 
determines a value for the vehicle's entire frontal area and headlight's frontal area by tracing them in the picture. The value for each can be related and with the known frontal area of the headlight measured, the entire frontal area can be calculated. From previous studies conducted, drag coefficient values for medium duty trucks, city busses, and heavy-duty trucks have been determined. With these previous values, an estimation for the test vehicle's drag coefficient for this study could be projected.

Traditional drag resistance testing includes vehicle coastdown tests. During a vehicle coastdown test, a vehicle is accelerated to a certain speed and allowed to coast down to a speed close to equilibrium between $1 \mathrm{mph}$ to $10 \mathrm{mph}$ depending on the testing requirements. Coastdown tests are conducted under idle conditions where the inclination angle of the road is approximately zero and near zero magnitude wind conditions. Once the vehicle is accelerated and the transaxle is shifted into neutral, the coastdown process begins and the time rate of change of velocity is recorded. Through a mathematical relationship, the aerodynamic drag of the vehicle can be determined and furthermore the vehicle's aerodynamic drag coefficient. This is described in Passmore, where a specific drag study was conducted using traditional coastdown methods for testing (19).

\subsection{Rolling Resistance}

As a vehicle travels on a surface, a resistive force is created through the vehicle's tires in contact with the road. This is the test vehicle's rolling resistance. There are five key elements that contribute to a vehicle's rolling resistance. The first contributing factor is the tire temperature. As a vehicle is set in motion, the tires' temperatures will increase non-linearly with a dramatic increase over the first thirty to forty miles of travel and then begins to level off and maintain a constant value. As the temperature is rising in this manner, the tire drag reduces inversely with a dramatic decrease over the warm-up period of approximately thirty miles before reaching a plateau and approaching an equilibrium state. In the case of short trips in the vehicle, advantages of reduced drag are never reached because of the tire temperature not being allowed ample time to warm up (11).

The second key element contributing to a vehicle’s tires' rolling resistance or drag is the inflation pressure of the tires in contact with the road surface. With tire sidewall deflection playing a major contributor to rolling drag, the tires' inflation load is a 
substantial element to consider since the internal tire pressure will determine the sidewall deflection. Different contact surfaces react differently to tire pressure and sidewall deflection also. In the case of sand, maintaining a lower tire inflation pressure allows a larger sidewall deflection, which in turn prevents surface penetration. When traveling on sand, surface penetration will significantly increase rolling drag and therefore it is better to operate at a lower inflation pressure and minimize the tire's travel depth. However, on a paved surface the opposite is true. Operating at a higher inflation pressure reduces sidewall deflection which at the same time will decrease the tires' contact area and rolling drag.

The third significant contributor to rolling resistance is the vehicle's velocity along with the tire's translational and rotational velocities. Tires contribute very high rolling resistance at higher speeds, but at lower velocities, the amount of tire drag is very small and in many cases is assumed to be constant. Problems with velocity arise in the higher speed ranges where vibrations and fatigue become and issue. At higher speeds, a free standing wave is produced within the tire carcass located behind the tire's contact patch with the road (11). This wave is the sole provider of the large increase in rolling resistance at higher speeds. Over periods of time, short or long, tire failure can occur as a result of this wave. Tire inflation, as discussed previously, acts in conjunction with the tire's velocity and if two problems such as under inflation pressure and a free standing wave combine, the chance of failure can increase significantly. Tire manufacturers rate tires for their operating speeds and inflation pressures to prevent such failures. Higher rated tires are implemented with design characteristics such as shoulder and sidewall stabilizers to dampen the standing wave created at higher speed ranges.

The material and design of a vehicle's tires is the fourth largest contributor to the overall rolling resistance. Manufacturers of tires modify and design tires with different tread heights, tire tread thickness, tire sidewall thickness, and tire material to try and develop tires that perform better under specific driving operations. As different design aspects are implemented, rolling resistance may increase or decrease respectively. A different tire material may have the ability to reach higher temperatures after the warmup period but which would decrease the tires' rolling drag, but at the same time may not be able to withstand the standing wave developed at higher speeds as discussed earlier 
and therefore may experience an increase in rolling resistance. Different combinations and designs of thickness, dimensions, and materials will play an important role in the magnitude of tires' rolling resistance.

The fifth and final contributor to rolling resistance is the tire's slip or slip angle. It has been shown that wheel slip has a non-linear effect on rolling resistance similar to that of the effects velocity has on tire drag. At higher slip angles, vehicles show much higher rolling resistance and follow an exponential relationship. With a small increase of slip angle approximately one to two degrees, the rolling resistance may as much as double, normally seen in high speed cornering.

There are two mechanisms within the contact of a tire to the traveling surface and are the vehicle's connections to rolling resistance. At the tire contact patch, the rubber is in meshing with the aggregate surface of the road which is where the two mechanisms of adhesion and hysteresis occur. As the rubber of the tire comes in contact with the road surface, the molecular bond, or adhesion that occurs between the two contributes to the majority of the traction or rolling resistance under dry conditions. However, under wet conditions, the adhesion is significantly reduced and prevented by the water on the road surface. In this situation, a decrease in traction occurs which is why traction is drastically less in the rain (11). Under wet conditions, the other of the two mechanisms becomes the primary source of traction and is the hysteresis. This occurs due to the weight of the vehicle causing the tires to deform around the aggregate on a minute scale and provide traction. A tire's hysteresis ability is not affected by wet conditions, but is significantly affected by the roughness or smoothness of the road surface. One balancing problem manufacturers are faced with is the fact that as rolling resistance is decreased, traction follows and is also decreased. Traction is needed to control the motion of the vehicle but there is a trade off. Sacrificing traction for a reduced rolling resistance and an increase in vehicle efficiency is under consideration in a tire's design and purpose. Figure 1 below displays the difference between the two mechanisms of tire traction and rolling resistance. 


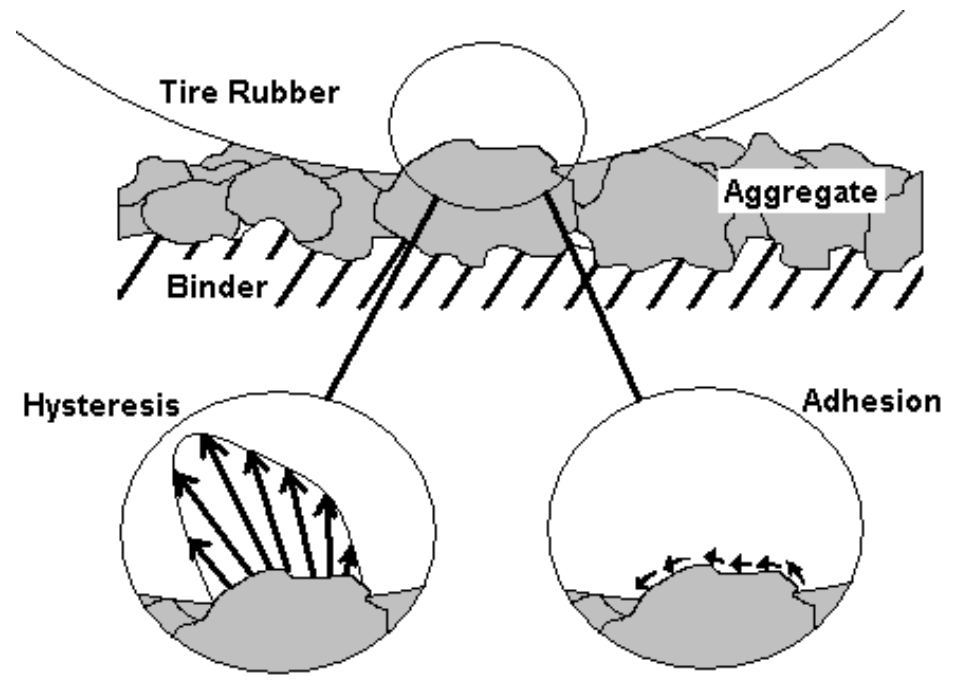

Figure 1: Tire Hysteresis and Adhesion Components of Tire Traction

A vehicle's rolling resistance is the most significant contributor to its total road load and is followed up by aerodynamic drag which is only significant at higher traveling speeds. For this study, the rolling drag or resistance of the test vehicle was determined using Equation 4 below.

\section{Equation $4 \quad W_{R}=f_{R} G_{N}$}

The rolling resistance is determined by multiplying the entire weight of the vehicle by the rolling force coefficient. Note that for this model that was developed, the aerodynamic lift that was created on the vehicle, either positive or negative, was neglected and the stationary weight of the test vehicle was used to determine the rolling resistance. A similar assumption was made in the study discussed earlier by the University of Saskatchewan (20). The affects of road-way surface on the overall rolling resistance of vehicles are described by Varat (28). It was shown how the age and composition of the road-way significantly affect the ability of the vehicle to gain traction and produce resistance due to rolling friction.

Coastdown testing is also used to determine a test vehicle's rolling resistance. With the time rate of change of the vehicle during a coastdown period recorded at an outside test location, the rolling resistance and aerodynamic drag are determined as a lumped sum. Further coastdown testing on a chassis dynamometer allows tests to eliminate any presence of wind resistance and the isolated rolling resistance due to tire friction, drive train loss, and bearing loss can be determined. The use of coastdown 
testing is an acceptable method of determining a vehicle's rolling resistance and aerodynamic drag resistance but fails to describe an accurate interpretation of a vehicle's entire road load under real-world driving conditions which is where this model stands. The mathematical approach of translating recorded coastdown velocities, or velocity rate of changes, is described in detail by Yasin (32).

\subsection{Climbing Resistance}

A significant amount of resistance is created when a vehicle is traveling on a surface with a slope or grade other than zero. A grade of zero represents a condition where climbing resistance is absent. On a road surface with a slope other than zero, there is a resistance that must be overcome as the vehicle is working against the Earth's gravitational pull and is proportional to the magnitude of the surface's climb angle. Figure 2 shows a component diagram of the weight of the vehicle traveling on an incline. Under conditions of a negative incline, or a down slope, the opposite effect occurs where the Earth's gravitational pull is working with the engine and helping to accelerate the vehicle. Under this condition, less power is needed to be produced by the vehicle's engine in order to overcome loading. Inclination angle was introduced to chassis dynamometer testing by West Virginia University where a virtual reality system was implemented to provide the test vehicle driver with a visual signal to simulate real-world driving on uneven pavement (24).

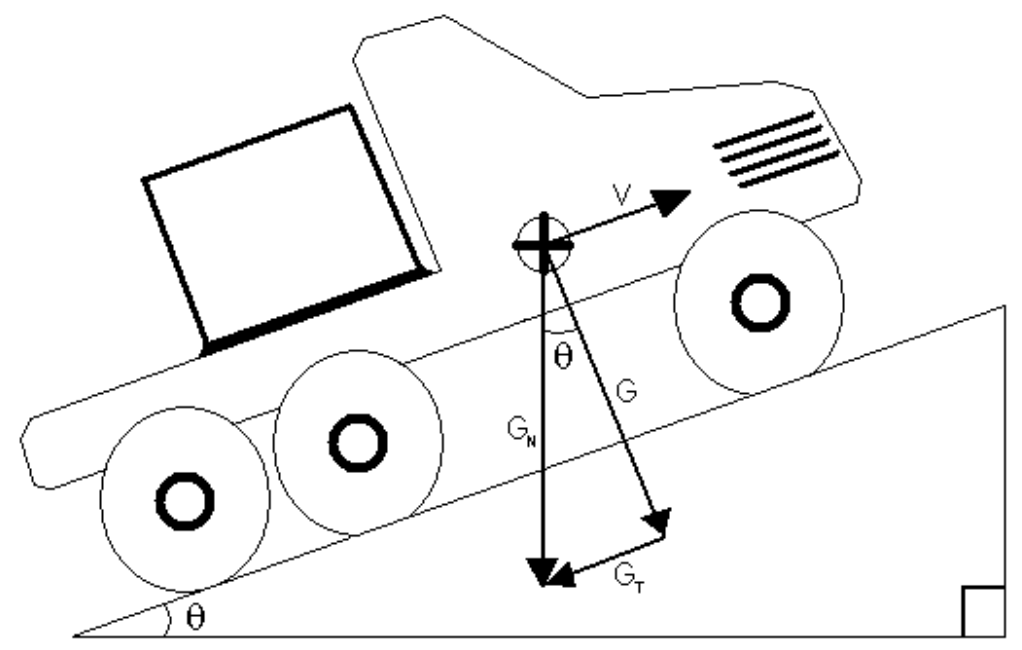

Figure 2: Climbing Force Component Diagram 
This resistance is simple to calculate once the altitude change or grade of the traveling surface is known, but determining that can be somewhat complicated. For this model, Equation 5 below was used to determine the climbing resistance of the test vehicle during testing.

Equation 5

$$
W_{C}=\sin (\theta) G
$$

In order to determine the grade of the test route described earlier, ambient pressure readings were taken along the test route for each test. This was done using the West Virginia University Mobile Emissions Measurement System (MEMS). Through the use of an ambient pressure transducer, pressure readings were recorded and reduced at a frequency of $5 \mathrm{~Hz}$. The procedure to determine the road grade along the test route is discussed in more depth in the Procedure section. With the slope, or inclination angle determined, the climbing resistance was found by taking the sine function of the angle and multiplying it by the test vehicle's weight component normal to the inclined surface. As mentioned in the discussion of the rolling resistance, lift due to aerodynamic effects was neglected for the construction of this study and the weight of the vehicle alone was used to describe the climbing resistance component of the total road load.

\subsection{Acceleration Resistance}

The final component that describes the total road load of a vehicle traveling is the acceleration resistance. This term usually is the least significant term in the road load equation when all four terms are present. At the same time, it is also one of the hardest to accurately determine. The acceleration resistance of a vehicle can be described as the force needed to overcome the linear and rotational accelerations of the test vehicle's components. Everything rotating on the test vehicle contains inertia and requires energy to create and maintain rotation. Some significant components included in the acceleration resistance term are the tires rotating, along with the transmission shafts, and gears rotating. Other rotating components that are accounted for in this term include the engine crankshaft, axle shafts, and the test vehicle's driveshaft. Every rotating mass on the vehicle that is being supplied energy through the engine's combustion process is accounted for here and Equation 6 below is the relationship used to calculate this term. 


$$
W_{A}=\dot{V}(1+\varepsilon) m
$$

With the acceleration values for the test recorded, the acceleration resistance term can be determined. Note that the process for determining the vehicle's acceleration is discussed in further detail in the Procedure section. The first term in Equation 6 above is the acceleration term and is multiplied by a function of epsilon. This epsilon value is a fractional value that encompasses, or describes the contribution of the rotating masses and their moments of inertia on and inside the vehicles drive train such as the rotation of the transmission gears (1). Finally, the equation is multiplied by the mass of the vehicle.

\subsection{Test Vehicle}

Testing was conducted using a 2002 Ford F650 medium duty truck rented from Stringfellow Truck Rentals in Nashville, TN. This vehicle was powered by a 2002 Cummins ISB compression ignition engine. Specifications for this engine along with the truck are shown below in Table 1.

Table 1: Test Engine and Vehicle Specifications

\begin{tabular}{|c|c|c|c|}
\hline \multicolumn{2}{|c|}{ Engine } & \multicolumn{2}{c|}{ Vehicle } \\
\hline Model & 2002 Cummins ISB 225 Diesel & Type & 2002 Ford F650 \\
\hline Family Number & 2CEXHO359BAB & Classification & Medium Duty / Single Axle \\
\hline Serial Number & 46218597 & Vehicle VIN Number & 3FDNF65Y33MB02010 \\
\hline Displacement & 5.9 Liter & Syle & 2-Door Flat Bed \\
\hline Power Rating & $225 \mathrm{Hp} \mathrm{@} \mathrm{2,300} \mathrm{RPM}$ & GVWR & 26,000 Lbs \\
\hline Timing Control & Electronic & Front / Rear GAWR & 8,500 Lbs / 17,500 Lbs \\
\hline
\end{tabular}

With the test vehicle's gross vehicle weight rating (GVWR), it was considered under the commercial vehicle limits and a non-Commercial Drivers Licensed driver was legal to conduct tests with it. It was chosen for this testing to load the vehicle at three weights and conduct multiple experiments, or data collections at each weight. The first loading was an empty weight where no additional weight was added to the test vehicle besides the necessary data collection equipment and a driver. The test truck is shown below in Figure 3. 


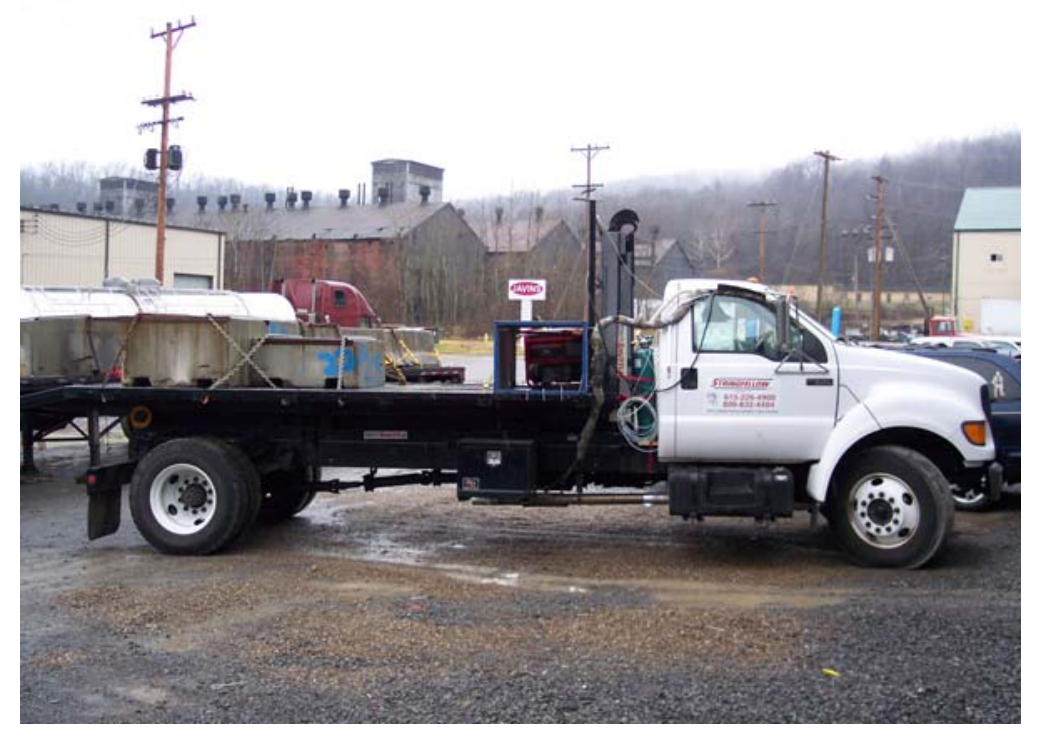

Figure 3: Ford F650 Test Vehicle

Table 2 below displays each test weight and the number of experiments conducted at each. The second test weight was one that was chosen to be approximately halfway between the test vehicle's empty weight and GVWR, and the third and final test weight was within $95 \%$ of the test vehicle's GVWR. Weight was added to the test vehicle's flatbed through concrete blocks securely mounted on the bed which can be seen above in Figure 3.

Table 2: Testing Weights and Number of Experiments

\begin{tabular}{|c|c|c|}
\cline { 2 - 3 } \multicolumn{1}{c|}{} & Test Weight (Lbs) & Experiments \\
\hline Empty Load & 17,140 & 6 \\
\hline Half Load & 21,220 & 6 \\
\hline Full Load & 25,220 & 6 \\
\hline
\end{tabular}

\subsection{Test Route}

The route chosen for testing was one that incorporated city driving as well as interstate situations with many variations in elevation and road grade. It can be seen below in Figure 4 where the starting and finishing location is defined by S/F (31). The testing route began at the West Virginia University Mobile Laboratory located in Westover, WV and traveled north on Industrial Park Rd. Continuing north, Industrial Park Rd. became Dupont Rd. and led to US route 19. The testing route continued traveling west on US route 19 and onto interstate I-79 south. Interstate I-79 south split and the testing route followed interstate I-68 east to the Sabraton exit \#3. After exiting, 
WV route 7 north (Earl Core Road) was taken through Sabraton and a right was taken onto Hartman Run Rd. which lead to US route 119 south (Mileground Rd.).

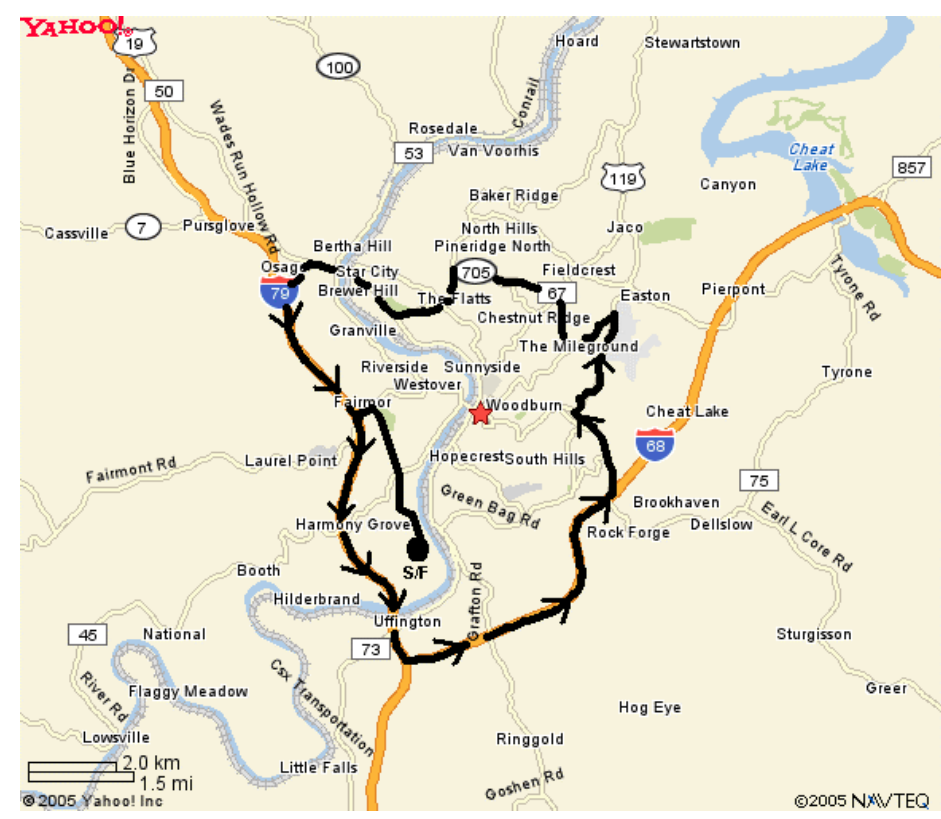

Figure 4: Vehicle Test Route Around Morgantown, WV

WV route 705 north was then taken which traveled through the city of Morgantown until meeting US route 19 north which traveled through Star City eventually turning leading to interstate I-79 south again. Interstate I-79 south was taken to the Westover exit where US route 19 north was taken back to Dupont Rd., eventually leading back to the WVU Mobile Laboratory on Industrial Park Rd. This route was completed six times for each of the different test weights described earlier with each test lasting approximately fifty minutes depending on traffic conditions and test weight. Furthermore, ambient conditions ranged from sunny days, to rain, to snow over the course of the testing period.

\subsection{Test Equipment}

\subsubsection{Measurement System}

During the testing period for this study, the test vehicle described earlier was outfitted with a complete MEMS system even though only a few parameters were needed and would be sufficient to establish the desired road load model. The extra data recorded could be used in further studies. The truck used for testing was outfitted with an Annubar mounted to a fabricated exhaust tube to draw flow from the exhaust pipe to an emissions 
box consisting of measurement devices used to determine amounts of emission constituents in the exhaust. Connecting the MEMS emissions box to the annubar box was a heated line to prevent condensation in the sampled exhaust as some of the measurements taken in the initial stages of the emissions box are wet measurements. Note that a detailed description of the MEMS testing equipment is located in Thompson (25).

\subsubsection{Data Acquisition}

The data acquisition system developed by West Virginia University is a computer platform constructed of National Instruments components making up the computer platform, data acquisition card, signal conditioning unit, and temperature and voltage cards. The data acquisition system has multiple serial port inputs for allowance of many different measurements to be taken all at once; ECU outputs and ambient pressure readings for this study. Mounted to the data acquisition system was a monitor to allow measurements being taken during testing to be viewed by the test engineer and prevent any unnecessary testing to be conducted if modifications were needed due to any problems. Power was supplied to the data acquisition unit through an onboard generator securely fixed to the bed of the test vehicle.

\subsection{Data Collection}

By reducing or minimizing the number of parameters needed for this model development, the complexity of the analysis was also kept to a minimum. As discussed by Cha, it has been shown that increasing the complexity of a road load model does not instinctively provide more accurate results (5). Instead of creating a complex model, more accurate results could be gathered by following a simpler approach and describing the test vehicle's constant parameters, such as its drag coefficient, in a manor based upon its size, dimensions, and body style, in a more realistic way.

\subsubsection{Engine Speed}

Engine speed was recorded through the output of the test vehicle's ECU. The vehicle measures its engine speed through the use of a variable reluctance pickup sensor which is a type of crank position sensor that is commonly found on most automobiles 
today. As the flywheel rotates, the teeth in the outer ring pass very close to the sensor and a voltage is induced as a result of the magnetic pick up and is recorded by the ECU. The ECU records the number of pulses it receives and also the increase or decrease in pulse width indicating an increase or decrease in engine speed respectively. Using a Deutsch connection located under the vehicle's dashboard, the ECU of the vehicle was connected to a Dearborn DPA Protocol adaptor. The output from this device was connected to the MEMS data acquisition system via a serial cable. Using the data acquisition system described previously, the test vehicle's engine speed could be monitored and recorded at a sampling rate of $5 \mathrm{~Hz}$ to be used in calculating the different components of the road load during testing.

\subsubsection{Ambient Pressure}

Ambient pressure readings were taken using an ambient pressure transducer manufactured by Omega. The specific transducer used, shown below in Figure 5, was a model PX176 ambient pressure transducer with an output voltage range of one to six volts DC (17). The PX176 transducer was in a waterproof casing allowing it to be used in a wide variety of weather conditions and operating temperature range of $-55^{\circ} \mathrm{C}$ to $105^{\circ} \mathrm{C}$. The specific model pressure transducer had an operating pressure range of 0 25psia with an accuracy of $\pm 1 \%$ of full scale. An aluminum casing, titled an ambient box, was used to protect the pressure transducer from environmental elements and allow the sensor to be securely fixed to the test vehicle during testing. Also installed within this ambient box was an ambient temperature and relative humidity sensors, but were not used or included in the data reduction. Voltages produced by the transducer were transferred to the MEMS data acquisition program and recorded during testing to be used in calculating changes in altitude discussed in further detail in the Procedure section of this paper. 


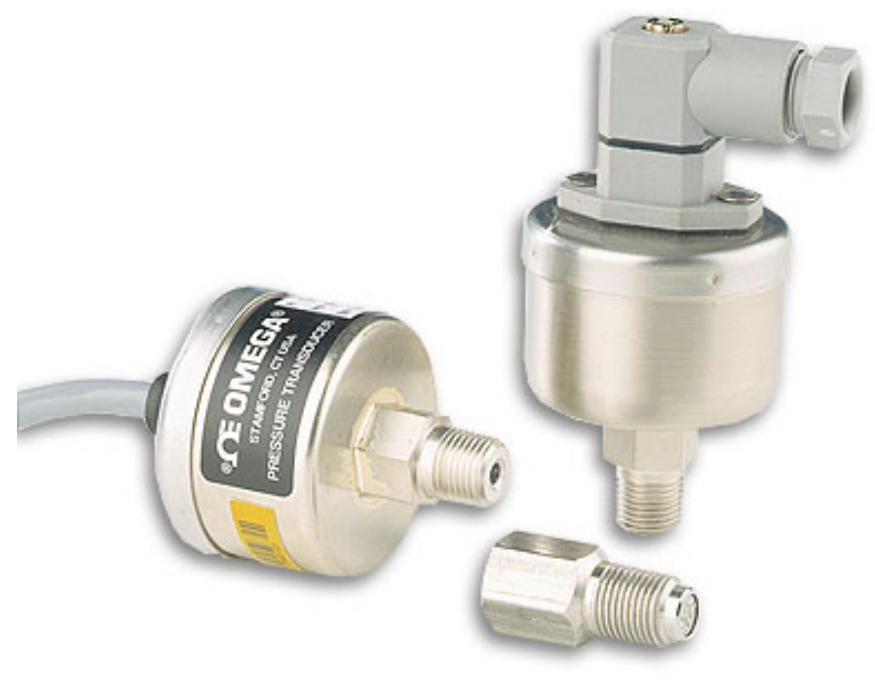

Figure 5: Omega Model PX176 Pressure Transducer

Using the MEMS data acquisition hardware and software, the Omega ambient pressure transducer was calibrated prior to each test run to ensure accurate measurements. This was done with the calibration software linked with the MEMS test program and a Heise model PTE-1 pressure calibrator. This specific pressure calibrator has a duel display liquid crystal display (LCD) monitor and has an accuracy of approximately $0.1 \%$ of full scale and is shown below in Figure 6 (8).

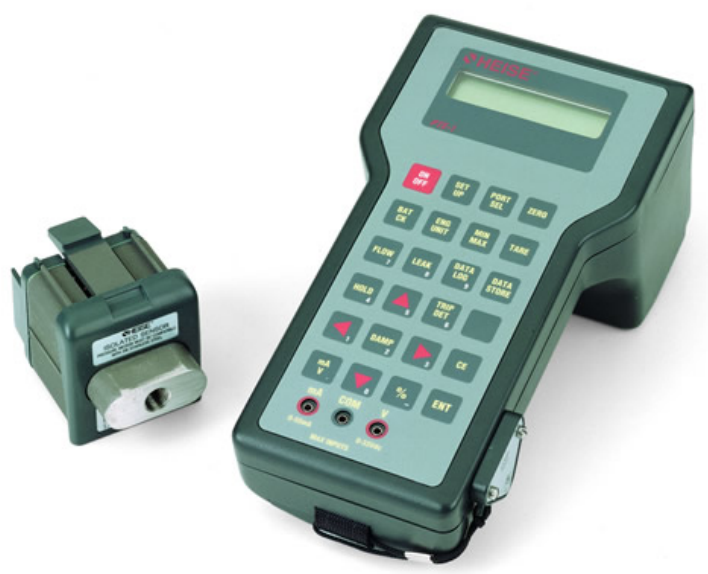

Figure 6: Heise Model PTE-1 Pressure Calibrator and Pressure Unit

\subsubsection{Vehicle Speed}

The vehicle speed used for the development of this model was the ECU vehicle speed output. Vehicle speed was detected by the test vehicle's ECU through the use of a 
similar variable reluctance pick-up sensor as described earlier for engine speed measurements. Located at the output shaft of the transmission, before the rear driveshaft, the pick-up sensor measured the rotational output speed of the transmission. This placement reduced complexity of measuring vehicle speed since transmission gear engagement was irrelevant. If the sensor was mounted ahead of the transmission, for example, the current gear engaged would have to be accounted for by the ECU to determine proper gear ratios and calculate the vehicle speed. With the sensor mounted aft of the transmission, the axle ring gear ratio, and tire size are the only two adjustments that need to be accounted for. These two factors remain relatively constant over the life of the vehicle with an assumption that tire wear or deflection does not affect the rotational speed of the rear axle significantly. Therefore, the accuracy of the ECU speed sensor was considered sufficient and used as the primary velocity values for this model.

A secondary method of recording vehicle speed for testing was through a global positioning sensor (GPS). Through the use of a connection between a roof-mounted sensor and satellites in space, the vehicle speed could be monitored and recorded through the MEMS data acquisition system. The GPS sensor broadcasted data at a rate of $1 \mathrm{~Hz}$, but was interpolated by the MEMS data reduction program to present the data collected at a rate of $5 \mathrm{~Hz}$ to match the other data parameters recorded by the test system. Note that GPS data was recorded as a backup to the vehicle's ECU vehicle speed data outputs and was used in a secondary study within this work to verify and check the ECU's accuracy, and show the GPS speed's accuracy and its possibilities of being the primary vehicle speed measurement device. However, for this work, the primary vehicle speed data used was collected through the ECU vehicle speed output.

\subsubsection{Inferred Torque and Power}

An alternate way of measuring engine torque is by inferring it from several ECU output measurements, a minimum load idle curve, and a supplied lug curve for the specific engine. By using the two engine curves and output values of the ECU engine speed and percent load, the torque produced by the engine can be calculated (26). The engine lug curve is a set of data that describes the specific engine's maximum torque producing abilities throughout its operating speed range. The purpose of the idle curve is 
to determine the fueling that is required by the engine to overcome its own internal loadings, and in the case of chassis dynamometer testing or on-road testing, the idle curve helps to determine loading from vehicle accessories such as air conditioners and alternators. 


\section{Procedure}

To begin reducing the data, each Microsoft Excel spreadsheet created by the MEMS data acquisition reduction program was simplified to include only the data needed to create the desired model. The three main components needed for the model were the time, ambient pressure readings, and the ECU vehicle speed. Note that for comparative purposes, the vehicle’s ECU power output was also recorded but not necessary.

This section encompasses the work performed to analyze the data recorded and produce comparisons for later results. Steps were taken to reduce outliers found within recorded data to begin the reduction. This section describes and justifies the logic used to eliminate the outlying data points. The data was then manipulated and expanded to create and describe the road load felt by the test vehicle's engine.

\subsection{Ambient Pressure}

It could be seen that within the ambient pressure readings that there was some noise that needed to be addressed. This electrical noise recorded could be contributed to multiple things such as the ambient pressure transducer being mounted on the outside of the test vehicle, which would allow it to be open to an extremely windy environment during the test route, especially at highway speeds. In order to decrease the noise, a moving window of an eleven point average was used, the relationship of which is shown below in Equation 7.

Equation $7 \quad y_{i}=\frac{y_{i-5}+y_{i-4}+y_{i-3}+y_{i-2}+y_{i-1}+y_{i}+y_{i+1}+y_{i+2}+y_{i+3}+y_{i+4}+y_{i+5}}{11}$

It can be seen in Equation 7 that each new ambient pressure reading was calculated using the five previous raw data points, the current raw data point, and the following five raw data points. This results in a two second moving window. Furthermore, within the data calculations, if the difference between two different raw ambient pressure data points changed by an absolute pressure value of $0.038 \mathrm{inHg}$ or greater, the current point was neglected and replaced with the previous. With the data being recorded at a rate of $5 \mathrm{~Hz}$, a change in 0.038 ” $\mathrm{Hg}$ over two data points would imply an altitude change of approximately $35 \mathrm{ft}$ over a $0.2 \mathrm{sec}$ period, which is unrealistic for the testing being conducted. This logic could have been more strict but the intent of it was 
just to eliminate any raw data points that were obviously outliers and irrelevant to the study at hand.

\subsection{ECU Vehicle Speed}

Similar reduction methods were used with the recorded ECU vehicle speed. An eleven point smoothing spread was used as shown above in Equation 7, and a similar logic statement was used. The difference between the ambient pressure logic, and the ECU vehicle speed was that if the difference between two raw vehicle speed data points, considering a current point in the data set and the previous one, was greater than $2 \mathrm{mph}$, the previous point was used instead of the current. With a change of $2 \mathrm{mph}$ or greater over a period of $0.2 \mathrm{sec}$, an acceleration would be produced of $10 \mathrm{mph} / \mathrm{sec}$. This would not be seen given the size and loading of the test vehicle being considered.

\subsection{Distance}

With each test being driven on a route that was as similar as possible for each run, it was difficult to relate and compare each run because of a few different factors. One factor was that each run had an undefined idle period once data recording had begun until the time that the test route was driven. Similarly, at the end of the test run, the vehicle data was recorded at another undefined idle period where different test parameters which were displayed through the MEMS data acquisition system were allowed to stabilize and reach equilibrium before the test was ended. In addition, because of the multiple loading magnitudes and uncontrolled traffic events, the total test time was uncontrollable. For those reasons, the tests were modified to be analyzed on a distance basis rather than a time basis. Through the use of the recorded ECU vehicle speed, and the recorded time, the instantaneous distance change could be determined for each point and the test run could be relative to a distance base. This was done by using Equation 8 below.

Equation 8

$$
d_{i}=d_{i-1}+V_{i} * 0.2 \mathrm{sec}^{*} \frac{5,280 \frac{\mathrm{ft}}{\text { mile }}}{3600 \frac{\mathrm{sec}}{\text { hour }}}
$$

In Equation 8 above, the instantaneous distance traveled was calculated by adding the previous distance calculated and the current velocity multiplied by the time interval, 
which was $0.2 \mathrm{sec}$. With the velocity being measured and displayed in miles per hour, the distance calculated was converted to feet with the applied conversions shown in Equation 8. Note that the velocity used in Equation 8 is the velocity value determined after smoothing techniques, discussed earlier, were implemented and not the raw data point.

After determining each tests' distance basis values, it was noticed that some of the runs were shorter than others due to modifications in the test route as a result of changing weather conditions. At the time of testing this was not assumed to be a problem, but when the tests were aligned, as described later in the inclination section of this work, problems occurred and some of the recorded tests were not considered to support the study. Similar to Table 2 shown earlier, Table 3 below shows the weights and number of tests conducted at those weights that were used in the model analysis. Moreover, one test presented a problem with the ECU output and was neglected in the analysis and comparison of power and work. To clarify, there were 13 tests producing applicable results with the exception of one test where ECU power data was erroneous and unreadable. Because of this, the 13 tests were used in all of the data reduction computations, but there were only 12 tests where a comparison could be made between the road load developed and engine power as well as the integrated work over the test.

Table 3: Final Testing Weights and Number of Experiments

\begin{tabular}{|c|c|c|}
\cline { 2 - 3 } \multicolumn{1}{c|}{} & Test Weight (Lbs) & Experiments \\
\hline Empty Load & 17,140 & 3 \\
\hline Half Load & 21,220 & 3 \\
\hline Full Load & 25,220 & 6 \\
\hline
\end{tabular}

\subsection{Air Density}

At this point in the data reduction, the ambient air density was determined, it's use briefly discussed earlier in the aerodynamic drag calculation. This was done by using Equation 9 below.

Equation 9

$$
\rho=\frac{p}{R T}=\frac{p(\mathrm{inHg}) * 144\left(\frac{i \frac{i}{2}^{2}}{f t^{2}}\right)}{R\left(\frac{f t l b_{f}}{l b_{m} R}\right) T(R)} * \frac{14.696\left(\frac{l b_{f}}{i n^{2}}\right)}{29.92(i n H g)}
$$

The instantaneous air density during the run was calculated using the ideal gas law with the term " $p$ " being the relative ambient pressure. Note that units for each term 
in Equation 9 above equation are shown in parenthesis. The universal gas constant " $R$ " was taken to be $53.33 \mathrm{ftll} \mathrm{b}_{\mathrm{f}} / \mathrm{lb}_{\mathrm{m}} \mathrm{R}$ for standard atmosphere and the relative ambient temperature was taken from measurements taken before and after each individual test, leaving the density calculated in units of pounds mass per cubic foot. With temperature values recorded pre and post each test, an average was taken assuming that altitude changes throughout the test route were minimal to the degree to which there would not be large fluctuations in ambient temperature values. Furthermore, the test times for each run was short enough that temperature changes before and after testing were on the order of $1^{\circ} \mathrm{F}$ or $1 \mathrm{R}$.

\subsection{Vehicle Acceleration}

In order to determine the test vehicle's acceleration, a differentiation of the ECU vehicle speed was taken with respect to the recorded test time. To accomplish this, two similar methods were considered and are shown below in Equation 10 and Equation 11.

$$
\begin{array}{cc}
\text { Equation 10 } & a=\frac{V_{i+1}-V_{i-1}}{2 h} \\
\text { Equation 11 } & a=\frac{-V_{i+2}+8 V_{i+1}-8 V_{i-1}+V_{i-2}}{12 h}
\end{array}
$$

Equation 10 is a statistical central difference method of differentiation with a step size order of $h^{2}$, and in this case with the sampling rate of the system recording at $5 \mathrm{~Hz}$, with a step size was 0.2sec. Similarly, Equation 11 is a differentiation method of determining the test vehicle's acceleration with an order of $\mathrm{h}^{4}$. After comparing both methods of calculating acceleration values, there was not very much difference between the two results, but in the end, Equation 11 was used because of its higher order and accuracy. Note that because of a possible resolution problem with the vehicle's ECU velocity output, at vehicle speeds existing below $10 \mathrm{mph}$, the acceleration was assumed to be zero and a negligible component to the vehicle's road load. In such a case, velocity changes of $1 \mathrm{mph}$ were reported by the vehicle's ECU over a $0.2 \mathrm{sec}$ interval which suggested an acceleration of $5 \mathrm{mph} / \mathrm{sec}$ which is highly unlikely for the category of test vehicle being considered. Also note that in both equations, instead of using the raw vehicle velocity measured by the vehicle's ECU, the calculated smoothed values were used. 


\subsection{Altitude}

With the ambient pressure recorded and the noise, and or assumed outliers removed, the altitude of the test vehicle during testing could be determined. With road grade being the primary calculation goal from the altitude calculation process, the changes in altitude were more important than the actual altitude values. Because of this, a reference altitude of $1200 \mathrm{ft}$ was chosen for the beginnings of each test located at the West Virginia University Mobile Laboratory in Westover, WV. This reference height was chosen and then compared with a topographic map and was found to be slightly greater, but with only changes in altitude under consideration, modifying the initial altitude would not change any results (27). Once the reference height, or altitude, was fixed, the instantaneous altitude values throughout the tests were determined using Equation 12 below.

\section{Equation 12}

$$
h_{i}=h_{i-1}-960\left(\frac{f t}{i n H g}\right) * \Delta p(i n H g)
$$

The change in pressure term was determined by the change in ambient pressure readings recorded, and the overall height was recorded in feet. Also note that units for each term are shown in parenthesis. The value of $960 \mathrm{ft} / \mathrm{inHg}$ was determined by calculating densities at multiple altitudes through the use of standard atmosphere tables and relating them to their corresponding values. Within the range of altitude changes associated with the conducted tests, an approximate value of $960 \mathrm{ft}$ was found for a change in ambient pressure of 1inHg (2).

With a global positioning system (GPS) connected to the MEMS data acquisition system, altitude, as well as vehicle speed, was recorded based upon satellite signals. This altitude data was recorded with intent to compare to the values calculated from Equation 12 above. However, a problem exists within GPS altitude data where the signal received from satellites in orbit is partially scrambled to cause the initial and final altitudes of a closed path that returns to the same position to be different. This was found to be true when analyzing GPS data recorded during testing. Although the initial and final positions were controlled to be exactly at the same point, a difference in altitude was recorded on the order of approximately $14 \mathrm{~m}$. 


\subsection{Road Inclination Angle}

\subsubsection{Individual Test Inclination Angle Calculations}

With the altitude determined from the changes in ambient pressure recorded, the road grade, or inclination angle, during the test was desired. The slope between the altitude and the distance traveled was then calculated by linearizing the altitude data within a ten second moving window. For each instantaneous point, this moving window helped to eliminate small spikes in the data collection by fitting a linear curve over the previous five second window, the current point under consideration, and the following five second window to determine the ratio of the change in vertical height, or altitude, and the change in horizontal distance. With instantaneous values for the "rise over run" or slope of the altitude distance relationship, the road inclination angle could be determined using Equation 13 below.

\section{Equation 13}

$$
\theta=\tan ^{-1}\left(\frac{\Delta h}{\Delta d_{h}}\right)
$$

Note that the change in distance term in Equation 13 is not the change in distance measured from the previous distance calculated with Equation 8. This change in distance is a horizontal value unlike the distance determined earlier, which is a tangential distance that travels along the altitude or velocity curve. The horizontal distance change was needed to find an accurate inclination angle and was calculated using Pythagorean's theorem for a ninety degree triangle stated below in Equation 14.

\section{Equation 14}

$$
\Delta d_{h}=\sqrt{\Delta d^{2}-\Delta h^{2}}
$$

For a visual description, Figure 7 below shows the triangle used to determine these different parameters. 


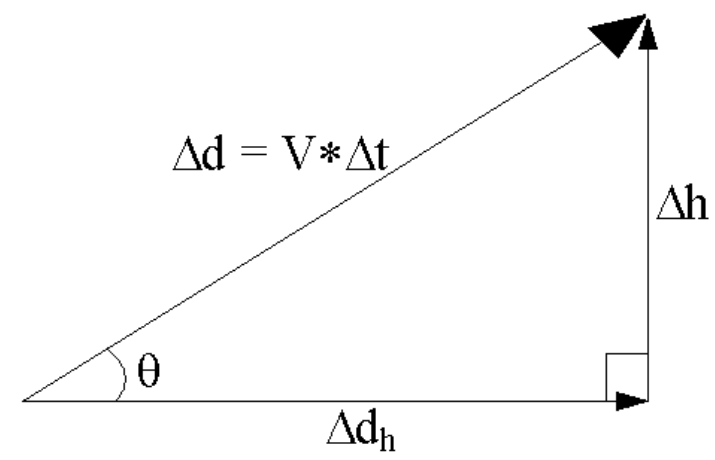

Figure 7: Inclination Calculation Triangle

\subsubsection{Overall Test Inclination Angle Calculations}

With road inclination angles determined for all instantaneous points during each test, it was noticed that there were still some spikes in the data that needed to be accounted for and corrected in some way. To resolve these data points, an overall or averaged inclination angle data set was calculated. In order to do this, the test-specific inclination angles calculated and their corresponding distance values were organized and grouped together to be manipulated further. With each test run containing different numbers of total data points, it was difficult to correlate each one with each other. To settle this problem, the data was aligned to one set of distance values. With all of the data aligned, an average value was calculated at each corresponding distance value. At this point, the overall inclination angle values were introduced back into each of the individual test runs the angles were imputed back within the recorded data and used from that point on. That is, the twelve valid test runs in Table 3 were used to obtain an average inclination angle as a function of distance.

\subsection{Power}

\subsubsection{Rolling Power}

With the ECU vehicle speed recorded, the power required to overcome rolling resistances could be calculated. Rolling power was determined using Equation 15 below. For each test, the value for the rolling friction coefficient for the test vehicle was assumed to be 0.02 while the weight varied for each test depending upon the test weight desired (3). 


$$
P_{R}=f_{R} G_{N} * V
$$

\subsubsection{Climbing Power}

After determining the inclination angles over the entire test run on a distance basis, the power required for the vehicle to overcome the Earth's pull of gravity could be determined and was done so using Equation 16. Note that as road inclination angles approach zero, the sine function of that angle will also approach zero and essentially eliminate the power needed for climbing.

Equation 16

$$
P_{C}=\sin (\theta) G^{*} V
$$

\subsubsection{Acceleration Power}

Although minor compared to the vehicle's rolling resistance and aerodynamic resistance at higher vehicle speeds, the power needed for the vehicle to overcome rotational accelerations taken place was still significant and needed to be calculated. This was done using Equation 17 below.

\section{Equation 17}

$$
P_{A}=a(1+\varepsilon) M * V
$$

The value for epsilon was a constant value of 0.25 used throughout the testing analysis to incorporate all of the rotating masses on or within the vehicle. Values for epsilon are representative of rotating masses on the test vehicle and varied depending on the quantity and size of the masses (1).

\subsubsection{Aerodynamic Power}

The aerodynamic resistance and the power needed for the vehicle to overcome it was determined using Equation 18 below.

\section{Equation 18}

$$
P_{D}=q_{\infty} C_{D} A^{*} V=\frac{1}{2} \rho V^{2} C_{D} A^{*} V
$$

It can be seen in the above equation that the velocity squared term along with the density make up what is called the dynamic pressure shown in the first form of Equation 18. The value for the drag coefficient was a constant used throughout the testing analysis and was assumed to have a value of 0.7 (5). The value for the frontal area was determined using a planimeter, described earlier, and was found to have a frontal area value of $43.4 \mathrm{ft}^{2}$. 


\subsection{Work}

With power values determined, the work could be determined. With the use of Equation 19 below, the power calculated previously could be multiplied by the length of time between measurements and provide values for the instantaneous work throughout the test period. By summing the instantaneous work values calculated, the total work performed by the vehicle's engine could be found. This was done for the power output by the vehicle's ECU and the values calculated by this model.

Equation 19

$$
W=\int P d t=\sum P \Delta t
$$

By calculating the vehicle inferred torque as discussed earlier, a third work value could be determined for comparative purposes. Equation 20 below shows how the torque was converted to power.

\section{Equation 20}

$$
P_{\text {Inferred }}=T_{\text {Inferred }} * N / 550\left(\frac{h p}{f t-l b s * \sec }\right)
$$

Note that the engine speed is recorded in revolutions per minute and the time needed to be converted such that it was used in the calculations in revolutions per second. With the inferred power determined, the inferred work could be determined using Equation 19 as described above.

\subsection{Uncertainty Analysis}

To finalize the study, an uncertainty analysis was conducted to describe the error associated with road load power values calculated due to uncertainties in the initial measured values. This allowed for the significance of each term in the road load equation to be considered and have the knowledge of what terms were more sensitive than others due to minor changes in recorded values such as the vehicle's speed measurements. Equation 21 below shows how the uncertainty analysis began.

Equation 21

$$
P=P_{\text {Average }} \pm \Delta P
$$

The $\Delta \mathrm{P}$ term in the above equation was the uncertainty value for the power combined from all the road load terms. Equation 22 below shows how this term was determined. 
Equation 22

$$
\Delta P=\sqrt{\sum\left(\frac{\partial P}{\partial x_{i}} \Delta x_{i}\right)^{2}}
$$

To perform Equation 22 above, the total road load was expanded and the partial derivative was taken with respect to each individual variable defining it. With the partial derivatives found, each was multiplied by the uncertainty of the individual parameter, squared, summed up over all the terms, and the square root was taken. This provided an uncertainty for the total road load values found. Then, as shown in Equation 21, the road load power values could be shown with an uncertainty value attached to it. 


\section{Results}

Results shown within this section are representative of one test conducted with a gross vehicle weight of $17,140 \mathrm{lbs}$. With the exception of comparison results and figures of power and work production, additional individual test results are located in the appendix of this work, Chapter 8 .

\subsection{Ambient Pressure}

Presented below in Figure 8 is the raw ambient pressure readings taken for the test. The noise associated with the raw pressure sensor can easily be seen and the necessity to reduce, or eliminate it becomes evident. Excluding the large gradients, or spikes, in the data due to noise, the ambient pressure displays an approximate interpretation of altitude changes with an increase in pressure indicating a decrease in altitude and vice versa.

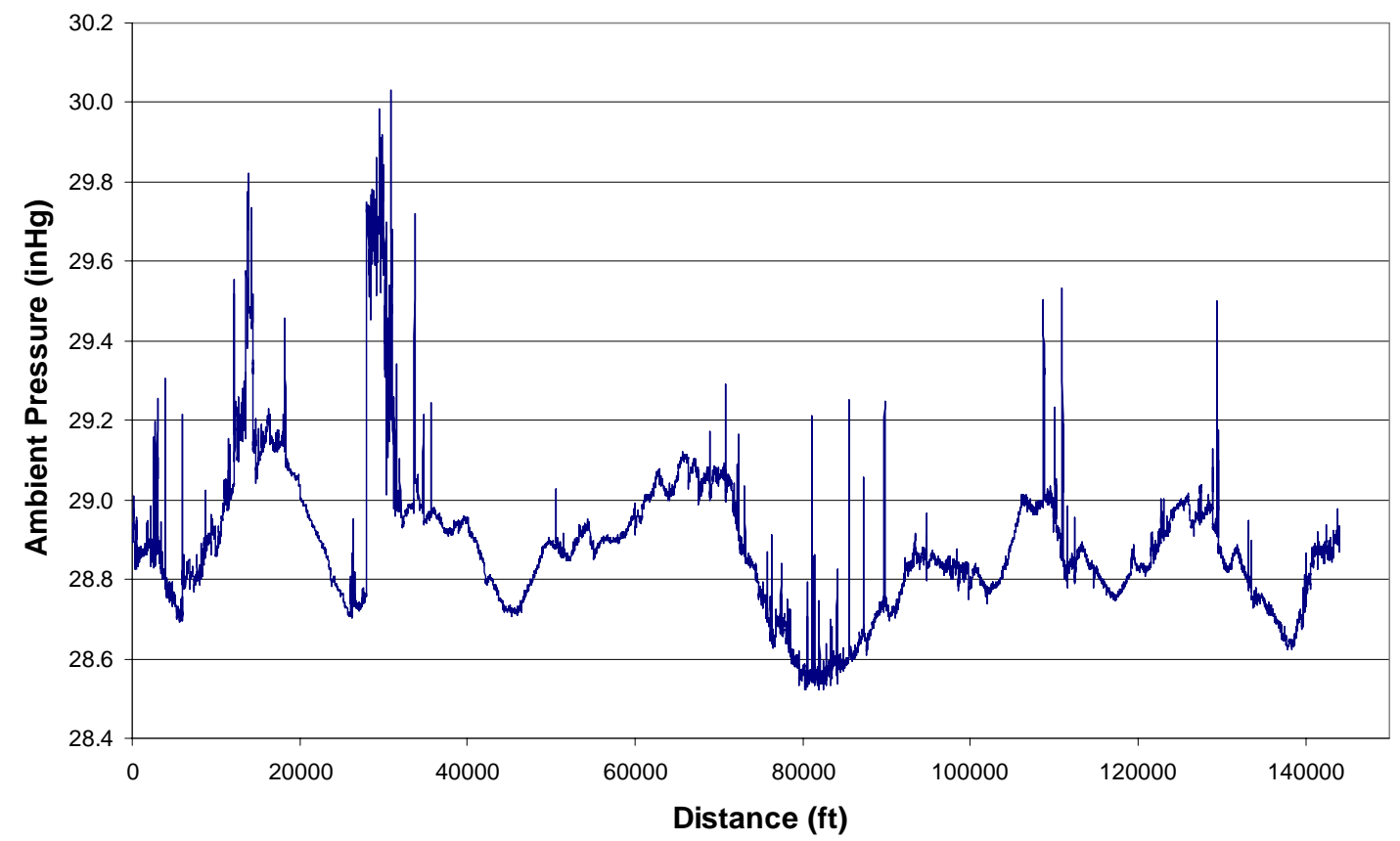

Figure 8: Ambient Pressure Readings During One Empty Load Test Run

\subsection{Vehicle Speed}

The ECU vehicle speed recorded through the MEMS data acquisition system is shown below in Figure 9 for the test. Noise issues, like those found in ambient pressure readings, are not present to a significant affect with the ECU vehicle speed output and 
recordings. Because of this, the noise reduction methods described earlier for the vehicle speed were insignificant and did not modify the data to any considerable extent but were still performed.

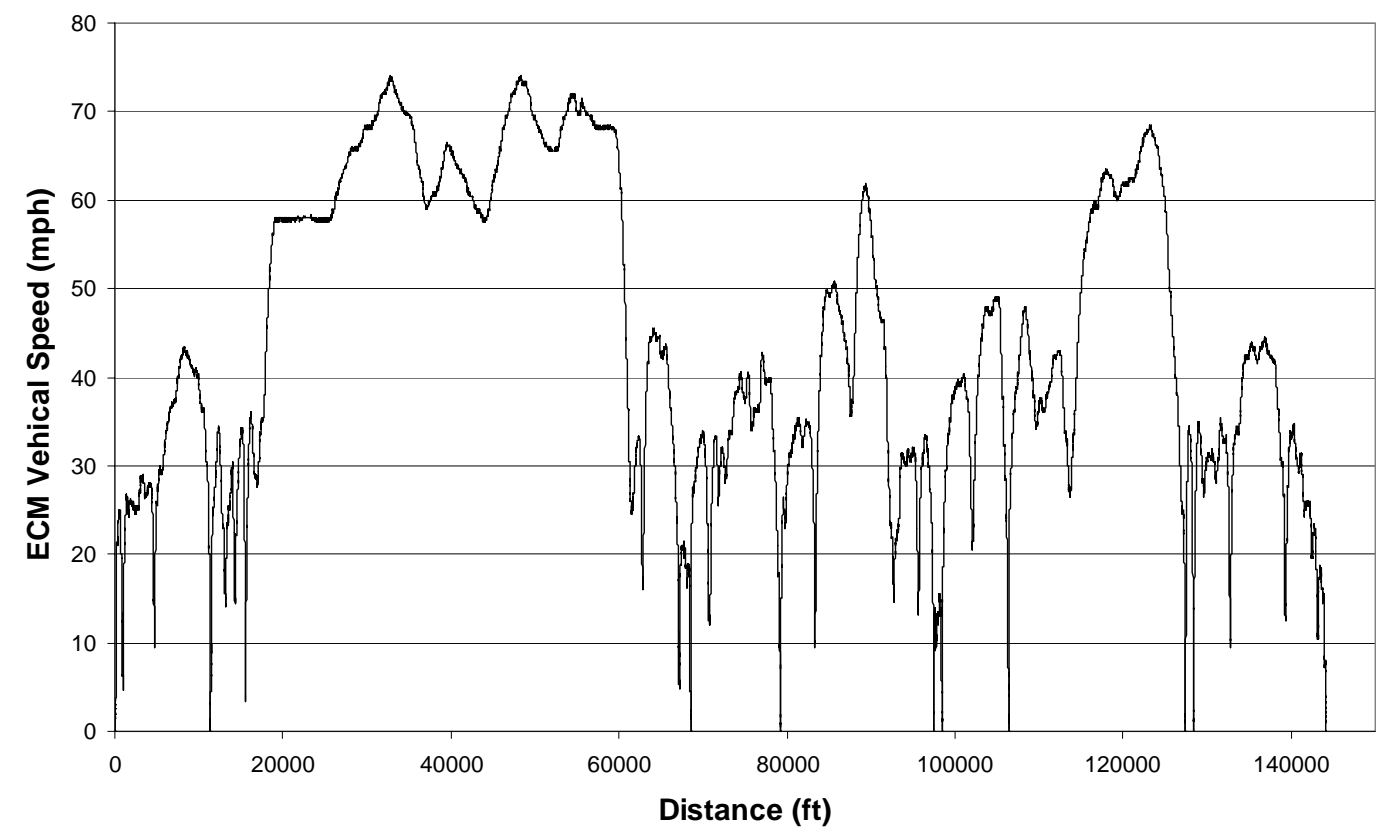

Figure 9: ECU Vehicle Speed During One Empty Load Test Run

Figure 10 below illustrates a comparison between the GPS speed recorded, and the ECU vehicle speed. The values broadcast by the GPS signal are similar to the ECU values and can be used as a viable backup for vehicle speed if needed. There are small variations in the data at higher speeds but the two correlate at lower and medium speeds. 


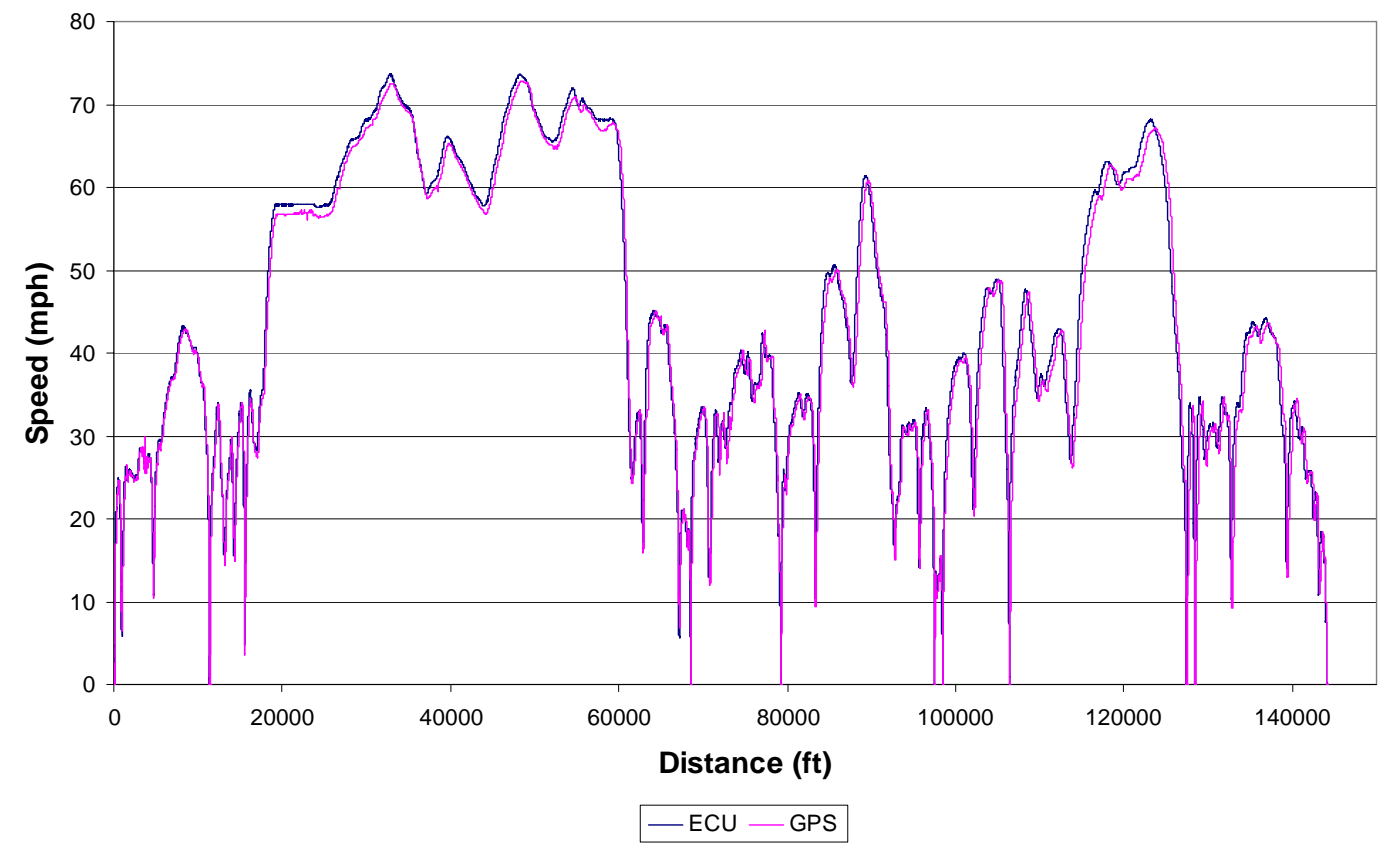

Figure 10: ECU and GPS Vehicle Speed Comparison

\subsection{Distance Base}

As stated earlier, by converting each test into a distance based relationship allowed multiple experiments to be compared together without introducing data alignment issues which would be present under a time based comparison because of the fact that there was an idle period at the beginning and end of each test run. This idle period differed from test to test and lasted on the average of $45 \mathrm{sec}$ to allow the data to be manipulated during reduction without interfering or eliminating any data that took place during the dynamic period of a test run. Figure 11 below displays the calculated distance for one test run. 


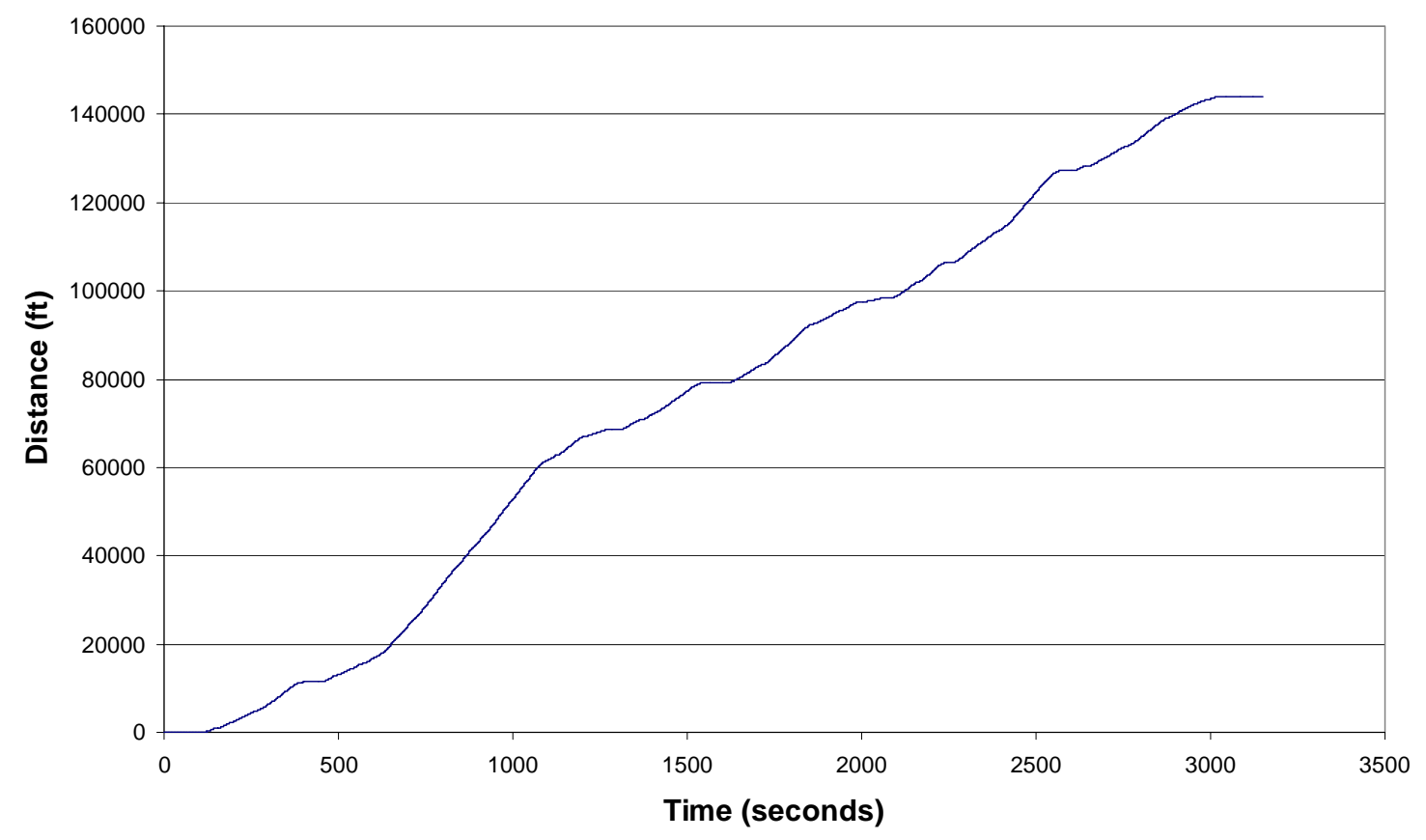

Figure 11: Test Distance Determined From ECU Vehicle Speed and Test Time

The average distance over the thirteen total tests that were considered for the model development was $144,342 \mathrm{ft}$ which is approximately 27.3 miles. Figure 12 , shown below, displays a distance comparison between each test run analyzed. The first four tests are of the 17,140lb empty load test weight, the next three are of the 21,220lb half load test weight, and the final six bars represent the 25,220lb full load test weight. As briefly described earlier, the empty load weight of $17,140 \mathrm{lbs}$ is the weight of the test truck with no additional weight added to its chassis. The full load weight of 25,220lbs was $97 \%$ of the test vehicle's GVWR of 26,000lbs. During testing at a vehicle's full load, because loading it to its exact legal loading limit is difficult, it is desirable to be within 95\% of its GVWR. This requirement of testing within 95\% of the test vehicle's GVWR was set forth by the Consent Decrees for on-road emissions testing. The half load weight of $21,220 \mathrm{lbs}$ was a test weight chosen that was close to half of the allowable weight addition to the test vehicle. 


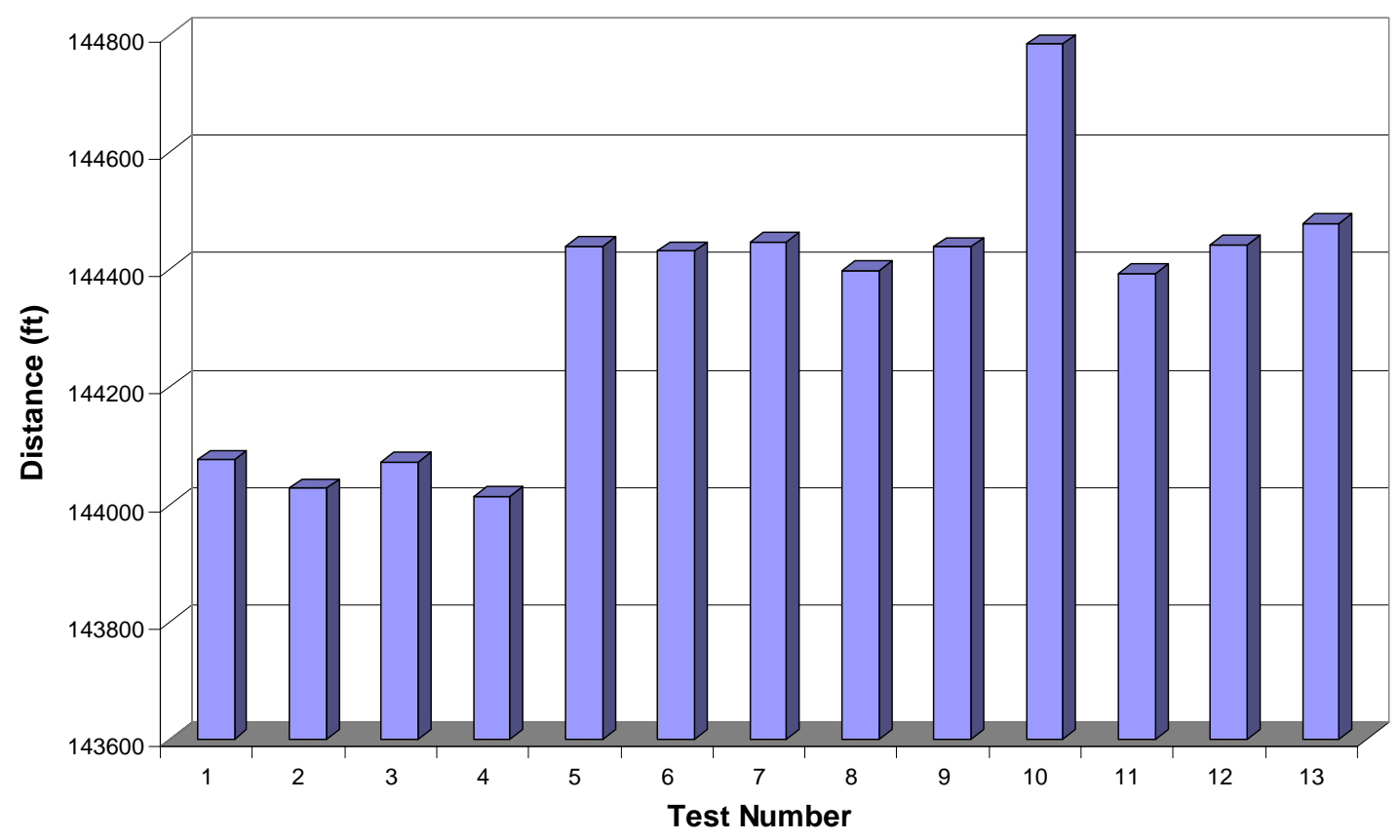

Figure 12: Total Distance Traveled During Each Test Run

Table 4 below shows the distance comparison for the thirteen tests conducted, along with average values and standard deviation values. It can be seen in Figure 12 above and Table 4 below that there were differences in the total driving distances for the different tests on the order of $770 \mathrm{ft}$, or approximately $0.5 \%$ of the average test distance, between the maximum and minimum distance. These differences can be attributed to such things as ECU vehicle speed resolution, weather conditions, vehicle test weights, and lane changes occurring during testing. The first four test runs $(17,140 \mathrm{lbs})$ maintained precise distances as they were conducted under the same weight, and weather conditions. Similarly, the next three tests conducted, although different than the first four's totals, produced precise results as they were tested under the same weight $(21,220 \mathrm{lbs})$ and weather conditions. Differences between these two sets of runs could be accounted for significantly because of the fact that the first set was tested under cloudy, dry conditions and the second set was tested under snowy conditions.

The vehicle's test weight could cause a difference in driving distances due to the fact that under larger vehicle loadings, there is a larger tire deflection. The tire deflection is going to cause the tire to rotate faster as it is acting as a smaller wheel and cause the overall test distance to increase. Tire pressure was not checked during the testing period 
and differences in test distance. Furthermore, due to the circular nature of the test route, and average test route radius of 1.7 miles, a difference in total distance traveled can be on the order of $75.4 \mathrm{ft}$ depending on weather the truck traveled in the outside lane or the inside lane for the testing period.

Table 4: Test Distance and Test Time Values

\begin{tabular}{|c|c|c|c|}
\hline Test Number & Test Weight (Ibs) & Distance (ft) & Time (sec) \\
\hline 1 & 17,140 & 144,076 & 3,151 \\
\hline 2 & 17,140 & 144,027 & 3,569 \\
\hline 3 & 17,140 & 144,072 & 3,151 \\
\hline 4 & 17,140 & 144,014 & 3,573 \\
\hline 5 & 21,220 & 144,440 & 3,213 \\
\hline 6 & 21,220 & 144,431 & 3,187 \\
\hline 7 & 21,220 & 144,447 & 3,419 \\
\hline 8 & 25,220 & 144,399 & 3,331 \\
\hline 9 & 25,220 & 144,438 & 3,507 \\
\hline 10 & 25,220 & 144,784 & 3,050 \\
\hline 11 & 25,220 & 144,393 & 3,297 \\
\hline 12 & 25,220 & 144,442 & 3,545 \\
\hline \multirow[t]{4}{*}{13} & 25,220 & 144,479 & 3,088 \\
\hline & Average (ft) \& (sec) & 144342 & 3,314 \\
\hline & Standar Deviation (ft) \& (sec) & 227.0 & 190.3 \\
\hline & Coefficient of Variation (\%) & 0.157 & 5.742 \\
\hline
\end{tabular}

One of the final six tests overall distance differed significantly while the weather conditions did not change drastically. A possible reason for this error could be a small error within the test vehicle's ECU velocity output that would cause the overall distance to be increased. Note that the difference for test number 10 may seem significant when closely compared to the other tests, but its difference is on the order of $0.3 \%$ of the average test distance values. Table 5 below summarizes the different weather conditions between the different test runs including the test date for each run, the pre and post testing weather conditions and temperatures. 
Table 5: Pre and Post Weather Conditions During Testing

\begin{tabular}{|c|c|c|c|}
\hline Test Run & Date & Weather Pre/Post & Temp Pre/Post $\left({ }^{\circ} \mathbf{F}\right)$ \\
\hline 1 & $1 / 24 / 2005$ & Overcast/Cloudy & $23 / 22$ \\
\hline 2 & $1 / 25 / 2005$ & Cloudy/Cloudy & $35 / 35$ \\
\hline 3 & $1 / 24 / 2005$ & Overcast/Overcast & $23 / 22$ \\
\hline 4 & $1 / 25 / 2005$ & Overcast/Overcast & $35 / 35$ \\
\hline 5 & $1 / 20 / 2005$ & Snow/Snow & $25 / 25$ \\
\hline 6 & $1 / 20 / 2005$ & Snow/Snow & $25 / 25$ \\
\hline 7 & $1 / 20 / 2005$ & Snow/Snow & $25 / 25$ \\
\hline 8 & $1 / 23 / 2005$ & Clear/Clear & $39 / 35$ \\
\hline 9 & $1 / 21 / 2005$ & Clear/Clear & $20 / 15$ \\
\hline 10 & $1 / 23 / 2005$ & Overcast/Overcast & $10 / 11$ \\
\hline 11 & $1 / 18 / 2005$ & Clear/Clear & $39 / 35$ \\
\hline 12 & $1 / 21 / 2005$ & Cloudy/Cloudy & $20 / 15$ \\
\hline 13 & $1 / 23 / 2005$ & Overcast/Cloudy & $10 / 11$ \\
\hline
\end{tabular}

\subsection{Acceleration}

With the ECU vehicle speed determined and the instantaneous test time known, the acceleration of the vehicle was calculated. Below in Figure 13, the values calculated for the vehicle's acceleration are shown. When compared with acceleration values determined for the other weights and tests, attached in the appendix, the highest acceleration values are found in the testing conducted at the test weight of $17,140 \mathrm{lbs}$. This would be expected because of the fact that a vehicle with a lower weight will have less resistance and will have the ability of accelerate at a higher magnitude. 


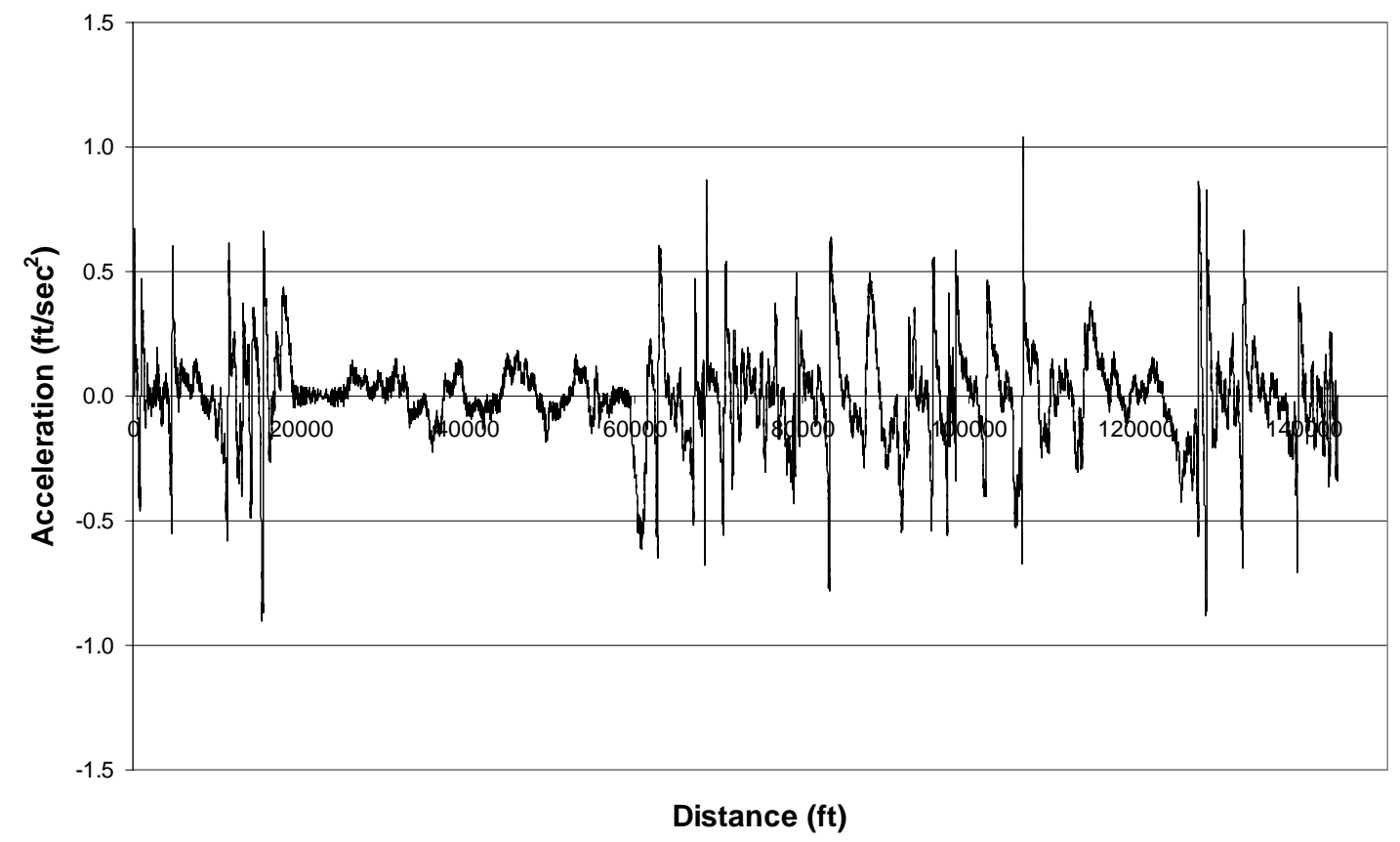

Figure 13: Vehicle Acceleration Over The Test Period

For further analysis, Figure 14 was created and shown below which entails the ECU vehicle speed layered onto the acceleration values. It can be seen that under constant vehicle speeds, the acceleration magnitude decreases and fluctuates about zero as would be expected. This test reached a maximum acceleration value of around $1 \mathrm{ft} / \mathrm{sec}^{2}$ which is approximately an increase in vehicle velocity of $0.7 \mathrm{mph} / \mathrm{sec}$ and is a reasonable value for the size and weight of the test vehicle. It is noted that the accelerations below $10 \mathrm{mph}$ were neglected. 


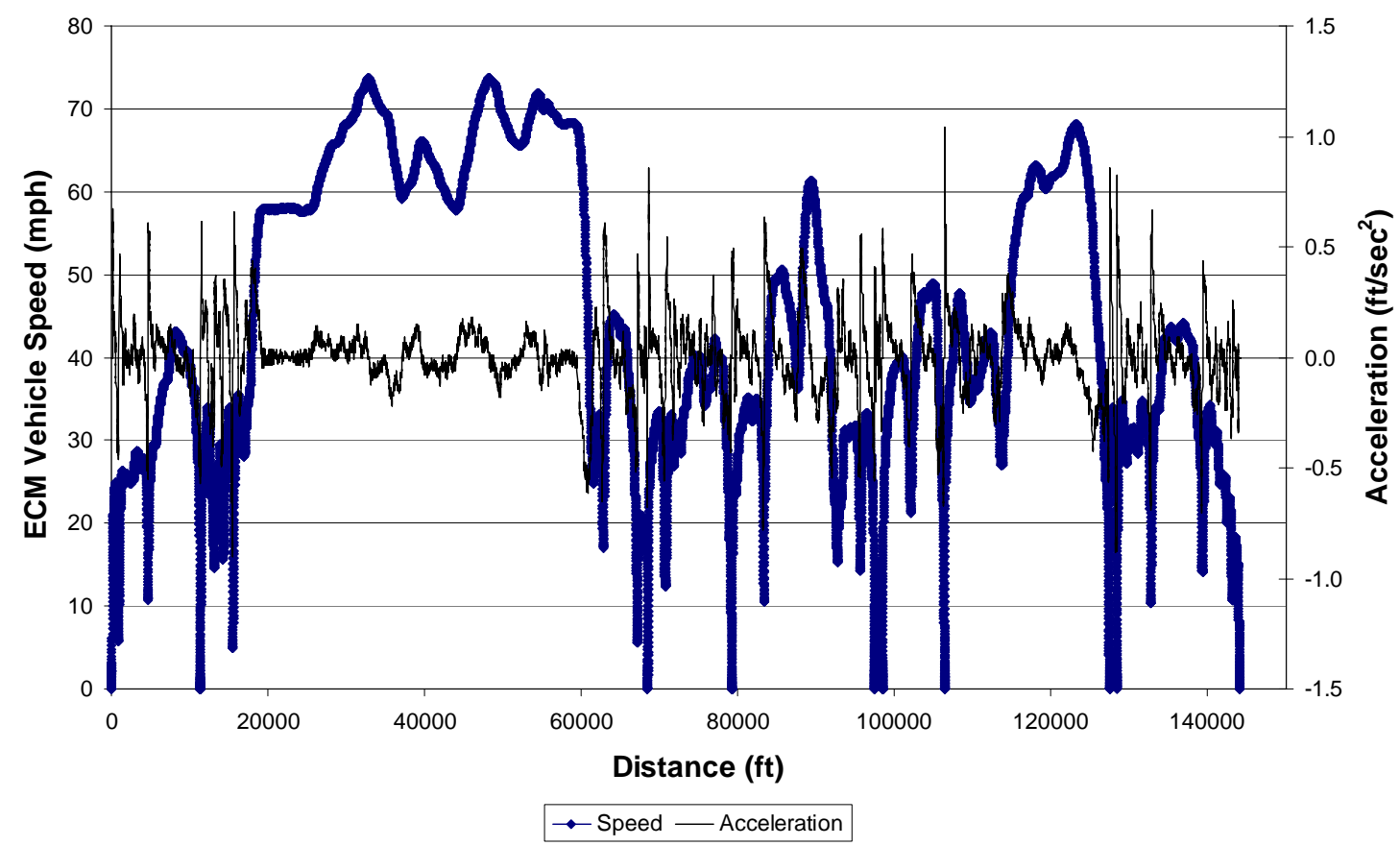

Figure 14: Vehicle Acceleration Layered With ECU Vehicle Speed

\subsection{Density}

Ambient air density, as discussed earlier was determined from ambient air pressure readings taken. Because of this, large spikes in the data were seen corresponding to the same spikes within the ambient pressure readings. However, with the use of the smoothing technique described in the procedure section of this work, the noise was decreased and in some cases eliminated. Figure 15 below shows the ambient air density values derived from the raw data of ambient pressure values. 


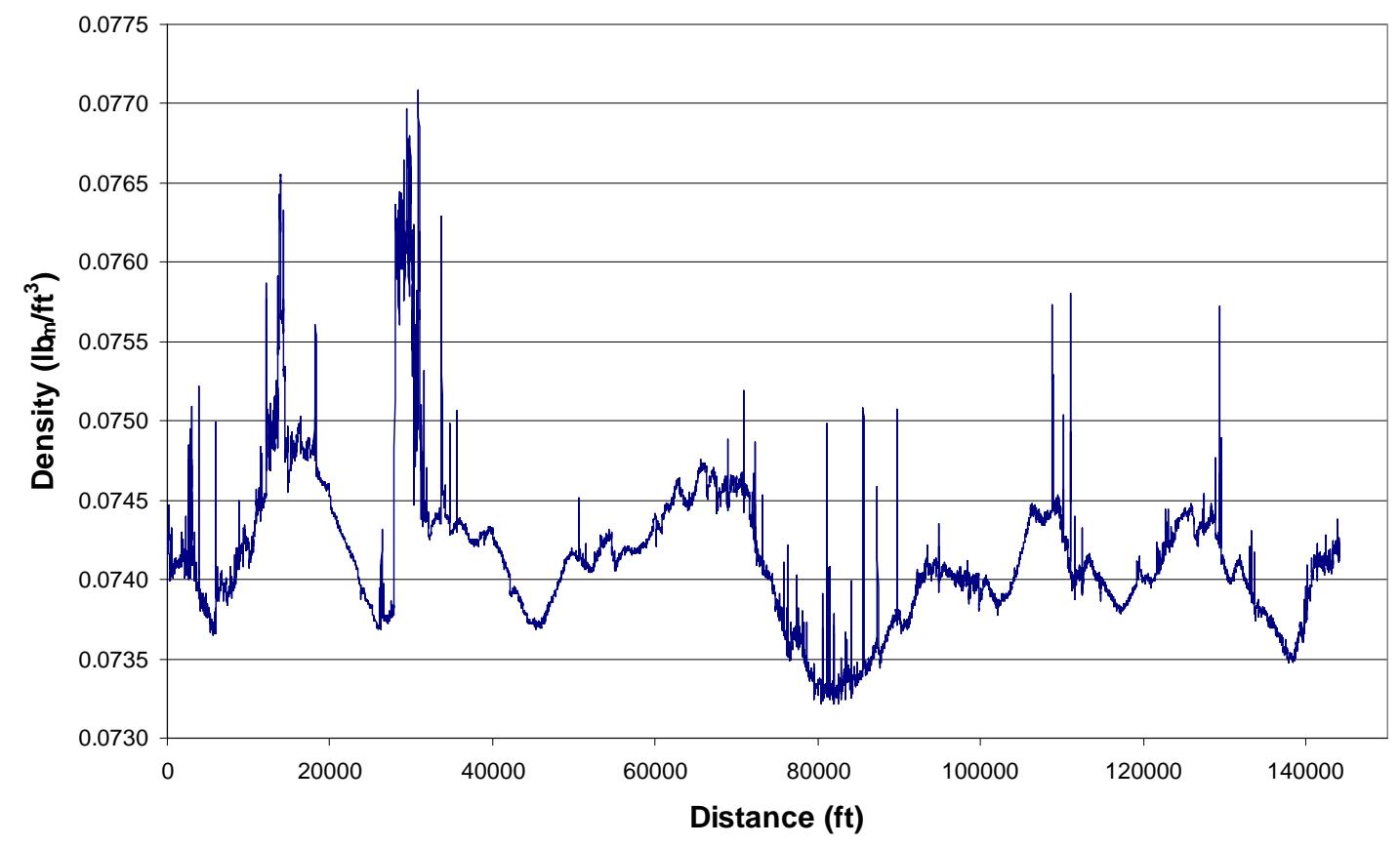

Figure 15: Ambient Air Density Determined From Raw Ambient Pressure Readings

\subsection{Altitude and Inclination Angles}

From the ambient air pressure readings taken, the altitude was determined and is shown below in Figure 16. Certain problems existed within the altitude calculations due to large fluctuations in the recorded ambient pressure readings, and can be seen below. Large altitude gradients were calculated which were obviously erroneous. Corrections were made to resolve these issues as discussed earlier. The correlation between the altitude in Figure 16 below and the previously two figures created for ambient pressure and density in Figure 8 and Figure 15 respectively. Notice that the large increase, or peak, in the ambient air pressure and density at approximately 30,000ft is interrelated with the valley in the altitude figure below which should be expected as altitude is inversely proportional to density and ambient air pressure. 


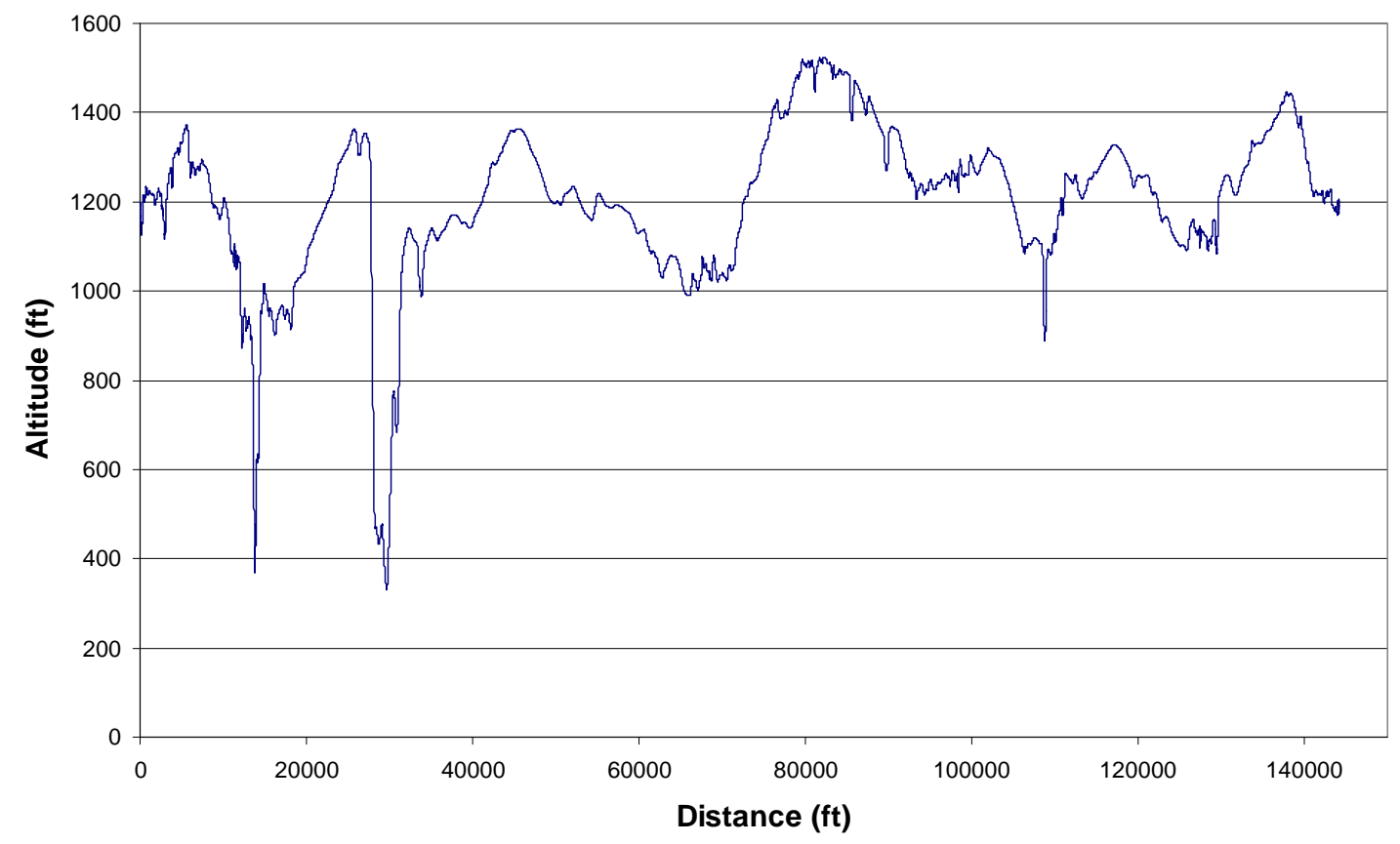

Figure 16: Altitude Values During Test Run Calculated From Smoothed Ambient Pressure Readings From the smoothed altitude, the initial values of road inclination could be found. Note that the first values of inclination angle were not the final values used in the test analyses, but were the first step in calculating an averaged inclination angle data set used for all of the tests. This was discussed in more detail in the procedure chapter of this paper. The initial inclination values are shown below in Figure 17. Throughout the figure showing the inclination angle, large spikes exist and are obviously incorrect. Certain points exist that suggest an inclination of the test route of $30^{\circ}$ in some points and even as high as $75^{\circ}$ at one point. 


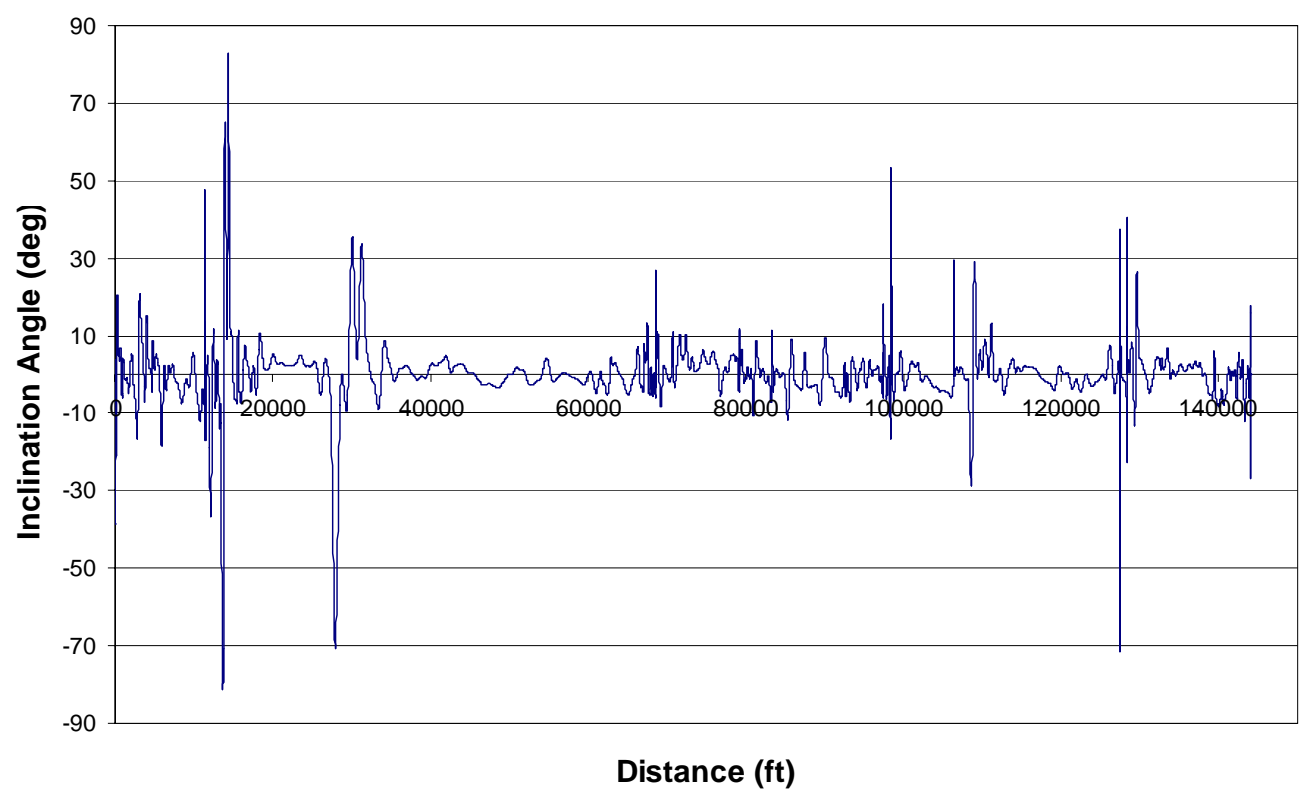

Figure 17: Primary Inclination Angle’s Determined From Smoothed Ambient Pressure Readings

Notice how it can be seen in Figure 17 that the large fluctuations found in the altitude figure displayed earlier have carried through to the road inclination angle values. After eliminating these large gradients, Figure 18 below was created and shows the initial inclination angles calculated layered onto the final inclination angles determined. It can be seen how erroneous values, due to the noise, were eliminated by the method described earlier and a smooth curve showing inclination angles was created. On a moderately steep hill on a highway or interstate is not uncommon to see road grade values of approximately 6-7\%. A grade of 7\% indicates that the road will increase or decrease in altitude $7 \mathrm{ft}$ for every $100 \mathrm{ft}$ traveled. Under this grade, the inclination angle of the grade is approximately $4^{\circ}$. After reducing the erroneous points found in the first calculations of the road inclination angles, values were determined with realistic magnitudes. 


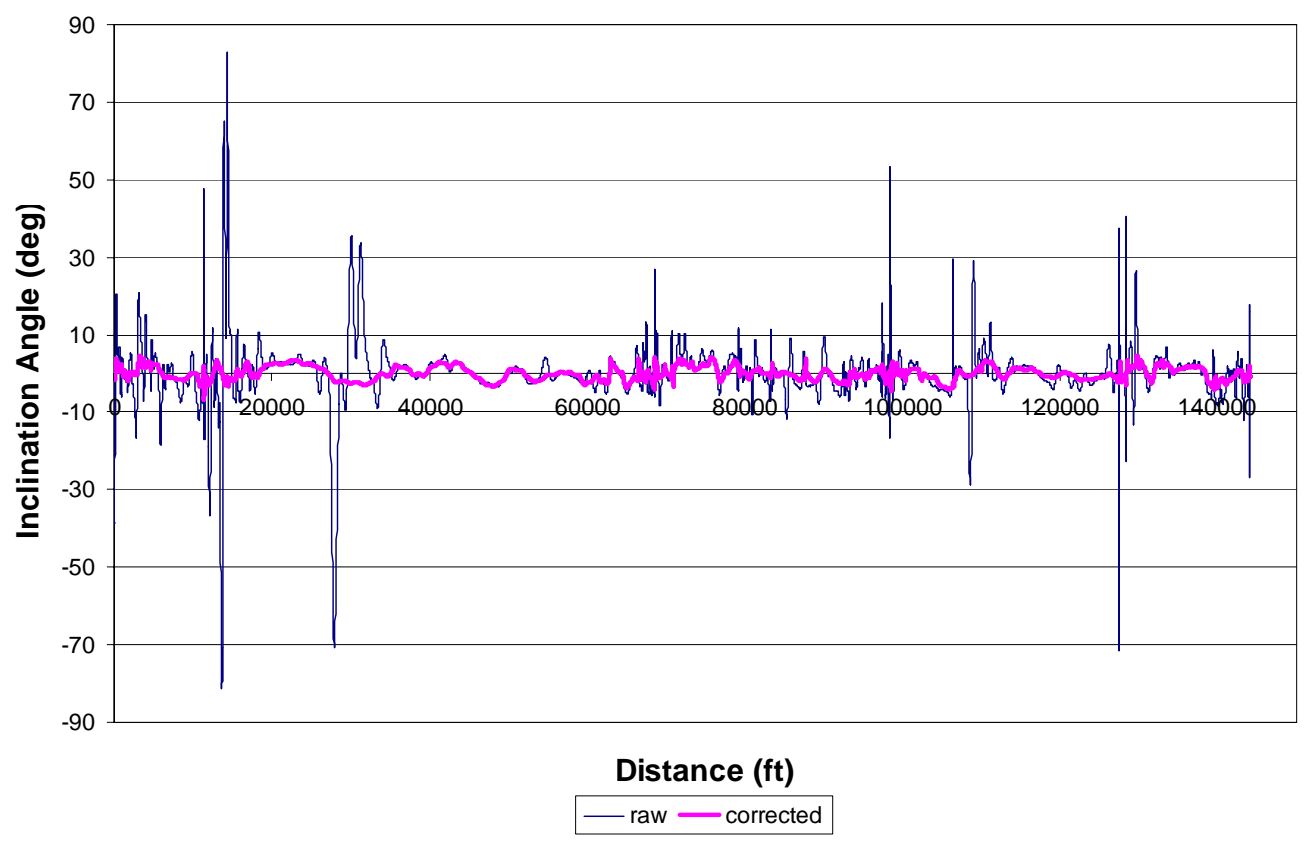

Figure 18: Primary and Final Test Rout Inclination Angles After Averaging All Test Runs

By zooming in on a smaller interval, a distance range between 15,000ft and $35,000 \mathrm{ft}$, the value of the method used to correct the road inclination angle can be seen and is displayed below in Figure 19. Large spikes indicating inclination angles of approximately $40^{\circ}$ and $-70^{\circ}$ are reduced and corrected. This portion of the test shown includes a large hill climb as the test route is followed and the first entrance onto Interstate 79 is made and should, for the most part, consist of a constant grade as the vehicle climbs the hill at a constant velocity. In Figure 19 below, the road inclination angle holds steady at approximately $4-5^{\circ}$ which would be expected. Other portions of the inclination angle data follow form as should after being corrected and represent the varying grade of the test route accurately and realistically. 


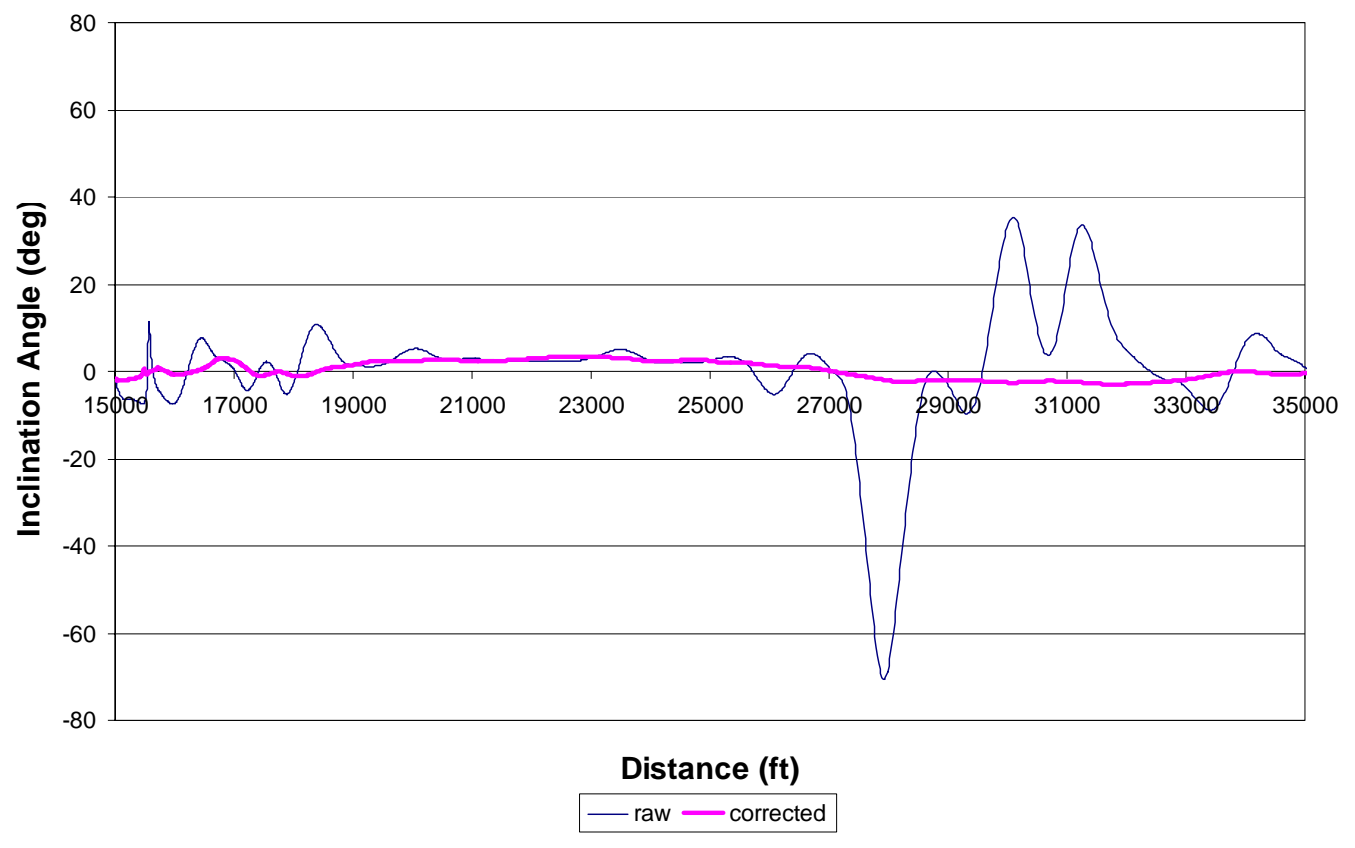

Figure 19: Inclination Angles Between 15,000ft and 35,000ft of Test

\subsection{Rolling Resistance}

With all variables needed for power calculations, the four components that make up the vehicle's theoretical road load were determined. Below in Figure 20, the power for the test vehicle to overcome its rolling resistance is shown. In comparison to the other components of the test vehicle's road load, the rolling resistance can easily be seen as the dominant constituent due to the fact that it reaches values on the order of 40hp and above for significant amounts of time. It can be seen in Equation 15 that the rolling resistance only changes with respect to velocity as the rolling resistance coefficient and vehicle weight were constant. Because of this, the rolling resistance increases as speed increases and holds a significant power requirement for a large portion of the test time. When compared to Figure 9, the rolling resistance curve follows it almost exactly and for the most part differs only in values of magnitude. 


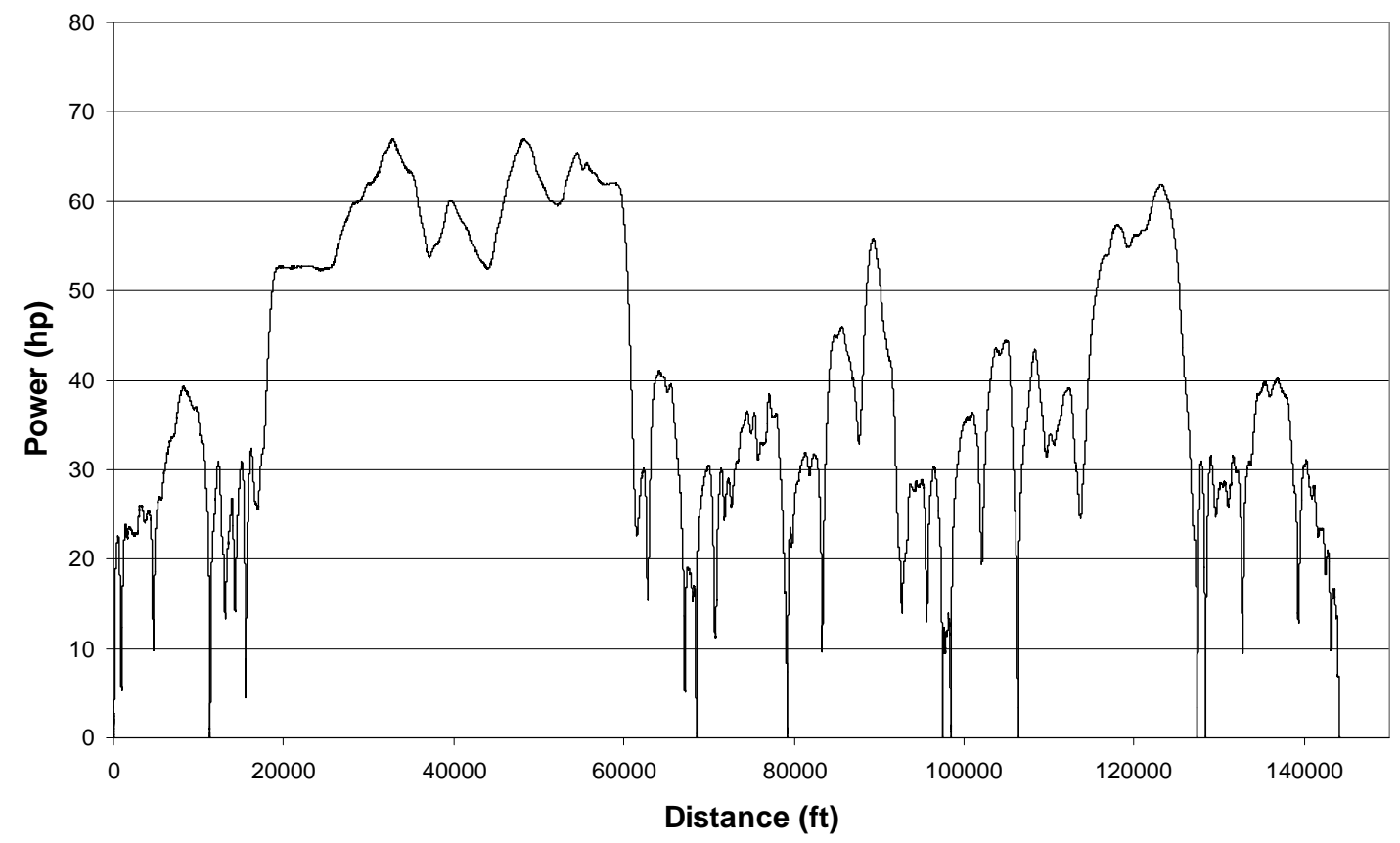

Figure 20: Vehicle Rolling Resistance Over Test Route

\subsection{Climbing Resistance}

Using the inclination angles found with the smoothed data, the climbing resistance was found and is shown below in Figure 21. Notice that with the exception of the large hill climb portion of the test route, the climbing power does not reach significant values for long periods of time. It can be seen from Equation 16 that the climbing resistance is largely affected by the inclination of the road and the velocity of the vehicle. On large incline angles such as five or six degrees, the power required to compete with gravity reaches values above 100hp. Although this is a significant value, the amount of time that climbing resistance is the dominant component of the entire road load is not very large and also become negated multiple times by inclines of a negative slope. It can be seen in the figure below that during the $15,000-35,000 \mathrm{ft}$ section of the test route, which includes the largest inclination angles over a period of time, the climbing resistance reaches a large magnitude of approximately 120hp and reduces to negative values of approximately -120hp as the peak of the hill is passes and a long decent began of a similar inclination angle as the climb. 


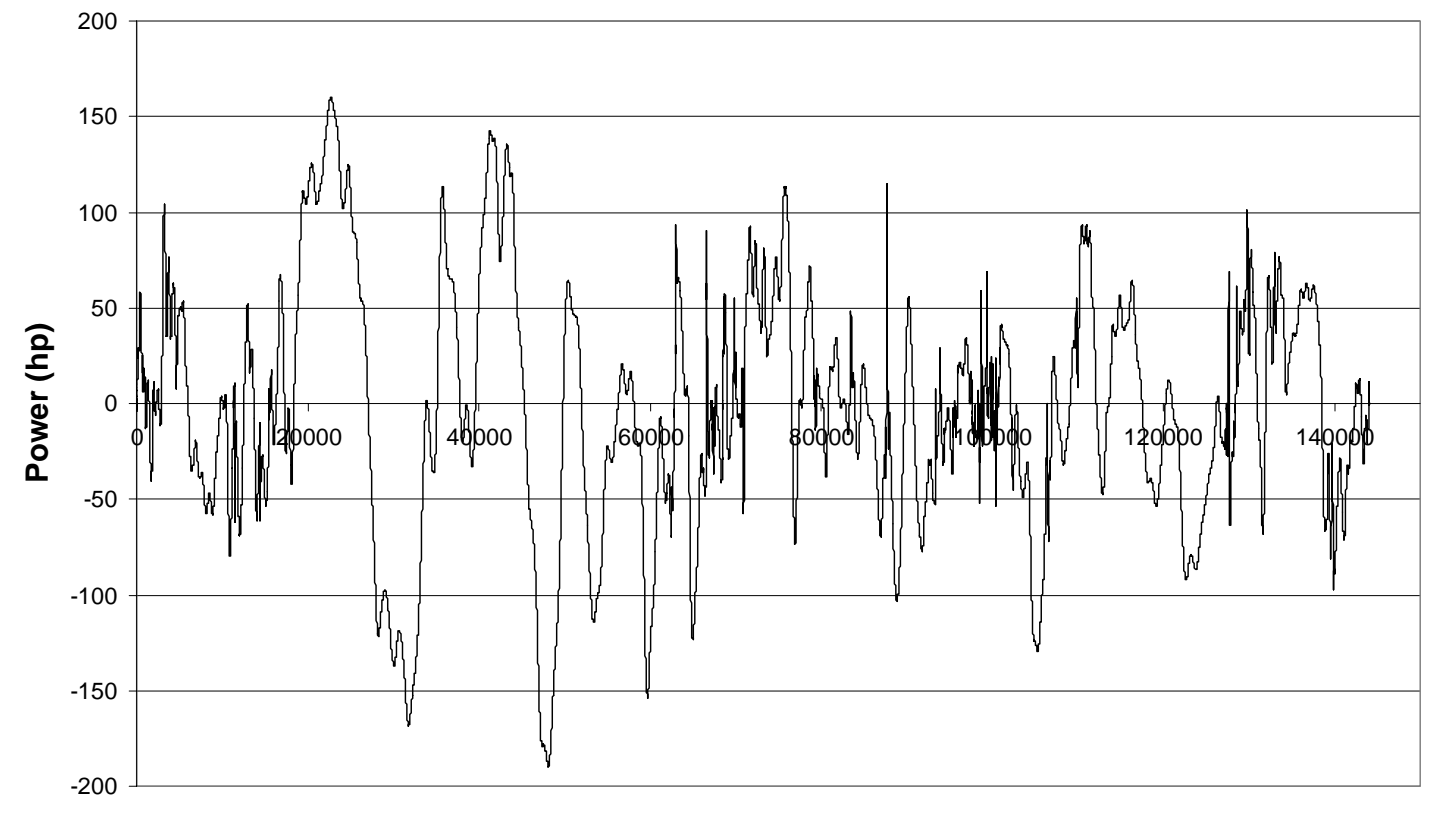

Distance (ft)

Figure 21: Vehicle Climbing Resistance Over Test Route

\subsection{Acceleration Resistance}

The least significant component of the vehicle's road load is the acceleration resistance. With the acceleration of the vehicle calculated, and compensation for rotating objects located on or in the test vehicle, the power needed to overcome acceleration resistance was found and is shown in Figure 22. Equation 17 shows how the acceleration resistance is primarily determined by changes in the vehicle velocity and during periods of constant velocity, the acceleration is approximately zero and the corresponding power requirement is also zero. The acceleration resistance seems sporadic at first glance but because it is based upon changes in velocity which are always taking place, acceleration values are always changing. A vehicle's velocity can remain constant theoretically but in real world driving situations, it is highly unlikely. 


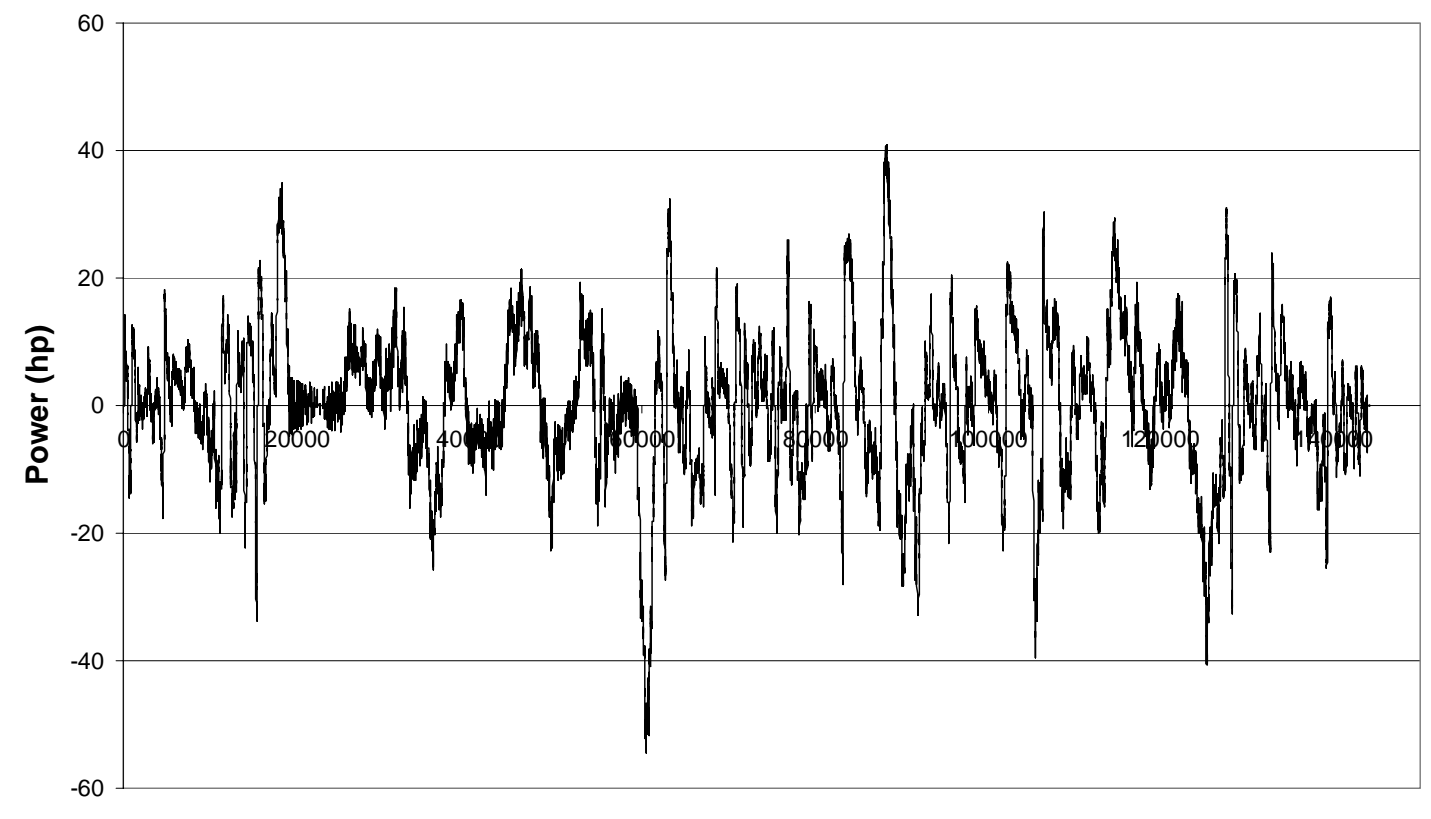

Distance (ft)

Figure 22: Vehicle Acceleration Resistance Over Test Route

\subsection{Aerodynamic Resistance}

The final road load component, the power magnitude needed to overcome aerodynamic resistance, was then found and is shown in Figure 23. This component is the second most significant factor describing the test vehicle's road load with large power magnitudes being reached over significant periods of time. With the test vehicle's frontal area remaining constant along with its drag coefficient, the aerodynamic resistance is primarily dependent upon the vehicle's speed as shown in Equation 18 with the velocity term on the order of $\mathrm{V}^{3}$. When comparing Figure 9, the vehicle's velocity, and Figure 23 below it can be seen that at lower vehicle speeds, the aerodynamic resistance is insignificantly low with values around 15-20hp but as the speed increases, the aerodynamic drag increases exponentially and reaches upper values around 60-70hp. 


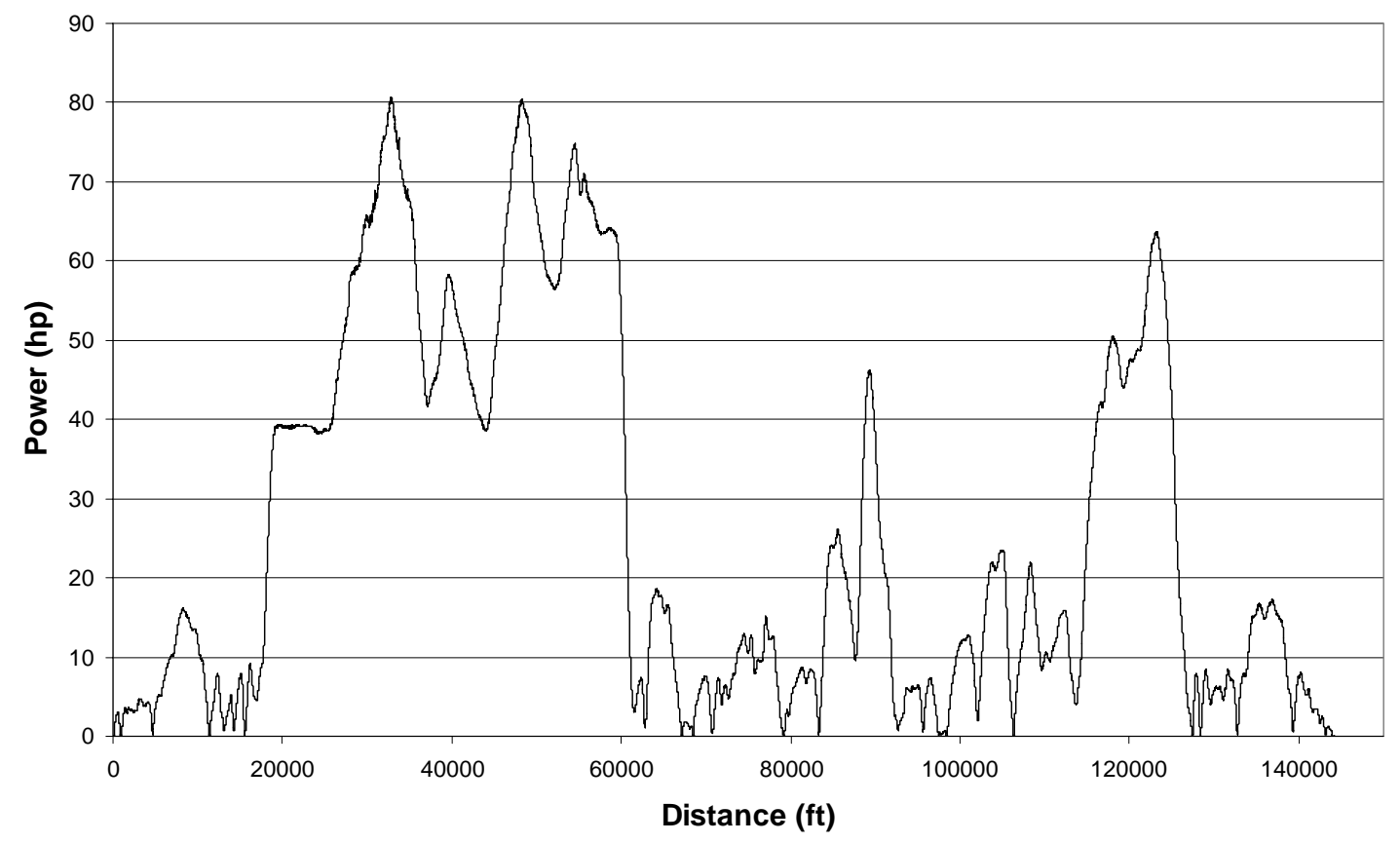

Figure 23: Vehicle Aerodynamic Resistance Over Test Route

\subsection{ECU Power}

From the vehicle's ECU, power output is recorded over the entire test period and is shown below in Figure 24. The values here were determined by the ECU by recording and analyzing multiple engine operating parameters and were needed to be verified. The vehicle's ECU is able to report torque by measuring such things as fuel injection timing, the volume of fuel injected, and engine speed. Factors that cannot be accounted for by the ECU which affect the actual power produced by the vehicle's engine are the efficiency of the engine which decreases with age, engine wear, and variations in fuel properties. Measured fuel and engine quantities are controlled by the ECU and using an algorithm developed by the engine manufacturer, the engine's power output can be determined. Accuracy of measured torque highly depends upon the complexity of the control algorithm developed (25). 


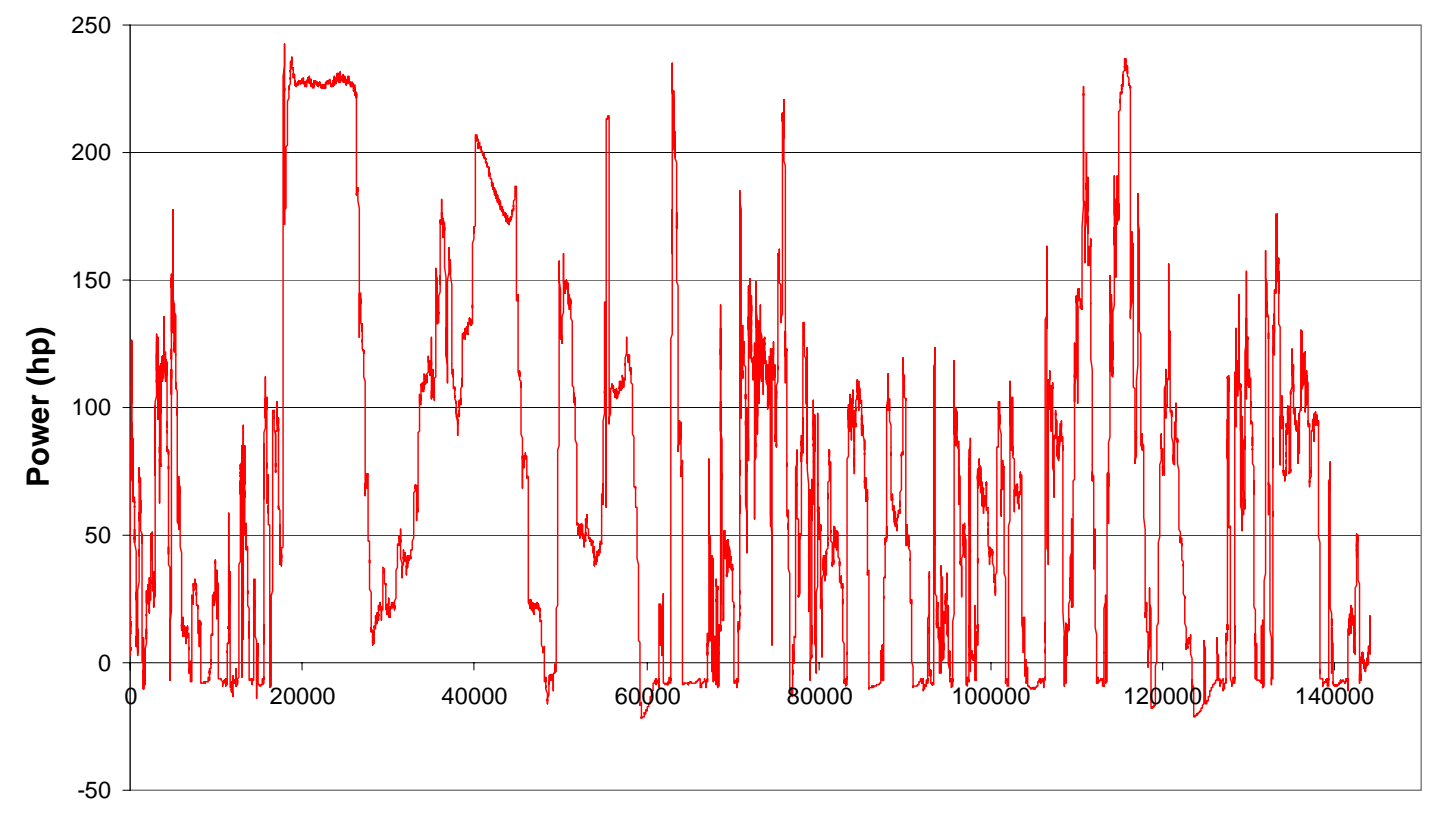

Distance (ft)

Figure 24: Test Vehicle ECU Power Output

In Figure 24 above, the values reported by the vehicle's ECU reach values below zero of approximately -10hp, which is considered motoring of the engine. Moreover, in Figure 25 power calculations show negative power values, or motoring, on the order of -50hp or more. The Consent Decrees do not require power to be accurately reported below zero, and because of this, the engine manufacturers only care about accurately reporting power within not to exceed zones (NTE) where they are required to by the Consent Decrees. Due to this fact, the accuracy of the motoring torque and power provided by the ECU is questionable. In Figure 24 above, the largest power producing period of the test is during the large hill climb area as discussed earlier where power magnitudes reach as high as 225hp approximately. As shown in Equation 2, by summing the four components of road load determined by this analysis and multiplying the values by the instantaneous vehicle speed, the road load could be calculated throughout the test run.

\subsection{ECU and Model Comparison}

Figure 25 below was created by layering the calculated power during the test period onto the output power data provided by the vehicle's ECU power data output. 


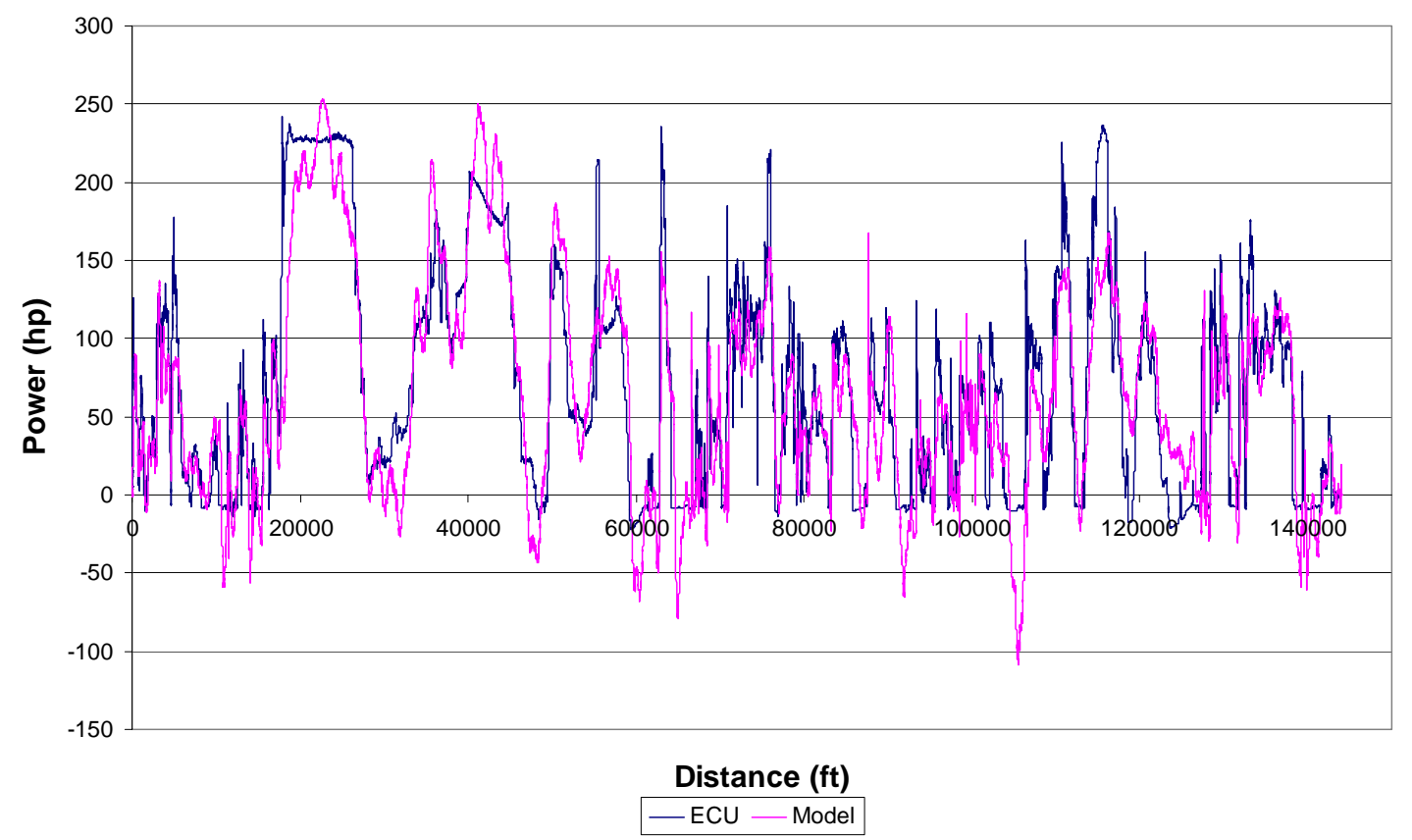

Figure 25: Vehicle Road Load From Vehicle ECU Values and Developed Model

Note that in Figure 25, it can be seen that at certain locations, the two power curves are not exactly equal and do not follow the same path. Certain factors such as driveline efficiency are not taken into account into determining the vehicle's road load. In the cases where the model curve does not reach the peaks of the ECU output power is because of the fact that the engine is producing more power to overcome losses unaccounted for within the analysis. As the ECU power output reaches its lower peaks, it can be seen that the model's values continue to decrease. Similar to the peaks not matching up between the two, a factor such as braking was not accounted for in the model which would absorb a large portion of the road load primarily due to negative road inclination angles or downhill sections.

Note that there are certain locations where the road load model developed over predicts the necessary power and raises above the broadcast ECU power values. One factor causing this is in the acceleration power component of the road load. At locations of approximately $23,000 \mathrm{ft}$ and $41,000 \mathrm{ft}$ there is a large spike in the model power that rises above the ECU power. At these two locations, a significant hill climb is ending and a downhill section begins. This induces a significantly large acceleration in the vehicle and provides power values of around 35hp. This can be seen in Figure 22 where there are 
large peaks in the acceleration power component. Combining this with the fact that the climbing resistance changes directions around these locations and begins helping, or pulling, the test vehicle down road, and a large spike or peak is created in the total road load.

\subsection{Weight Effects on Road Load}

By averaging power values for each of the three test weights, the effect of weight on road load was determined and shown below in Figure 26. It can be seen that the maximum road load power values are created at the vehicle loading of 25,220lbs. This would be expected due to the higher vehicle payload and overall weight, more work would be required to overcome road load resistances. Over the course of the entire test, the power for the different weights overlap very closely for the majority of the time, but there are instances where the three different curves diverge a bit and they can easily be seen individually. In most of these cases, the 25,220lbs test weight is above the other two curves representing the lower two test weights.

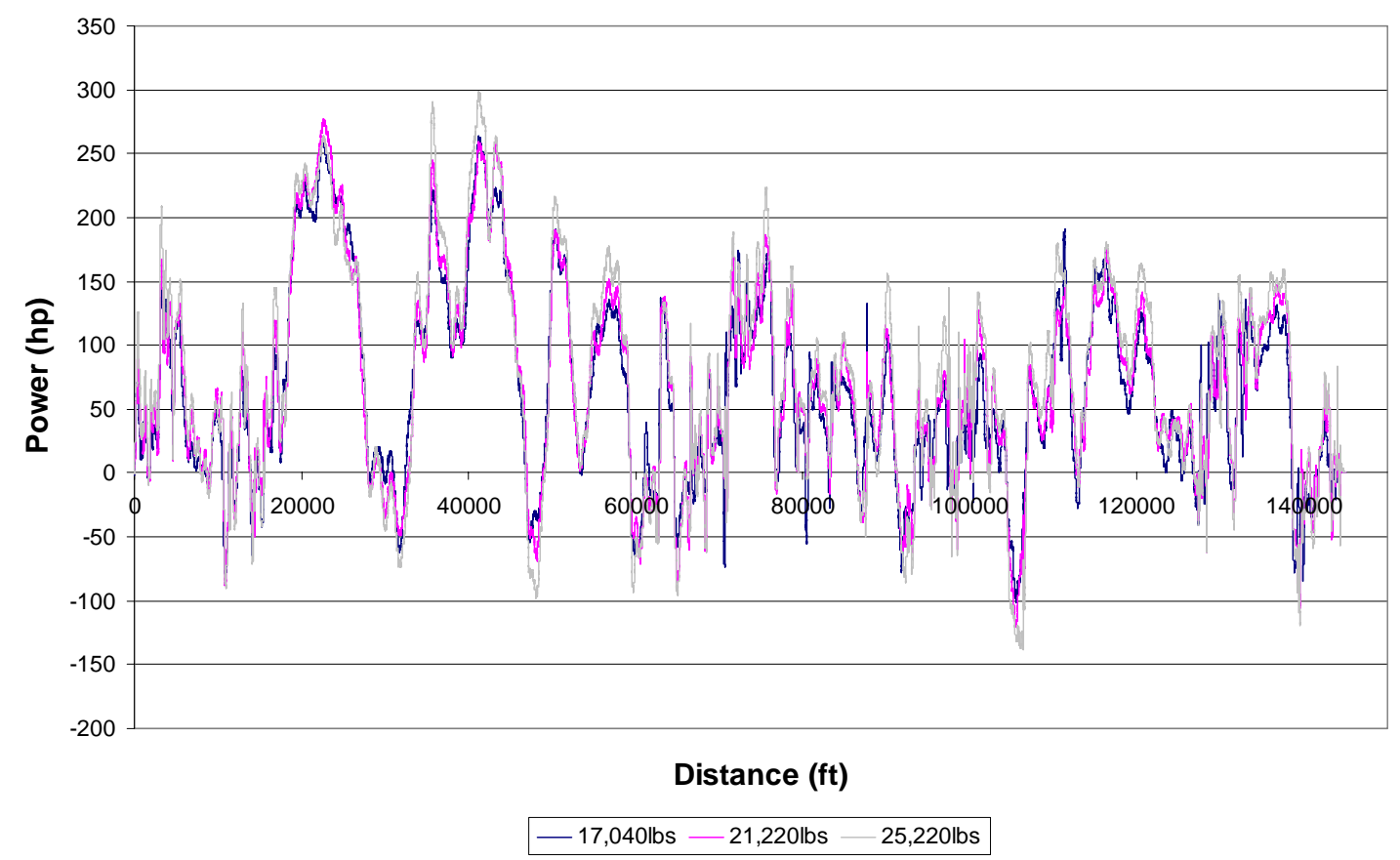

Figure 26: Calculated Road Load Power Averaged for Three Test Weights

To further compare the three loadings road load values calculated, Figure 27 below was constructed showing the average speeds for each test weight over the course of the test runs. It can be seen that where the road load powers differ significantly is 
directly related to differences in speed. Consider the large hill climb portion of the test route, beginning around 20,000ft. As the higher weights have lower vehicle speeds, shown in Figure 27, their corresponding road load values are also less as shown in Figure 26. As the crest of the hill was reached at around $30,000 \mathrm{ft}$, the vehicle speeds converged as well as the calculated road load values.

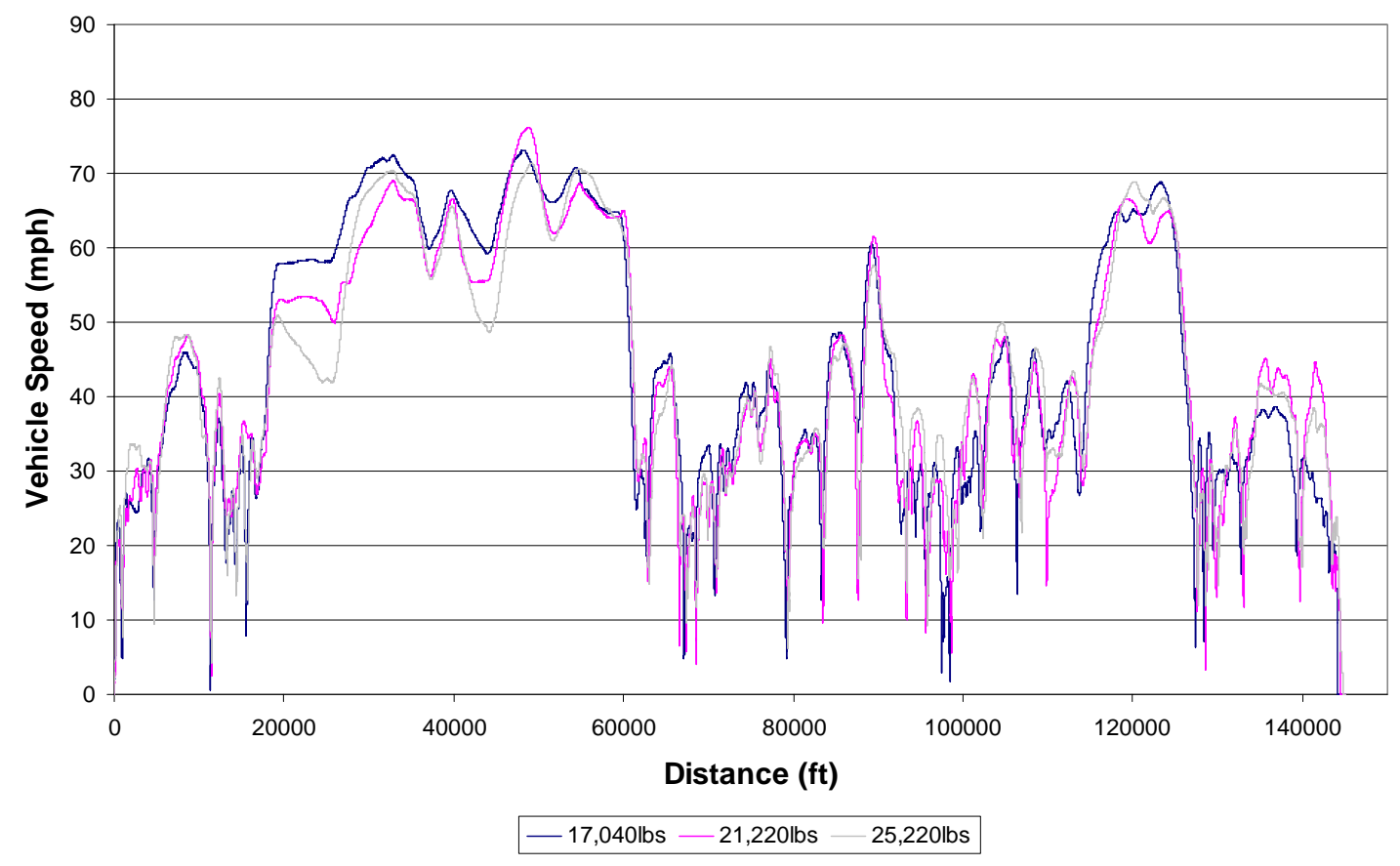

Figure 27: Averaged ECU Vehicle Speeds for Each Test Weight

\subsection{Work}

Once the values for work were determined for one single test run of the empty loading, Figure 28 below was created. This figure distinguishes between negative and positive work values for vehicle acceleration and road inclination angles calculated over the entire test run. Note that both of these components negate themselves over the course of an entire test. This would be expected since over the test route the starting and finishing locations are the same. Because of the fact that the test vehicle returned to the same initial altitude, there was approximately an equal amount of time on positive inclination hills and negative inclination hills. Similarly, since the vehicle began and returned to an equilibrium position at rest, the acceleration over the course of the test run would be approximately zero. 


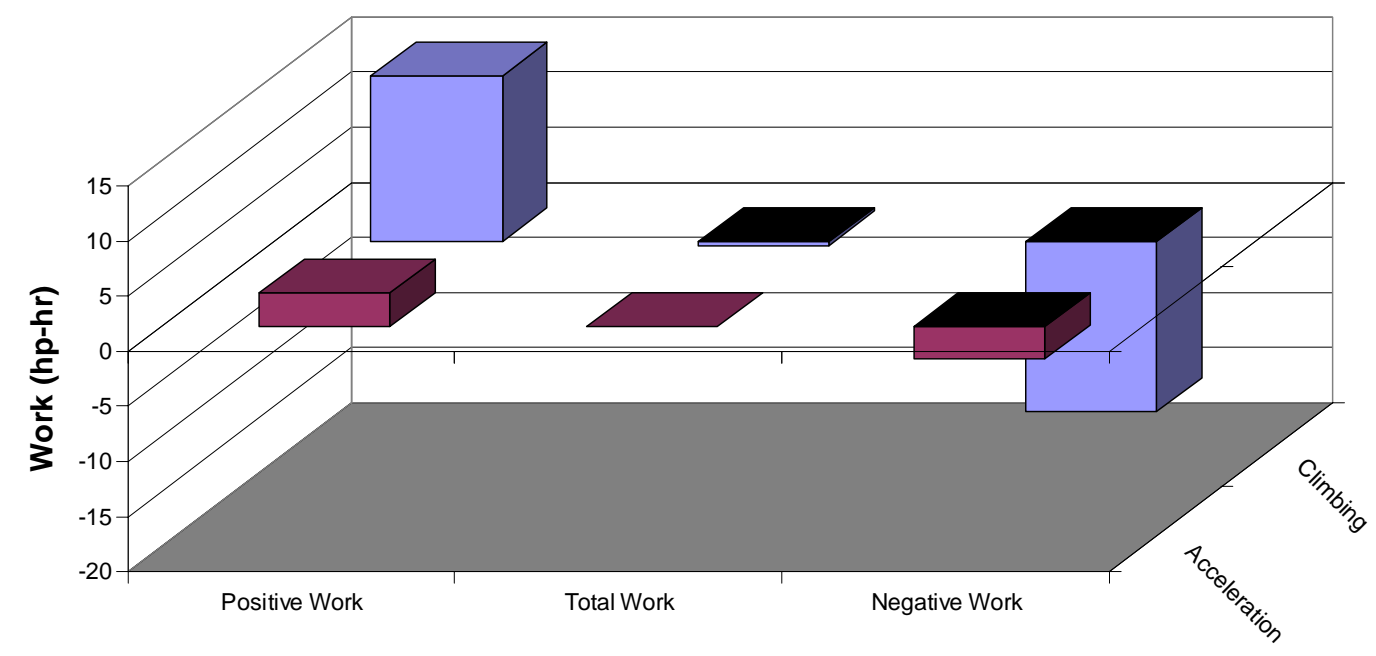

Figure 28: Positive, Negative, and Total Work Due To Acceleration and Inclination Angle

With all values of work determined, Figure 29 below was developed. It can be seen in the figure that the work associated with climbing resistance and acceleration resistance are negligible over a closed test route and the two significant components of work are due to rolling resistance and aerodynamic resistance. The column in Figure 29 titled Total Work is representing the summation of the four work components determined by this study. The Total ECU Work column is determined from the output of the vehicle's ECU, while the inferred work is determined from calculations using Equation 19 and Equation 20. Note that Figure 29 is a representation of the work comparison for one single test run at the empty loading test weight.

As mentioned earlier, inefficiencies due to the mechanical losses within the test vehicle's drive train were neglected which include losses from the gearbox and axle. This is the reason for the large difference between the two power curves created and shown in Figure 25 above. If you refer back to Equation 2, it can be seen how these values for efficiency affect the values calculated for the power. Furthermore, the differences between the overall work calculated from the road load calculations and the vehicle ECU provided an accurate representation of the losses experienced from the vehicle's drive train. By dividing the work determined by the road load calculations by 
the work broadcast by the ECU, a value of approximately 82\%, which provides a reasonable value for the vehicles gearbox and axle efficiency that would be expected.

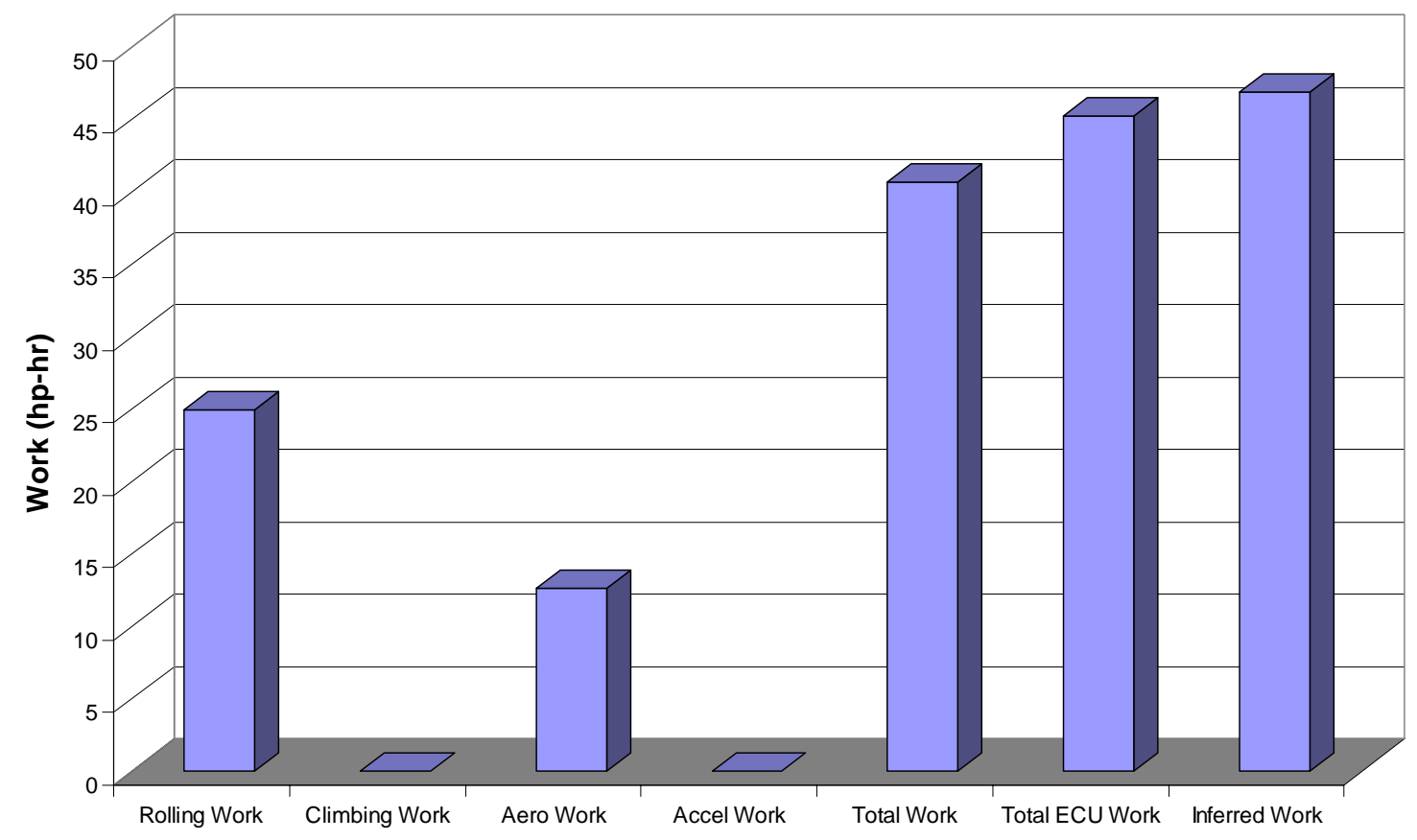

Figure 29: Work Comparison Over One Test at 17,140lb Test Weight

\subsection{Uncertainty Analysis}

The results of the uncertainty analysis are shown below in Figure 30. It can be seen that maximum uncertainty values exist on the order of $\pm 7 \mathrm{hp}$. This occurs at locations where the vehicle's engine is producing its maximum power and is approximately 200hp, as can be seen in Figure 25 shown earlier, which represents an uncertainty of around $\pm 3.5 \%$. Also note that higher uncertainty values are located around the higher road load calculations and vice versa. This is due to higher order measurements being taken during those time periods leading to higher uncertainty values in the calculations. 


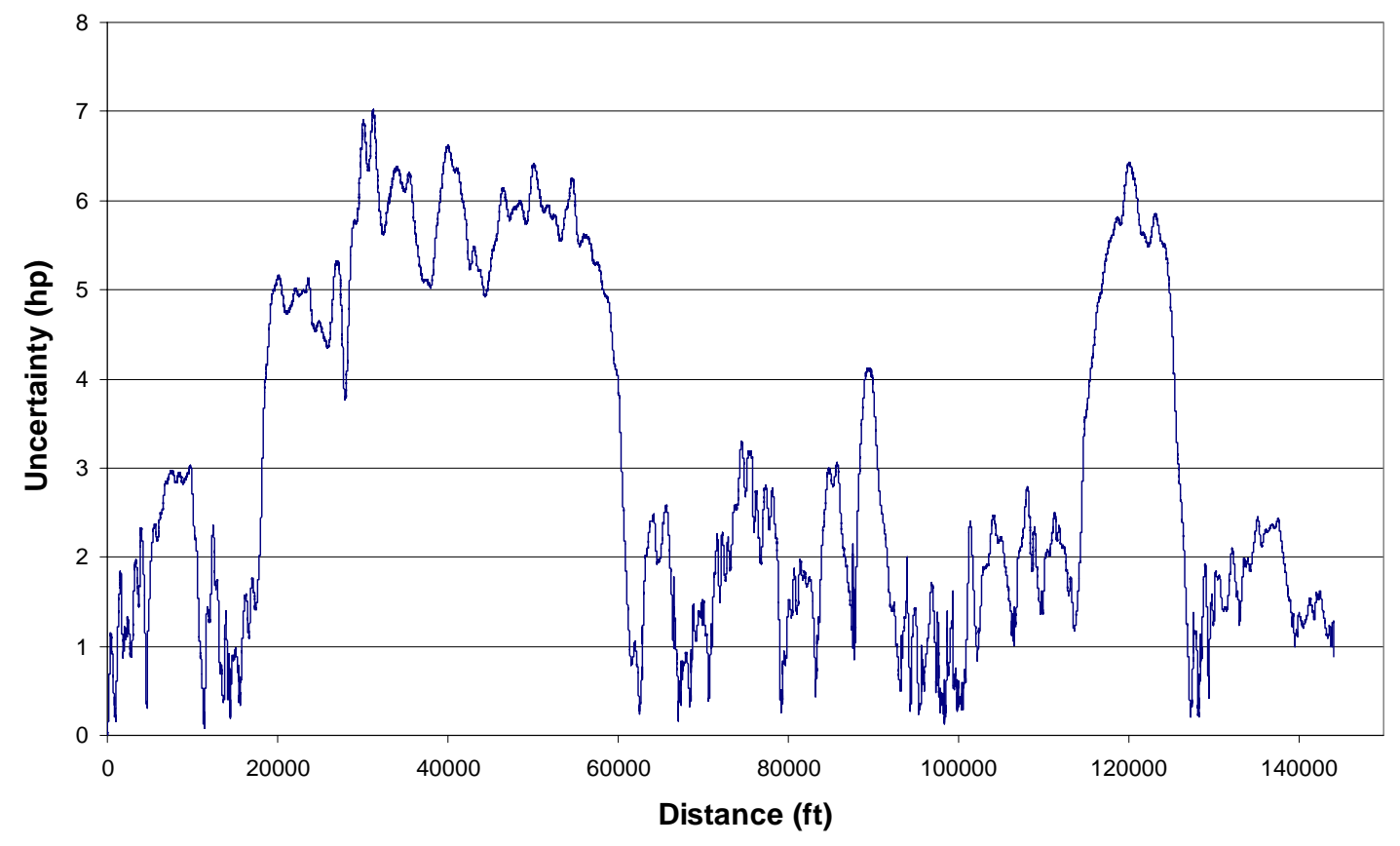

Figure 30: Power Calculations Uncertainty Results 


\section{Conclusions and Recommendations}

\subsection{Conclusions}

After developing the model discussed in this work, the values of power produced by the vehicle's ECU were matched by the calculated values. Although the two curves were not exactly the same magnitude and duration for some portions of the tests, that was not the primary objective of this study. The primary objective of this work was to develop a model to verify the ECU output for an in-use test route and this was done. With the testing conducted, such factors as driveline efficiency and driver interactions could not be accounted for which would have a significant effect on matching the two curves closer, but were not needed to show, or verify real-world driving resistance on an instantaneous basis and on a closed test route.

\subsubsection{Integrated Work}

It can be seen in the bar chart below in Figure 31 that the values determined for work changed throughout testing, while efficiency values remained relatively constant. The first three tests and second three tests are corresponding to the empty weight and half weight tests respectively. While the final six tests, seven through twelve, correspond to the full payload weight. It can be seen that as the weight is increased the necessary work to perform also increases. As the test weight increases, the vehicle's engine must produce more work to overcome the additional mass that is being moved and accelerated. This would account for the vehicle's ECU broadcasting higher values of work and also higher values being calculated by the model as the weight of the vehicle is a crucial term in each of the four components of road load. 


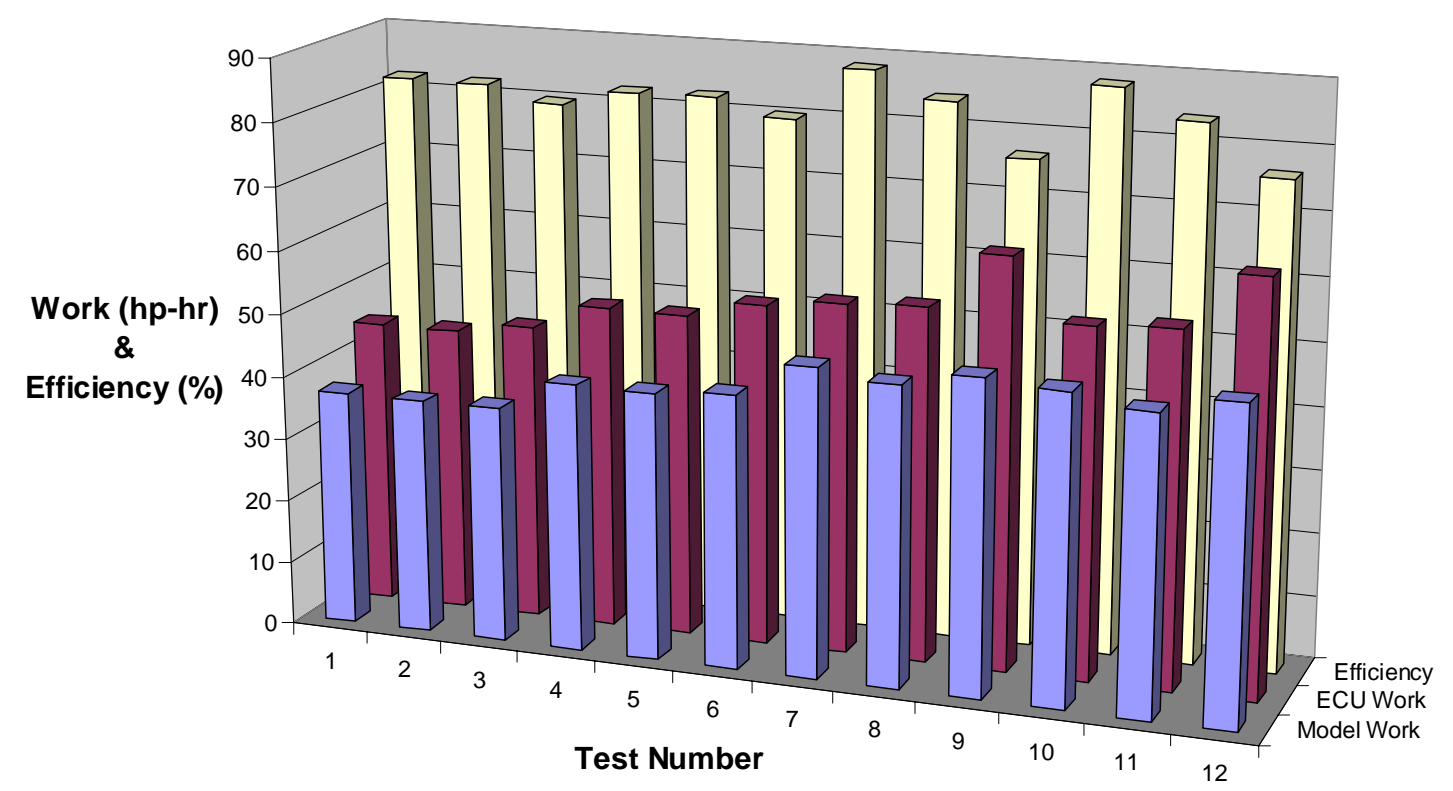

Figure 31: Integrated Work for All Tests Conducted

\subsubsection{Efficiency}

From the calculations involving power and work, it was found that there was a difference between the road load values calculated and the values reported by the vehicle's ECU were found to have an average of $82.2 \%$. This was due to the fact that efficiencies of the mechanical systems of the test vehicle were neglected in the analysis, and therefore, is represented by the difference between the road load and engine power values. Differences between these values can also be accounted for greatly in driver response or actions. During testing, braking provided by the driver performing the test could not be accounted for and would produce a significant effect between the road load and ECU power. The efficiency values were determined from the division of the model values for work, and the ECU values for work calculated. Furthermore, the uncertainty analysis for the calculations of road load performed in this analysis presented verification that the values determined were accurate and were on the order of $\pm 3 \%$ or below. 


\subsection{Future Studies and Experiments}

\subsubsection{Ambient Pressure}

For future work, one recommendation would be to record the ambient pressure during testing with a different instrument or an additional one for multiple comparisons of altitude calculations. The ambient pressure transducer used in this work produces signals with significant values of noise that caused complications during the data reduction phase of this study. One alternative would be to use the Heise instrument described earlier. This instrument has the ability to read ambient pressure values and output them through a serial cable. This serial cable could be connected to one of the many available electrical signal input ports located within the MEMS data acquisition hardware and recorded in addition to the other connected sensors. After using the Heise pressure instrument, it was seen that the values it displayed were stable and may produce ambient pressure readings more accurately and precise, with less noise than the ambient pressure transducer used produced by Omega.

\subsubsection{Inclination Angles}

Another recommendation for adjustments to the data collection previously described would be to gain accurate road inclination angles over the test route from an outside source. This could be done through such things as a detailed topographical map. This will help to verify the ECU values over the prescribed test route, but one problem that exists is that this model is intended to be used in real-world driving situations and although was performed on a closed test route, it has the ability to provide accurate information on a non-prescribed path beginning at any starting point desired.

\subsubsection{Acceleration}

In order to have multiple acceleration values to compare and contrast, an accelerometer could easily be implemented into the system. The purpose of an accelerometer is to measure an object's acceleration, as described earlier in the review of literature section of this work. By measuring and recording the electrical output of an accelerometer securely fixed to the test vehicle through the MEMS data a secondary set of acceleration data could be used to validate the vehicle acceleration values determined by differentiating the ECU vehicle speed output data. Having two measurements of the 
same parameter will not only provide the ability for each parameter to validate each other, but in the case of a problem occurring during testing where one measurement may fail, the other can be used to complete the test and provide reduction results. This is applicable to any of the measurements taken during testing within this study.

Acceleration values for this study were neglected at lower speeds as discussed earlier. Further experiments need to be performed that focus on collecting accurate acceleration values at lower speeds. Multiple methods need to be considered to collect or measure the vehicle's acceleration, not just at low speeds, but throughout the vehicle's normal operating range. This will allow for acceleration resistance values to be recorded that can be compared to, if not replace, the values determined through calculations involving the broadcast vehicle speed.

\subsubsection{Wind Loading}

Additional testing would be relevant to this study that looked at the aerodynamic resistance in more depth. In particular, the effects of yaw angles other than zero or headon. Tail winds would produce significant effects on the aerodynamic resistance felt by a vehicle traveling and would play an important role in the road load of the vehicle since the aerodynamic resistance becomes a dominant component of the road load as vehicle speed increases. Furthermore, the drag coefficient for the test truck in this study was assumed and was derived from previous studies of similar trucks that determined drag coefficients. Conducting tests to determine a more accurate drag coefficient for the test vehicle would also provide a significant increase in the model's accuracy.

\subsubsection{Friction}

In order to increase the models integrity further, studies could be conducted to determine factors such as the rolling friction coefficient of the test vehicle, and values for mechanical losses within the test vehicle. By determining an accurate friction coefficient for the vehicle's tires, the assumed value could be replaced with an accurate one. Furthermore, in this study, as stated earlier, driveline efficiencies were neglected and were shown in the differences between the model's and ECU's power and work values. By incorporating accurate correction values, for the specific test vehicle, for axle losses, transmission losses, bearing losses, and engine accessories, the calculated road load 
values could be calculated and possible tighten around the broadcast values of the ECU. The two curves could potentially follow the same path very closely and the percent difference between the two could become closer and closer to zero. 


\section{References}

1. Aerodynamics of Road Vehicles, Butterworth and Company, Wurzburg, West Germany, 1987.

2. Anderson J. D. Jr.: Introduction to Flight, McGraw-Hill, Boston, Massachusetts, 2000.

3. Bosik A. J., Dunn T. R., and Critch C. J.: Comparison of Laboratory and OnLong Road and Truck Tire Rolling Resistance for Various Tire Tread Depths, SAE Paper 880584, SAE International Congress and Exposition, Detroit, Michigan, February 29-March 4, 1998.

4. Buckley F. T. Jr., Marks C. H., and Walston W. H. Jr.: Analysis of Coast-Down Data to Assess Aerodynamic Drag Reduction on Full-Scale Tractor-Trailer Trucks in Windy Environments, SAE Paper 760850, SAE Truck Meeting, Indianapolis, Indiana, November 1-4, 1976.

5. Cha S. and Sloan R. L.: Study of Models for the Prediction of Average Road Load of In-Use Delivery Trucks, SAE Paper 831799, SAE Truck and Bus Meeting and Exposition, Cleveland, Ohio, November 7-10, 1983.

6. Consent Decrees: "Notice of Filing of Consent Decree Under the Clean Air Act," Federal Register, Vol. 63, No. 212, Office of the Federal Register, National Archeives and Records Administration, Washington, DC, November 3, 1998.

7. DeRaad L. W.: The Influence of Road Surface Texture on Tire Rolling Resistance, SAE Paper 780257, SAE Congress and Exposition, Detroit, Michigan, February 27-March 3, 1978.

8. Dresser Inc.: Addison, Texas, World Wide Web, http://www.heise.com/index.cfm, July 25, 2005.

9. Elliott D. R., Klamp W. K., and Kraemer W. E.: Passenger Tire Power Consumption, SAE Paper 710575, Mid-Year Meeting, Montreal, Quebec, Canada, June 7-11, 1971.

10. Environmental Protection Agency: Washington, DC, World Wide Web, http://www.eva.gov, August 9, 2005.

11. Gillespie T. D.: Fundamentals of Vehicle Dynamics, Society of Automotive Engineers Inc., Warrendale, Pennsylvania, 1999.

12. Handman D. and Poff R.: A Triaxial Accelerometer Small Enough to Fit In Your Ear, SAE Paper 2000-01-1379, SAE 2000 World Congress, Detroit, Michigan, March 6-9, 2000. 
13. Hayashi I., Idogaki T., Ishihara T., Sugitani T., Inoue H., and Yoneyama M.: Vehicle Acceleration Sensor Applied with Magnetic Fluid, SAE Paper 920475, SAE International Congress and Exposition, Detroit, Michigan, February 24-28, 1992.

14. Iwase H., Yamada S., and Koga H.: A New Approach to Measuring Road Load by Chassis Dynamometer and Wind Tunnel Tests, SAE Paper 820377, SAE International Congress and Exposition, Detroit, Michigan, February 22-26, 1982.

15. Kobayashi K. and Watanabe K.: Speed Measurement of Vehicles by Radio Wave - Absolute Speed Measurement of Automobiles, SAE Paper 920256, SAE International Congress and Exposition, Detroit, Michigan, February 24-28, 1992.

16. Mayer W. and Wiedemann J.: Road Load Determination Based on DrivingTorque-Measurement, SAE Paper 2003-01-0933, SAE World Congress, Detroit, Michigan, March 3-2, 2003.

17. Omega Engineering Inc.: Stamford, Connecticut, World Wide Web, http://www.omega.com, July 25, 2005.

18. Pacejka H. B.: Tire and Vehicle Dynamics, Butterworth-Heinemann, Woburn, Massachusetts, 2002.

19. Passmore M. A. and Le Good G. M.: A Detailed Drag Study Using the Coastdown Method, SAE Paper 940420, SAE International Congress and Exposition, Detroit, Michigan, February 28-March 3, 1994.

20. Remenda B. A. P., Krause A. E., and Hertz P. B.: Vehicle Coastdown Resistance Analysis Under Windy and Grade-Variable Conditions, SAE Paper 890371, SAE International Congress and Exposition, Detroit, Michigan, February 27-March 3, 1989.

21. Shepherd P.D.: The Effect of a Tire's Reinforcing Material on Rolling Resistance, SAE Paper 770333, SAE International Automotive Engineering Congress and Exposition, Detroit, Michigan, February 28-March 4, 1977.

22. Smith J. R. and Tracy J. C.: Tire Rolling Resistance - A Speed Dependent Contribution, SAE Paper 780255, SAE Congress and Exposition, Detroit, Michigan, February 27-March 3, 1978.

23. Thompson G. D.: Prediction of Dynamometer Power Absorption to Simulate Light Duty Truck Road Load, SAE Paper 770844, SAE Passenger Car Meeting, Detroit, Michigan, September 26-30, 1977.

24. Thompson G. J., Clark N. N., Atkinson R. J., Luzader Z., VanScoy F. L., Baker V., and Chandler J.: Development of and Interface Method for Implementing Road Grade in Chassis Dynamometer Testing, ICEF2004-896, Fall Technical 
Conference of the ASME Internal Combustion Engine Division, Long Beach, California, October 24-27, 2004.

25. Thompson, G. J., Gautam M., Clark N. N., and Lyons D. W.: Assessment of Mobile Monitoring Technologies for Heavy-Duty Vehicle Emissions, Department of Mechanical and Aerospace Engineering, College of Engineering and Mineral Resources, West Virginia University, Morgantown, West Virginia, March 10, 1999.

26. Thompson G. J., Clark N. N., Gautam M., Carder D. K., and Lyons D. W.: Inference of Torque and Power from Heavy-Duty Diesel Engines for On-Road Emissions Testing, SAE Paper 2002-01-0614, SAE World Congress, Detroit, Michigan, March 4-7, 2002.

27. US Geological Survey, and US Forrest Service: Reston, Virginia, World Wide Web, http://nmviewogc.cr.usgs.gov/viewer.htm, July 25, 2005.

28. Varat M. S., Kerkhoff J. F., Husher S. E., Armstrong C. D., and Shuman K. F.: The Analysis and Determination of Tire-Roadway Frictional Drag, SAE Paper 2003-01-0887, SAE World Congress, Detroit, Michigan, March 3-6, 2003.

29. White R. A. and Korst H. H.: The Determination of Vehicle Drag Contributions from Coast-Down Tests, SAE Paper 720099, SAE Automotive Engineering Congress, Detroit, Michigan, January 10-14, 1972.

30. White, R. G. S. : A Method of Estimating Automobile Drag Coefficients, SAE Paper 690189, International Automotive Engineering Congress, Detroit, Michigan, January 13-17, 1969.

31. Yahoo Inc: Sunnyvale, California, World Wide Web, http://maps.yahoo.com/, July 25, 2005.

32. Yasin T. P.: The Analytical Basis of Automotive Coastdown Testing, SAE Paper 780334, Congress and Exposition, Detroit Michigan, February 27-March 3, 1978.

33. Yuting R., Saleem F., and Zhou J. H.: Road Load Simulation Using Effective Road Profile, SAE X International Conference on Vehicle Structural Mechanics and CAE, Troy, Michigan, April 8-10, 1997. 


\section{Appendix}

\subsection{Empty Load}

\subsubsection{Test 1 / Empty Load}

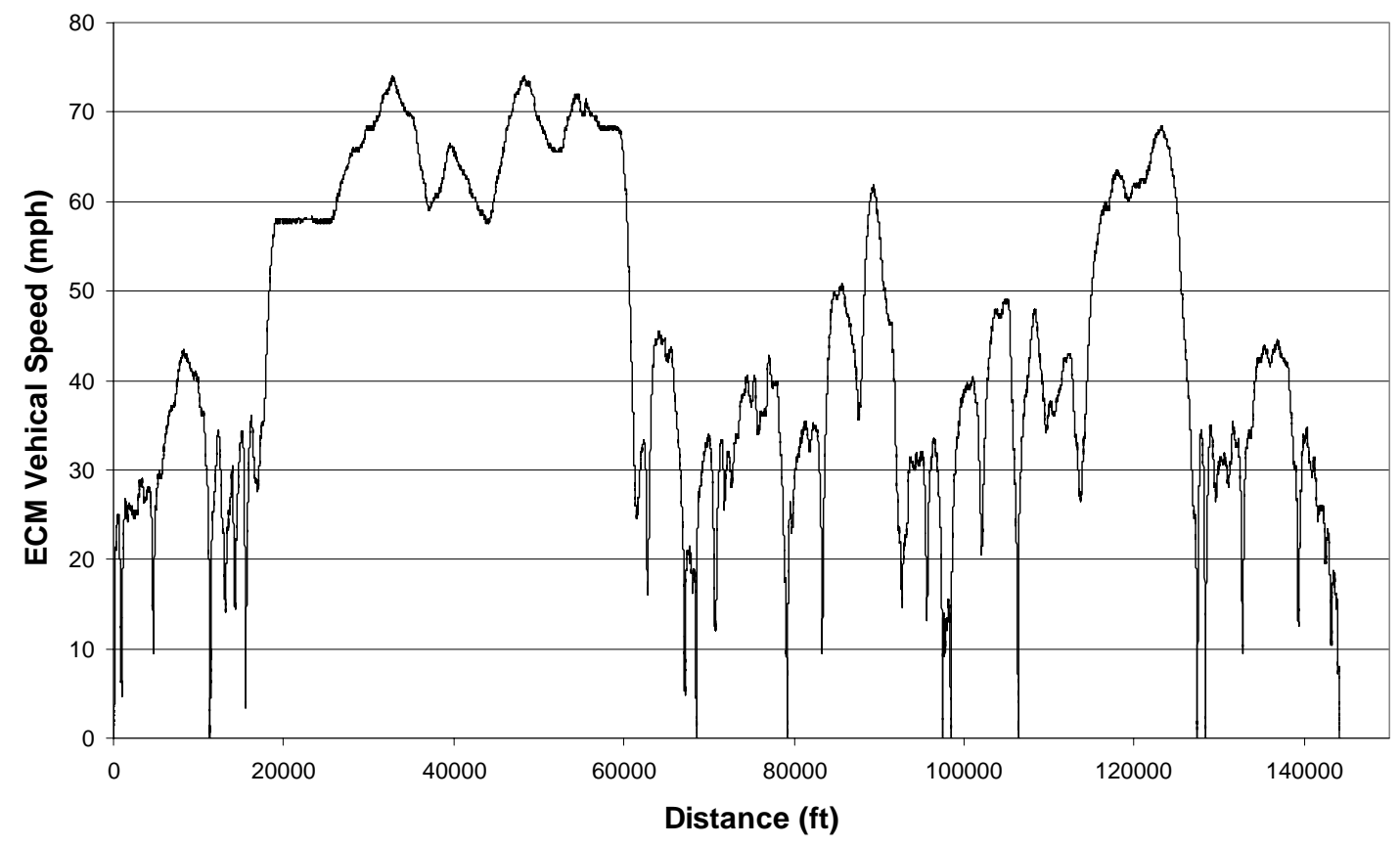

Figure 32: Test 1 / Empty Load ECU Vehicle Speed

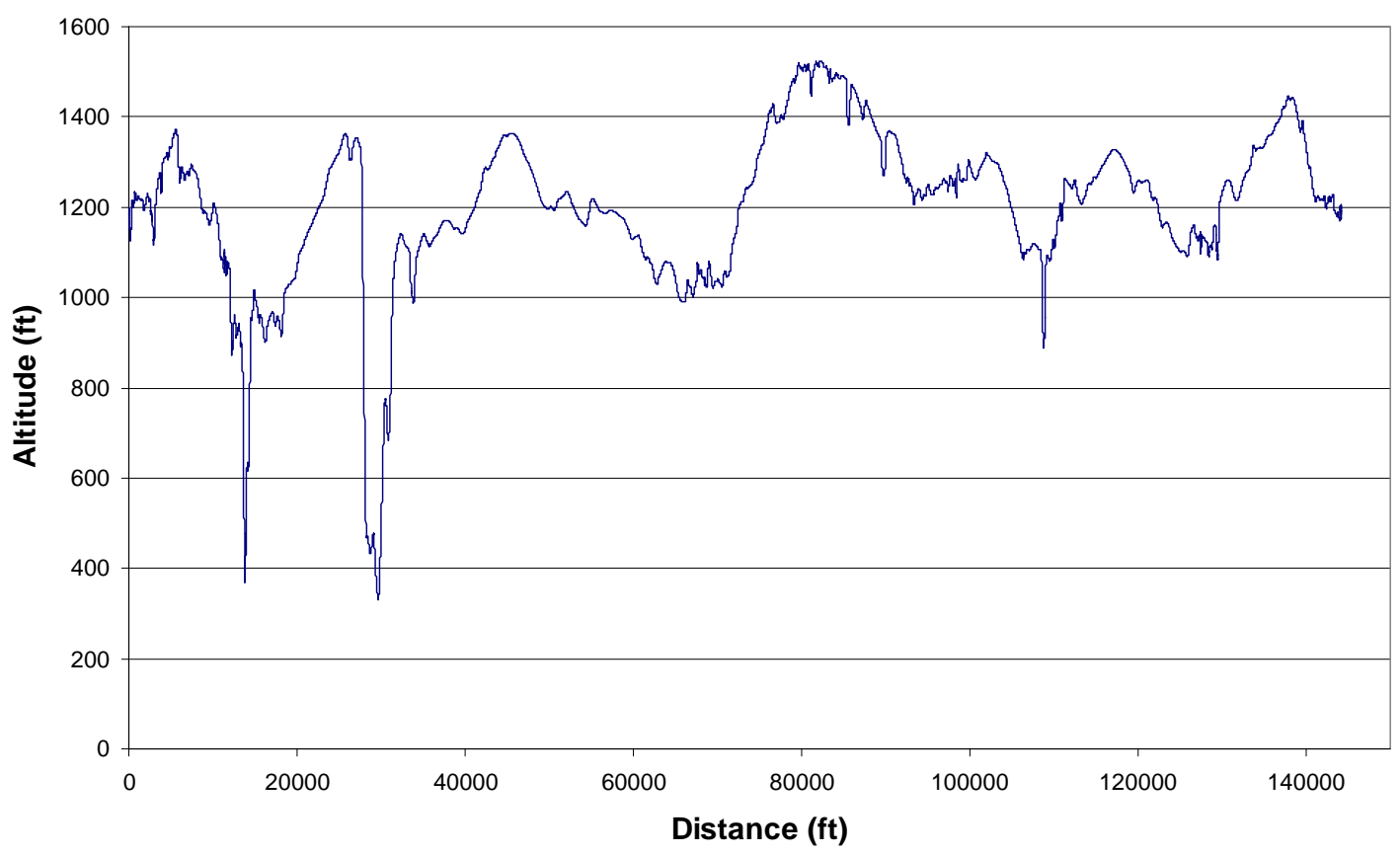

Figure 33: Test 1 / Empty Load Altitude 


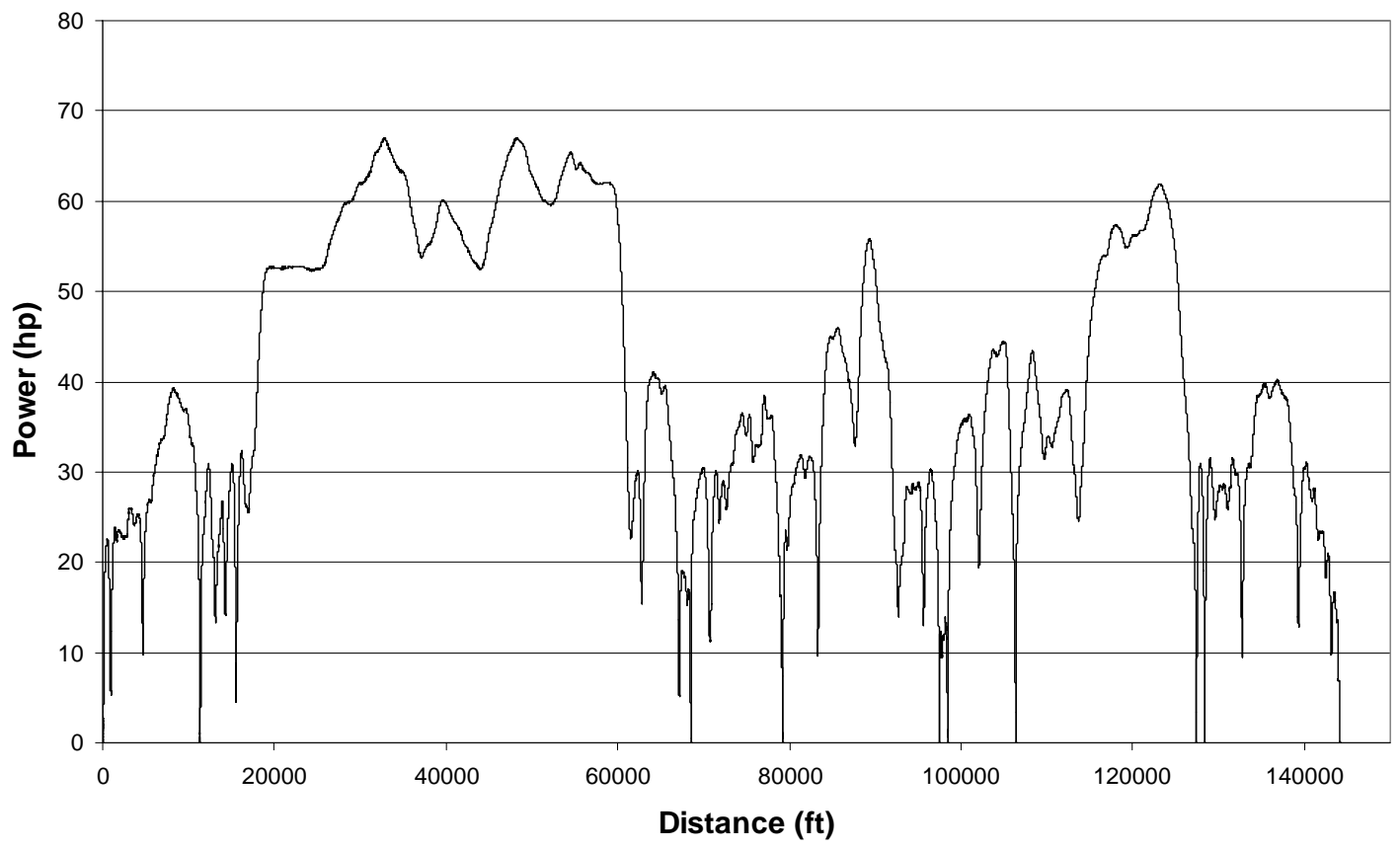

Figure 34: Test 1 / Empty Load Rolling Power

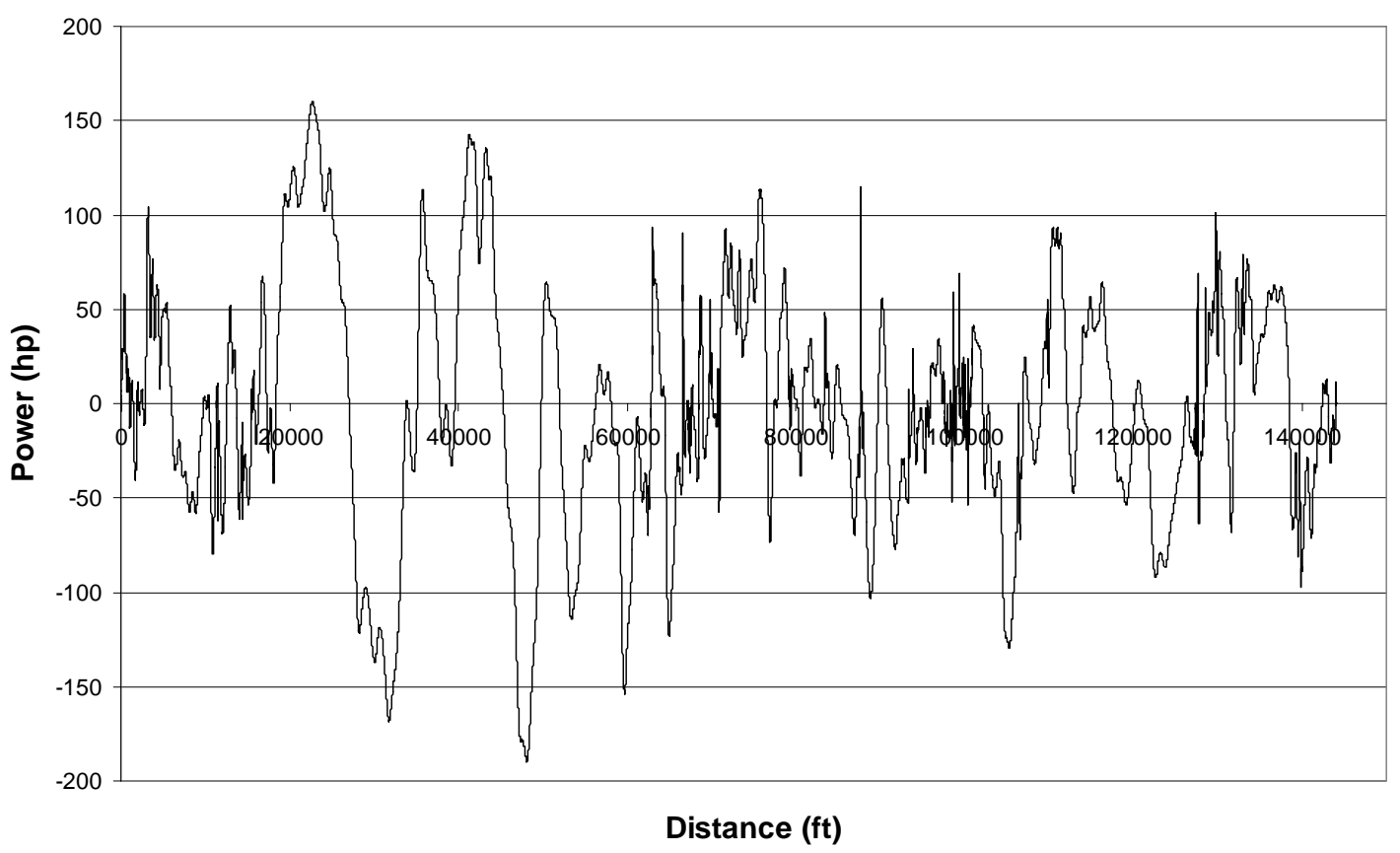

Figure 35: Test 1 / Empty Load Climbing Power 


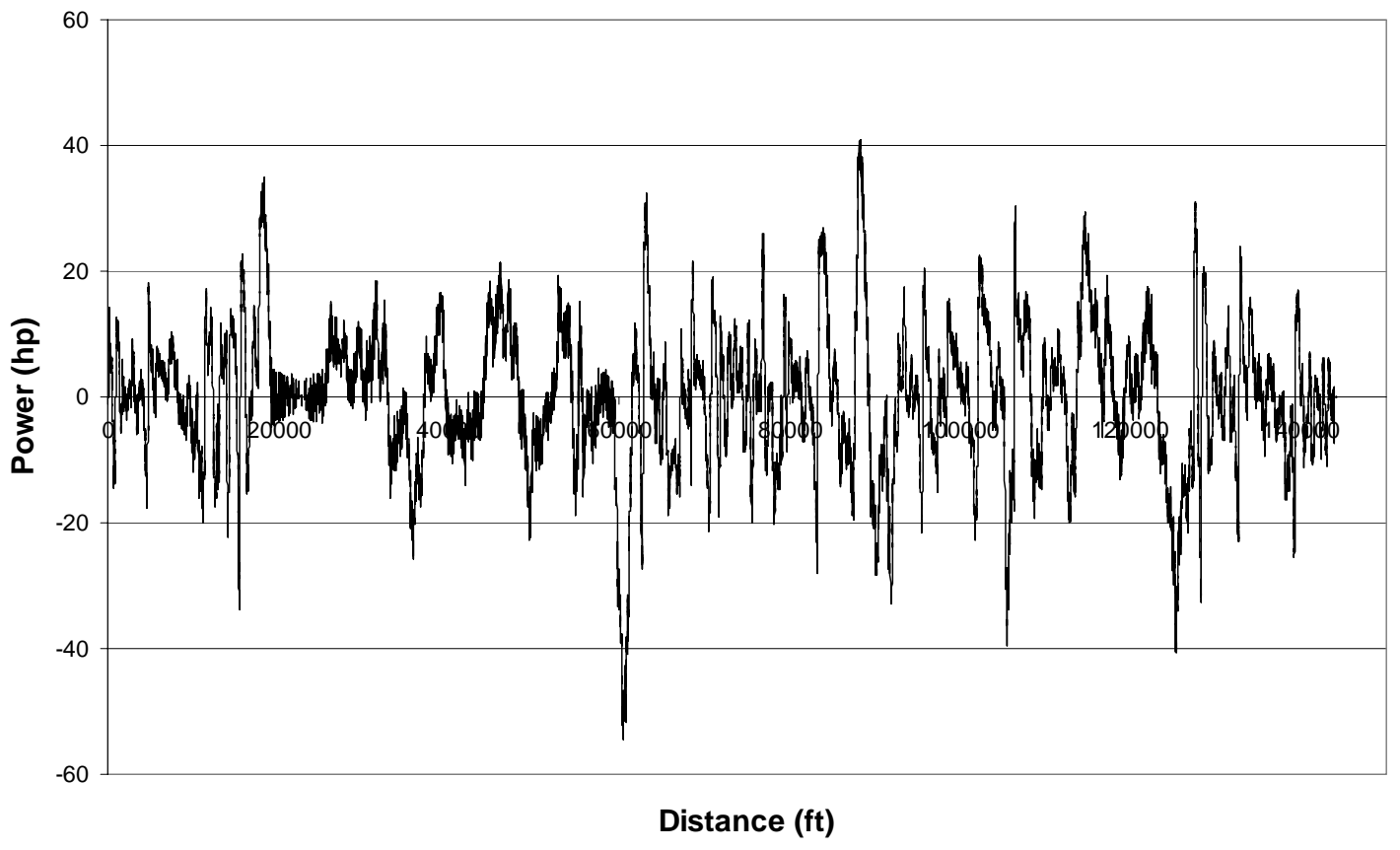

Figure 36: Test 1 / Empty Load Acceleration Power

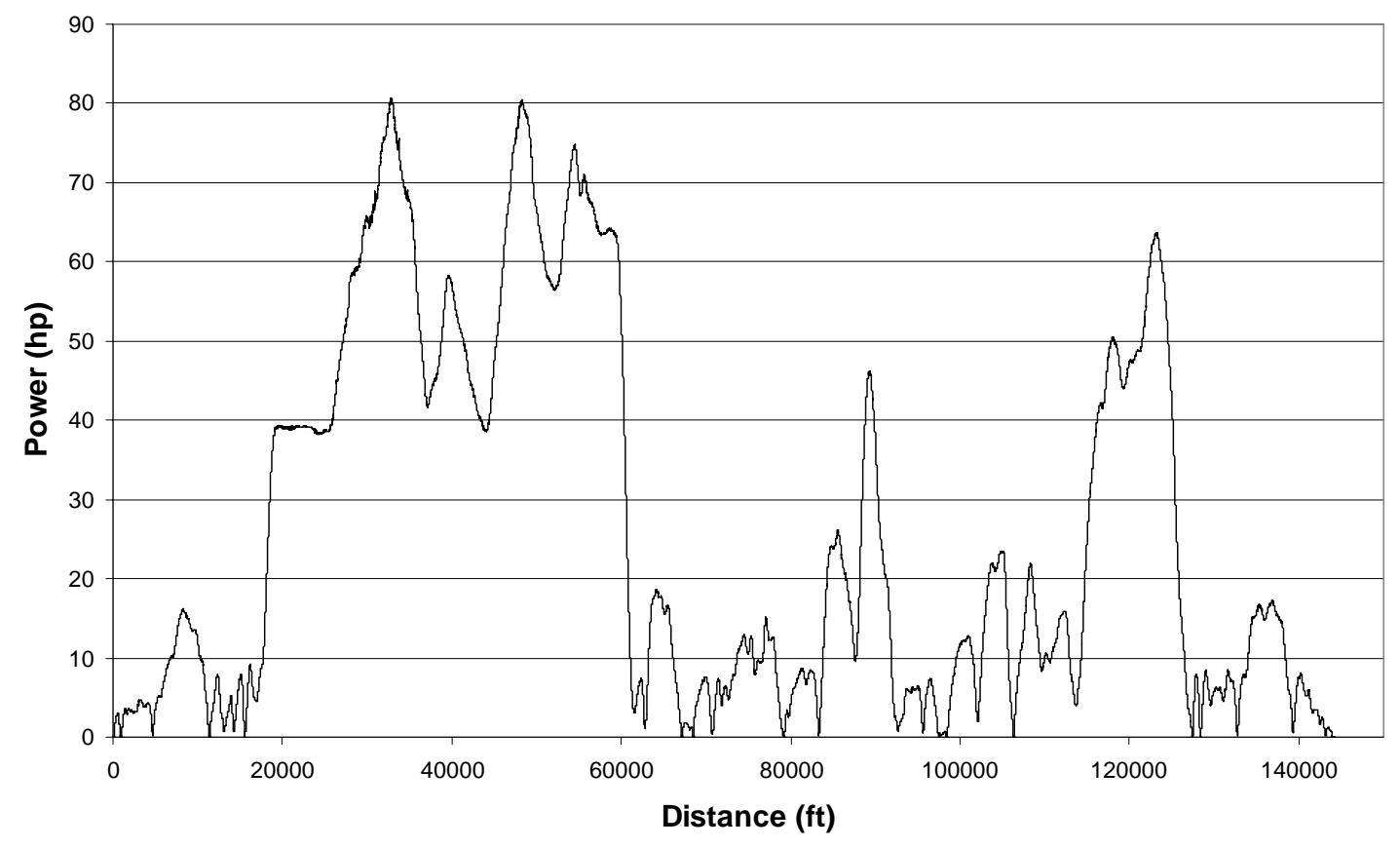

Figure 37: Test 1 / Empty Load Aerodynamic Power 


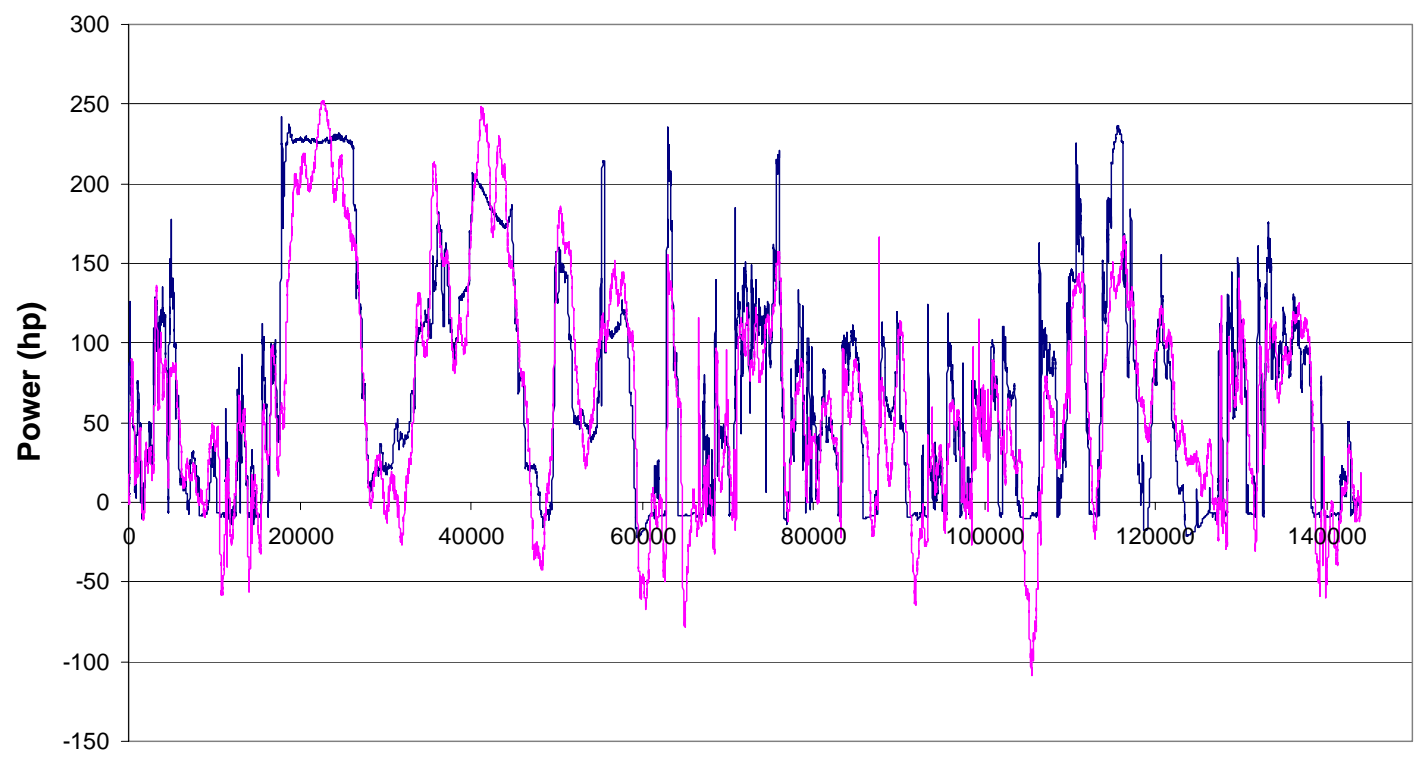

\section{Distance (ft) \\ - ECM - Model}

Figure 38: Test 1 / Load Weight Power Comparison

\subsubsection{Test 2 / Empty Load}

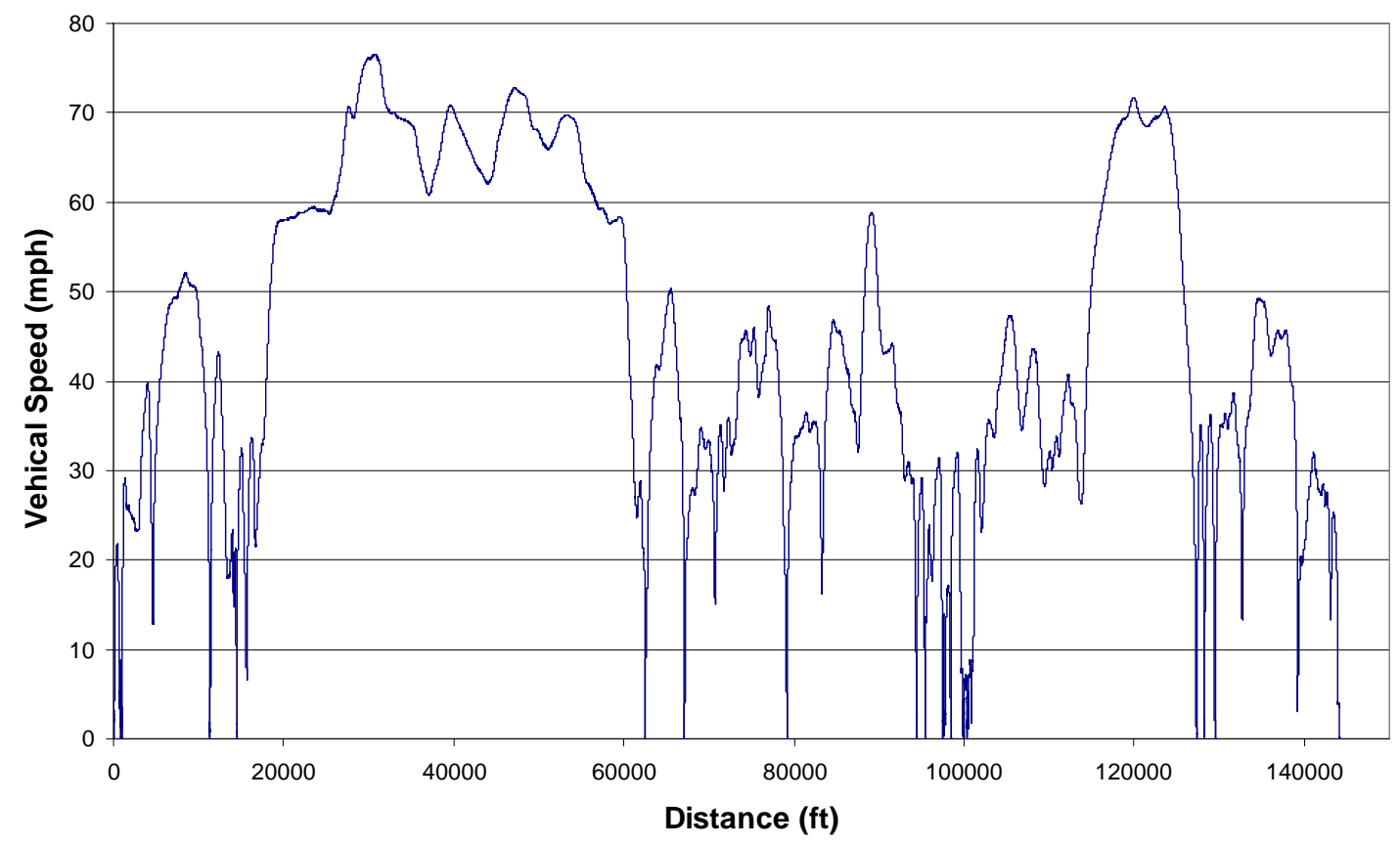

Figure 39: Test 2 / Empty Load ECU Vehicle Speed 


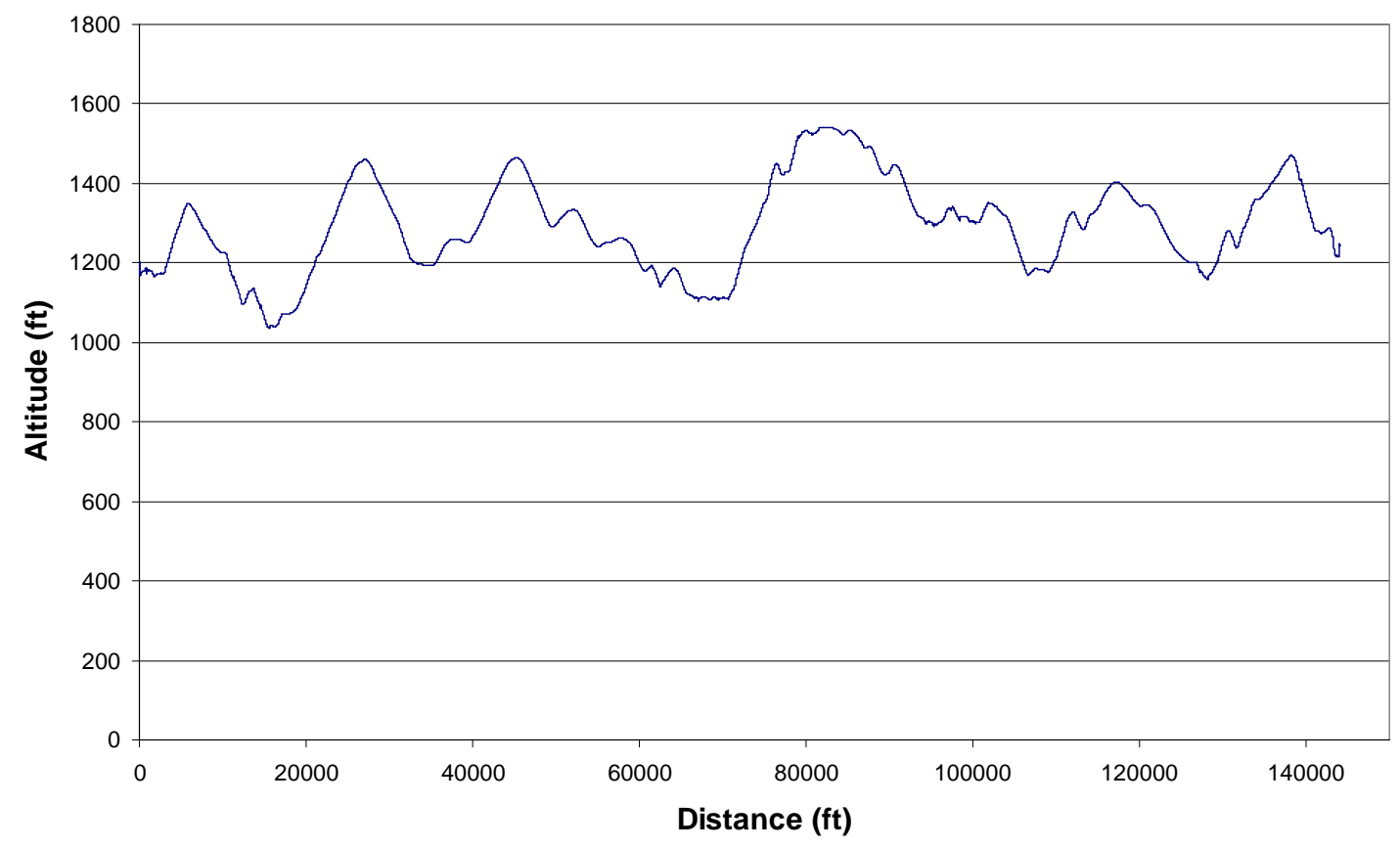

Figure 40: Test 2 / Empty Load Altitude

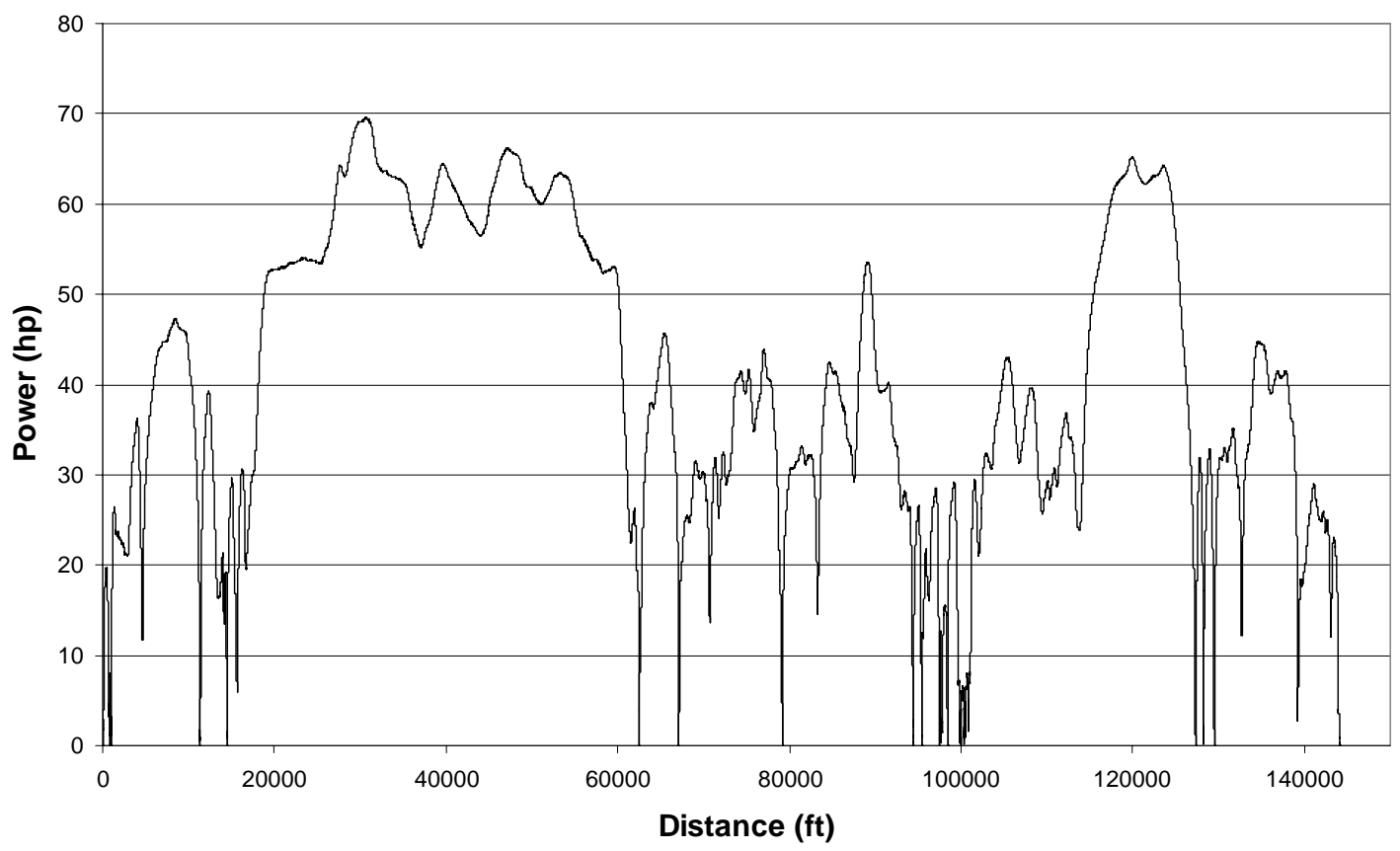

Figure 41: Test 2 / Empty Load Rolling Power 


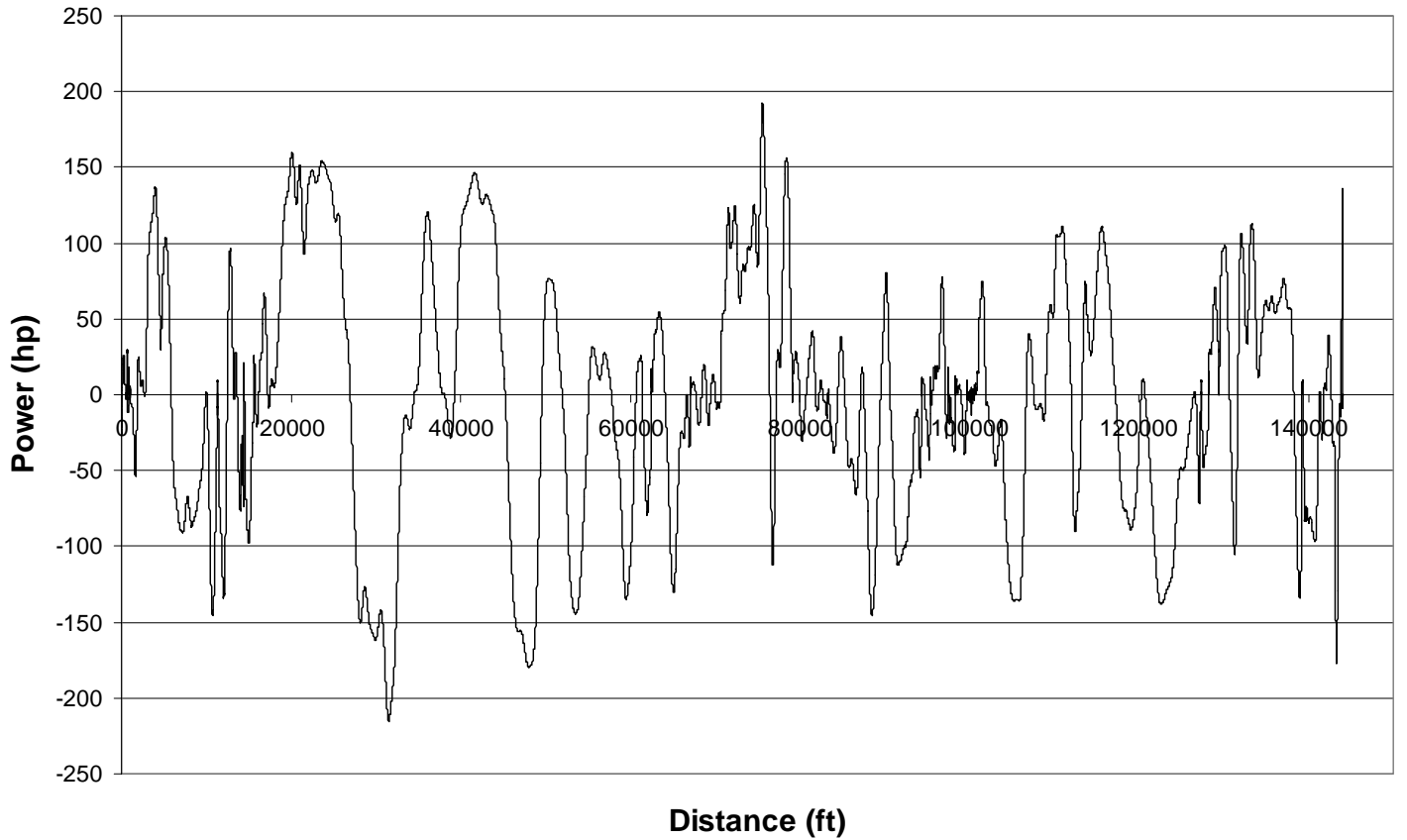

Figure 42: Test 2 / Empty Load Climbing Power

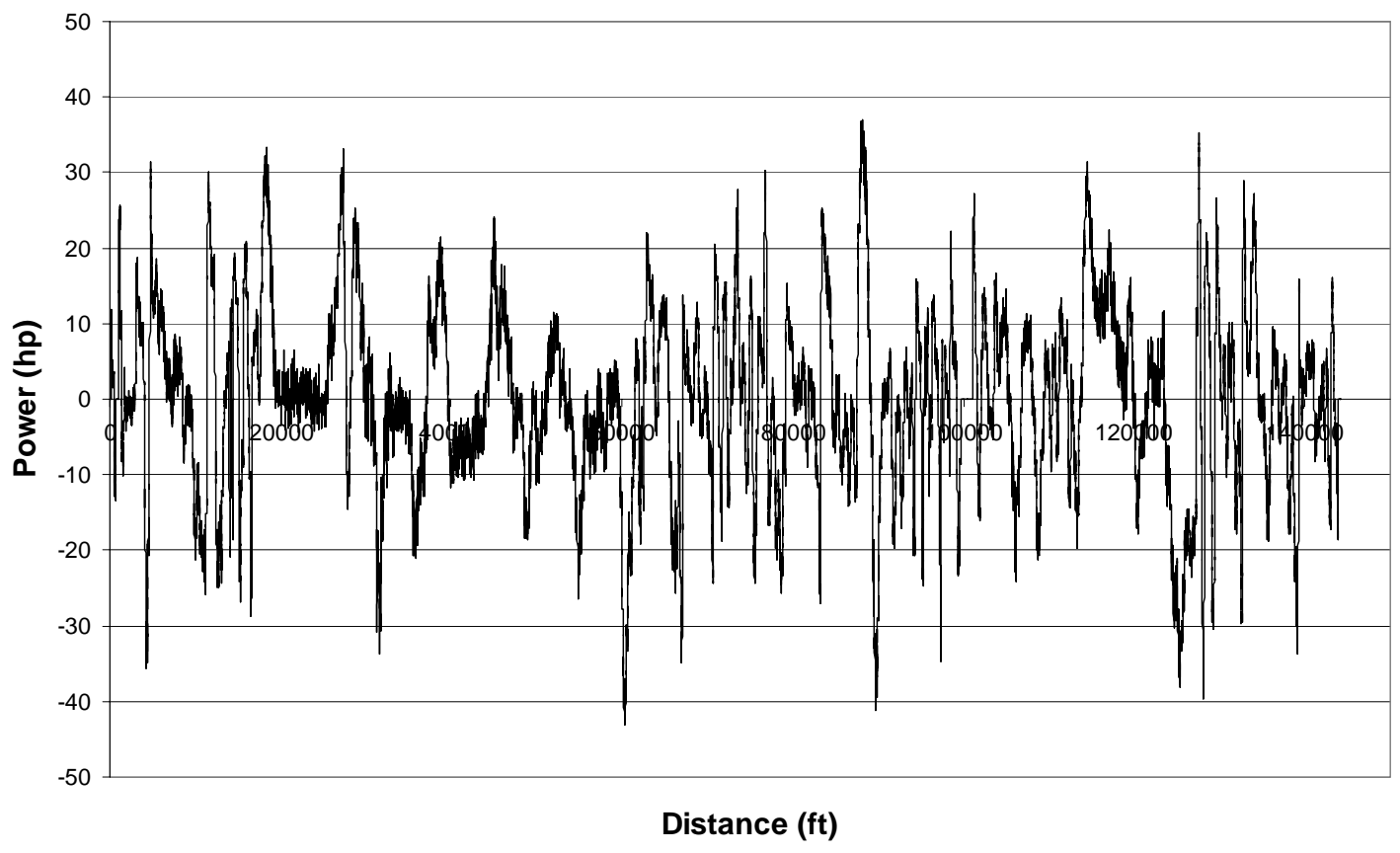

Figure 43: Test 2 / Empty Load Acceleration Power 


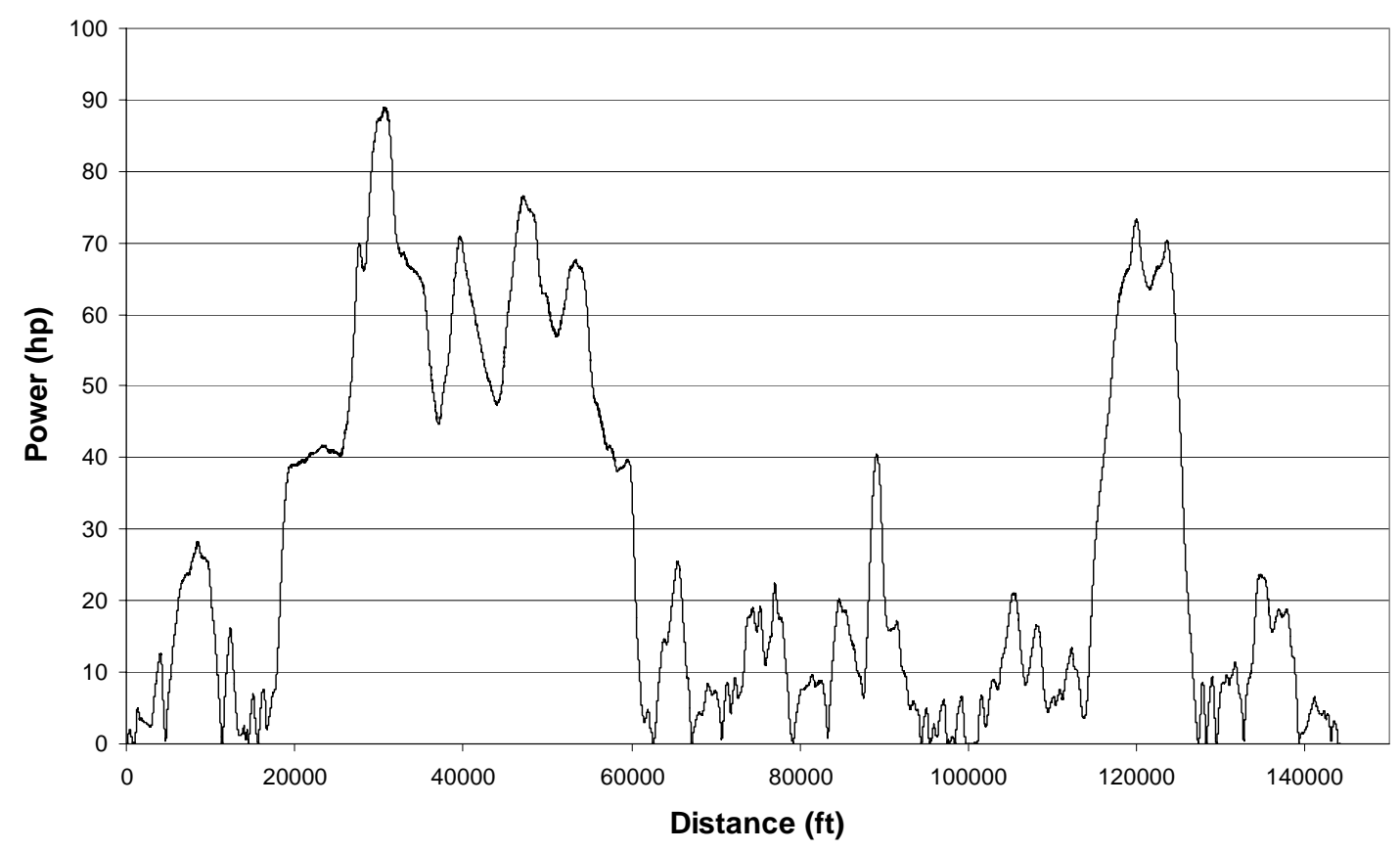

Figure 44: Test 2 / Empty Load Aerodynamic Power

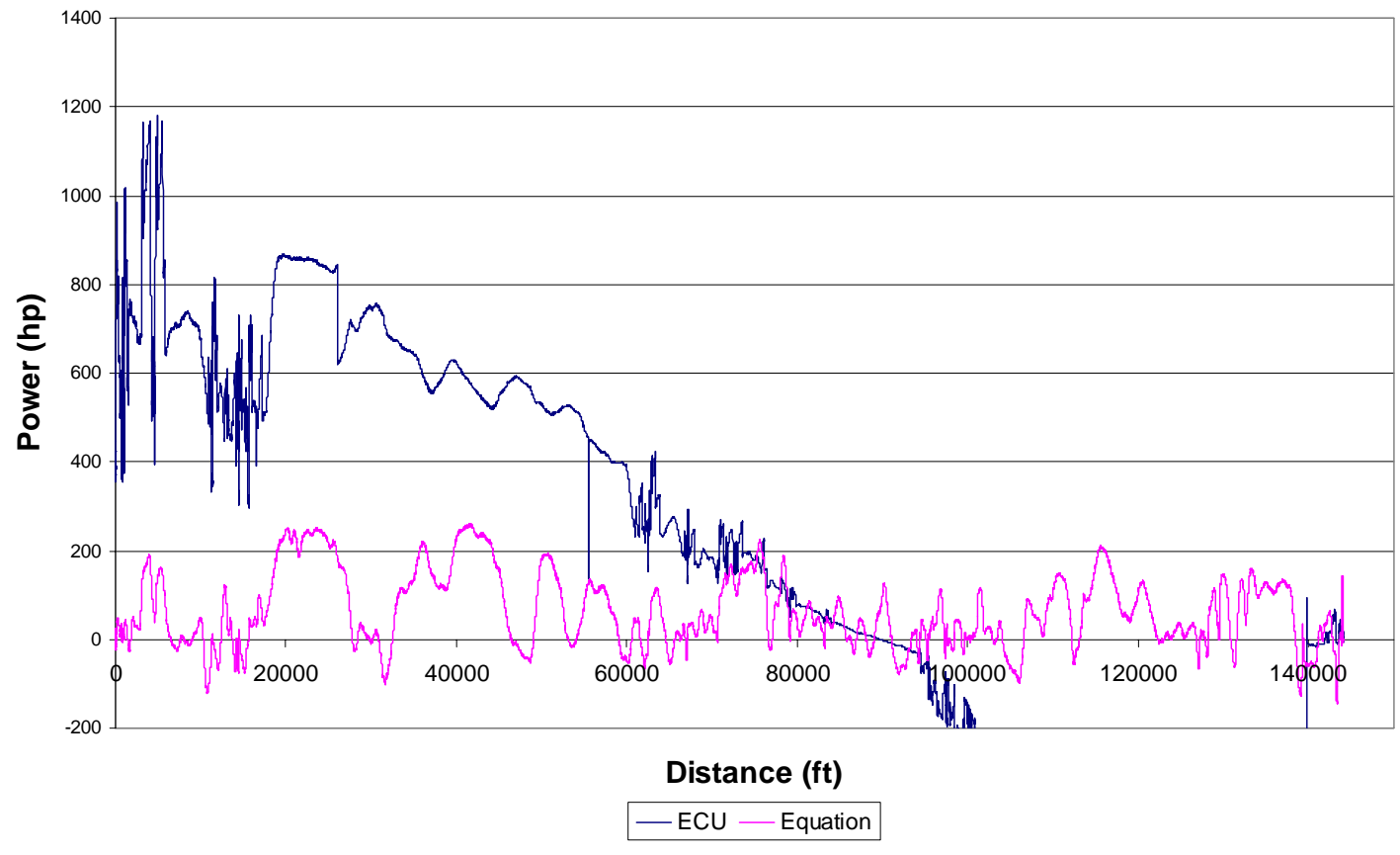

Figure 45: Test 2 / Empty Load Power Comparison Showing Problem in ECU Power Output 
8.1.3. Test 3 / Empty Load

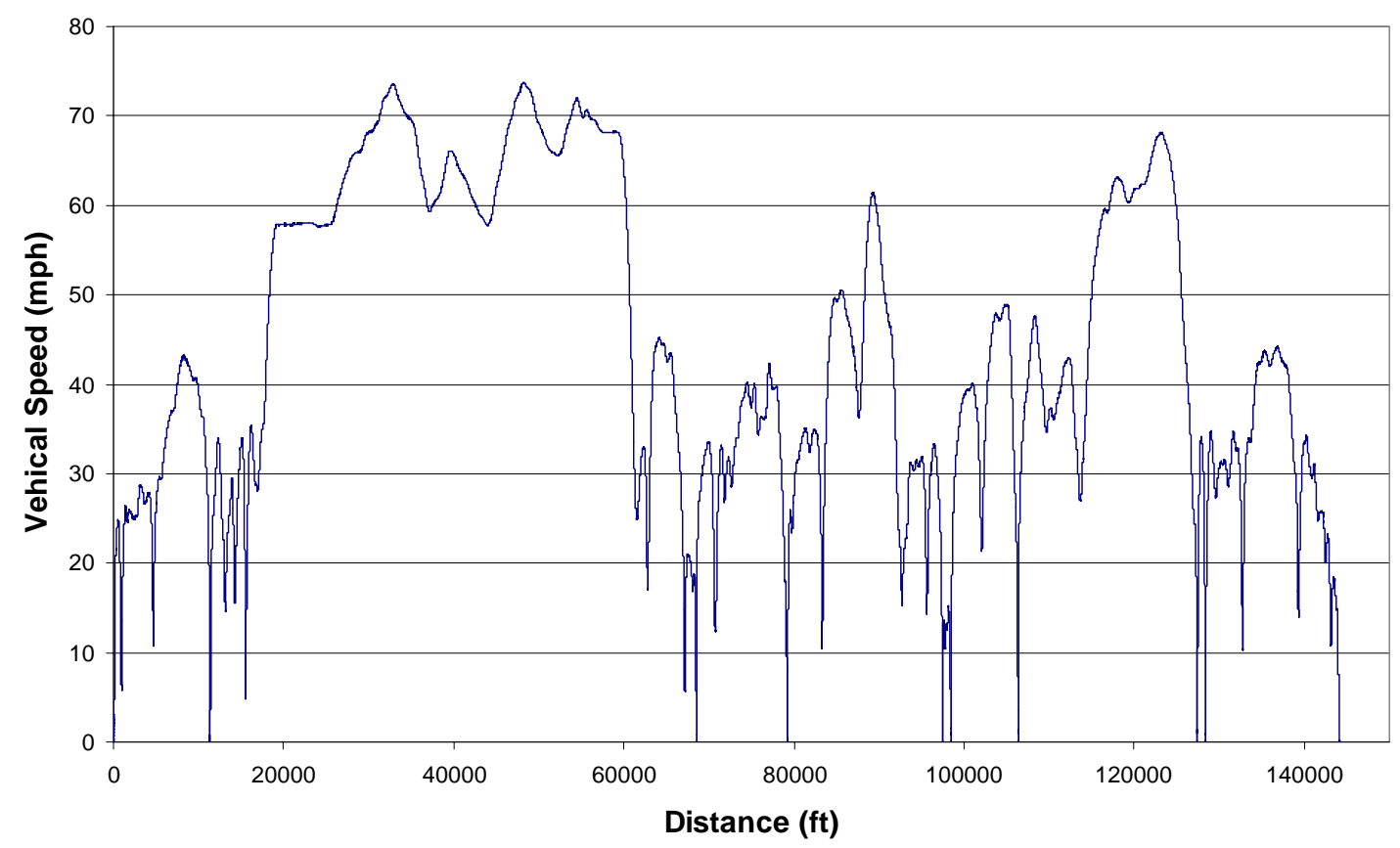

Figure 46: Test 3 / Empty Load ECU Vehicle Speed

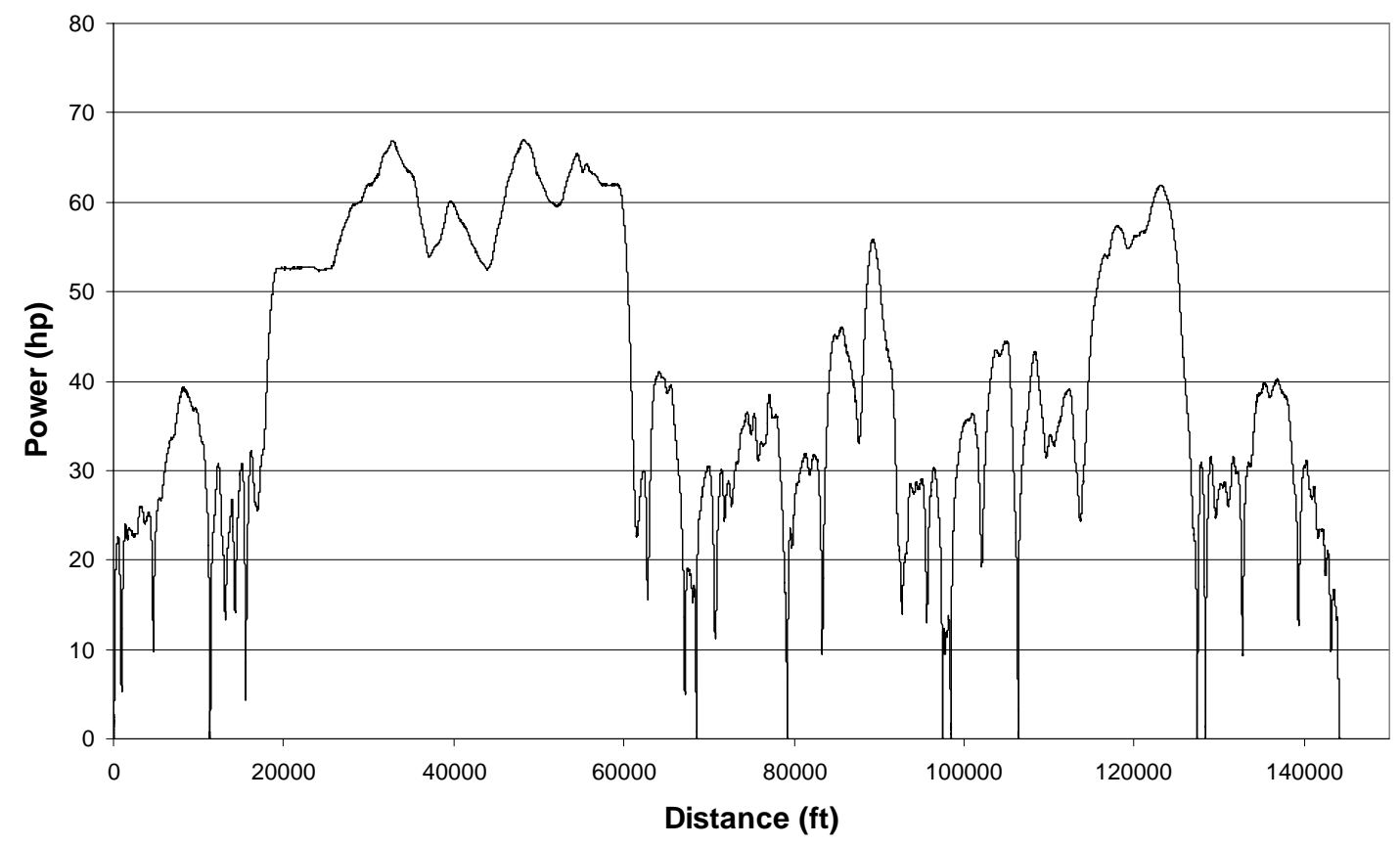

Figure 47: Test 3 / Empty Load Rolling Power 


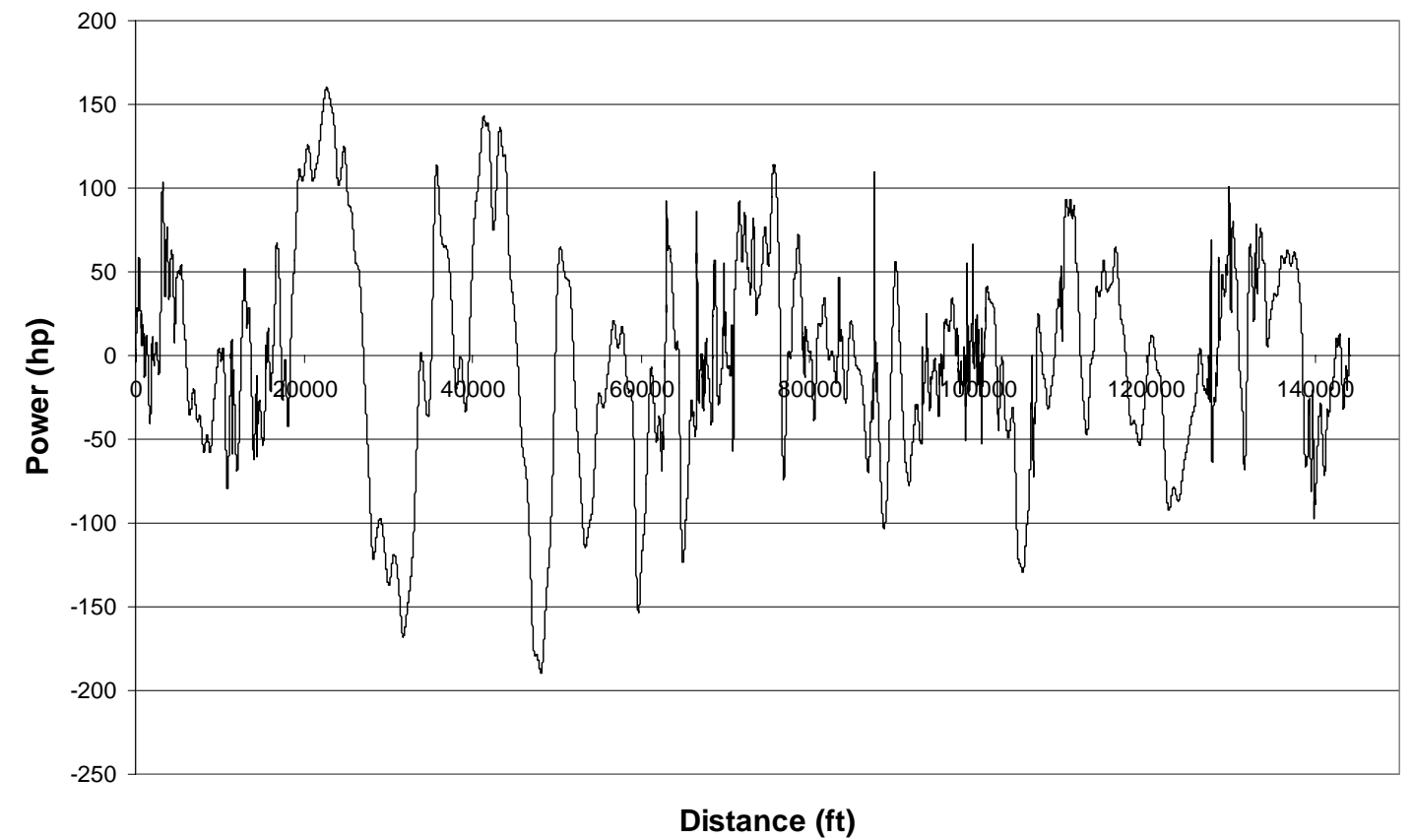

Figure 48: Test 3 / Empty Load Climbing Power

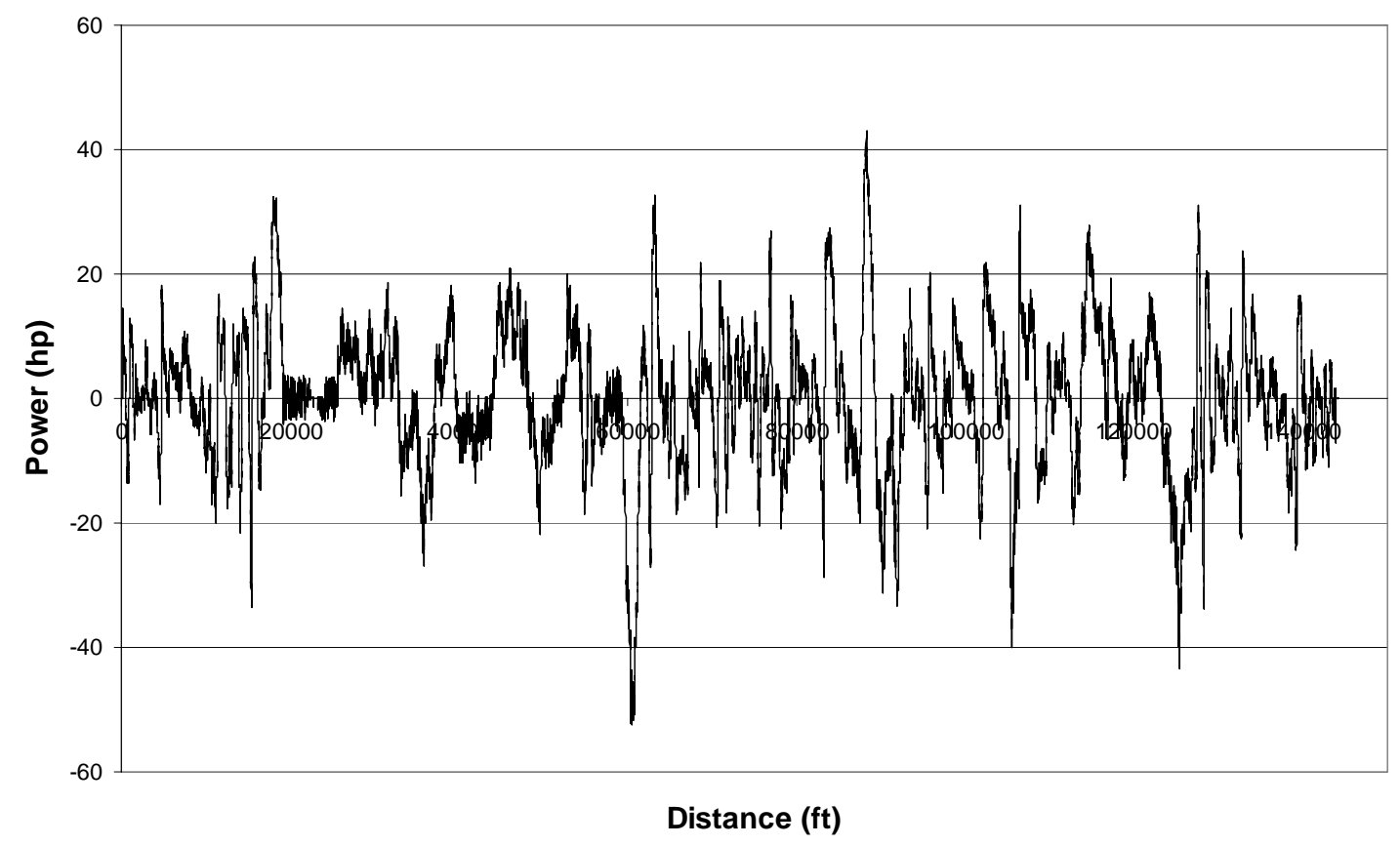

Figure 49: Test 3 / Empty Load Acceleration Power 


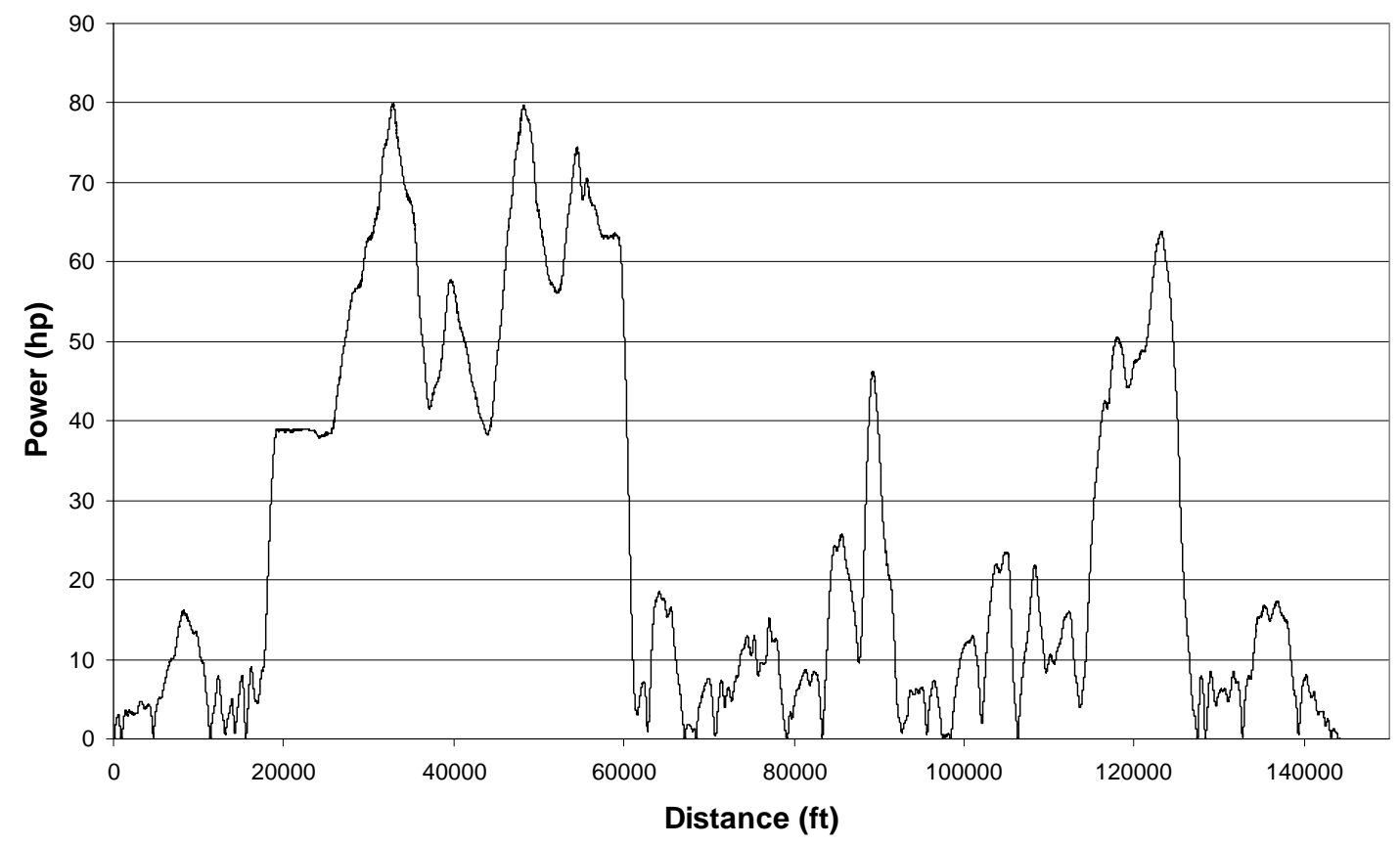

Figure 50: Test 3 / Empty Load Aerodynamic Power

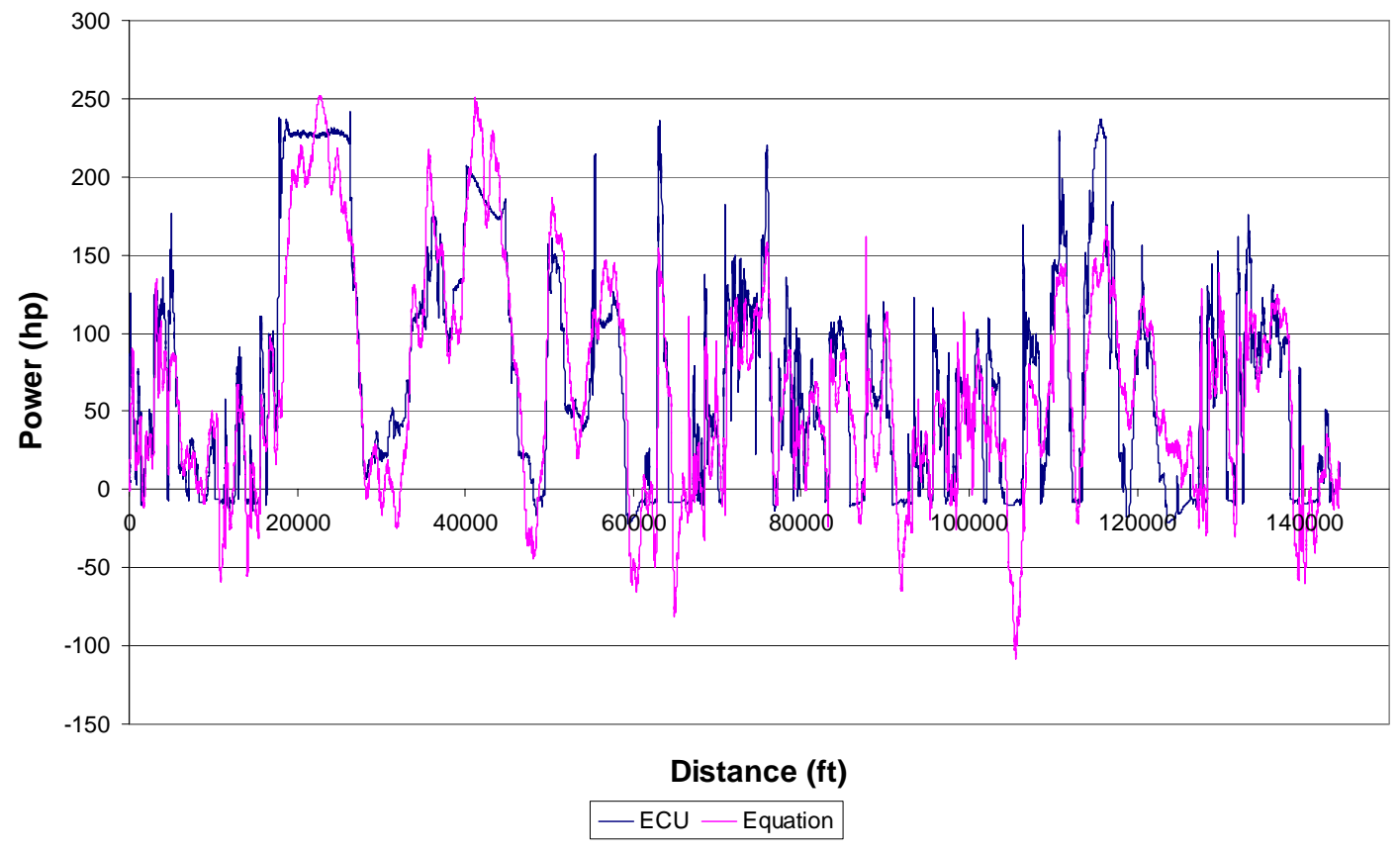

Figure 51: Test 3 / Empty Load Power Comparison 
8.1.4. $\quad$ Test 4 / Empty Load

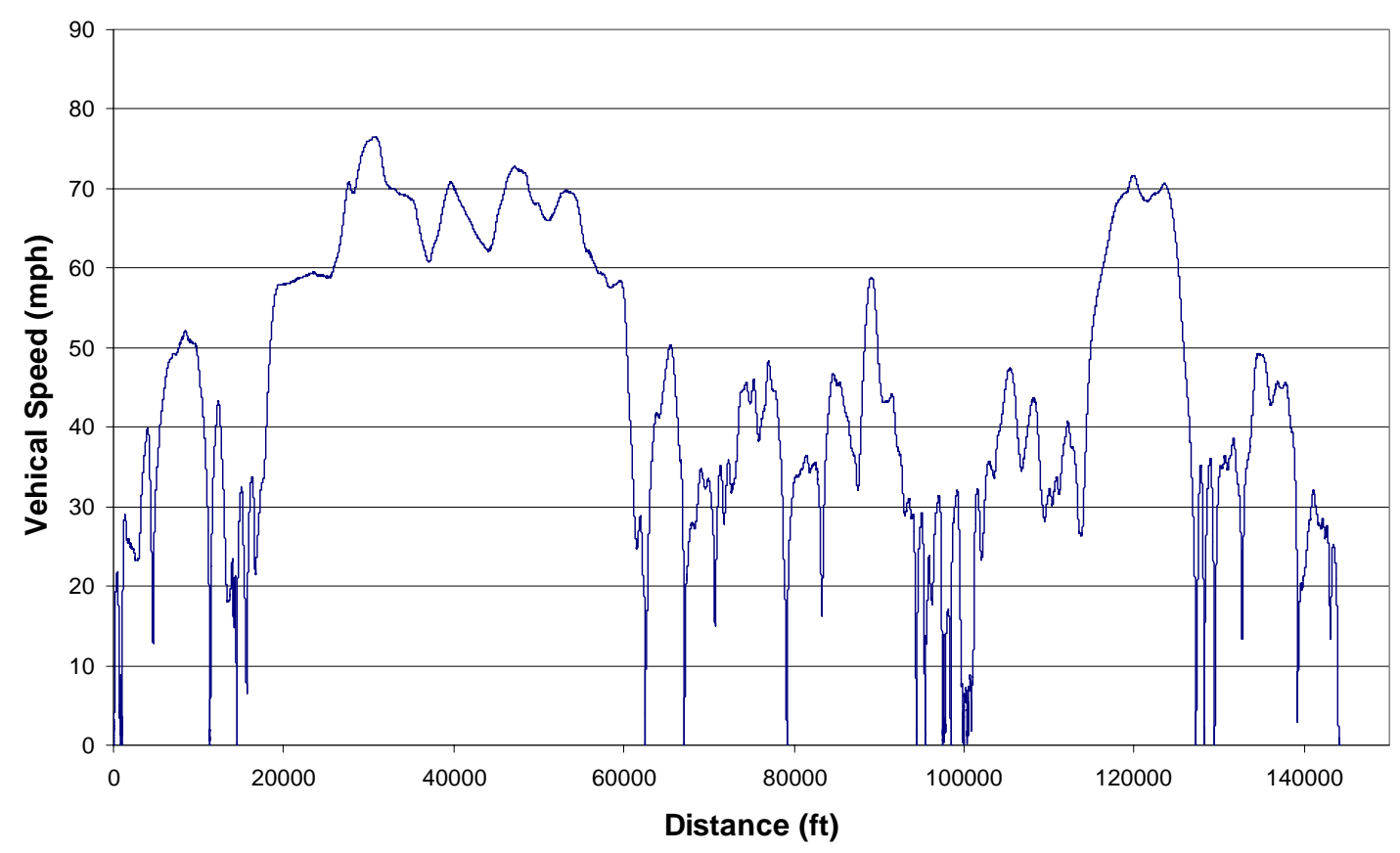

Figure 52: Test 4 / Empty Load ECU Vehicle Speed

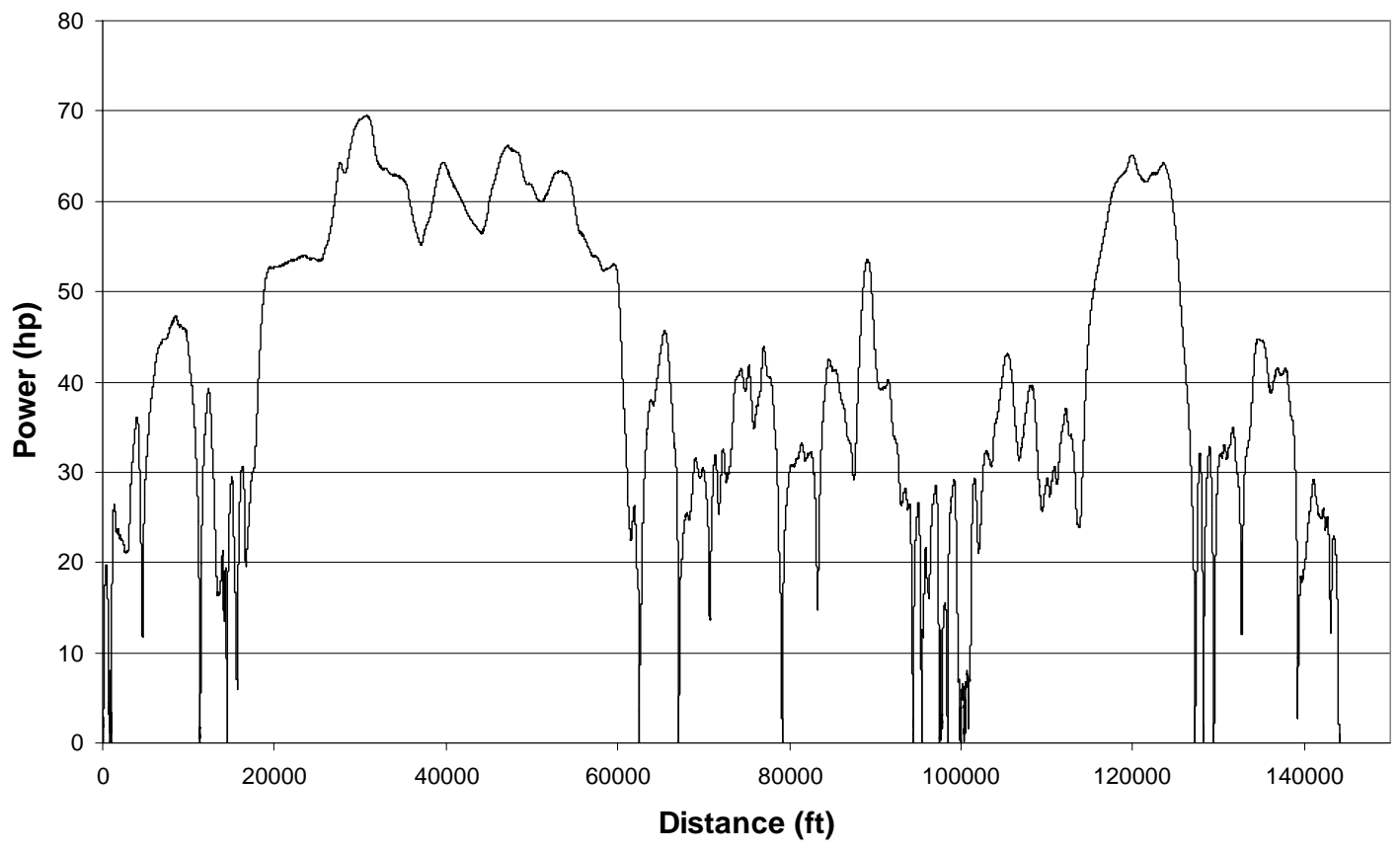

Figure 53: Test 4 / Empty Load Rolling Power 


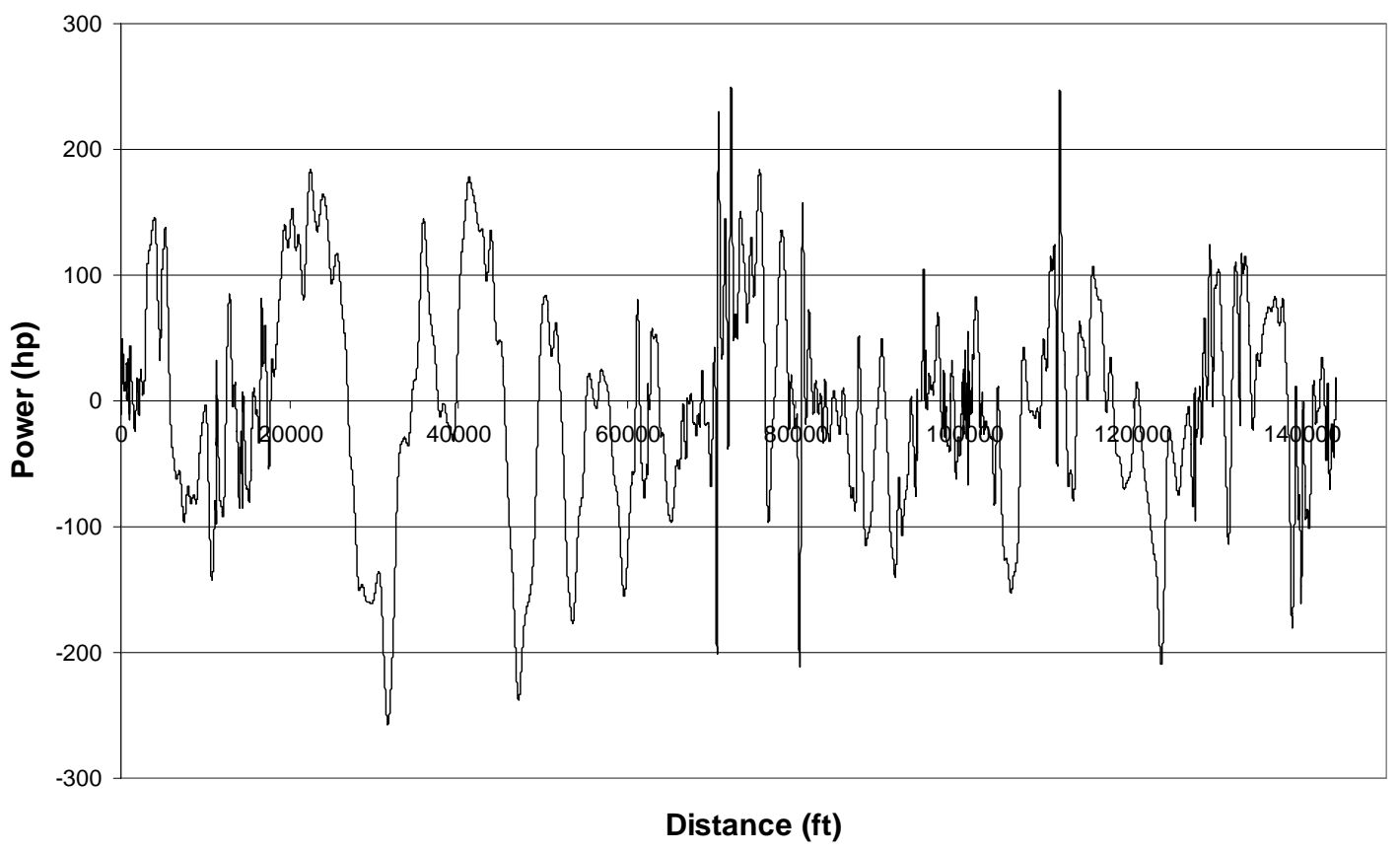

Figure 54: Test 4 / Empty Load Climbing Power

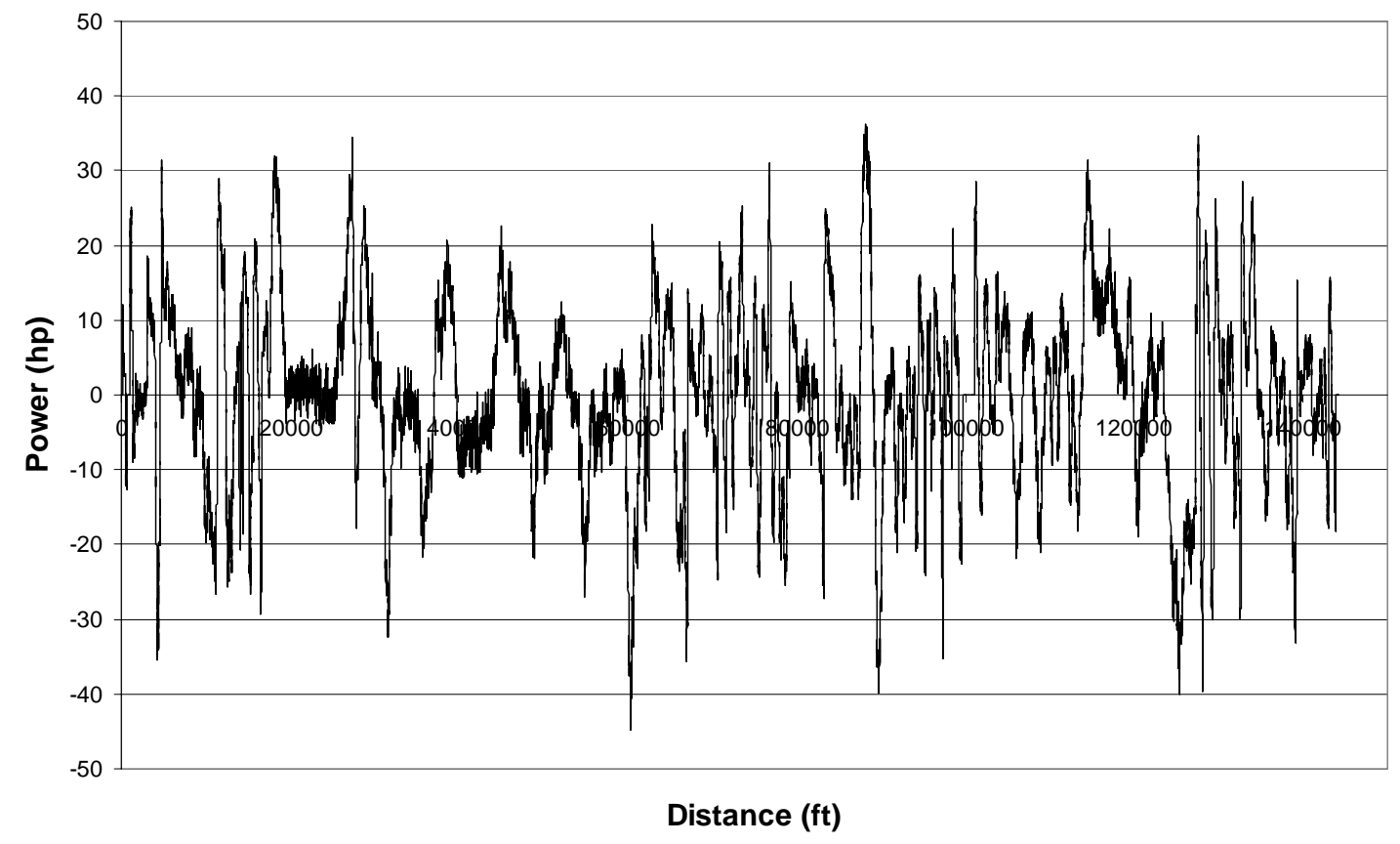

Figure 55: Test 4 / Empty Load Acceleration Power 


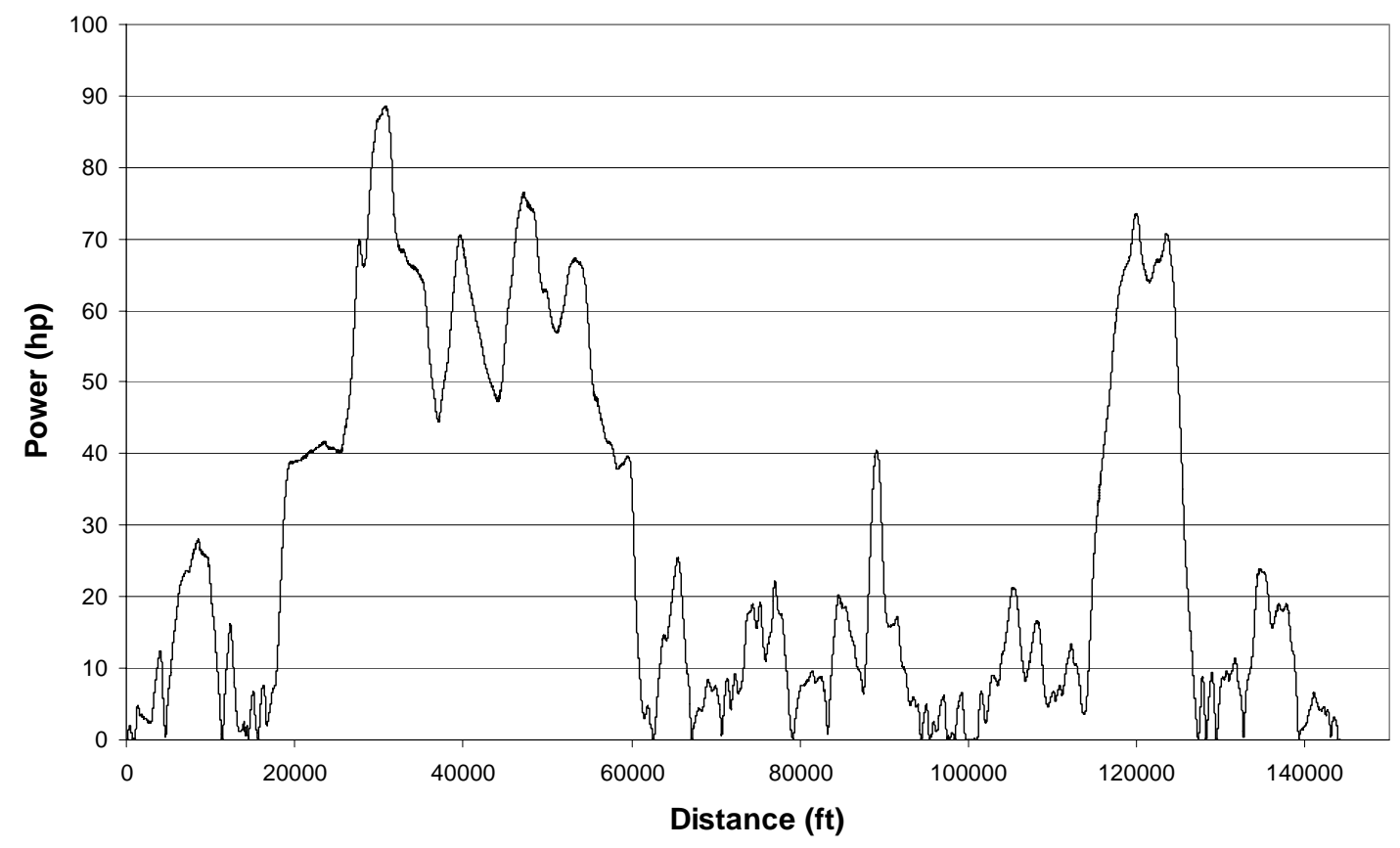

Figure 56: Test 4 / Empty Load Aerodynamic Power

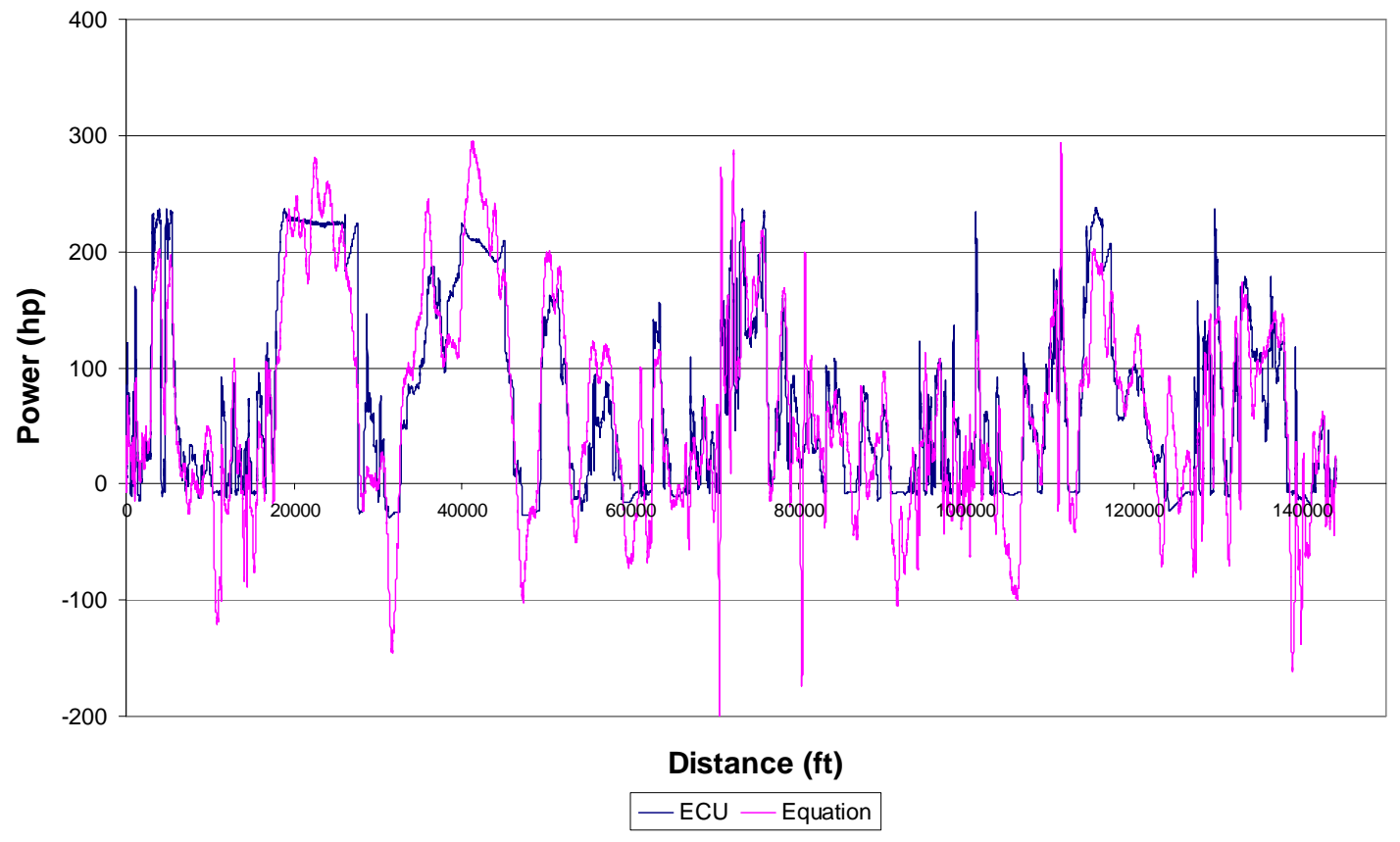

Figure 57: Test 4 / Load Weight Power Comparison 
8.2. Half Load

\subsubsection{Test 1 / Half Load}

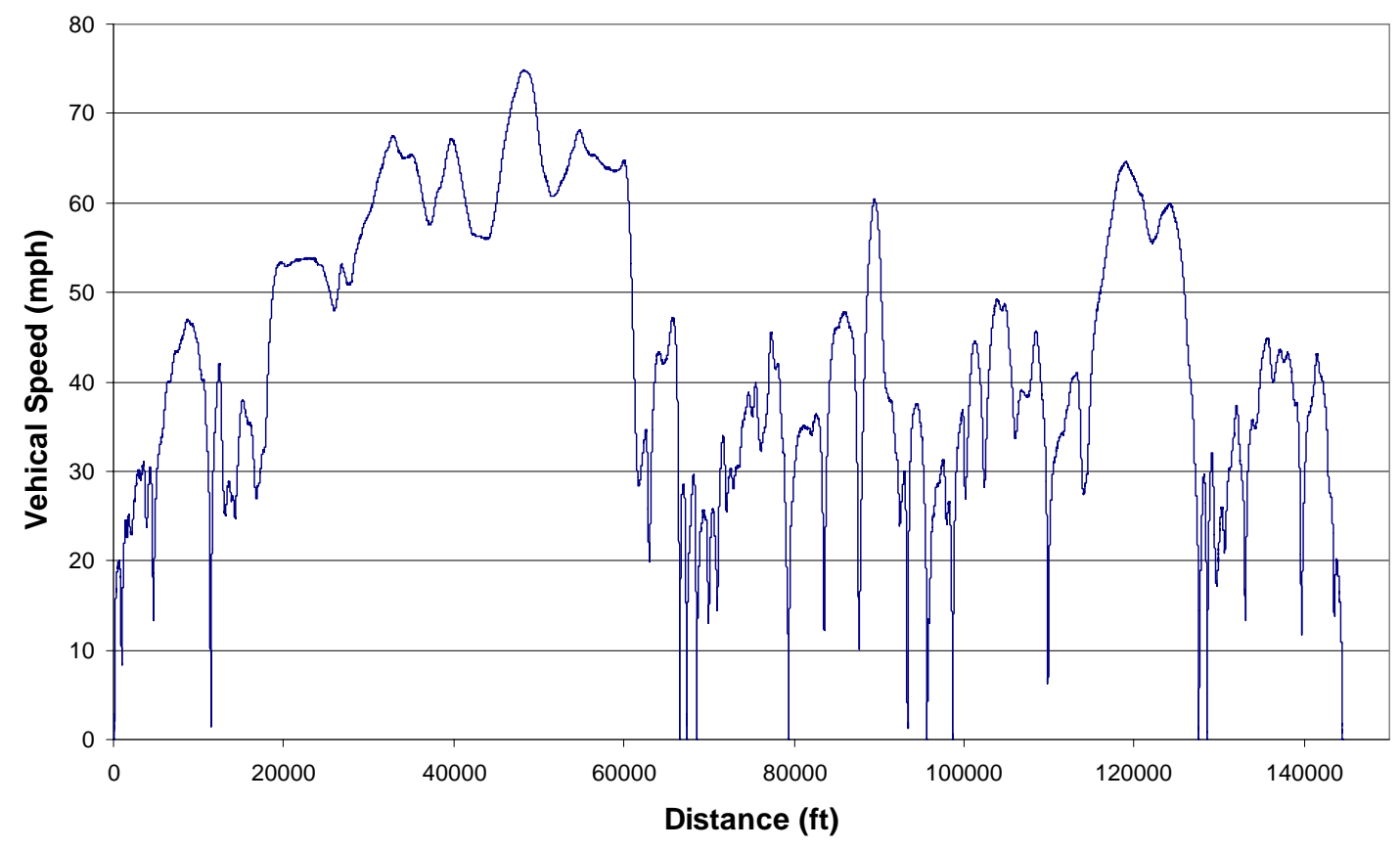

Figure 58: Test 1 / Half Load ECU Vehicle Speed

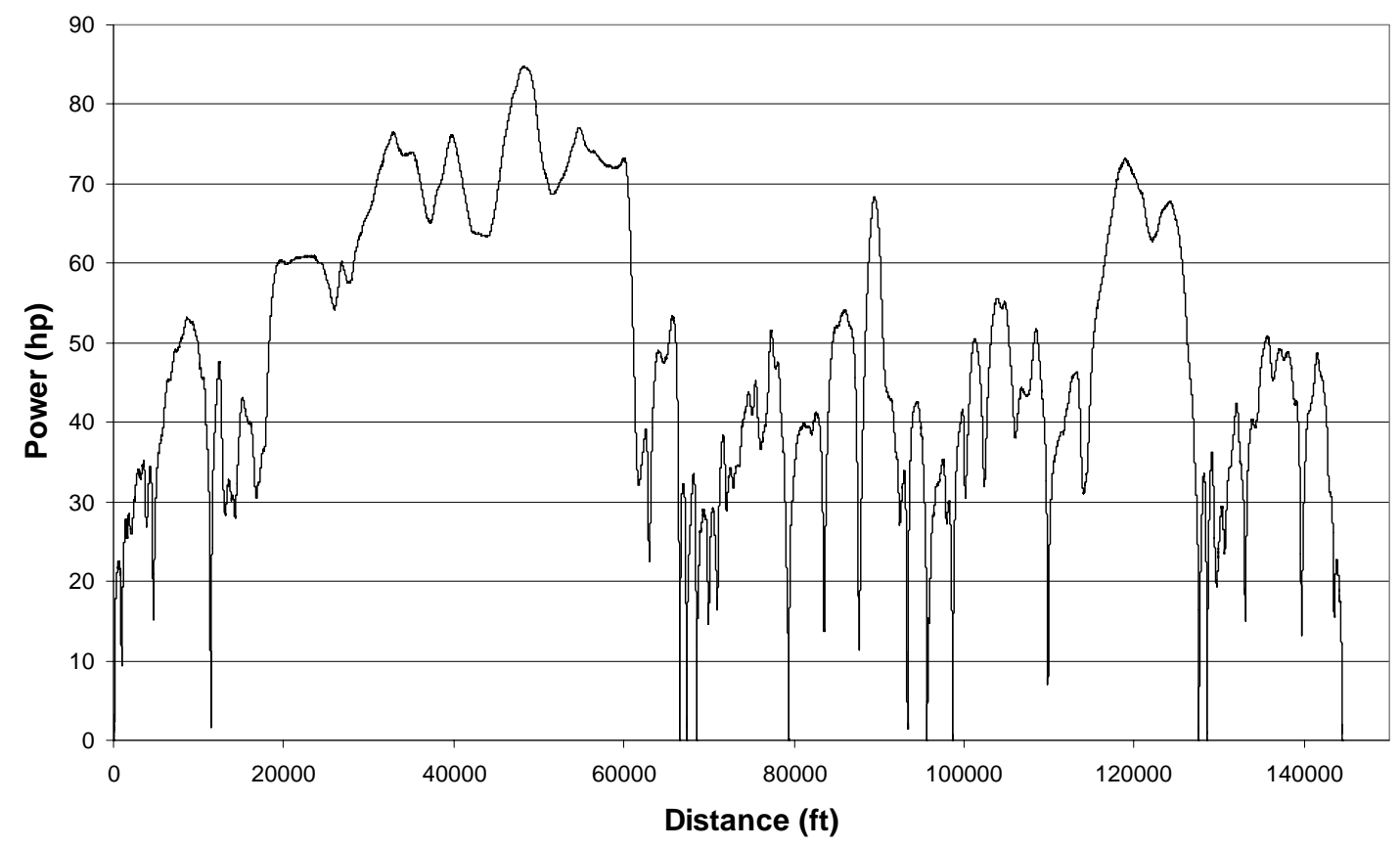

Figure 59: Test 1 / Half Load Rolling Power 


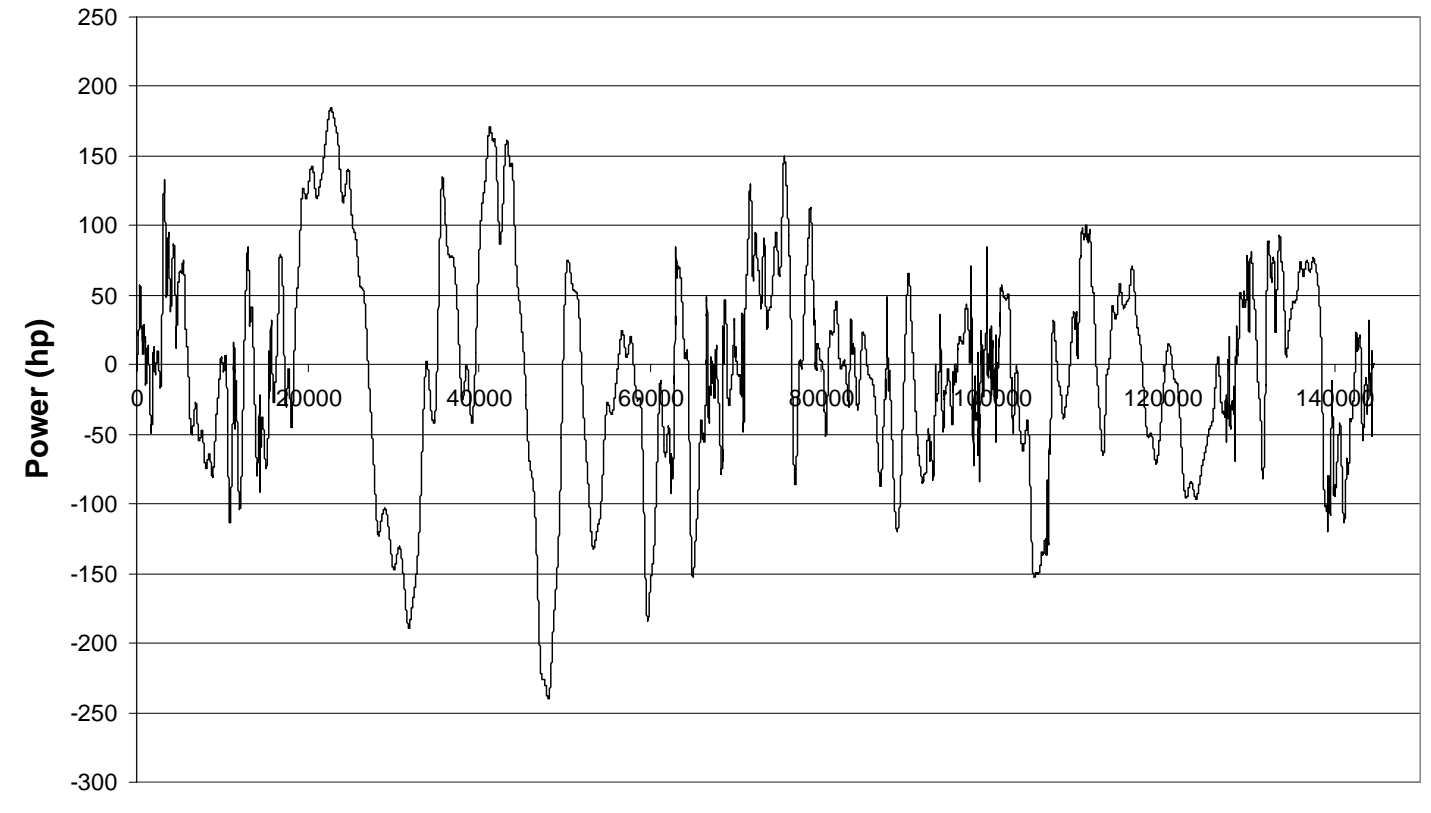

Distance (ft)

Figure 60: Test 1 / Half Load Climbing Power

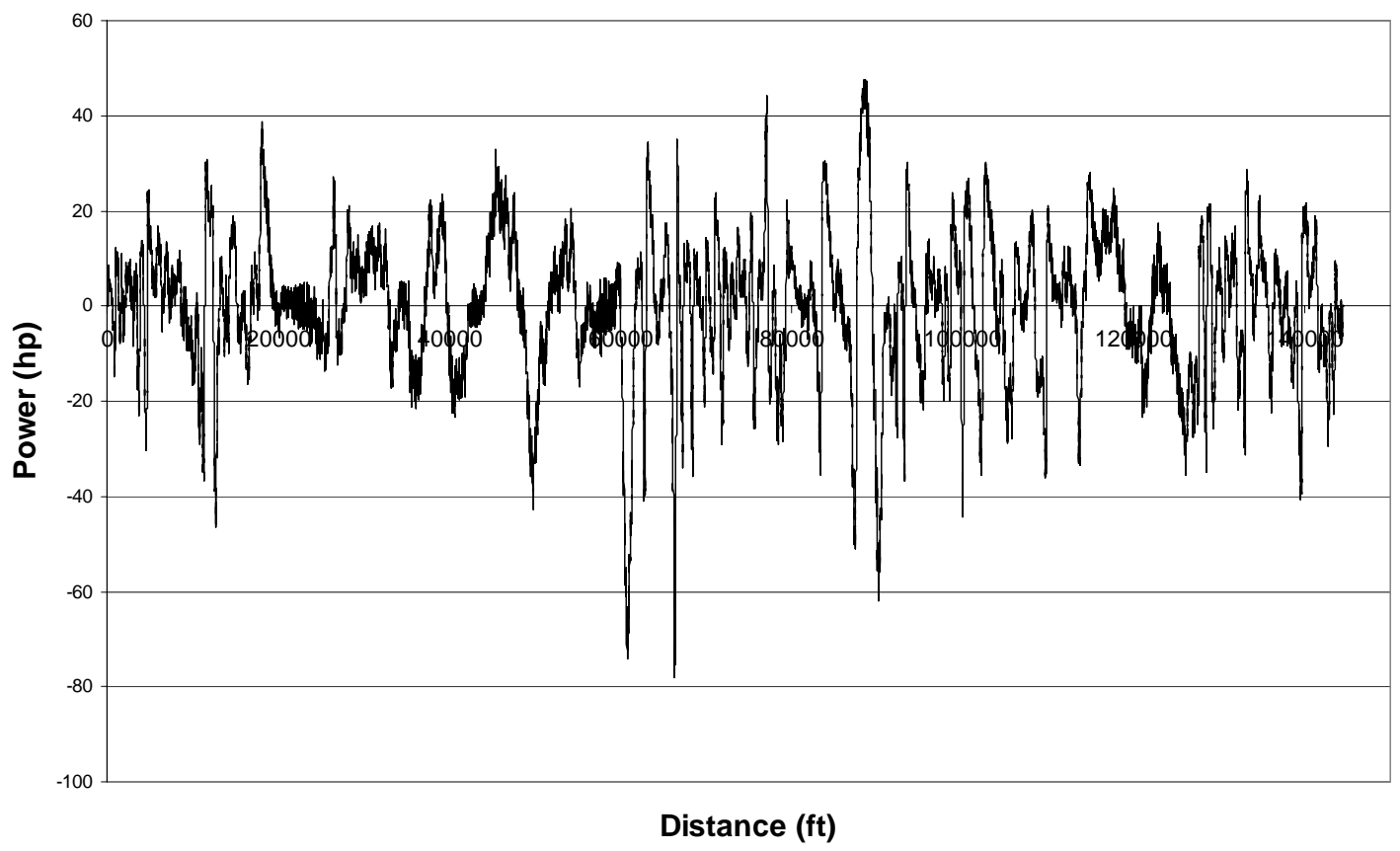

Figure 61: Test 1 / Half Load Acceleration Power 


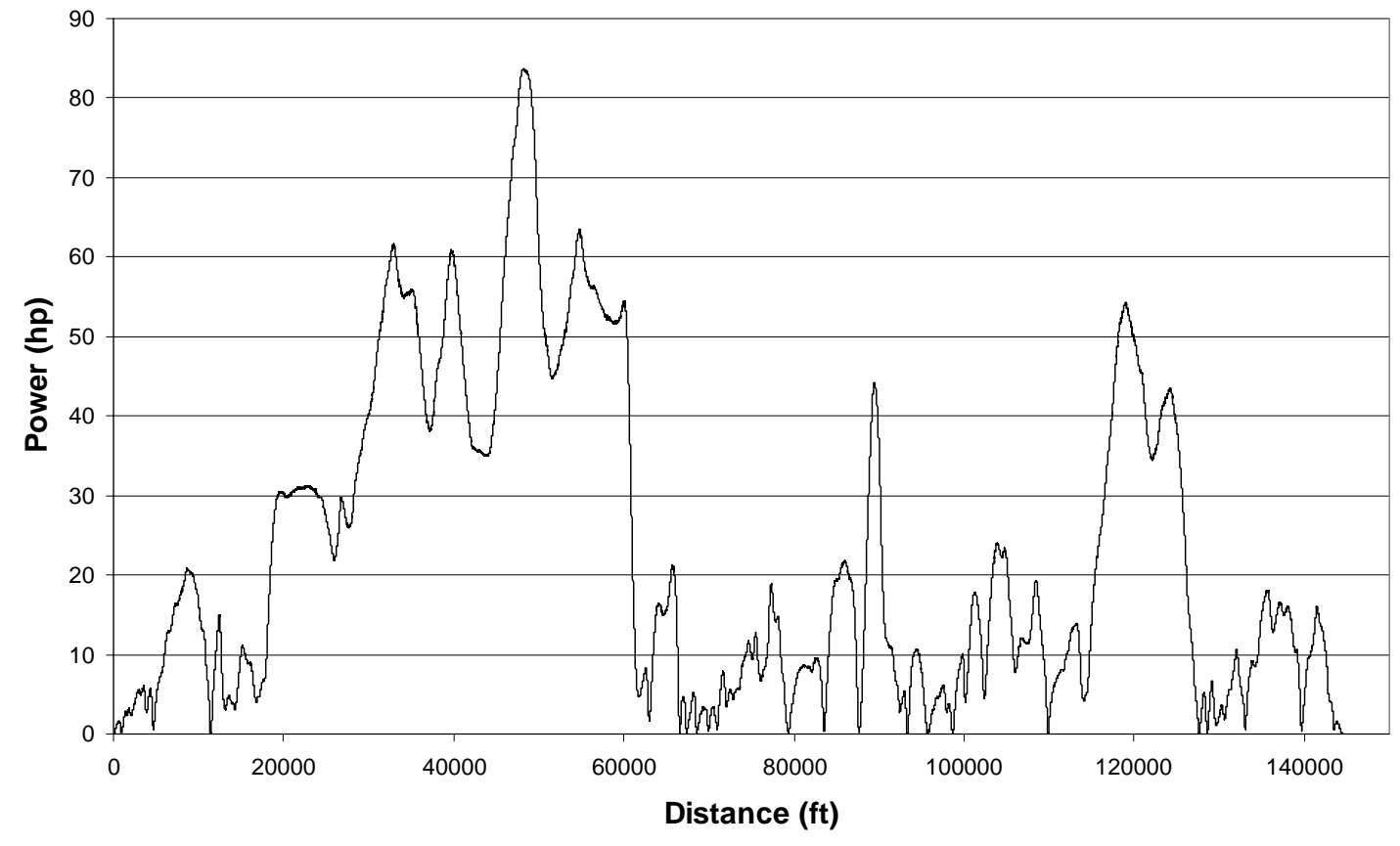

Figure 62: Test 1 / Half Load Aerodynamic Power

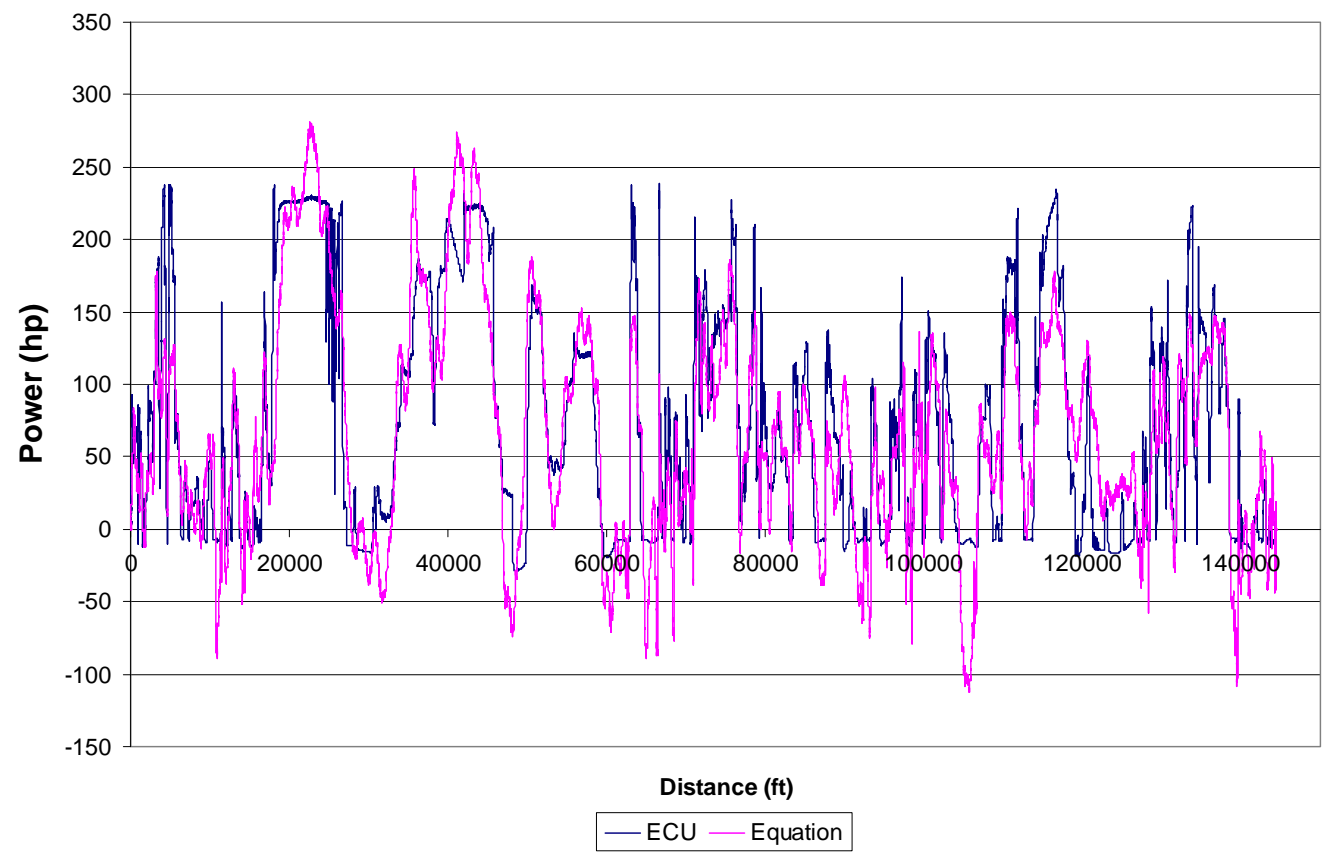

Figure 63: Test 1 / Half Load Power Comparison 
8.2.2. Test 2 I Half Load

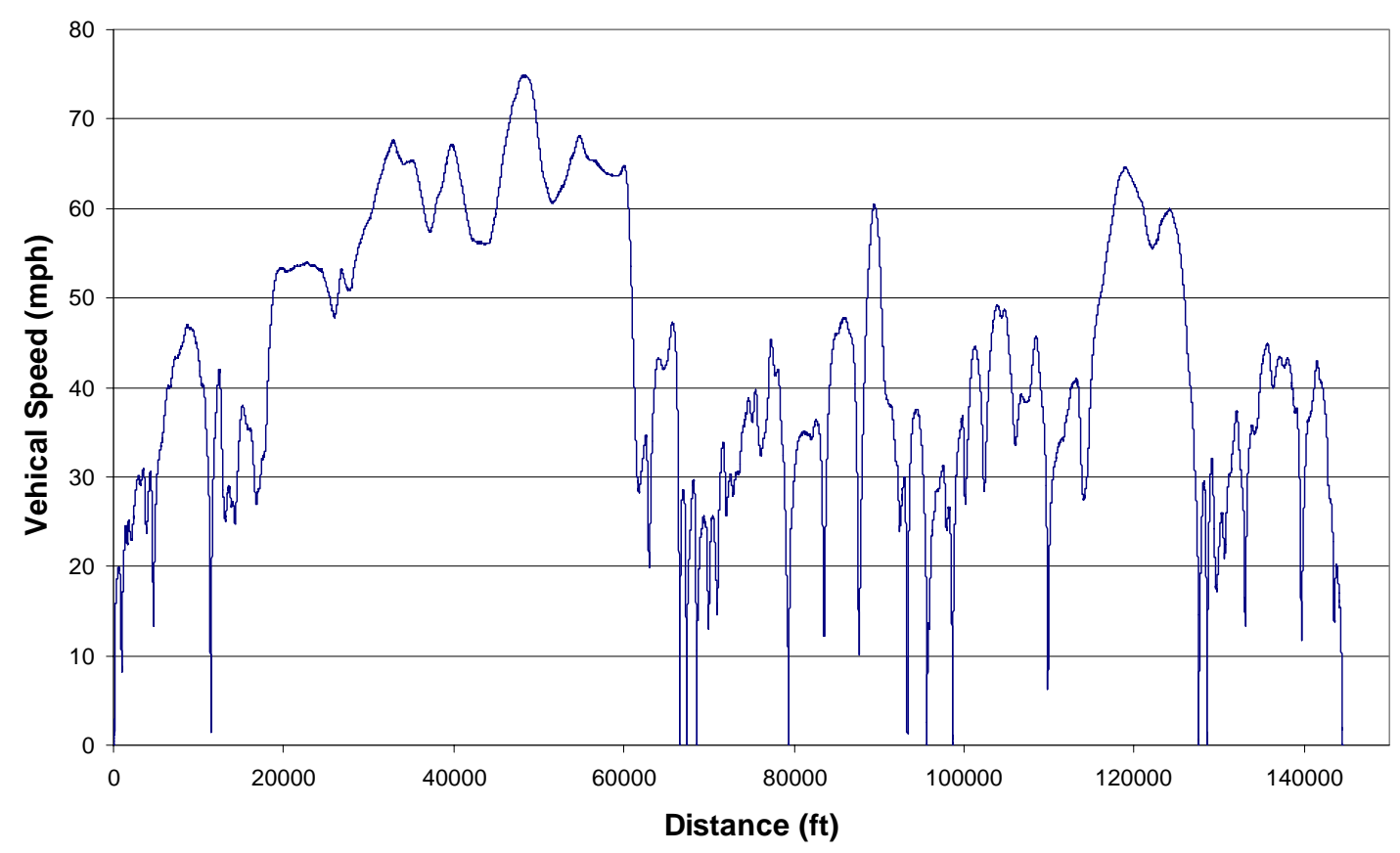

Figure 64: Test 2 / Half Load ECU Vehicle Speed

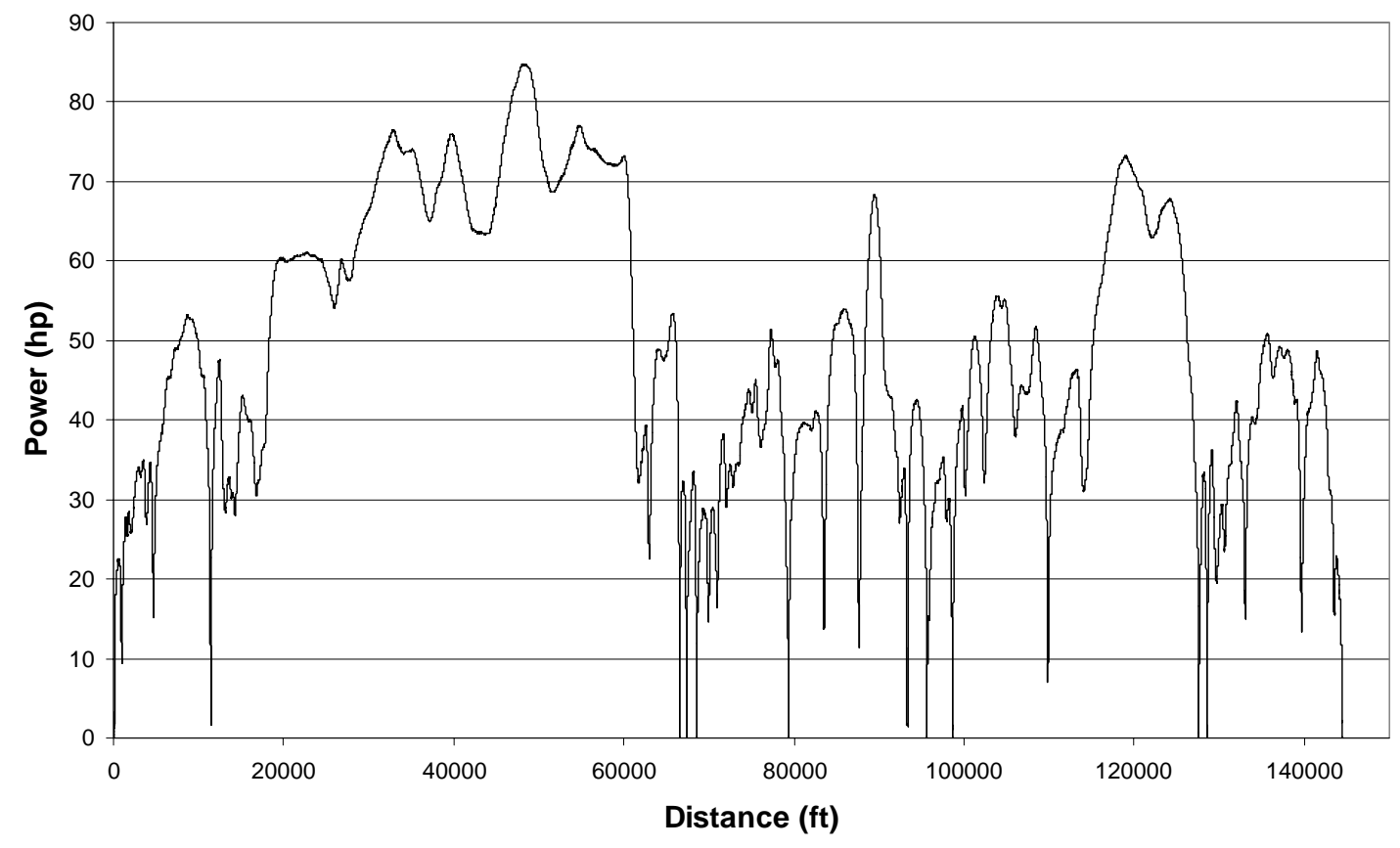

Figure 65: Test 2 / Half Load Rolling Power 


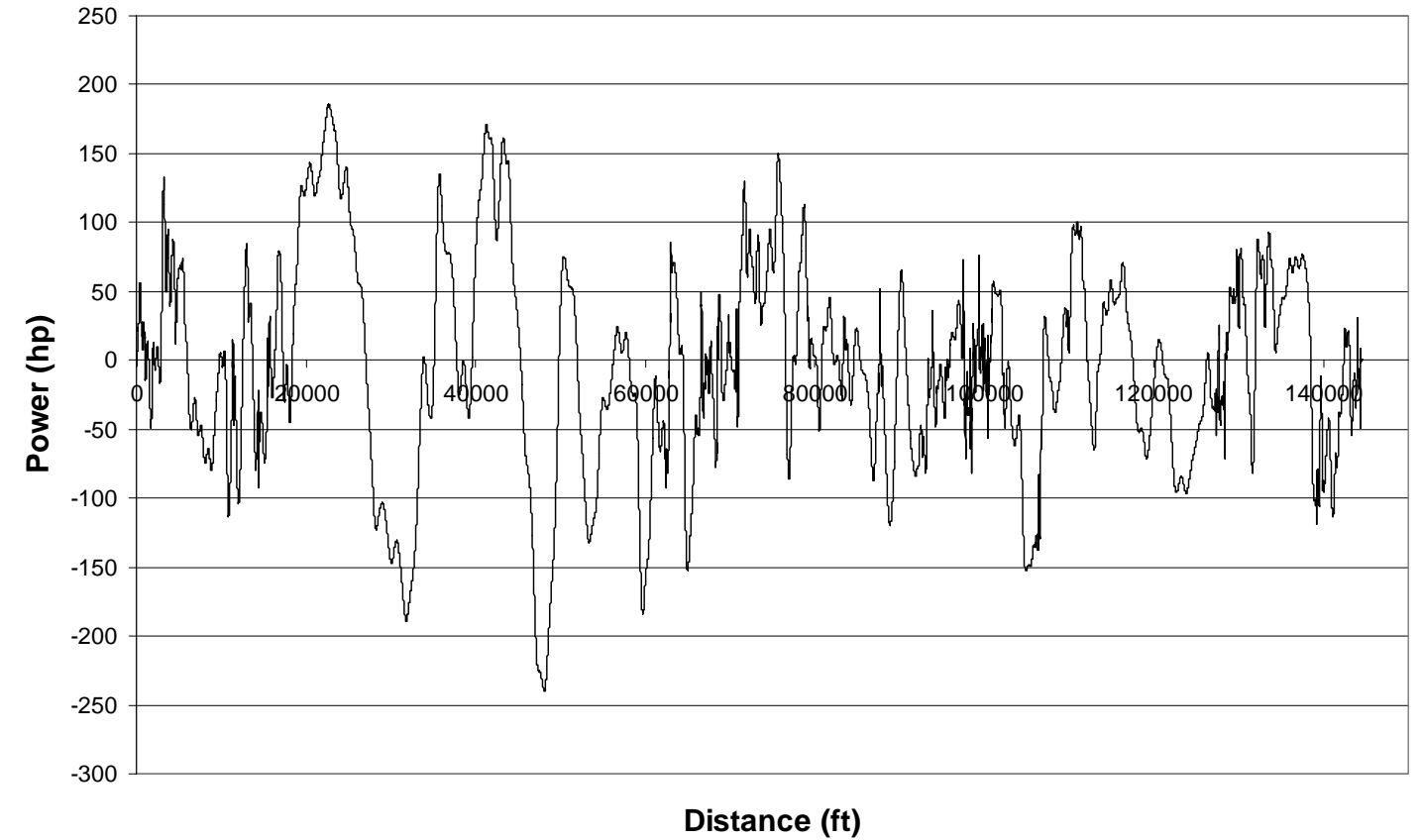

Figure 66: Test 2 / Half Load Climbing Power

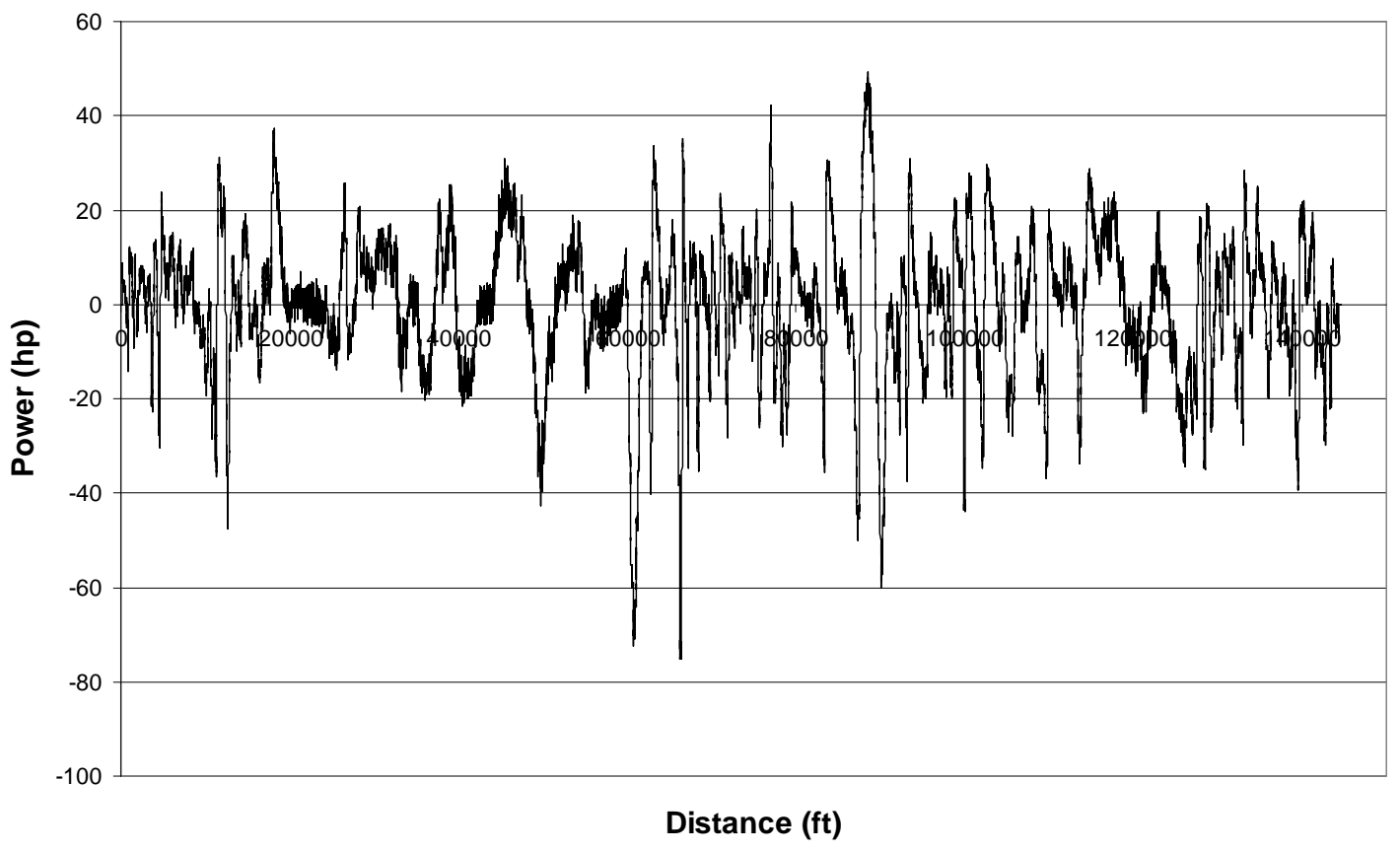

Figure 67: Test 2 / Half Load Acceleration Power 


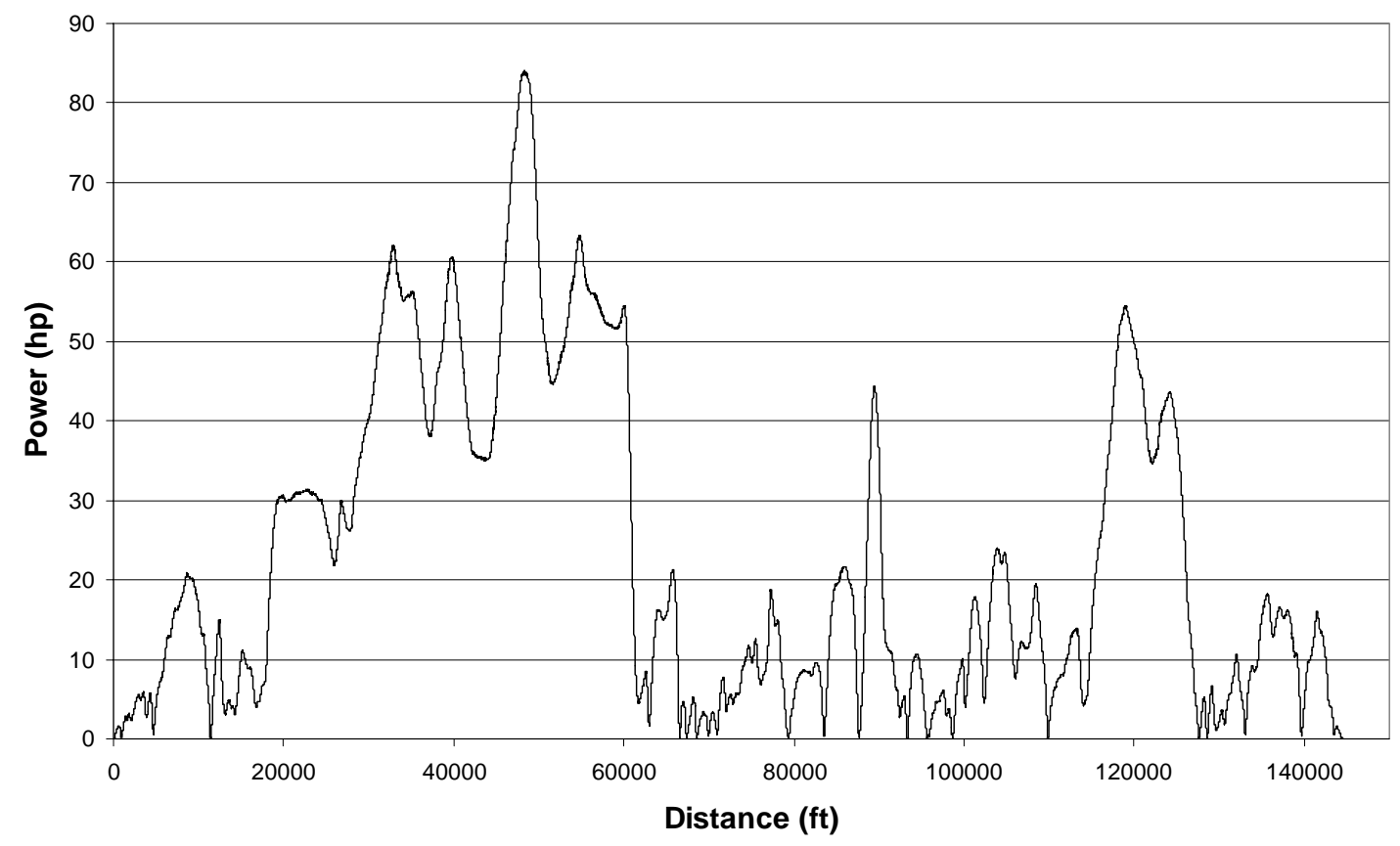

Figure 68: Test 2 / Half Load Aerodynamic Power

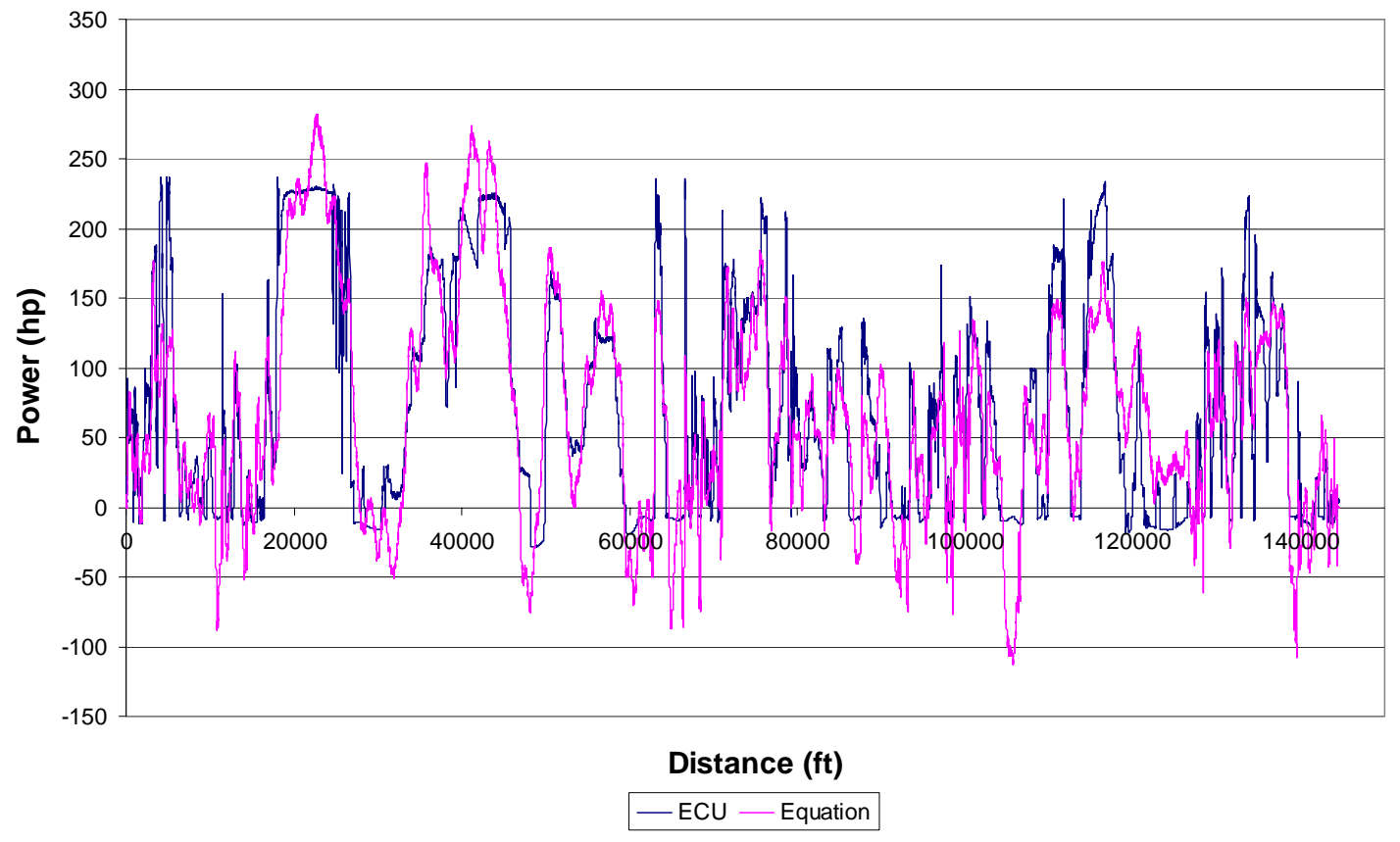

Figure 69: Test 2 / Half Load Power Comparison 


\subsection{3. $\quad$ Test 3 I Half Load}

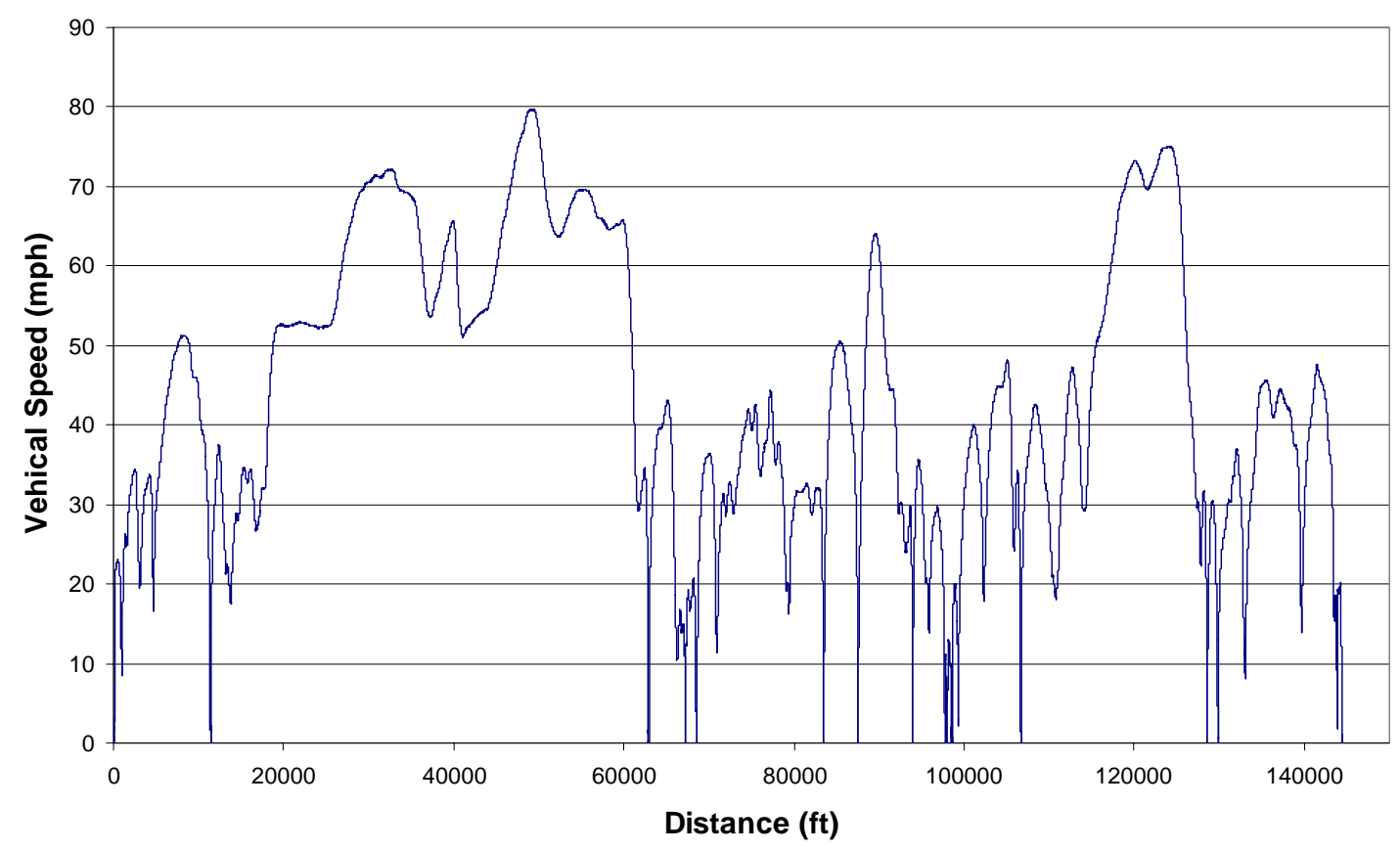

Figure 70: Test 3 / Half Load ECU Vehicle Speed

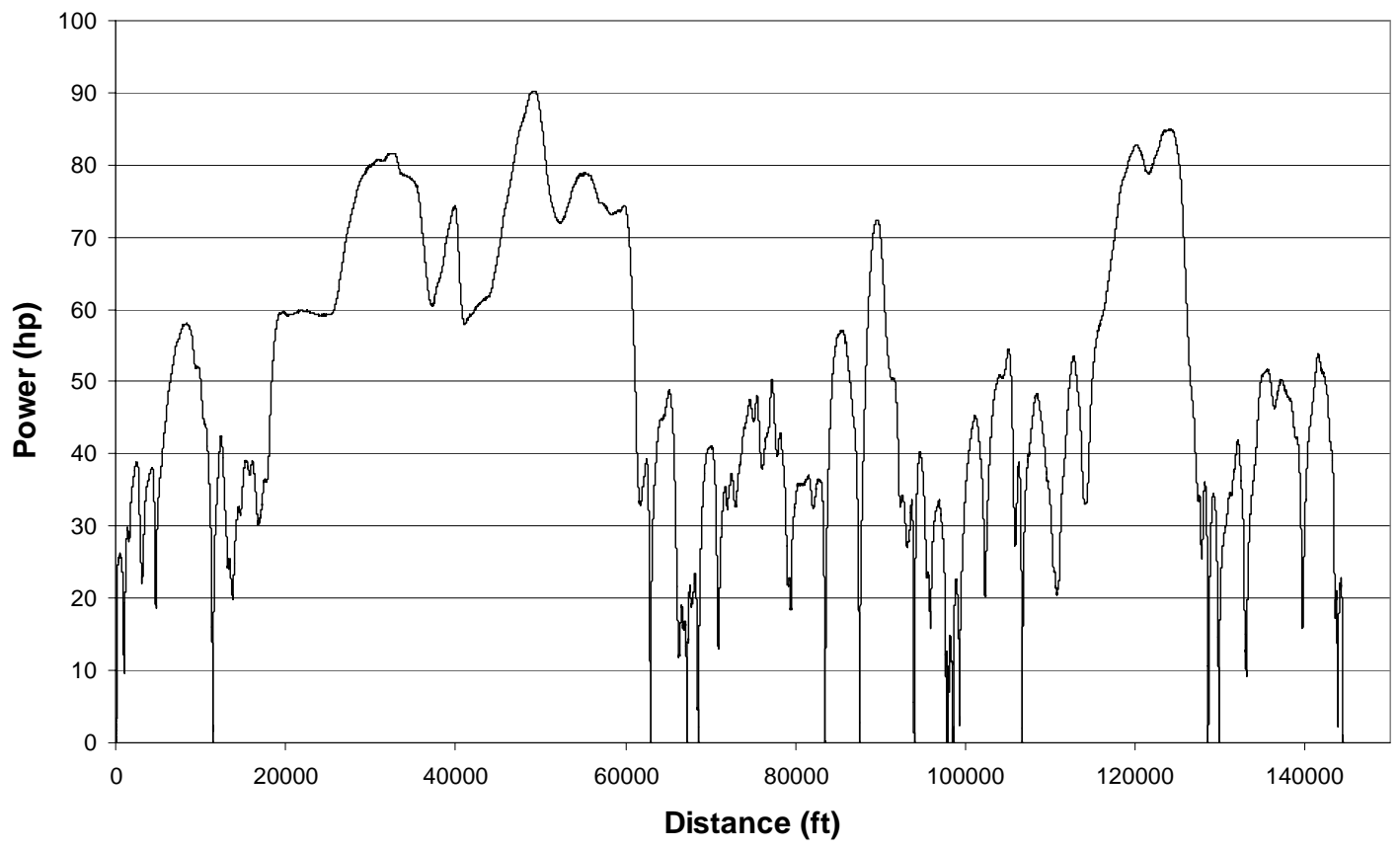

Figure 71: Test 3 / Half Load Rolling Power 


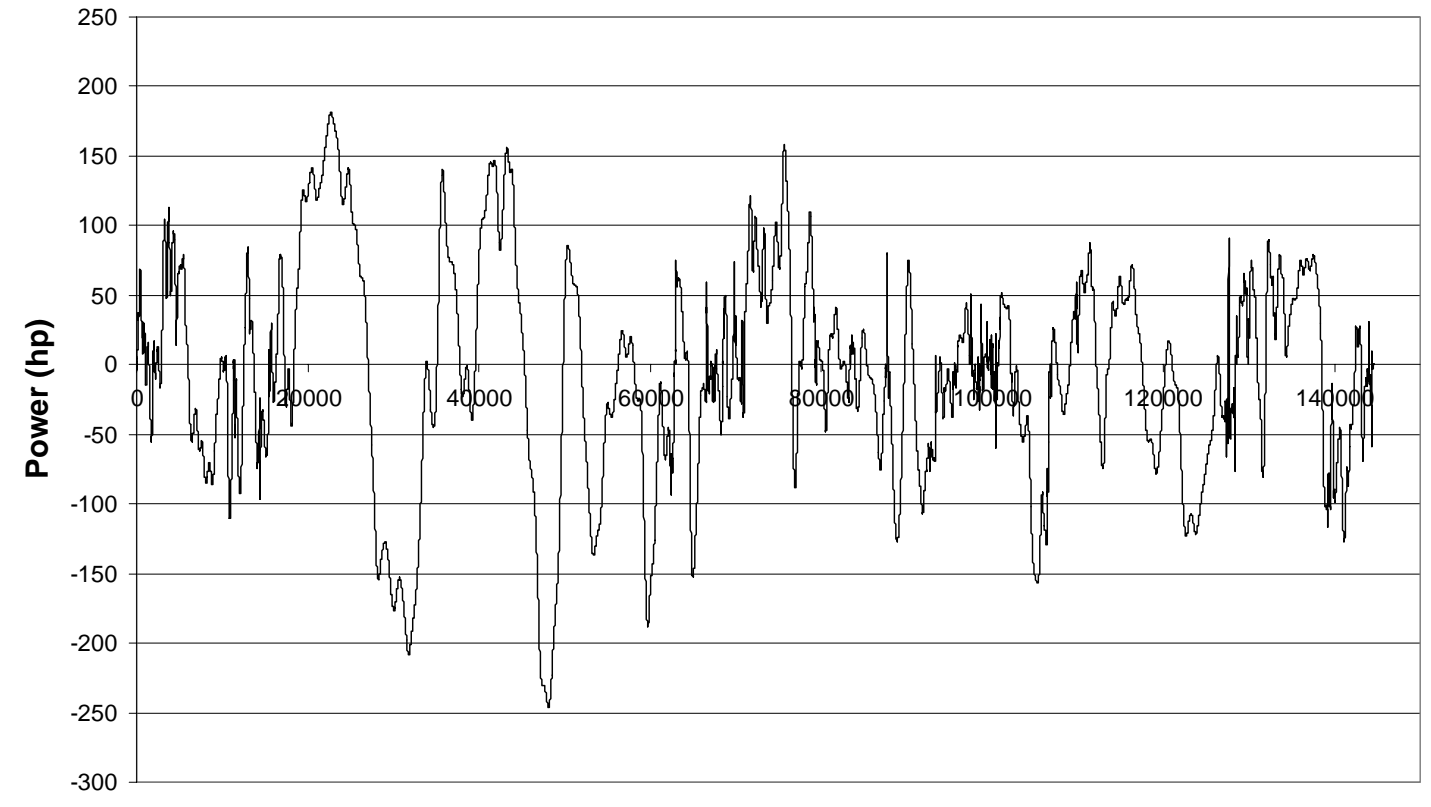

Distance (ft)

Figure 72: Test 3 / Half Load Climbing Power

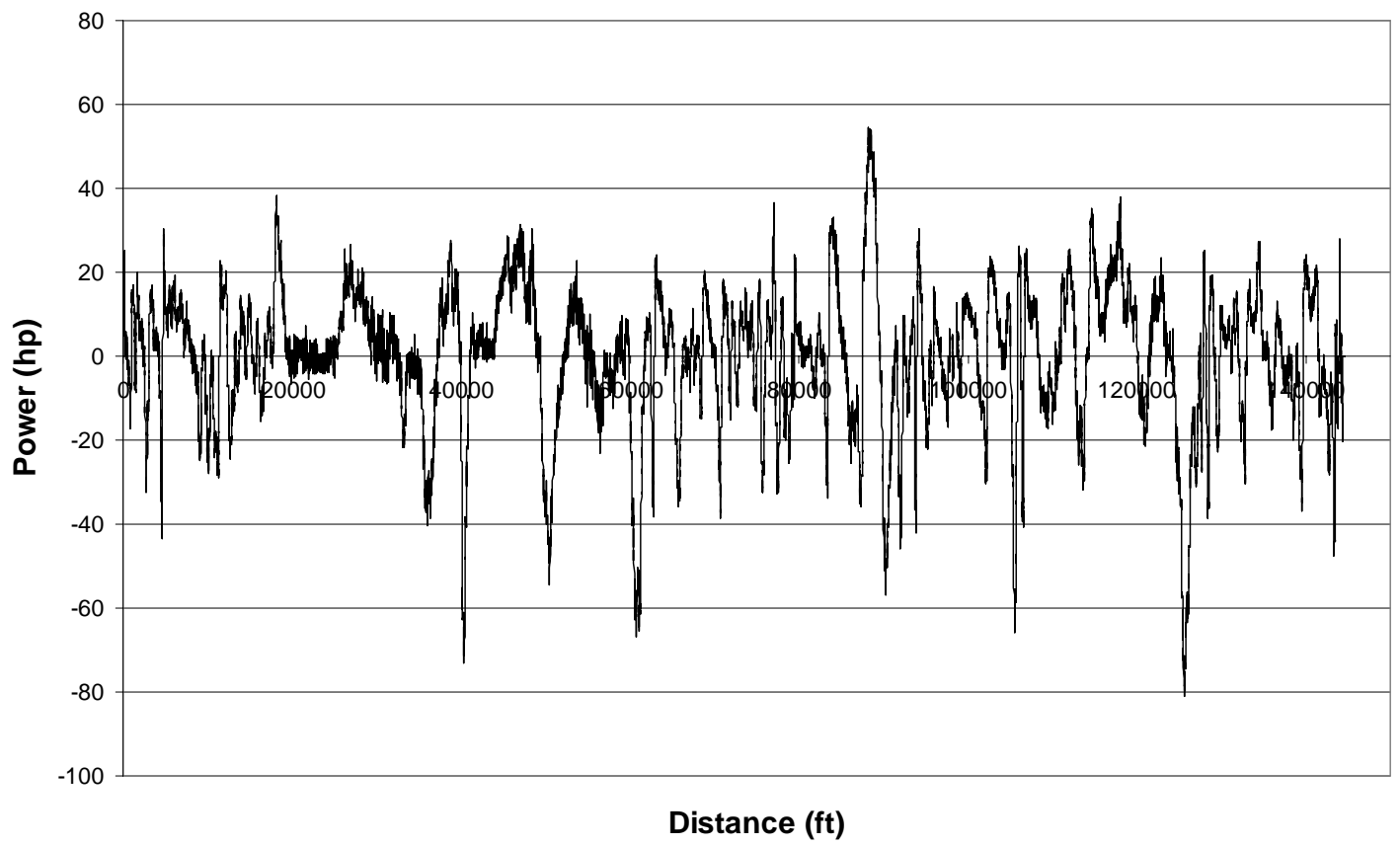

Figure 73: Test 3 / Half Load Acceleration Power 


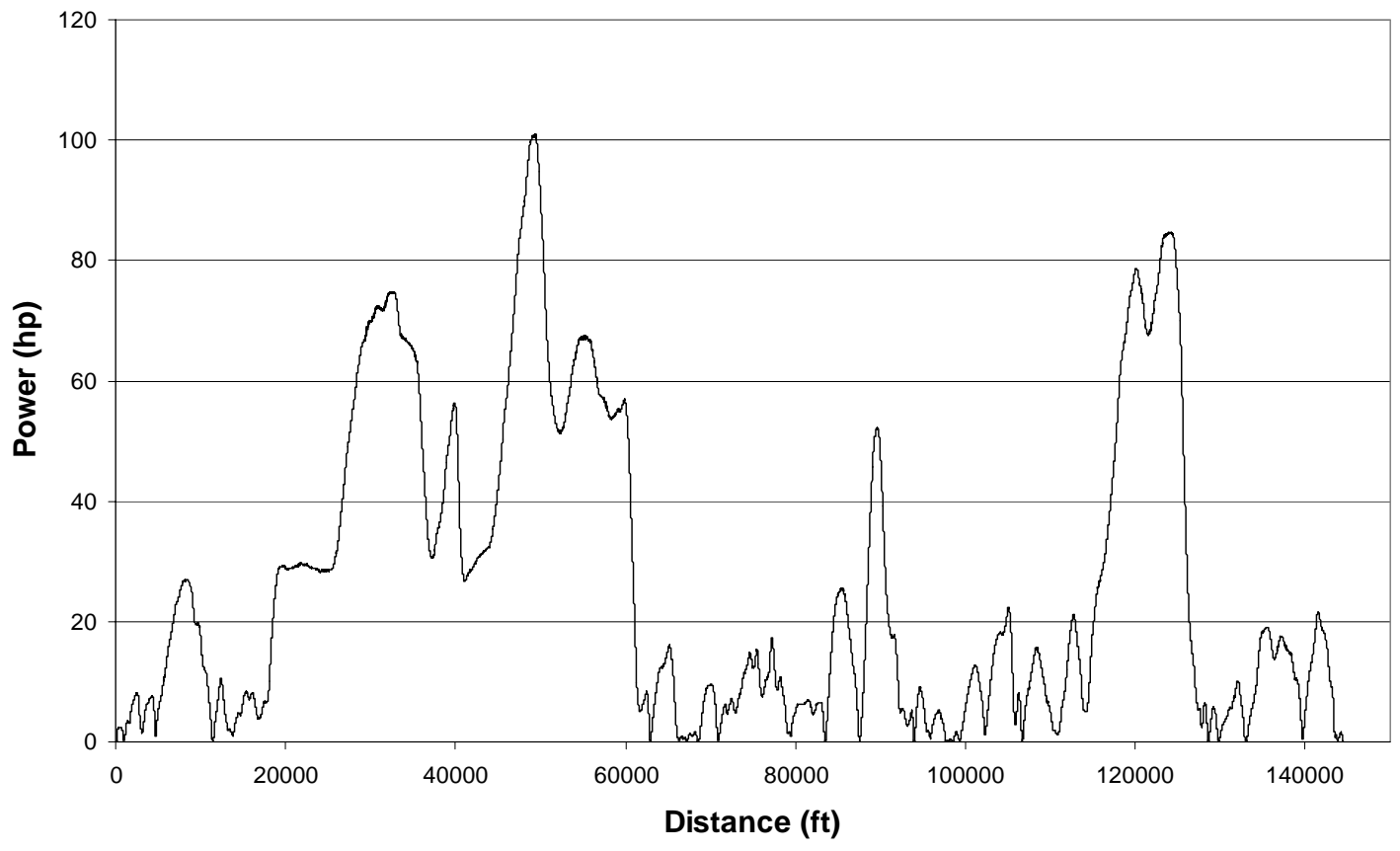

Figure 74: Test 3 / Half Load Aerodynamic Power

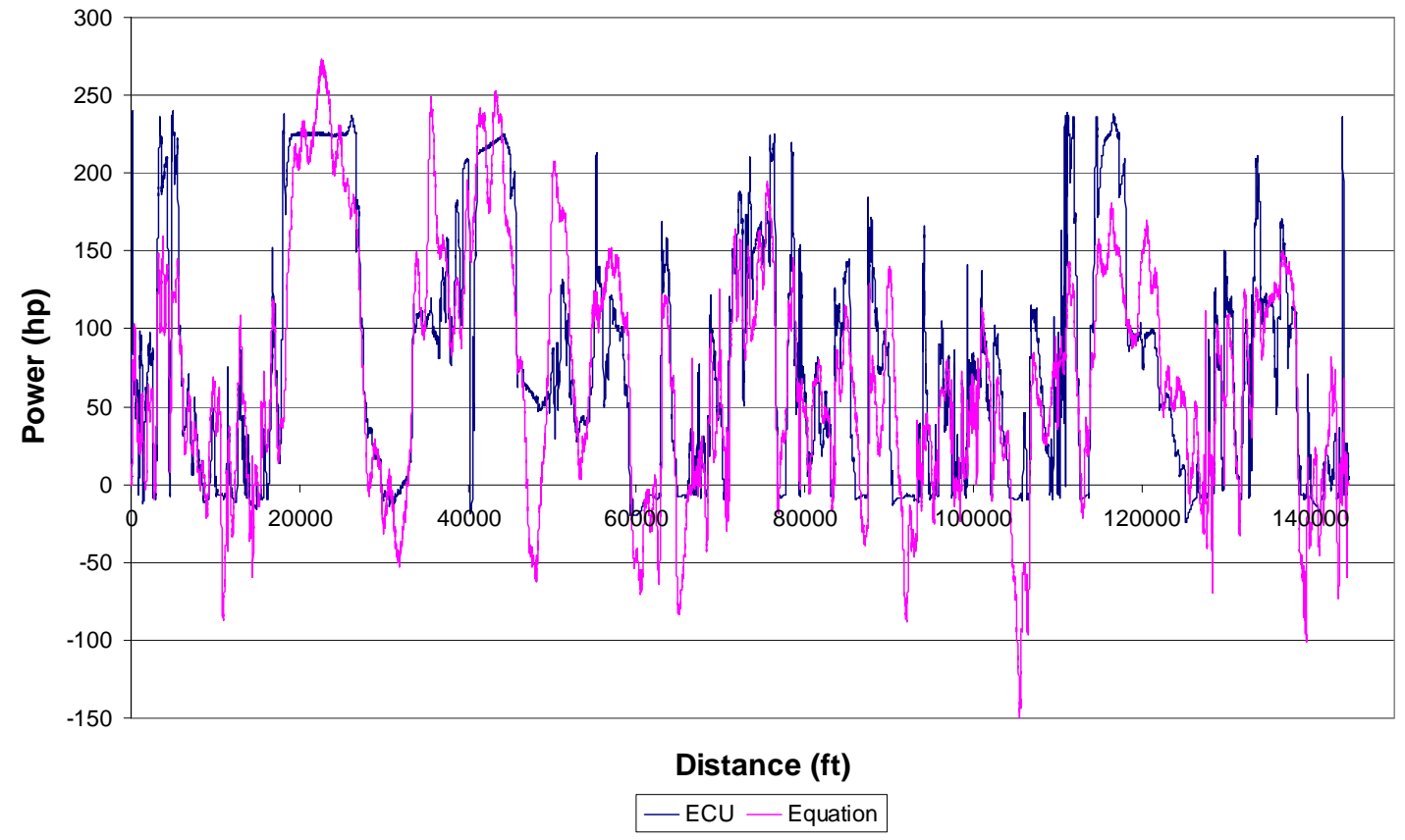

Figure 75: Test 3 / Half Load Power Comparison 
8.3. Full Load

\subsubsection{Test 1 / Full Load}

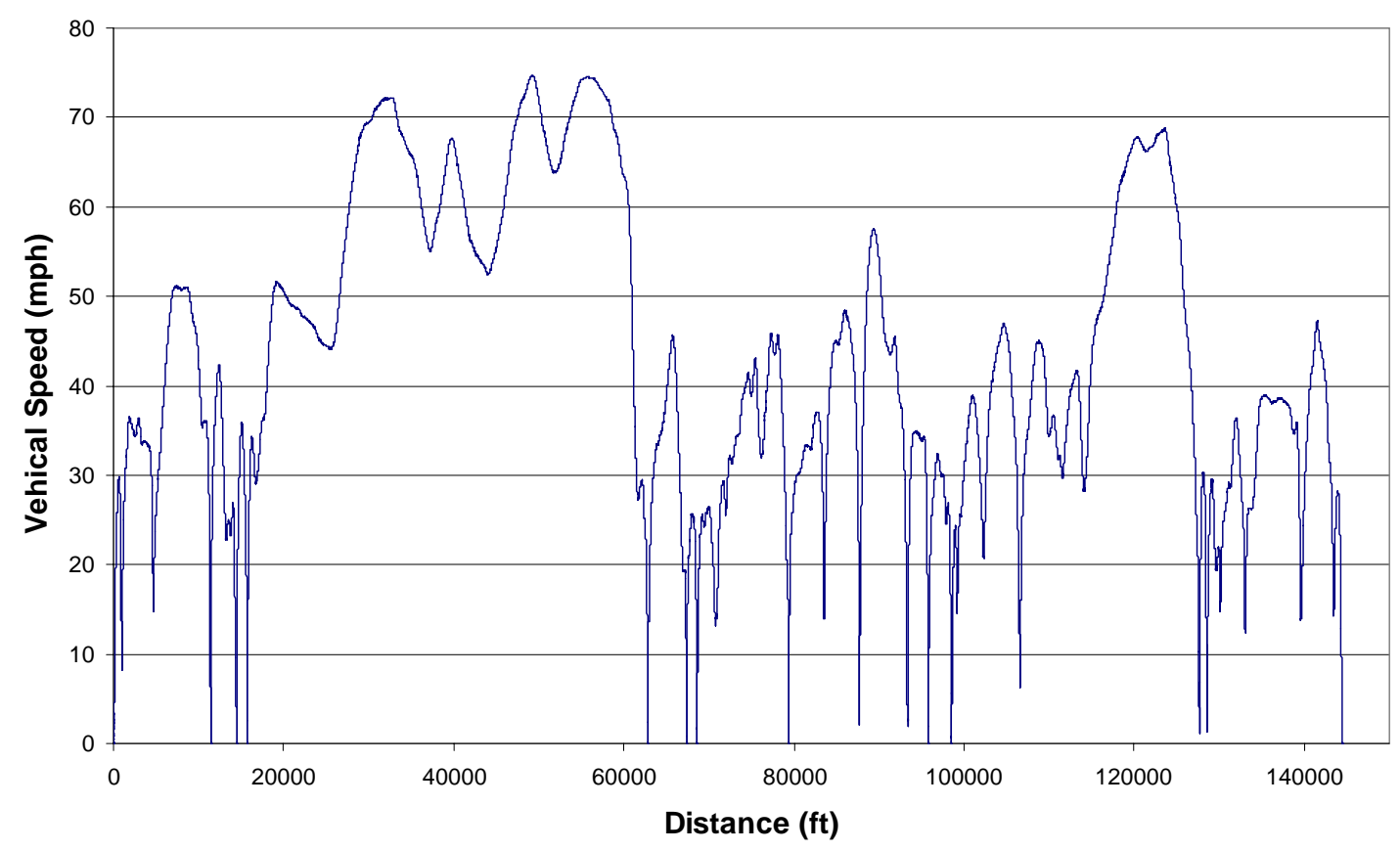

Figure 76: Test 1 / Full Load ECU Vehicle Speed

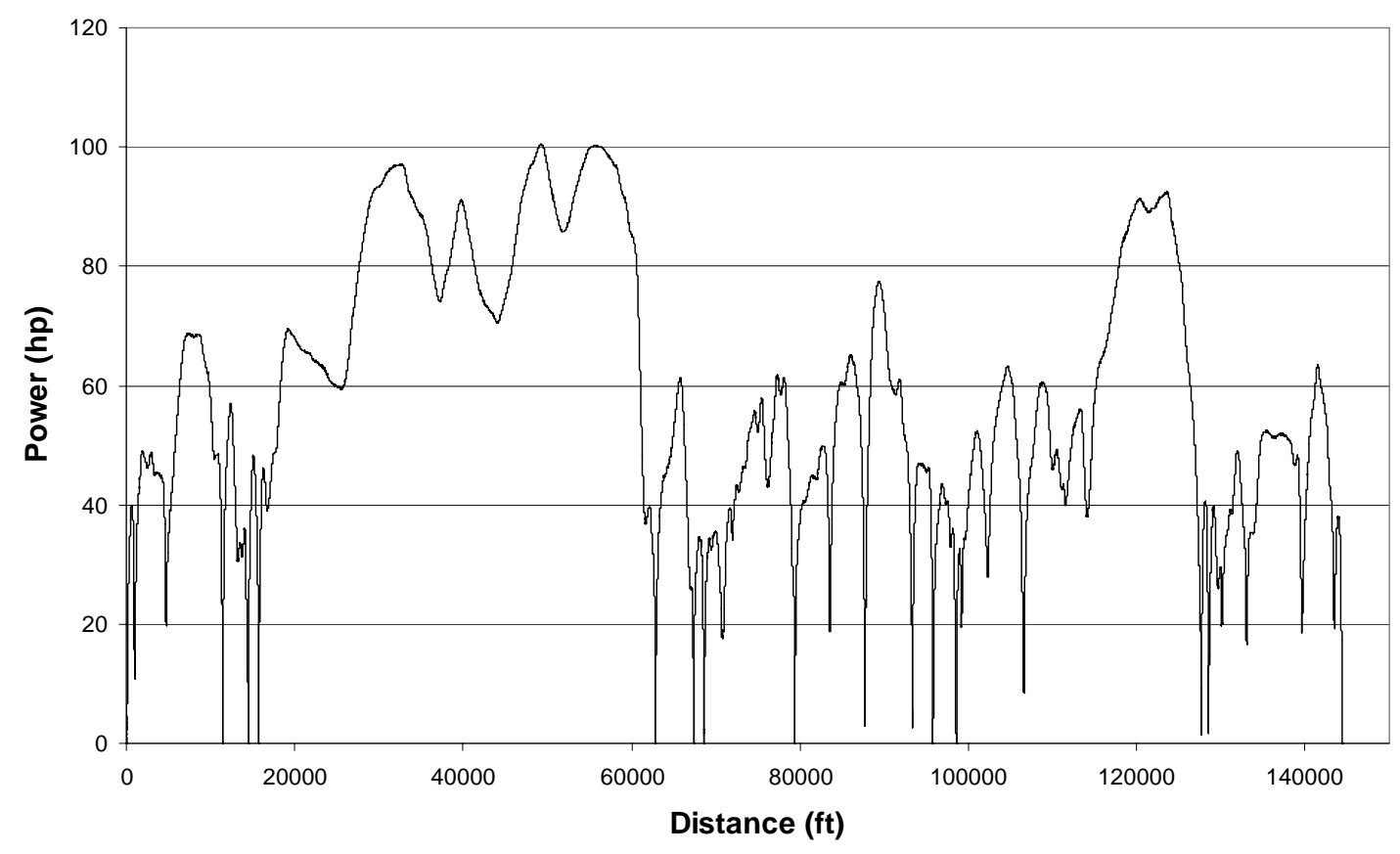

Figure 77: Test 1 / Full Load Rolling Power 


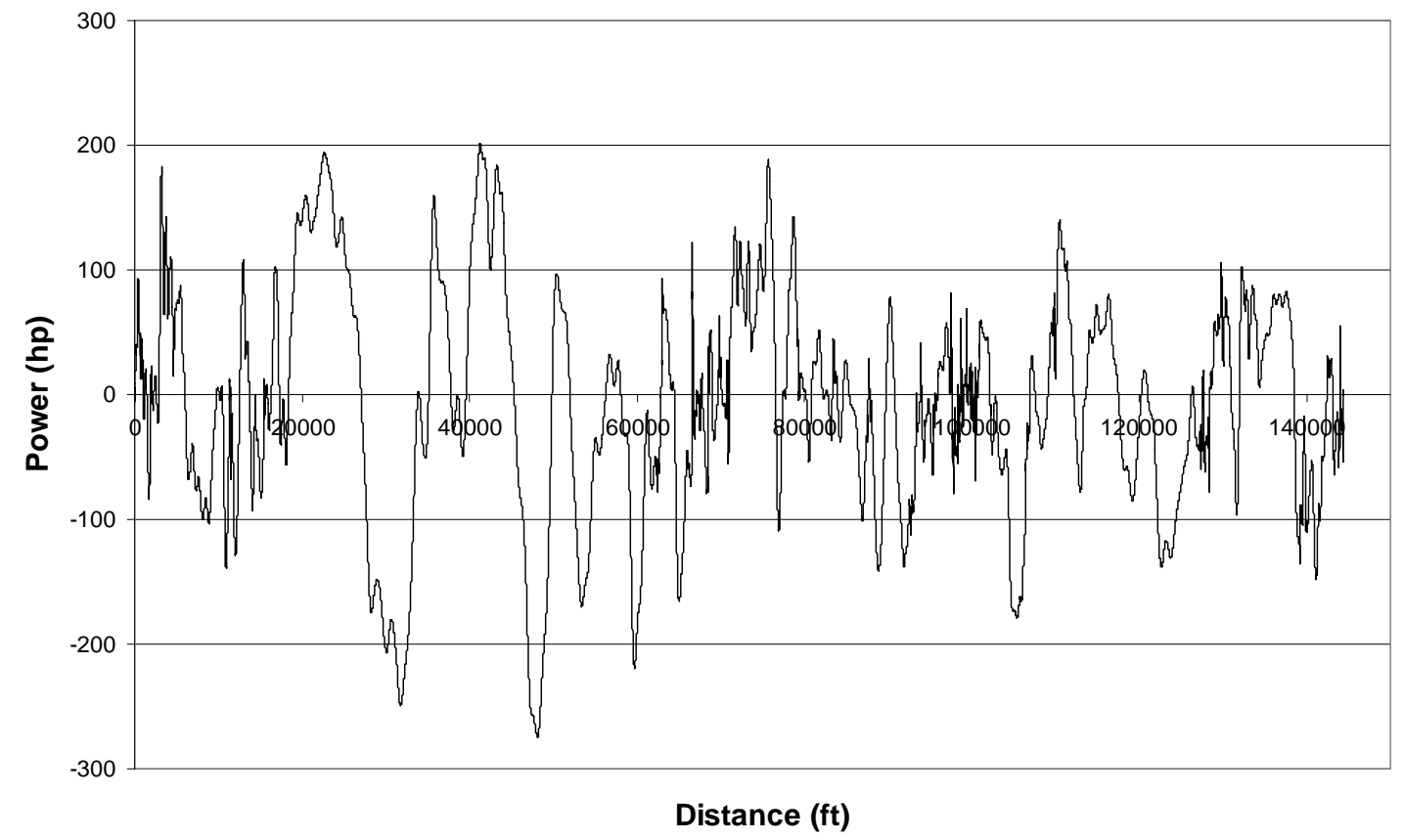

Figure 78: Test 1 / Full Load Climbing Power

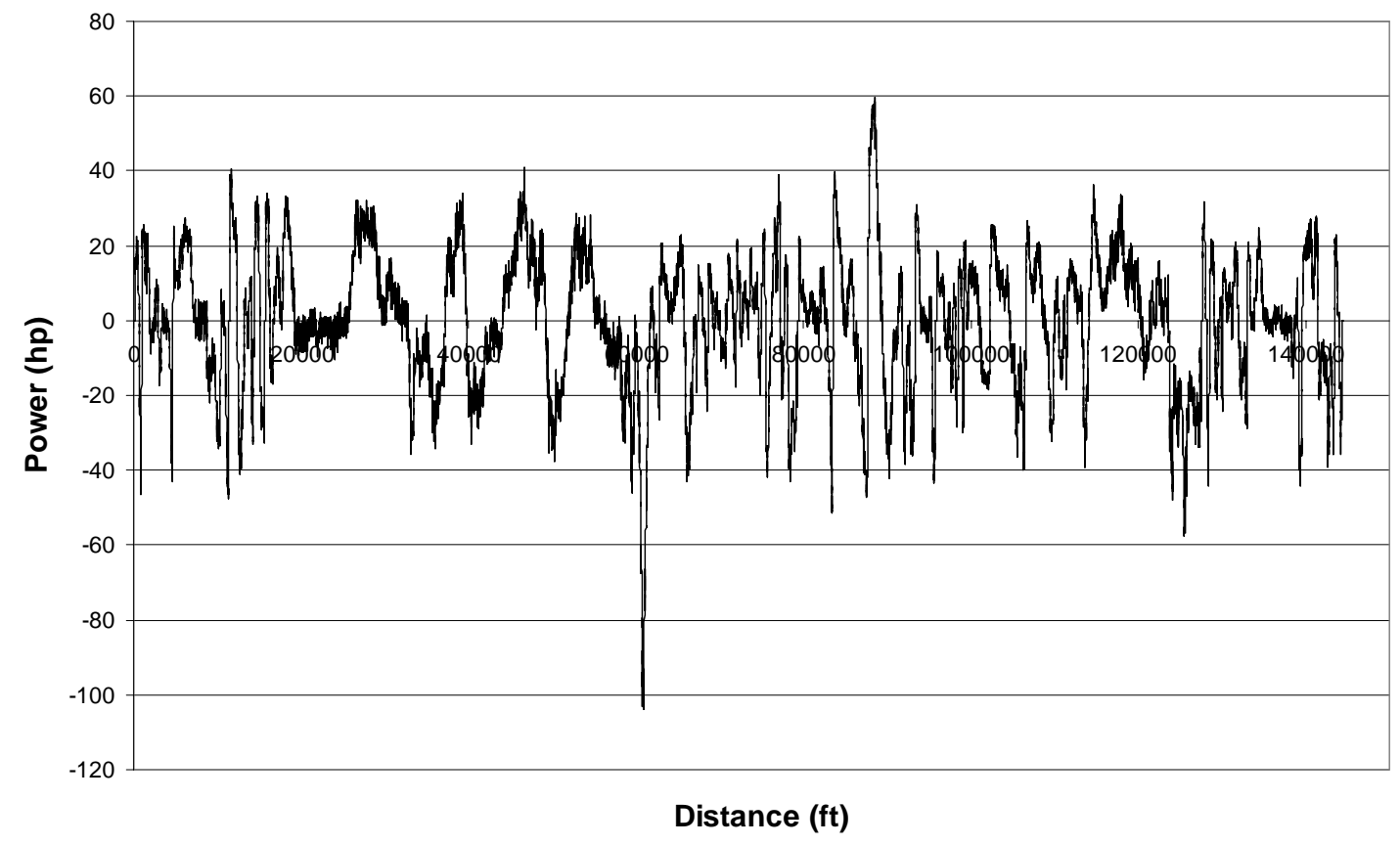

Figure 79: Test 1 / Full Load Acceleration Power 


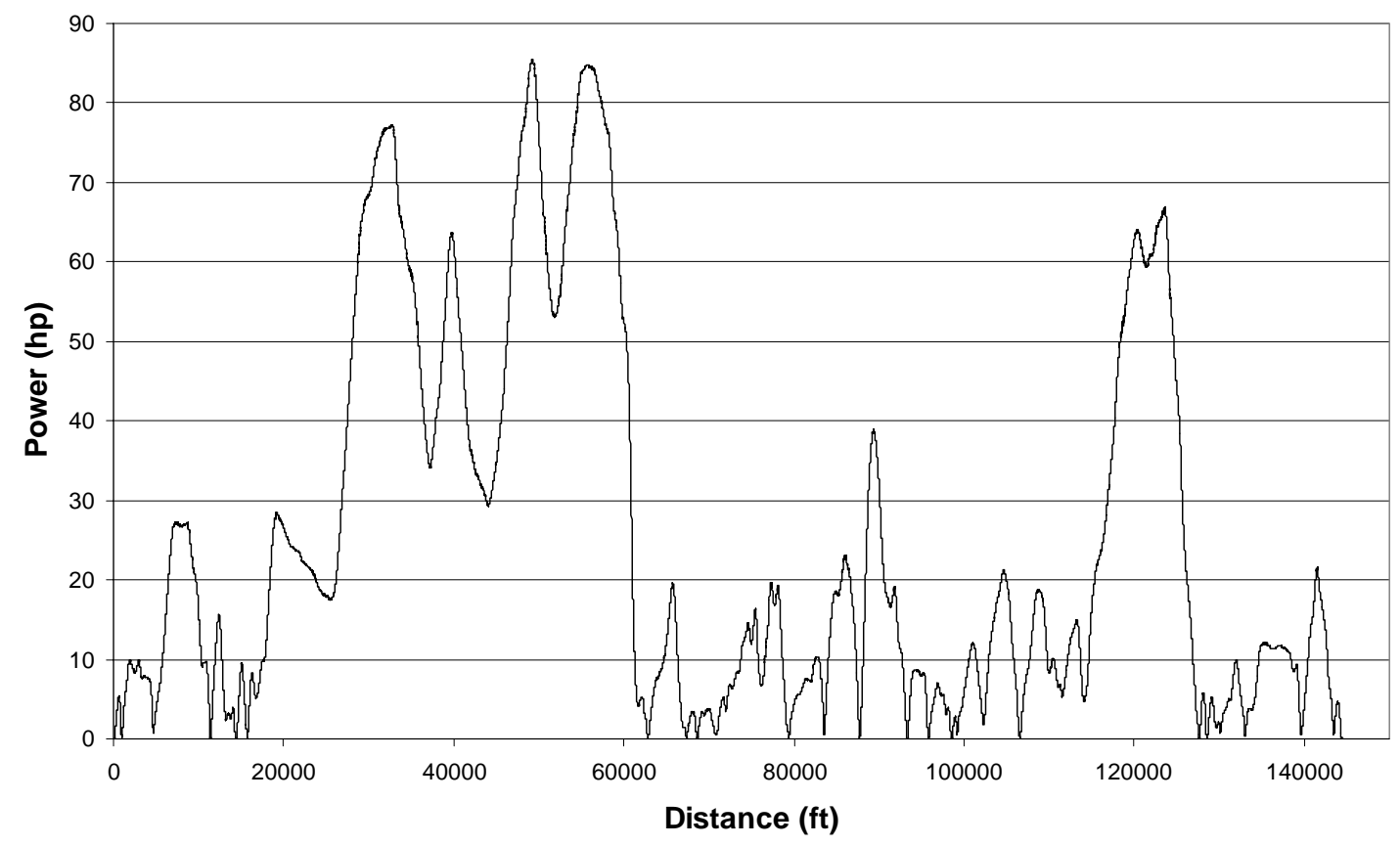

Figure 80: Test 1 / Full Load Aerodynamic Power

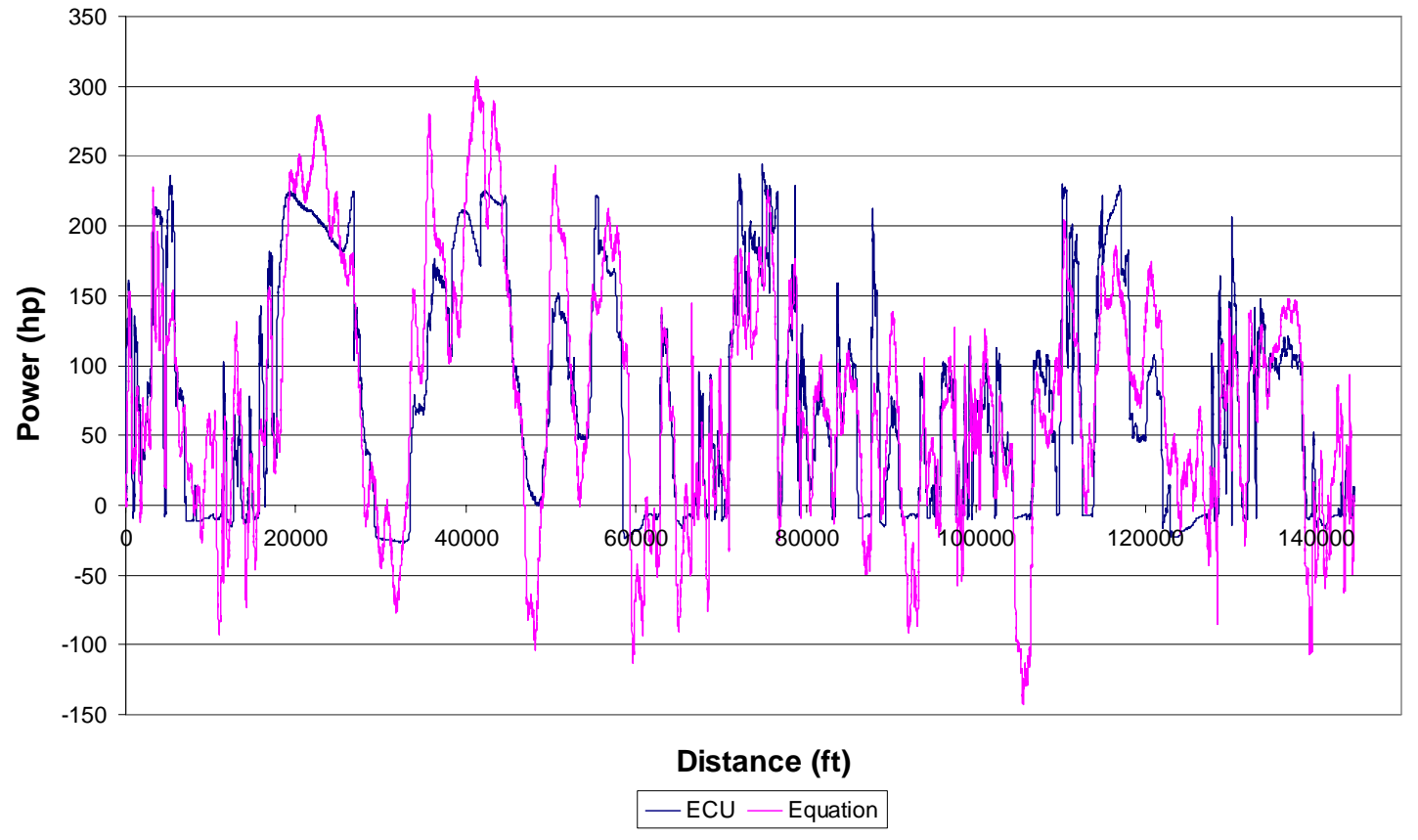

Figure 81: Test 1 / Full Load Power Comparison 


\subsubsection{Test 2 I Full Load}

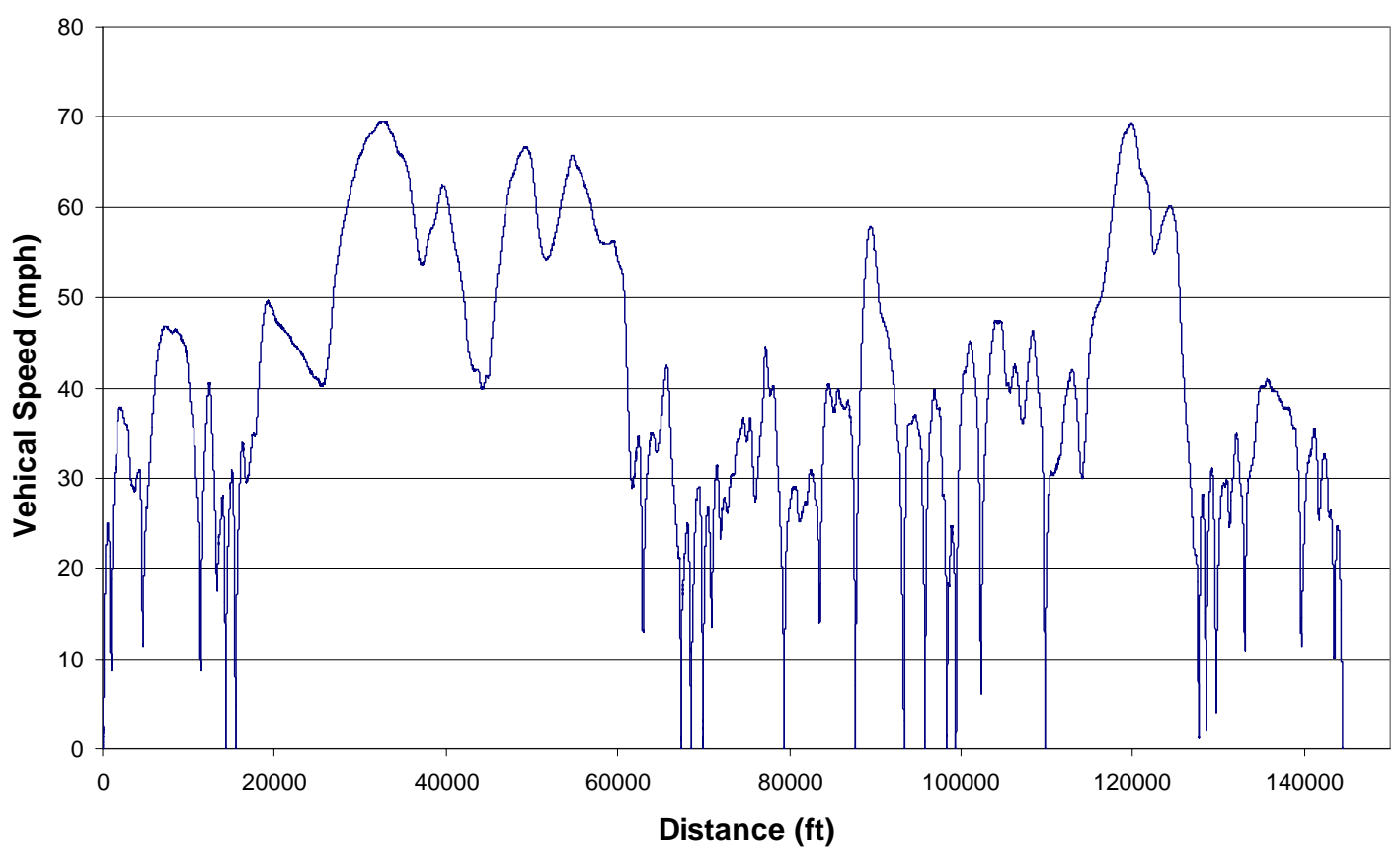

Figure 82: Test 2 / Full Load ECU Vehicle Speed

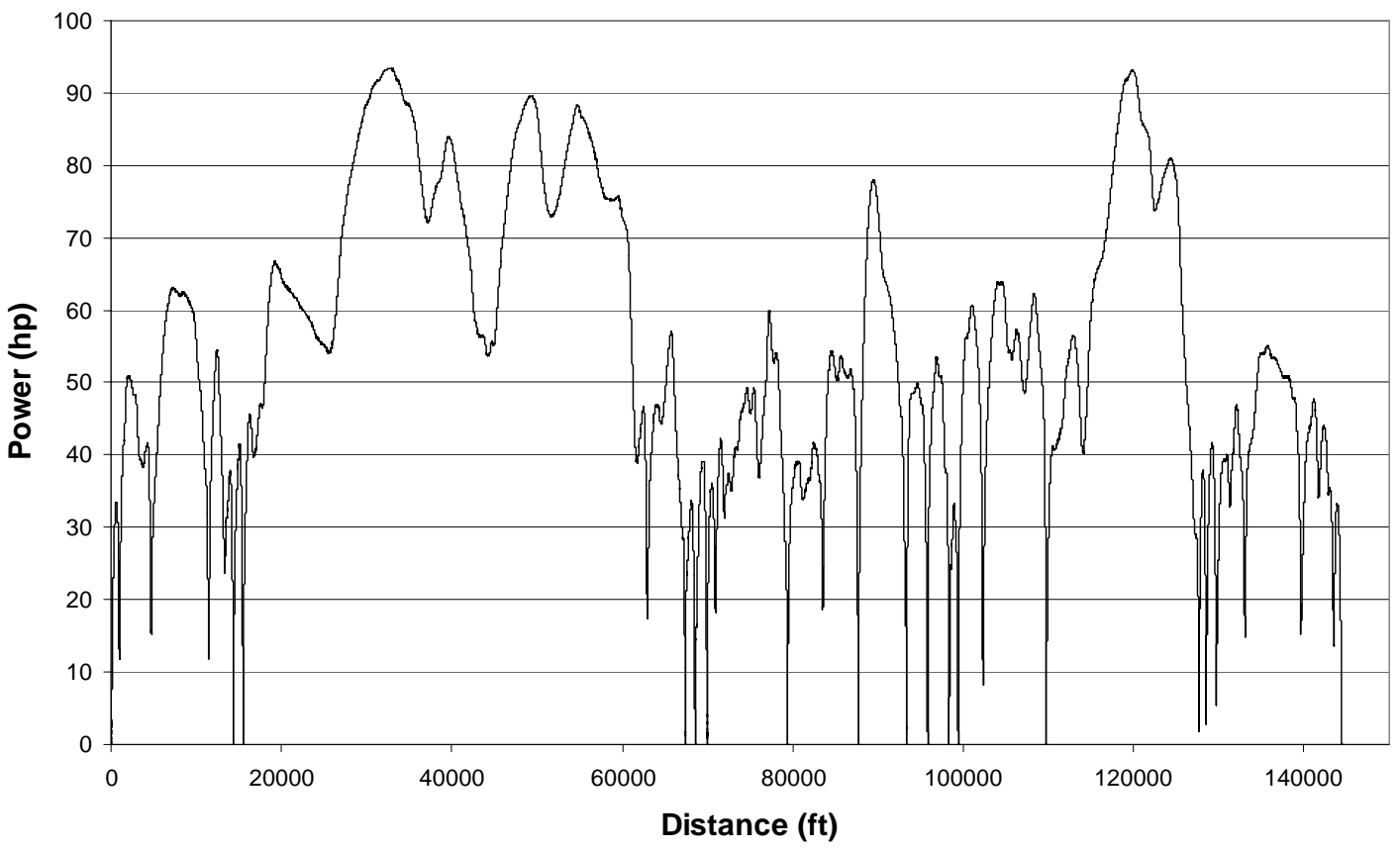

Figure 83: Test 2 / Full Load Rolling Power 


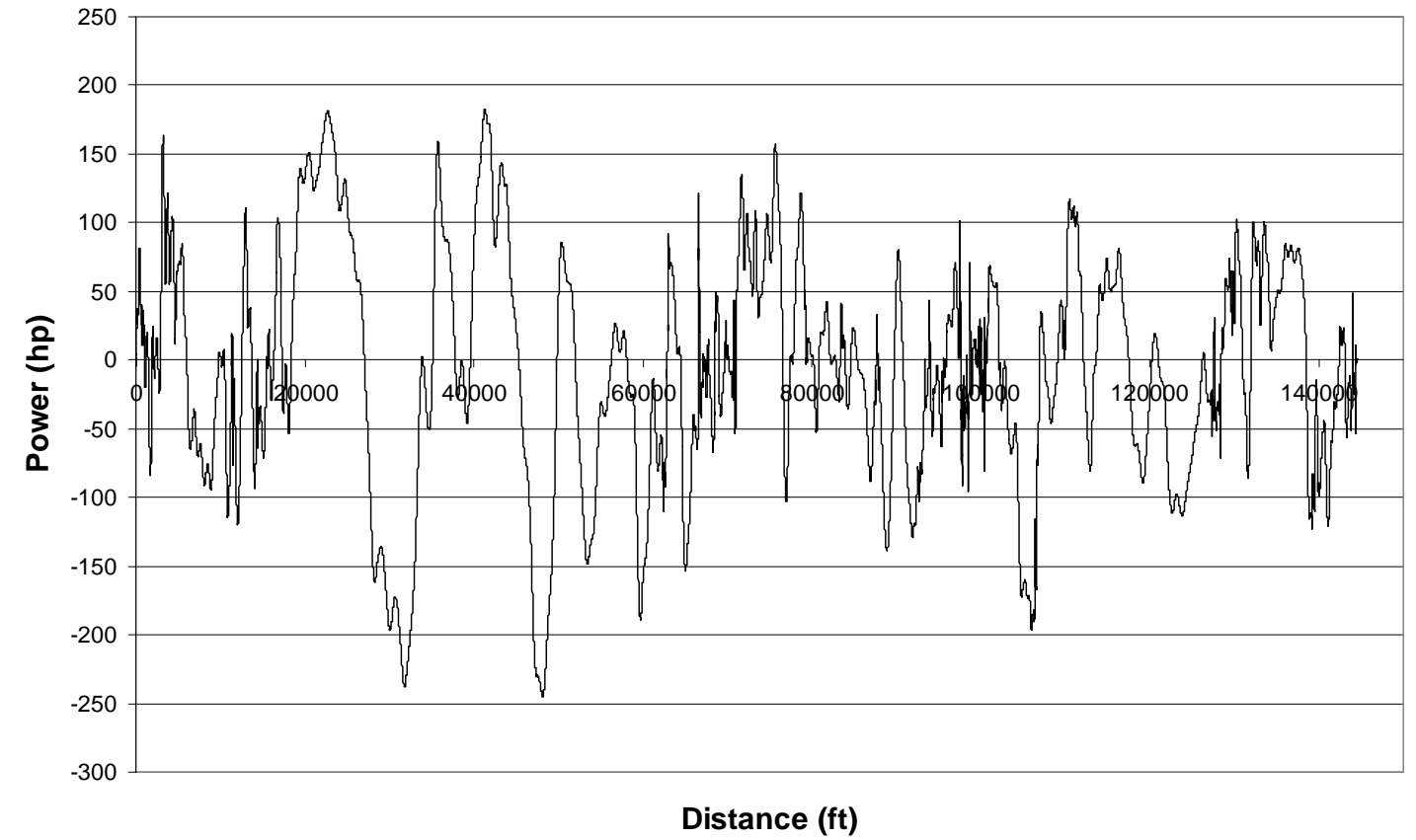

Figure 84: Test 2 / Full Load Climbing Power

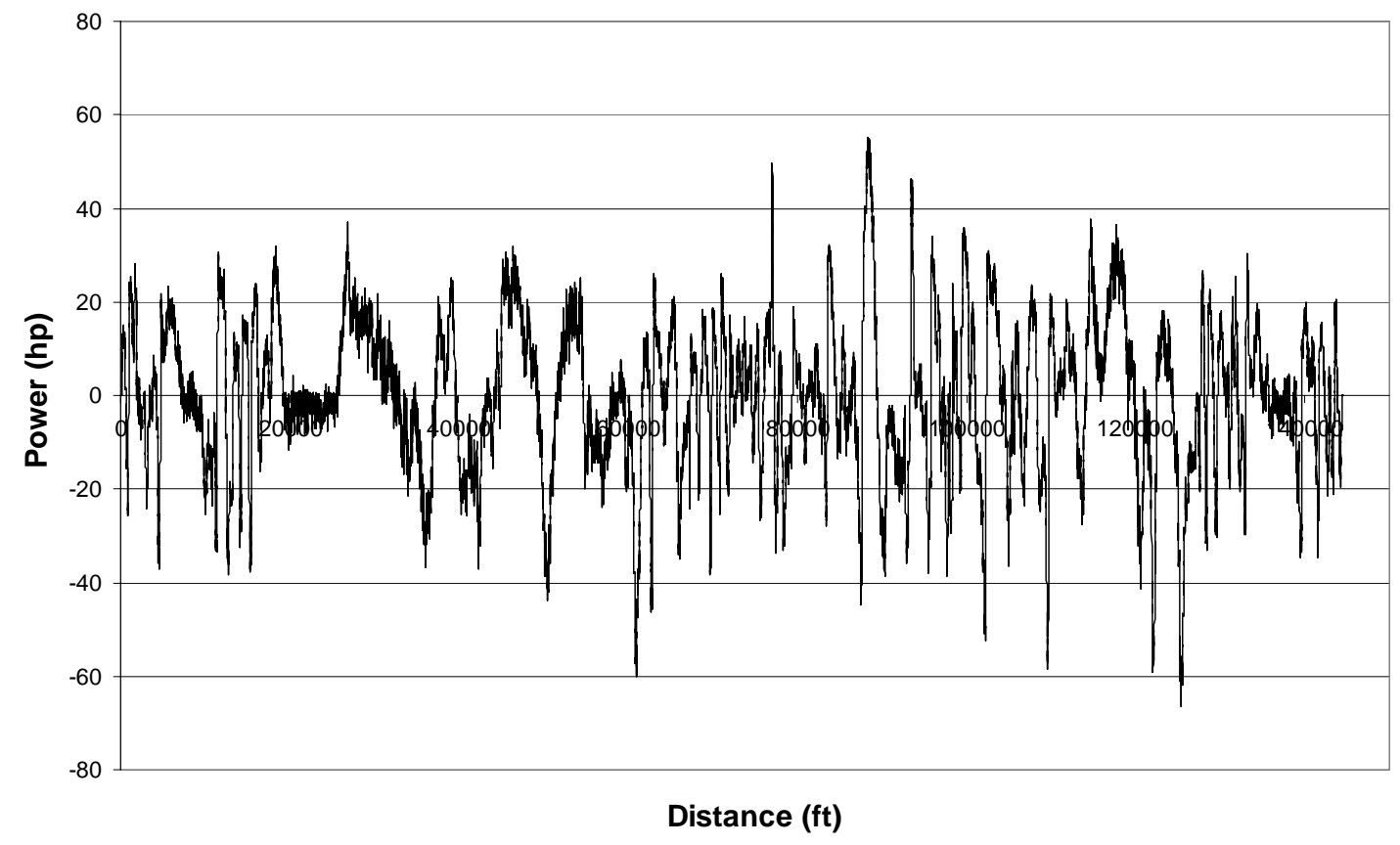

Figure 85: Test 2 / Full Load Acceleration Power 


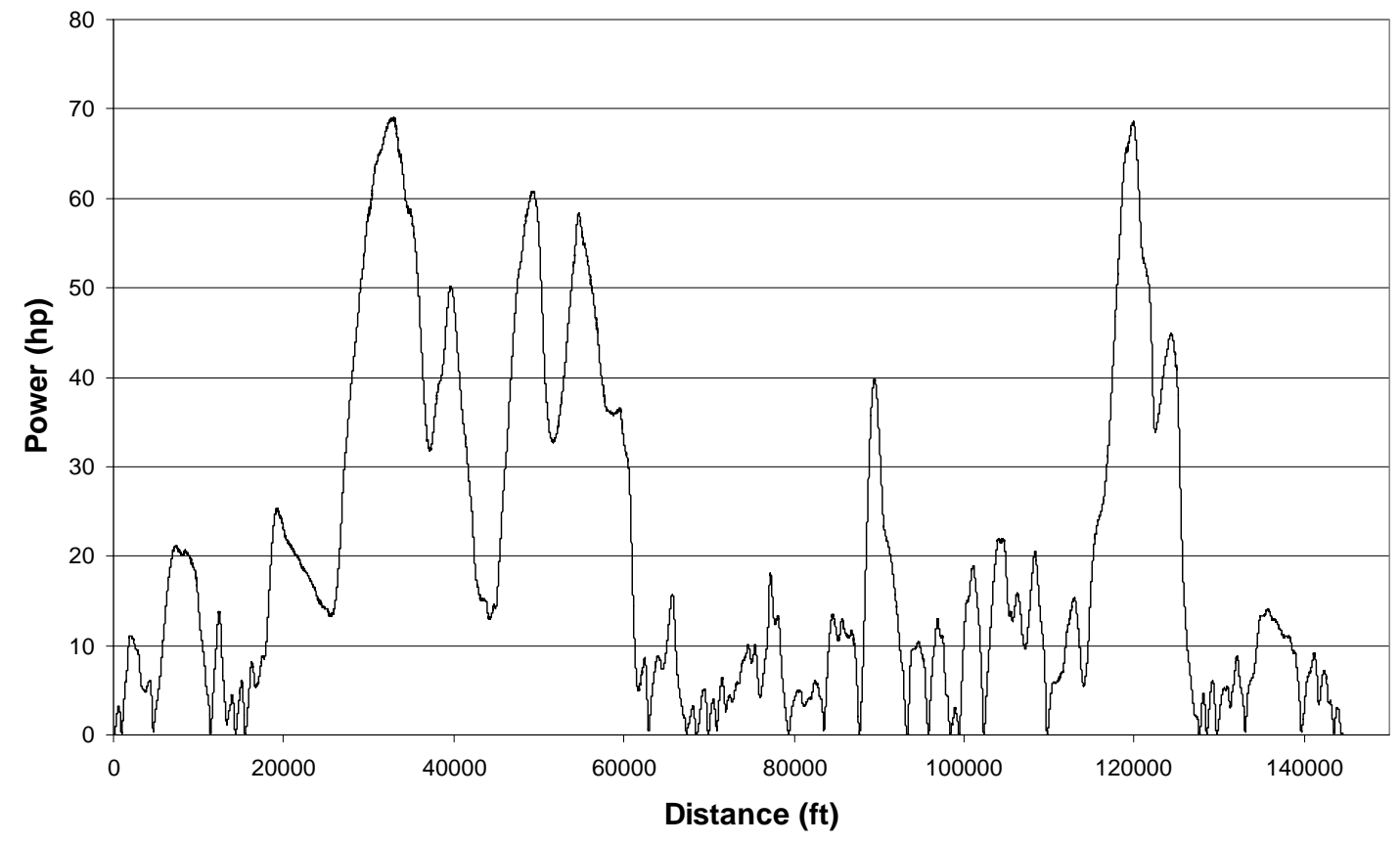

Figure 86: Test 2 / Full Load Aerodynamic Power

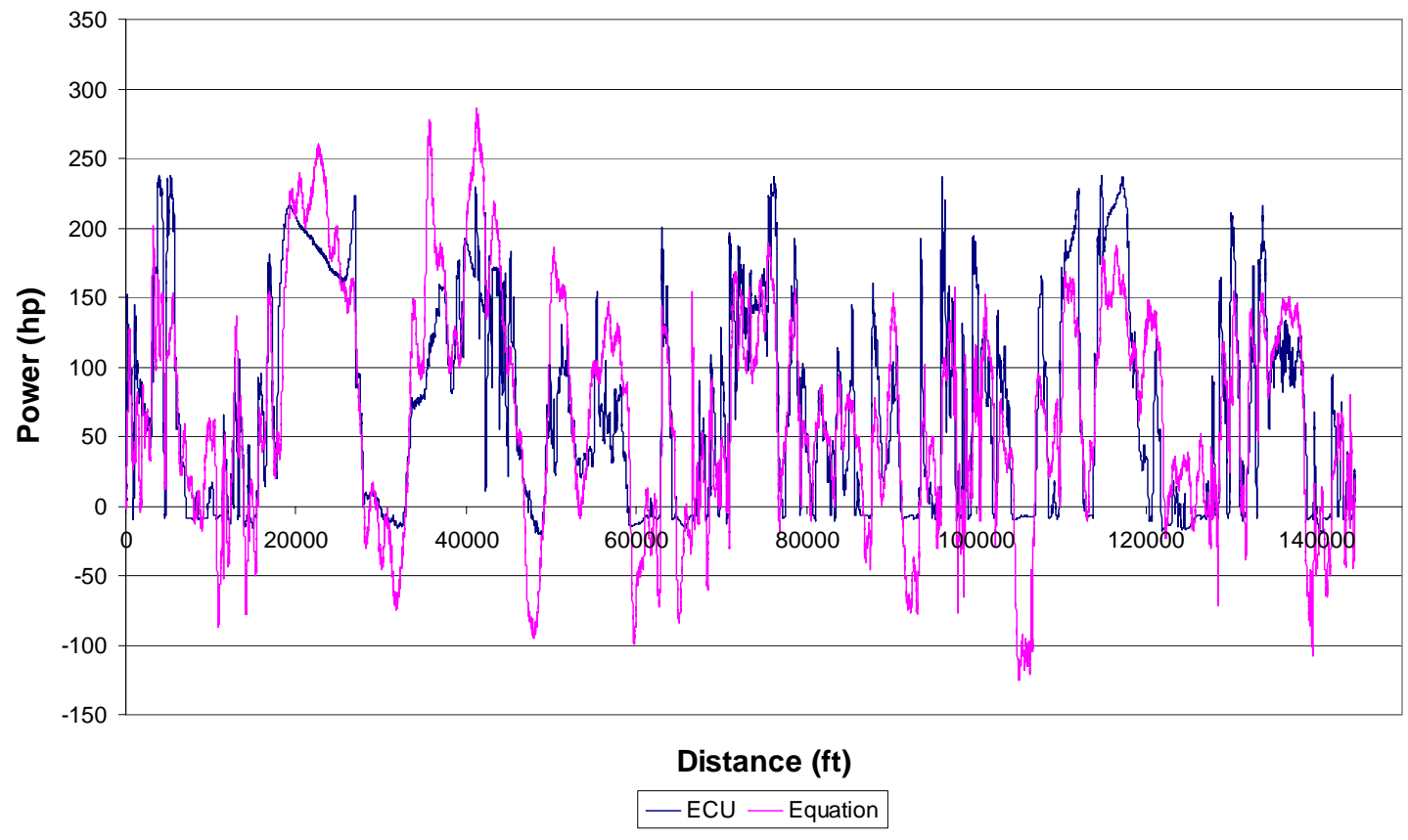

Figure 87: Test 2 / Full Load Power Comparison 


\subsubsection{Test 3 / Full Load}

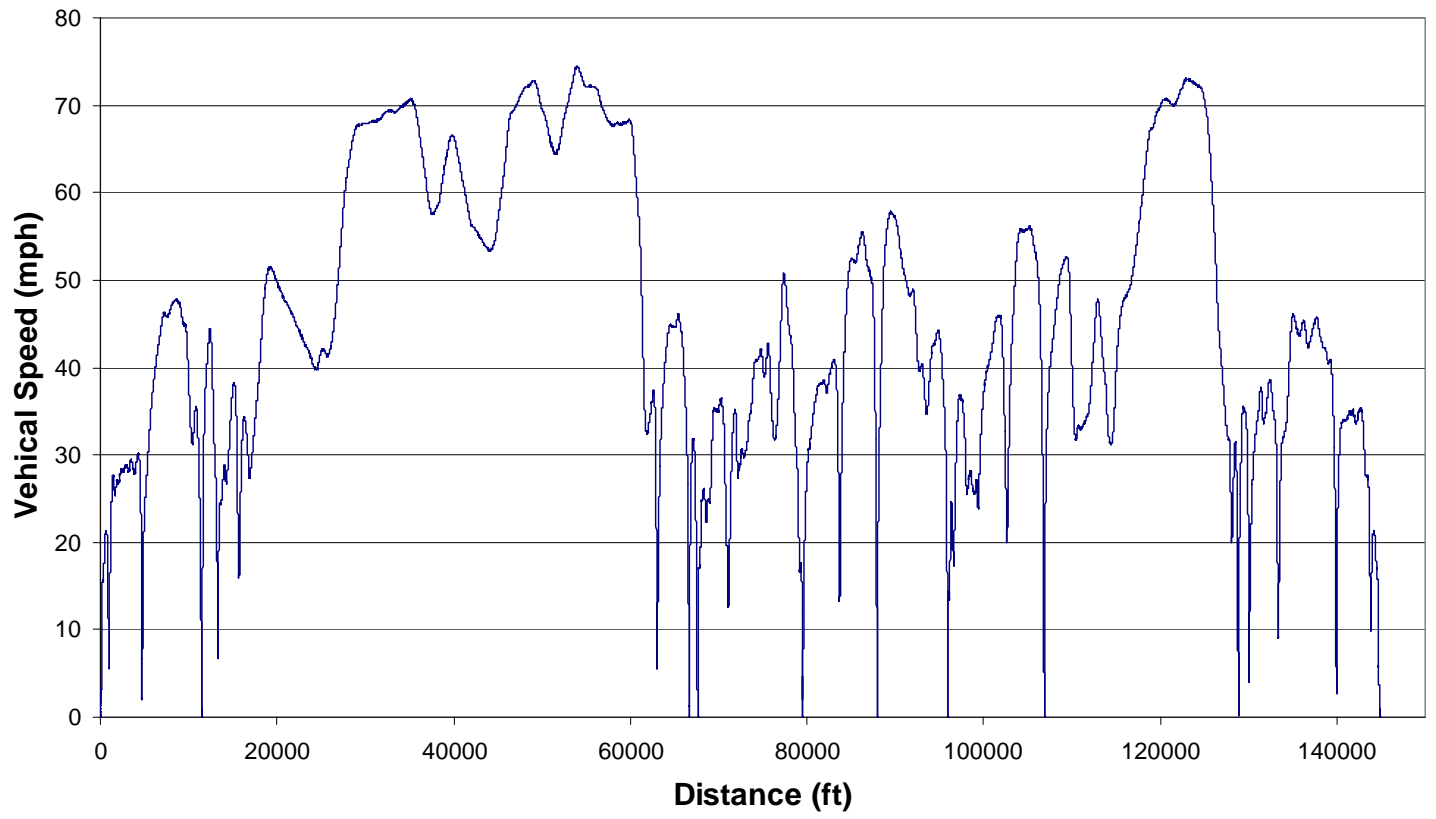

Figure 88: Test 2 / Full Load ECU Vehicle Speed

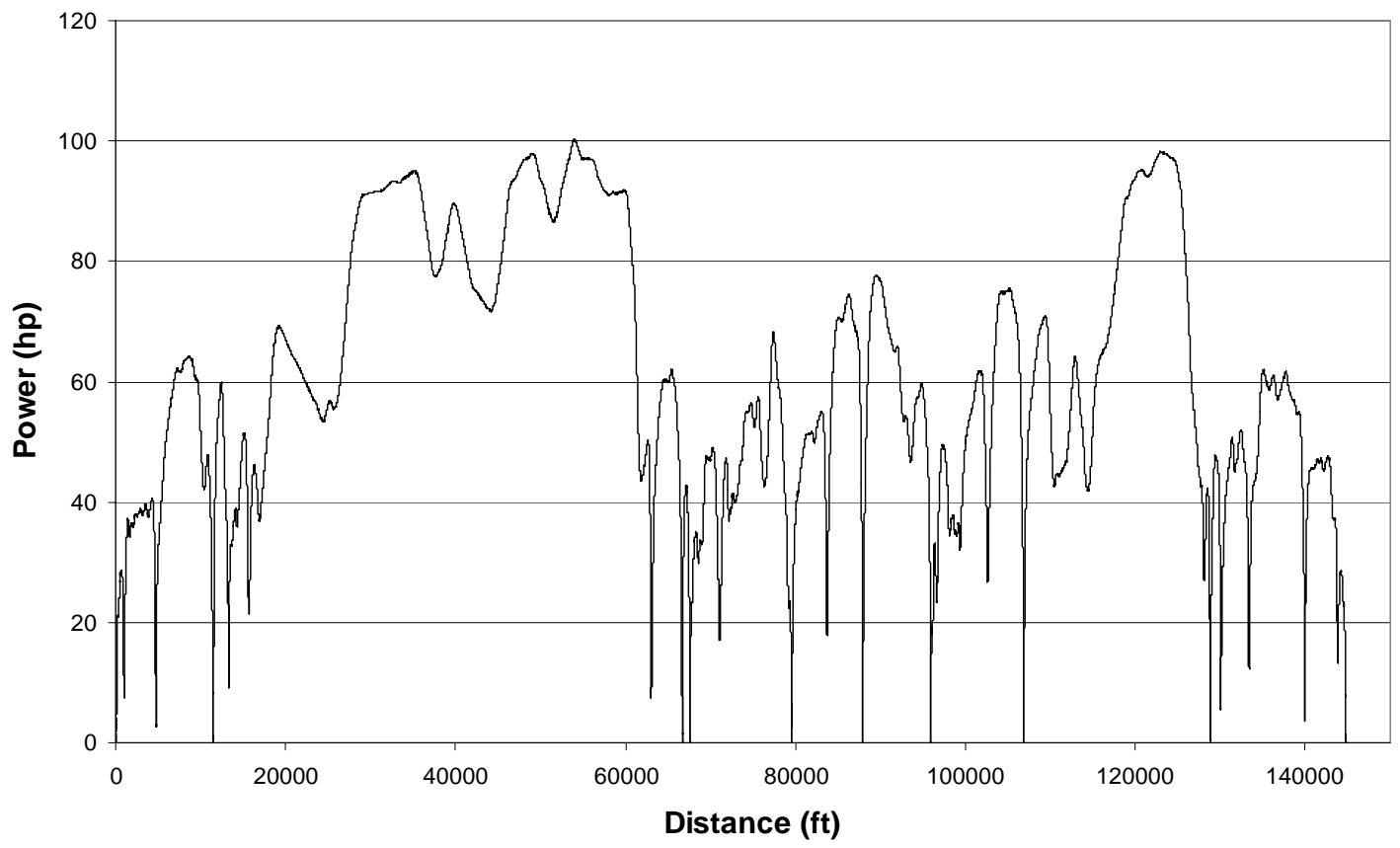

Figure 89: Test 3 / Full Load Rolling Power 


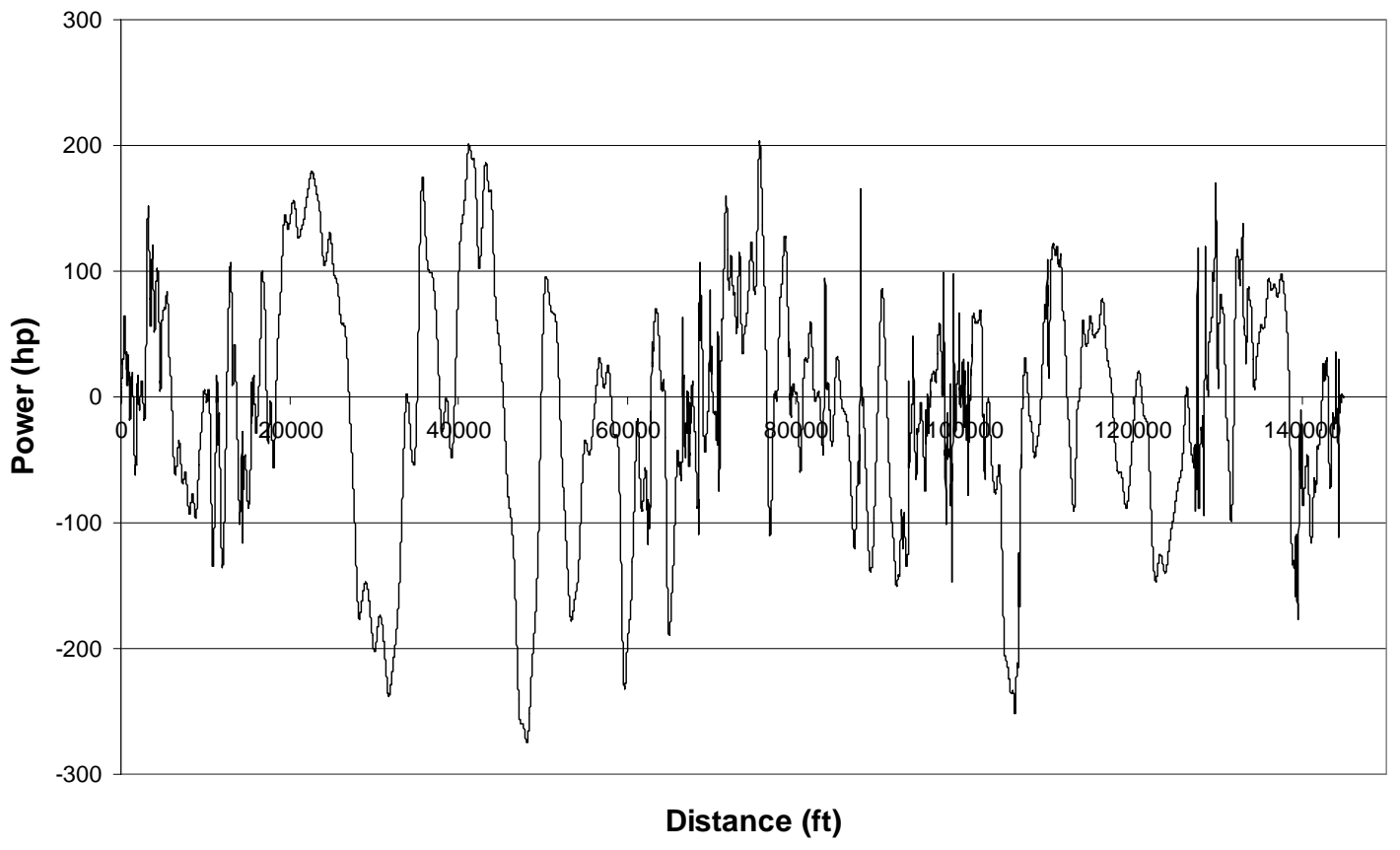

Figure 90: Test 3 / Full Load Climbing Power

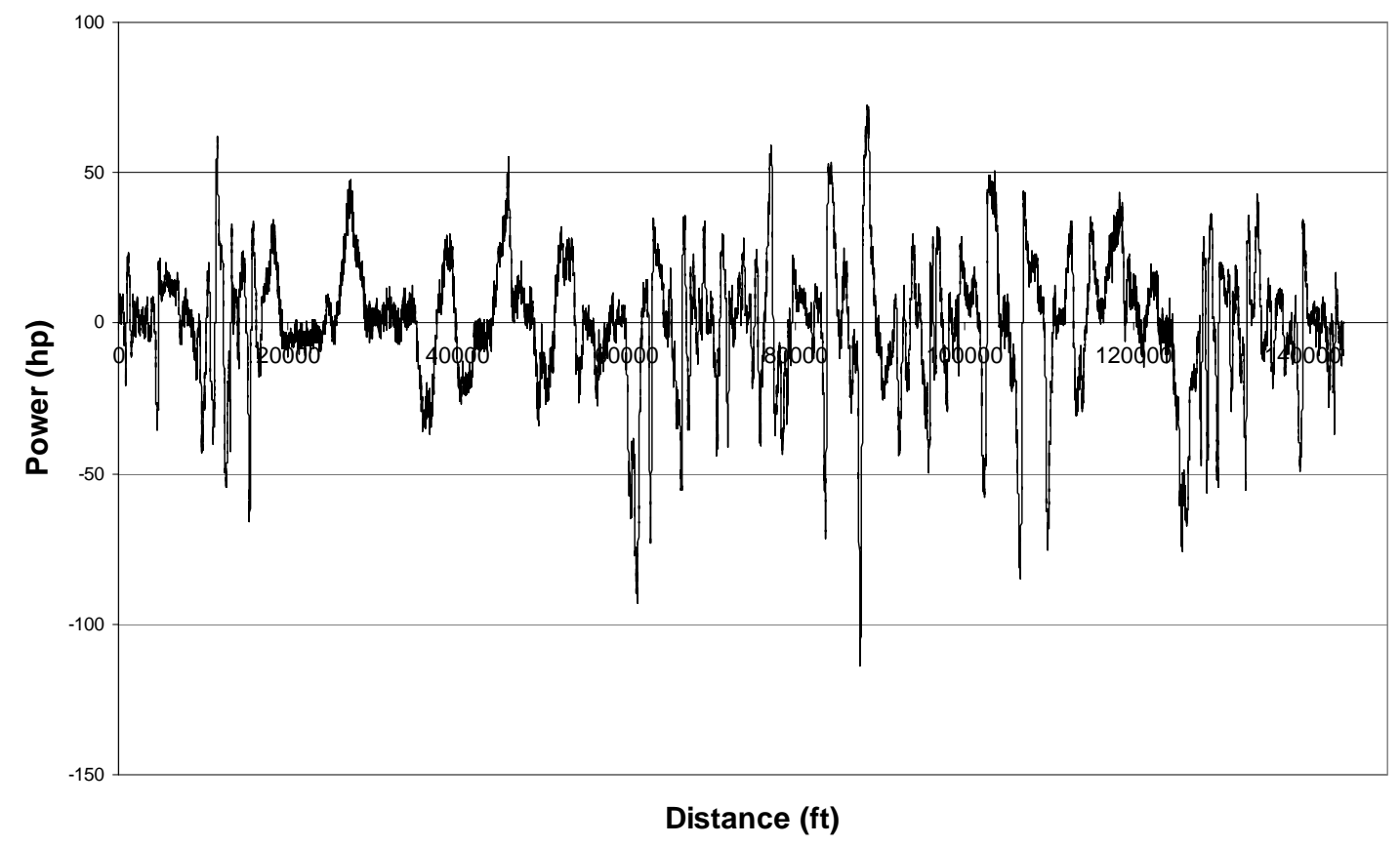

Figure 91: Test 3 / Full Load Acceleration Power 


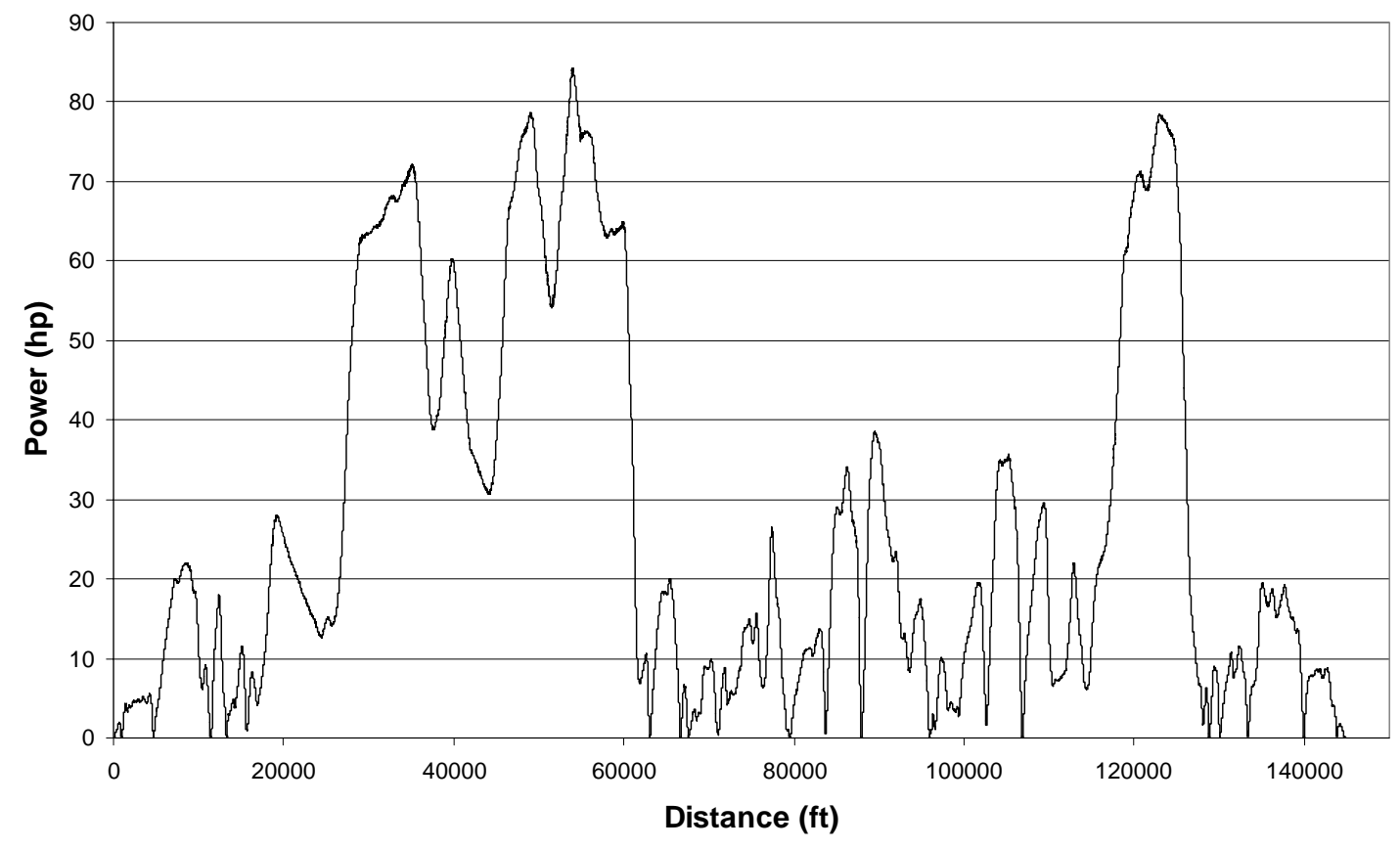

Figure 92: Test 3 / Full Load Aerodynamic Power

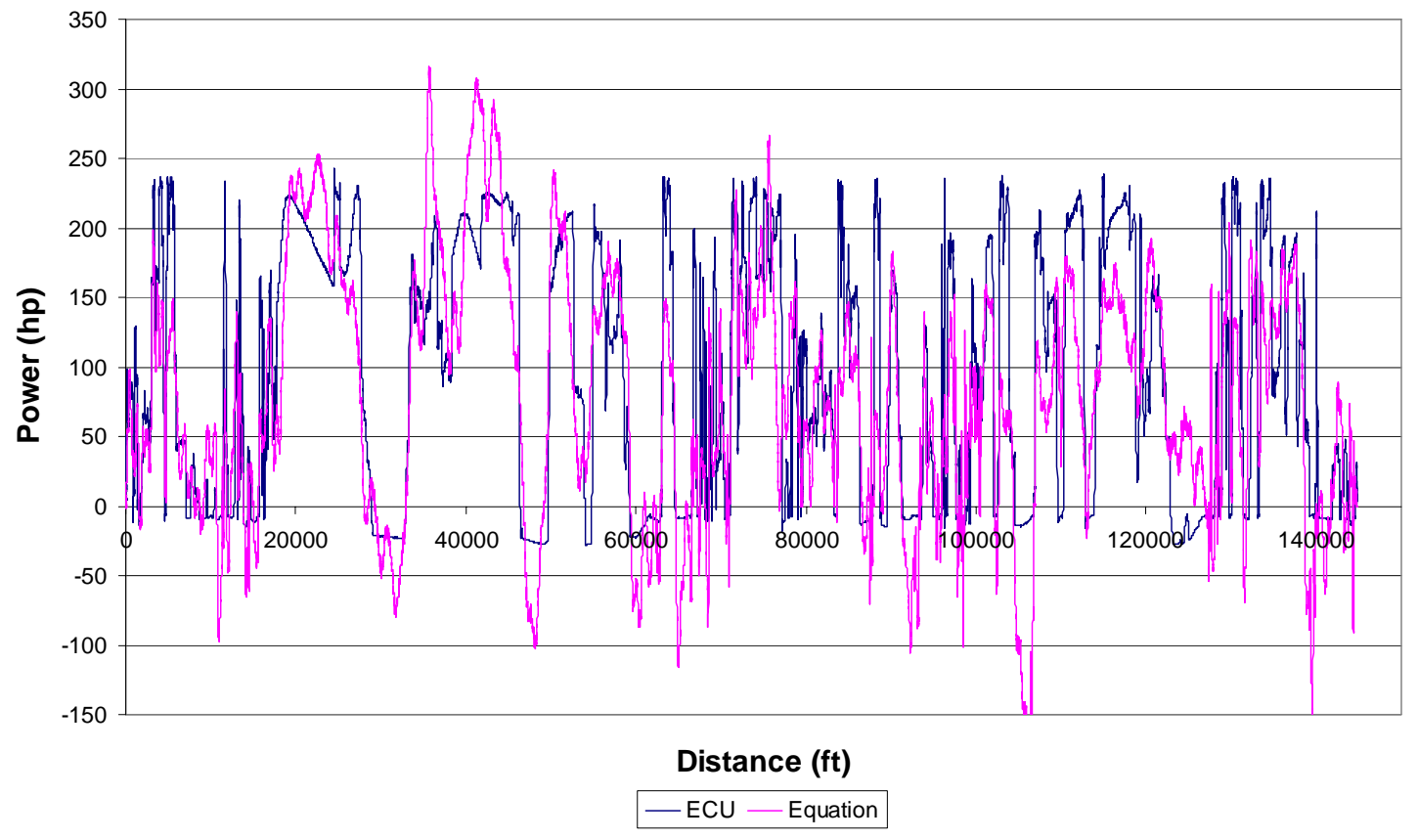

Figure 93: Test 3 / Full Load Power Comparison 


\subsection{4. $\quad$ Test 4 / Full Load}

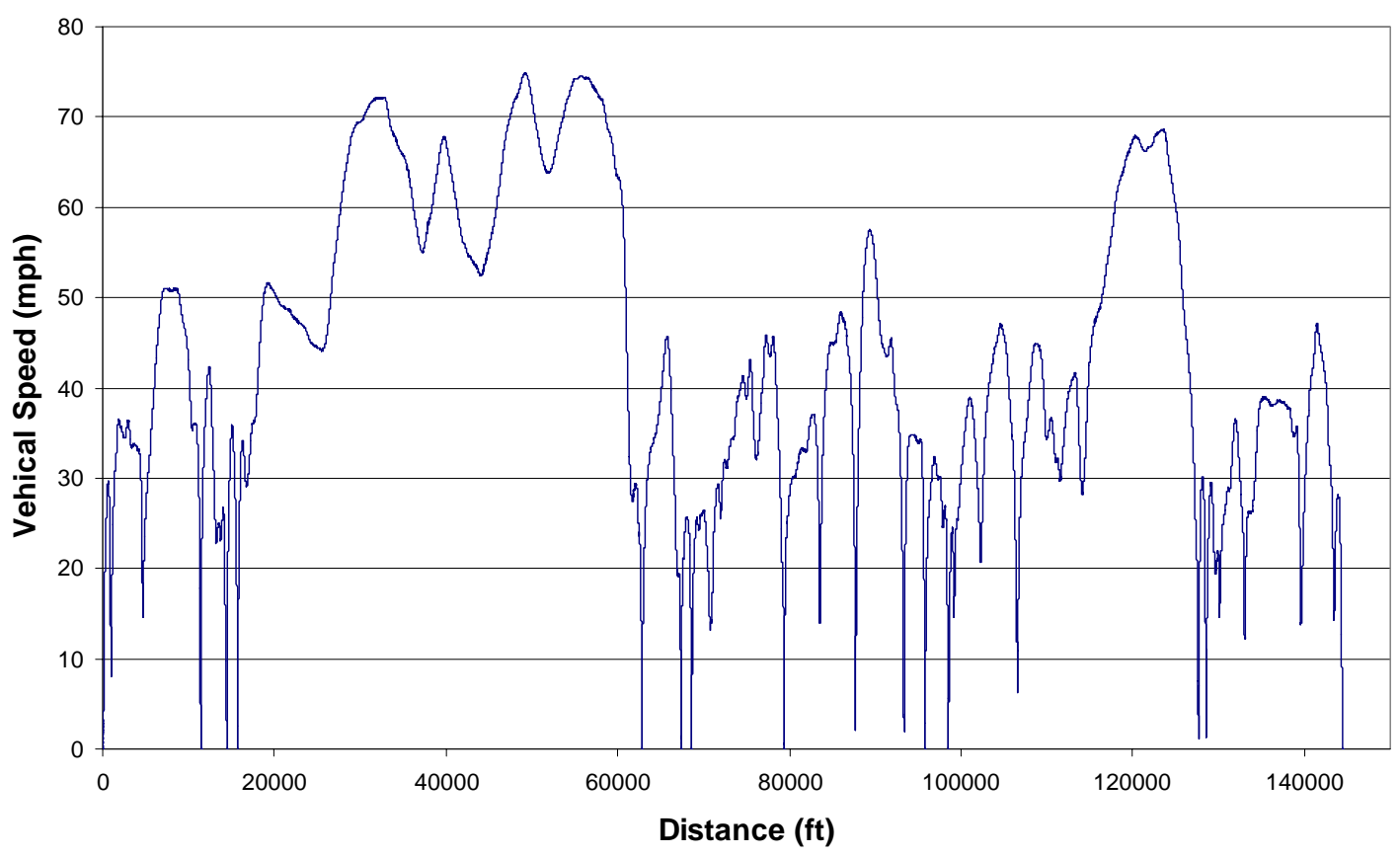

Figure 94: Test 4 / Full Load ECU Vehicle Speed

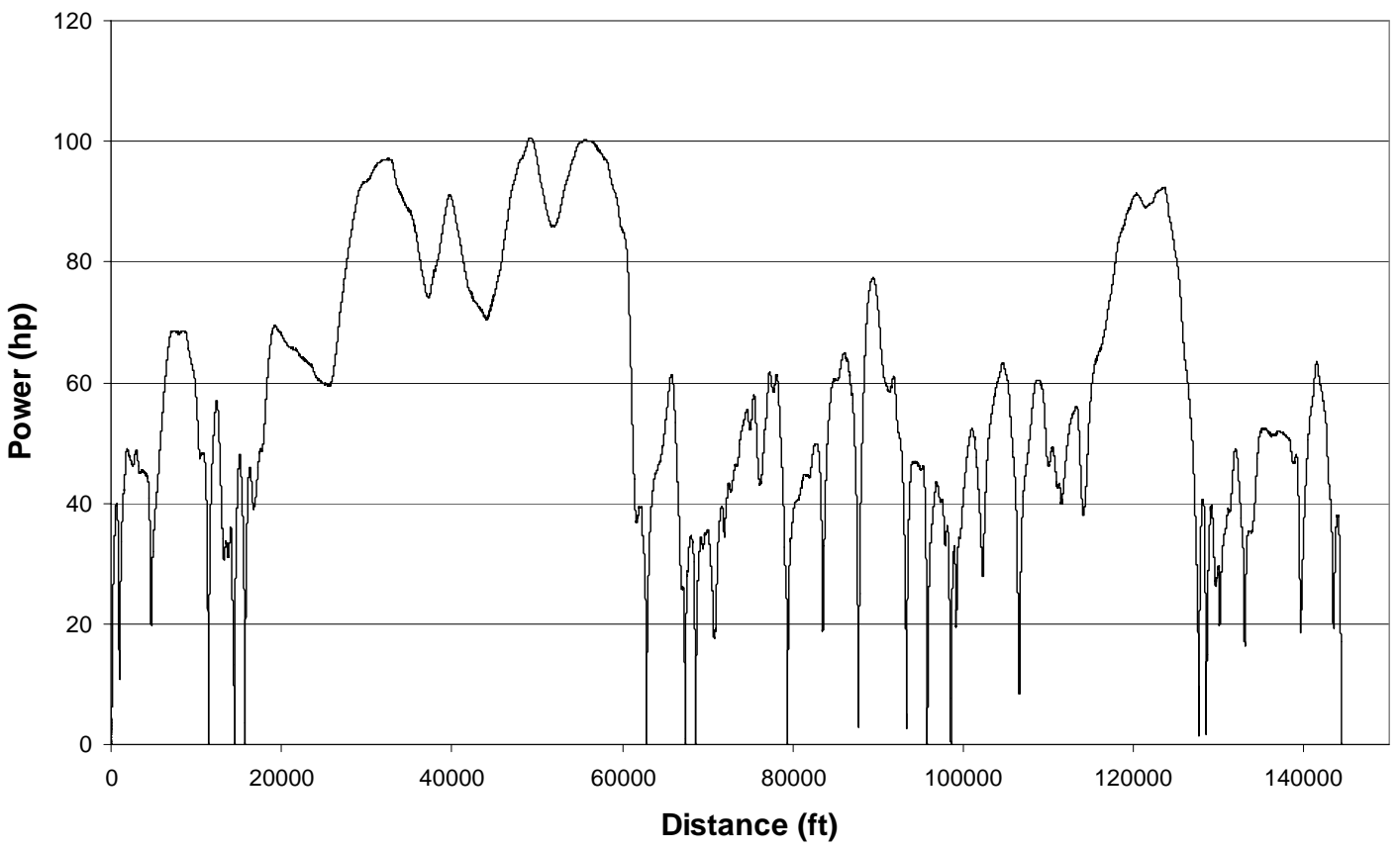

Figure 95: Test 4 / Full Load Rolling Power 


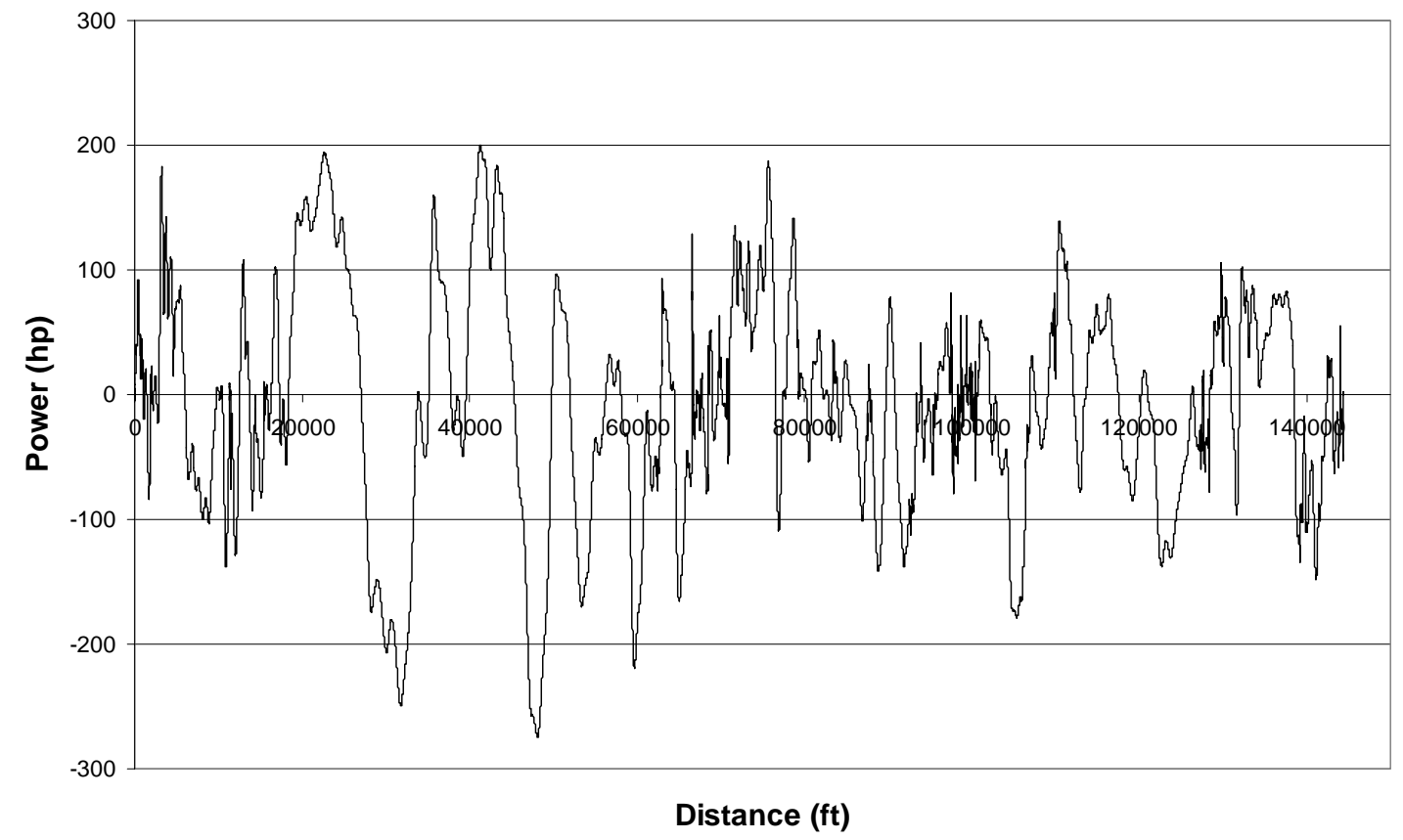

Figure 96: Test 4 / Full Load Climbing Power

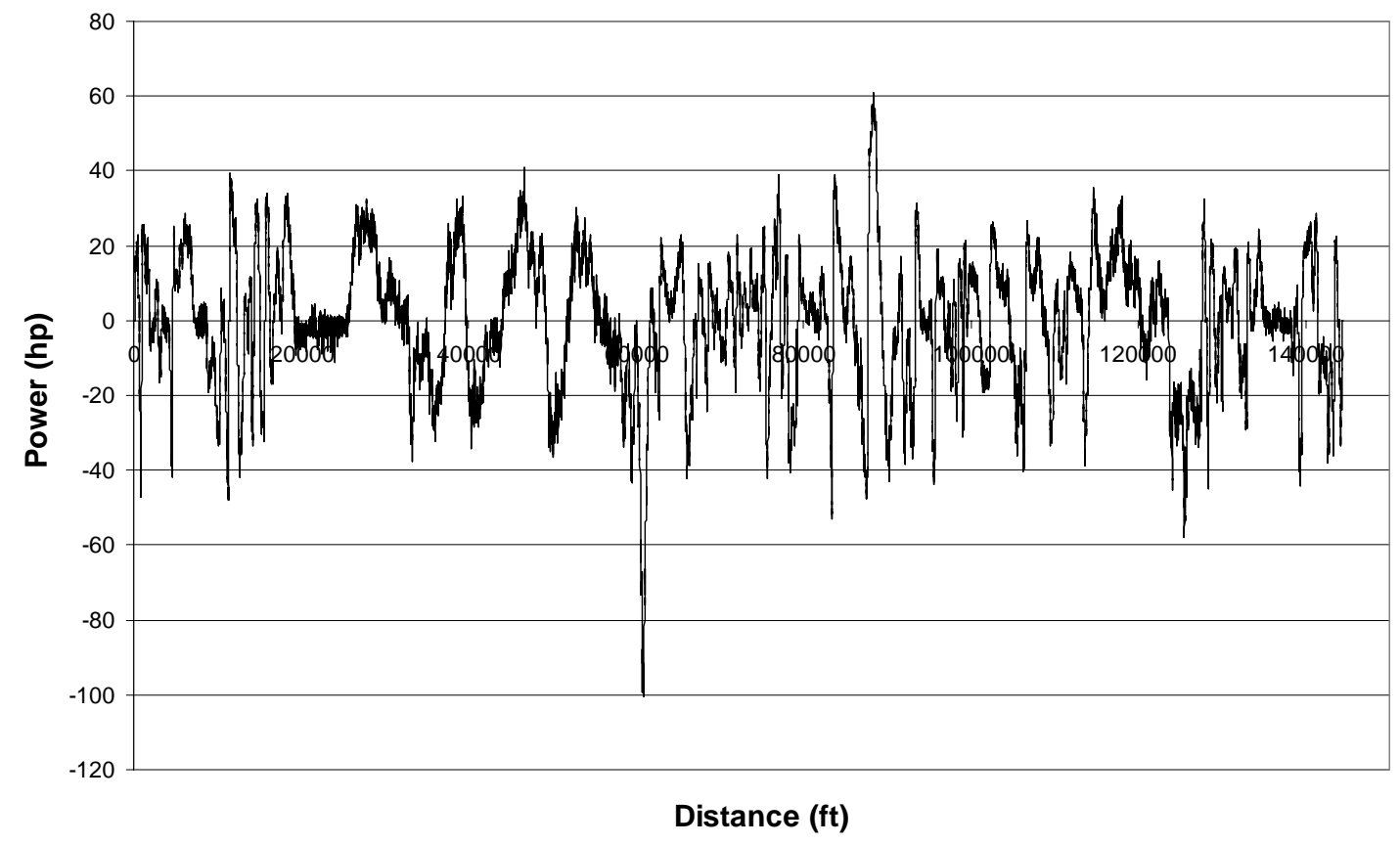

Figure 97: Test 4 / Full Load Acceleration Power 


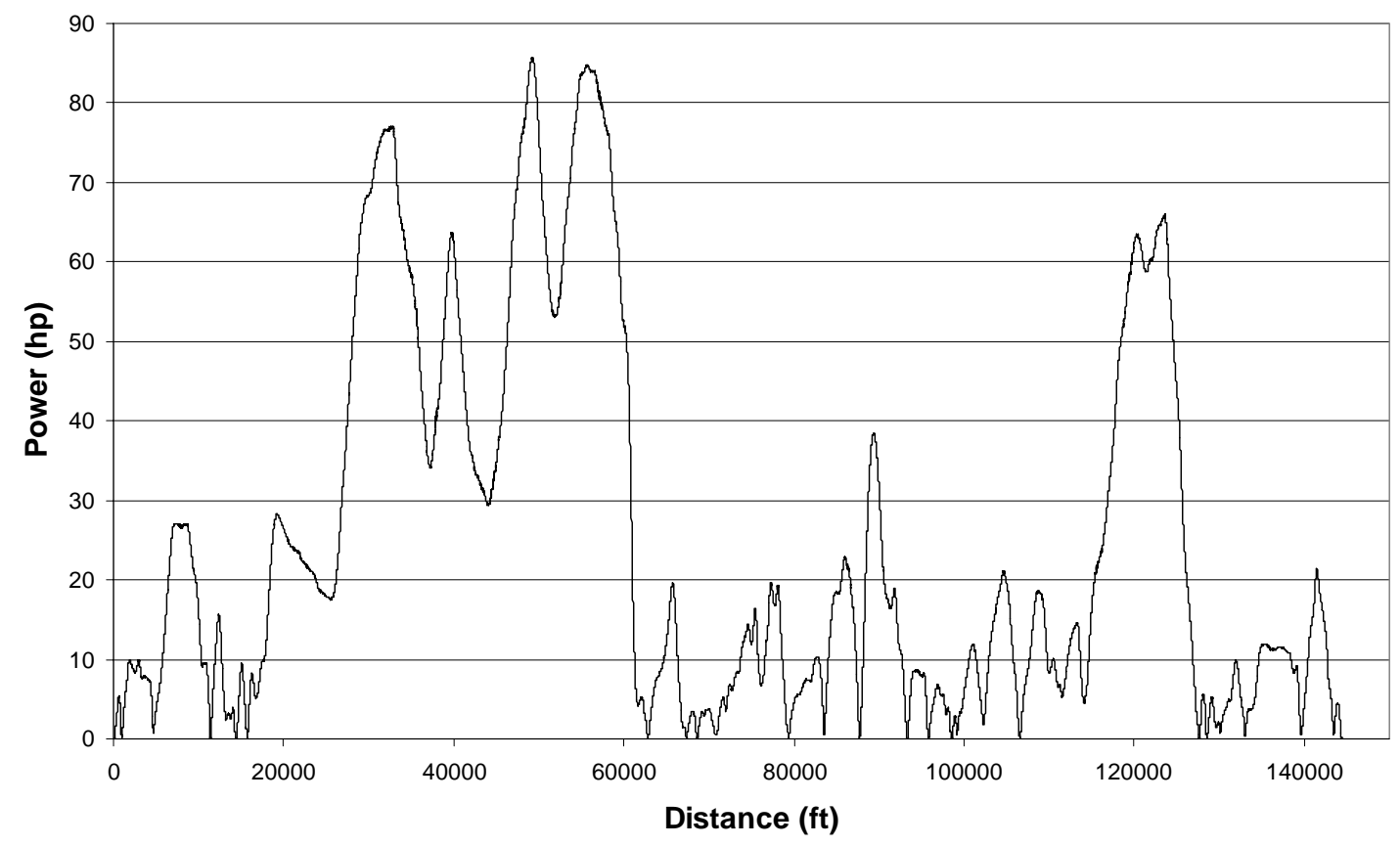

Figure 98: Test 4 / Full Load Aerodynamic Power

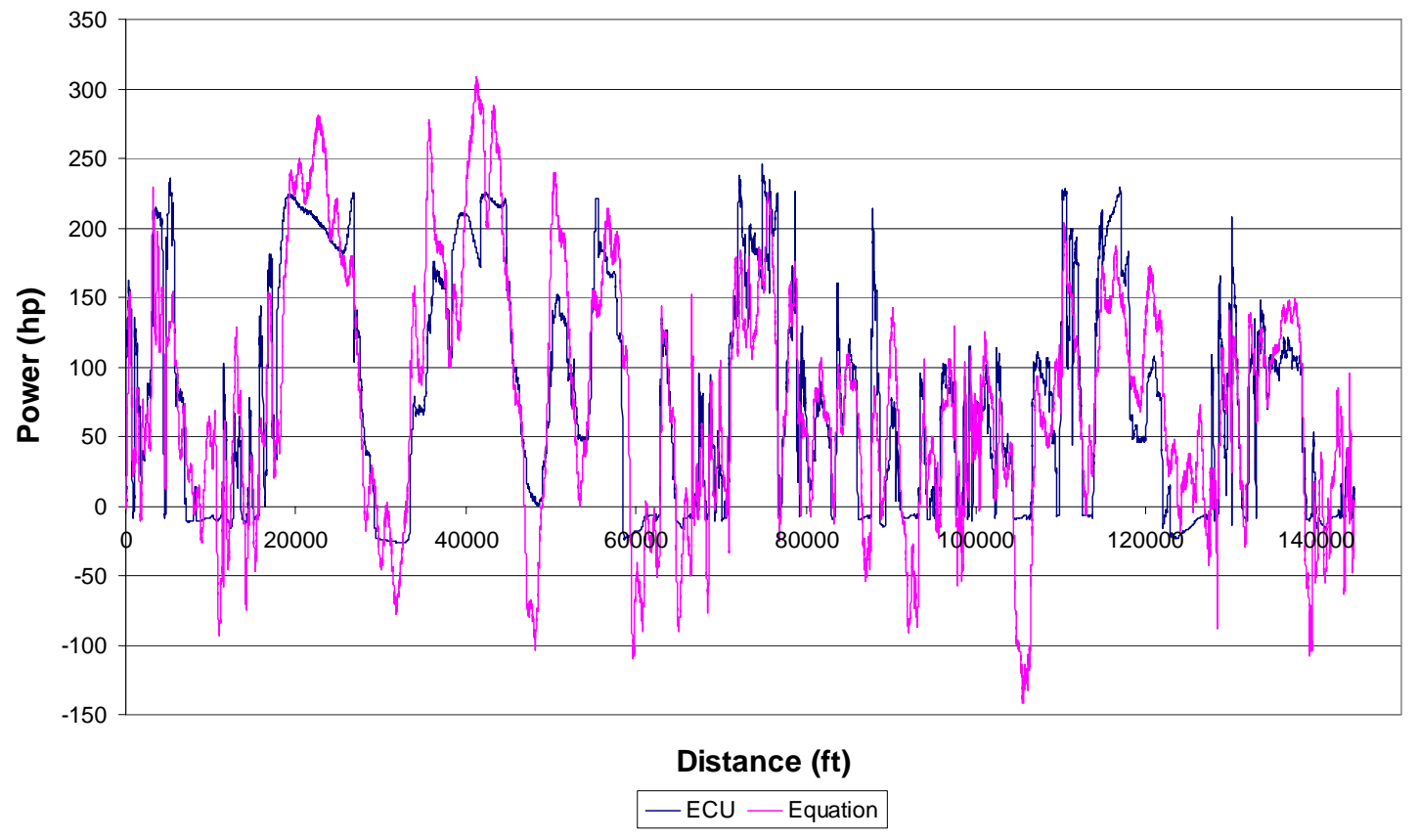

Figure 99: Test 4 / Full Load Power Comparison 


\subsubsection{Test 5 / Full Load}

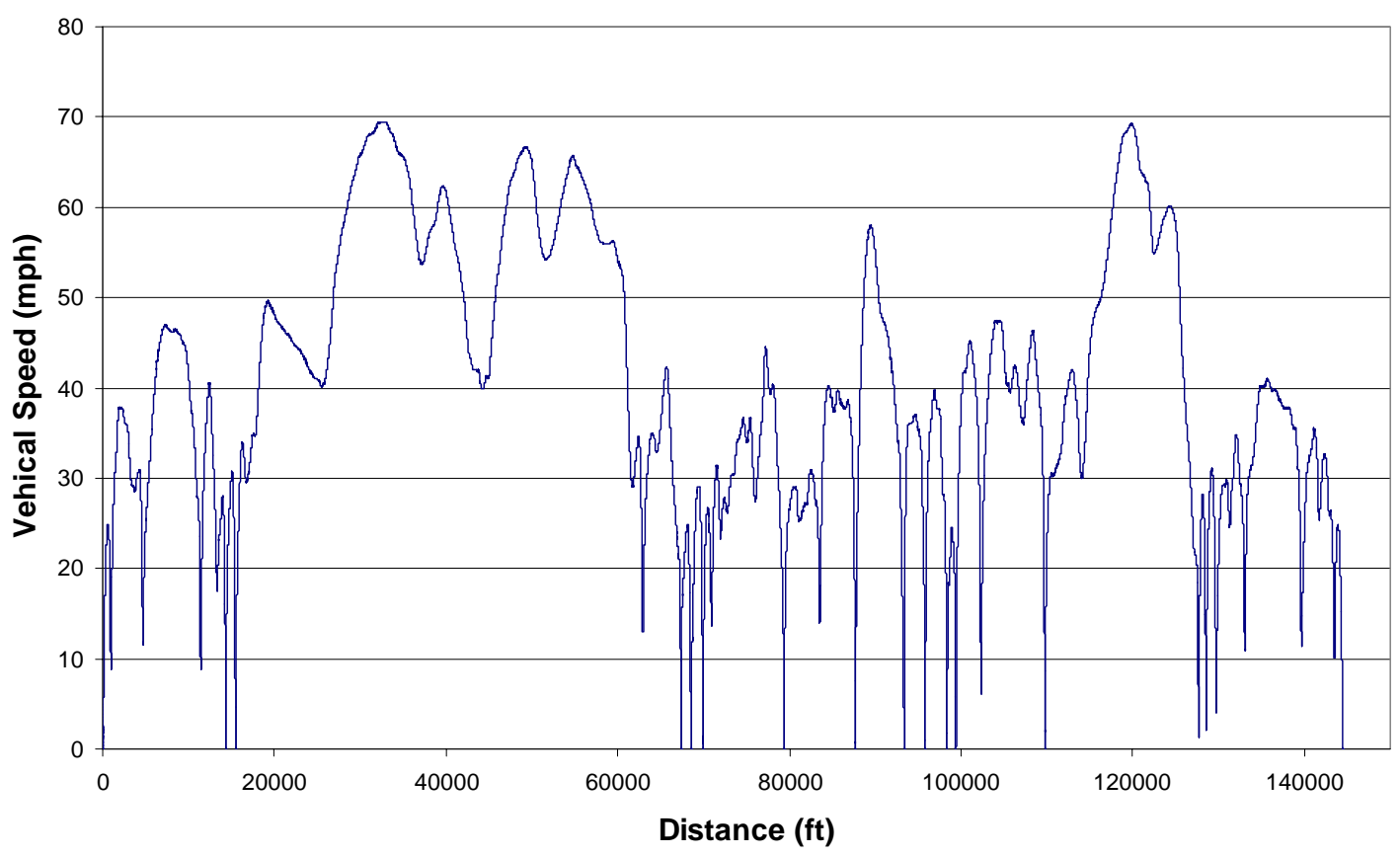

Figure 100: Test 5 / Full Load ECU Vehicle Speed

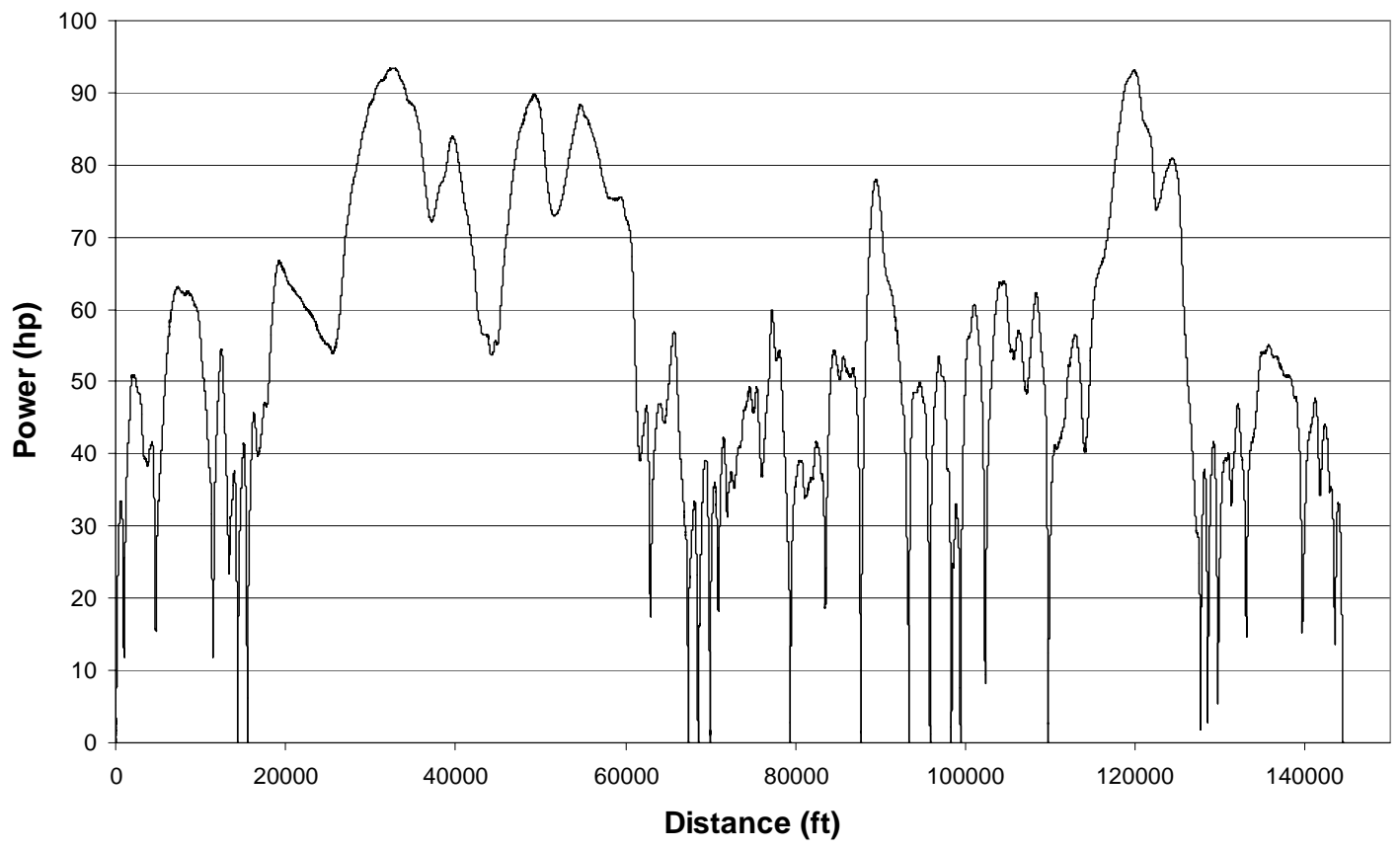

Figure 101: Test 5 / Full Load Rolling Power 


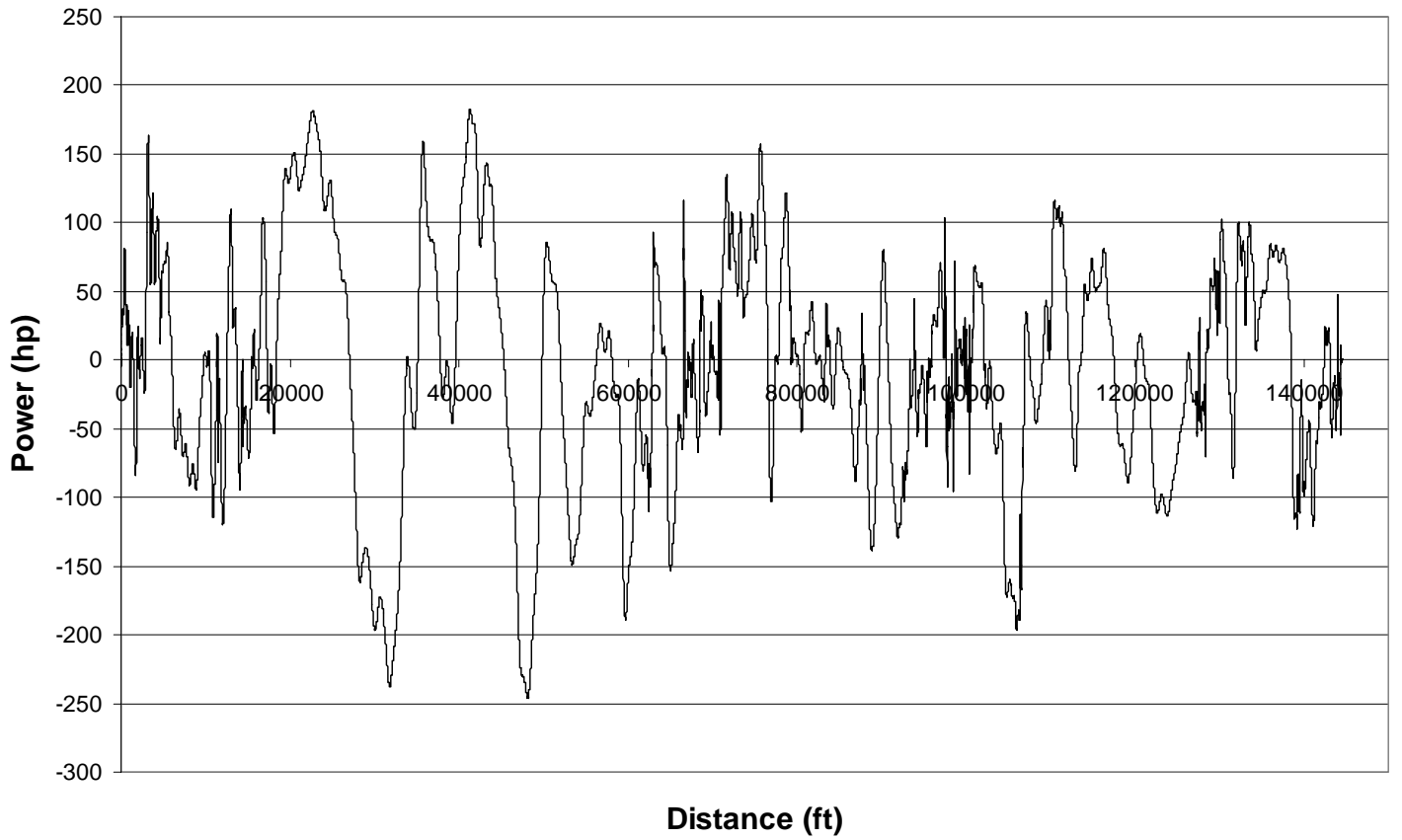

Figure 102: Test 5 / Full Load Climbing Power

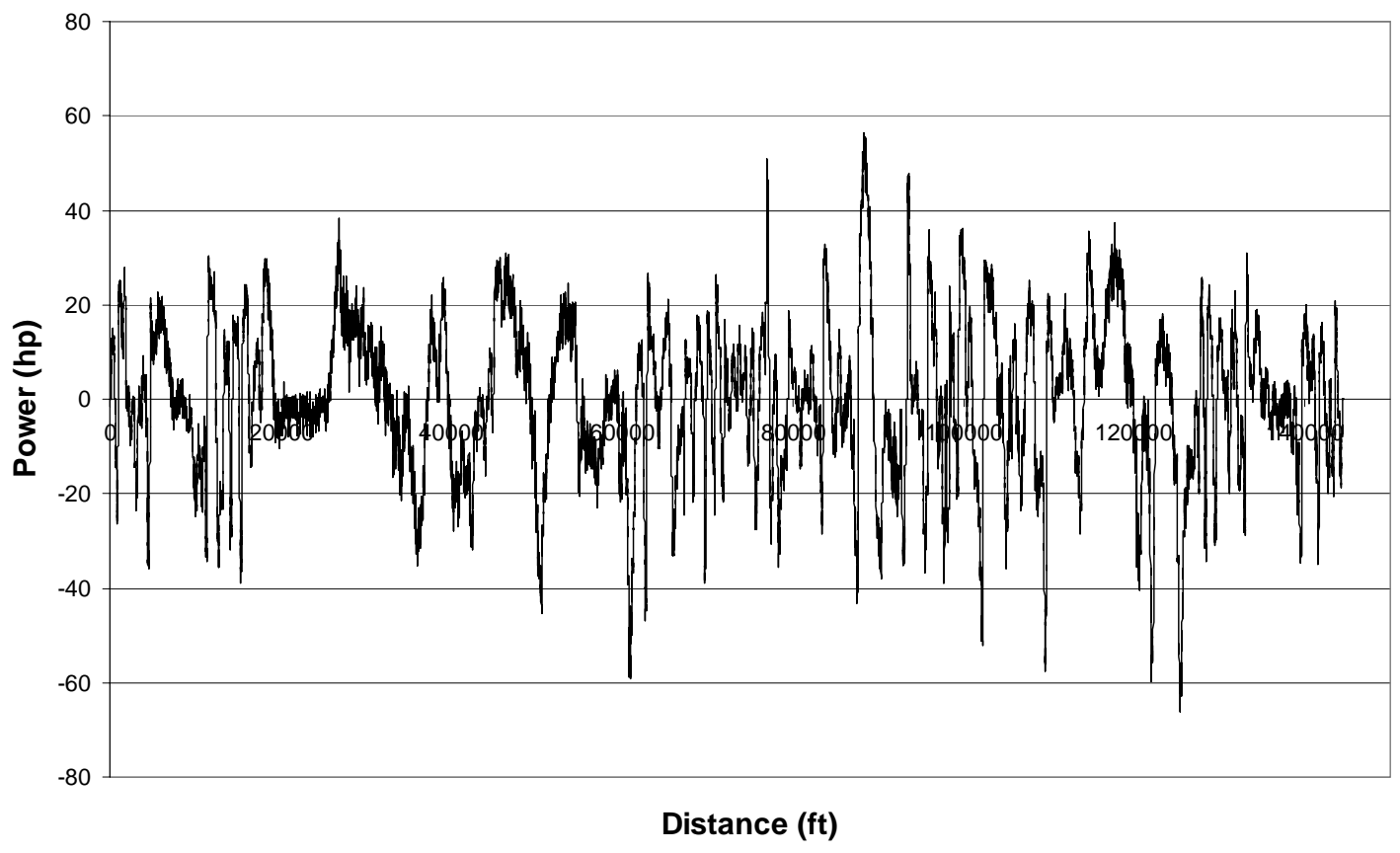

Figure 103: Test 5 / Full Load Acceleration Power 


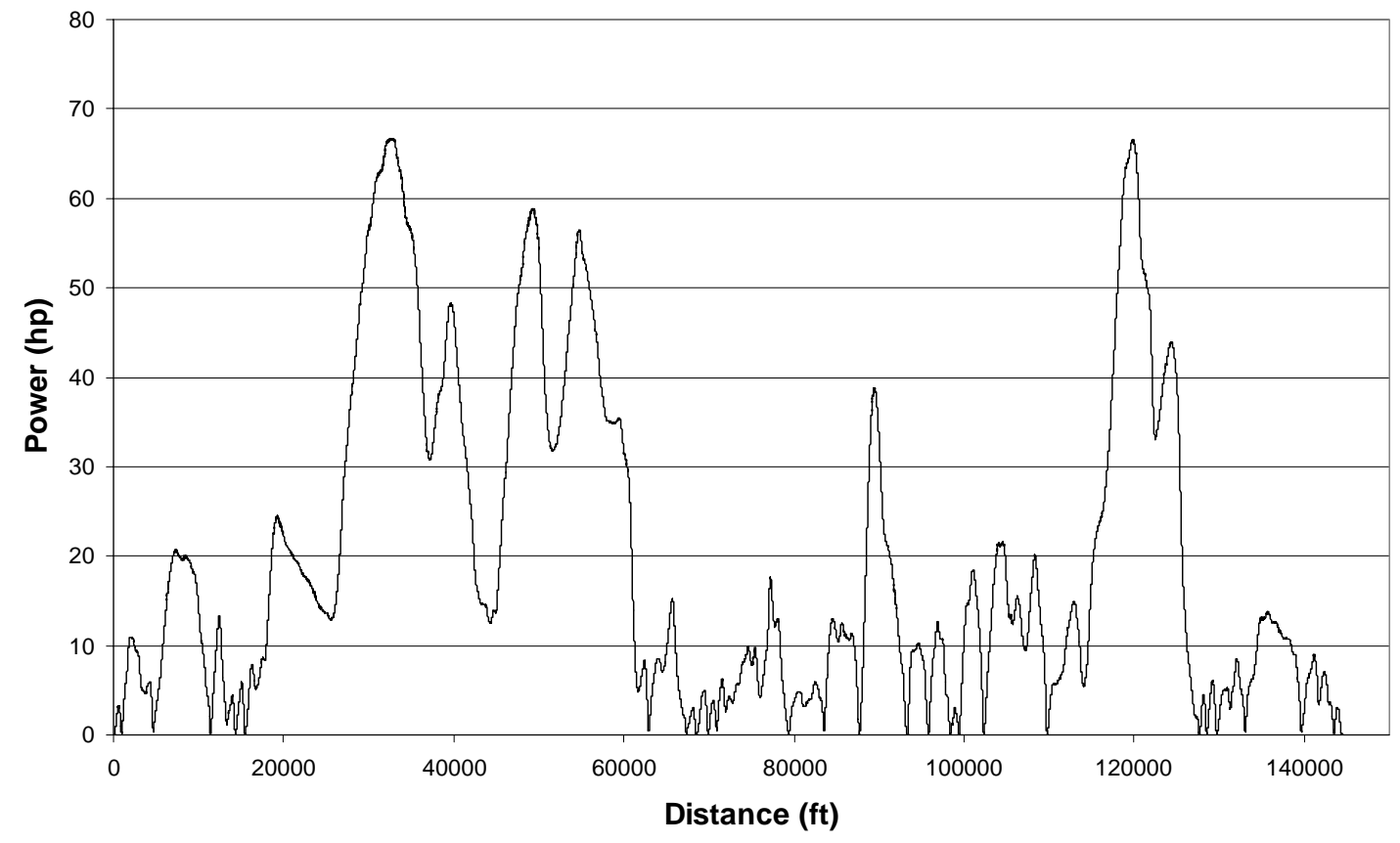

Figure 104: Test 5 / Full Load Aerodynamic Power

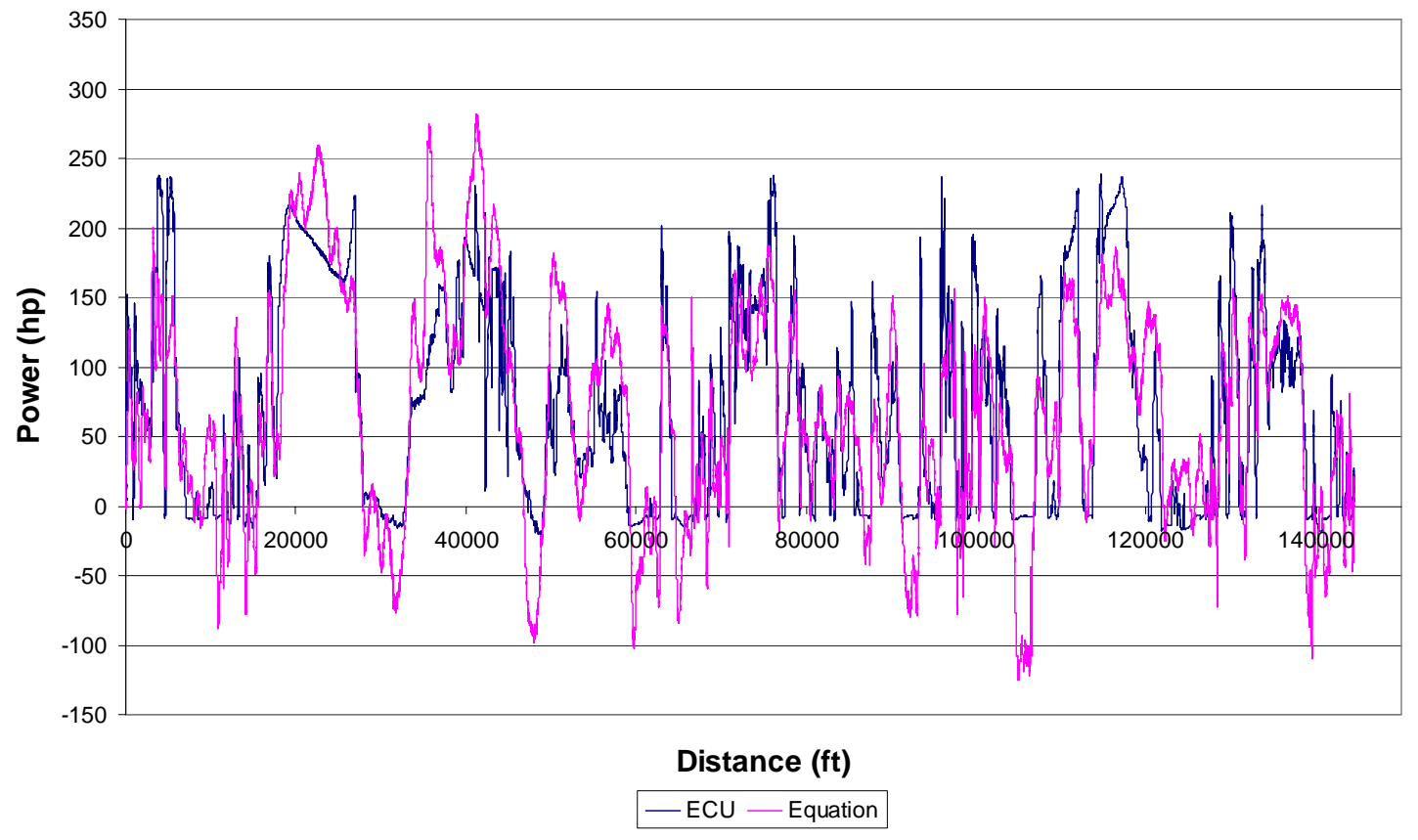

Figure 105: Test 5 / Full Load Power Comparison 


\subsubsection{Test 6 / Full Load}

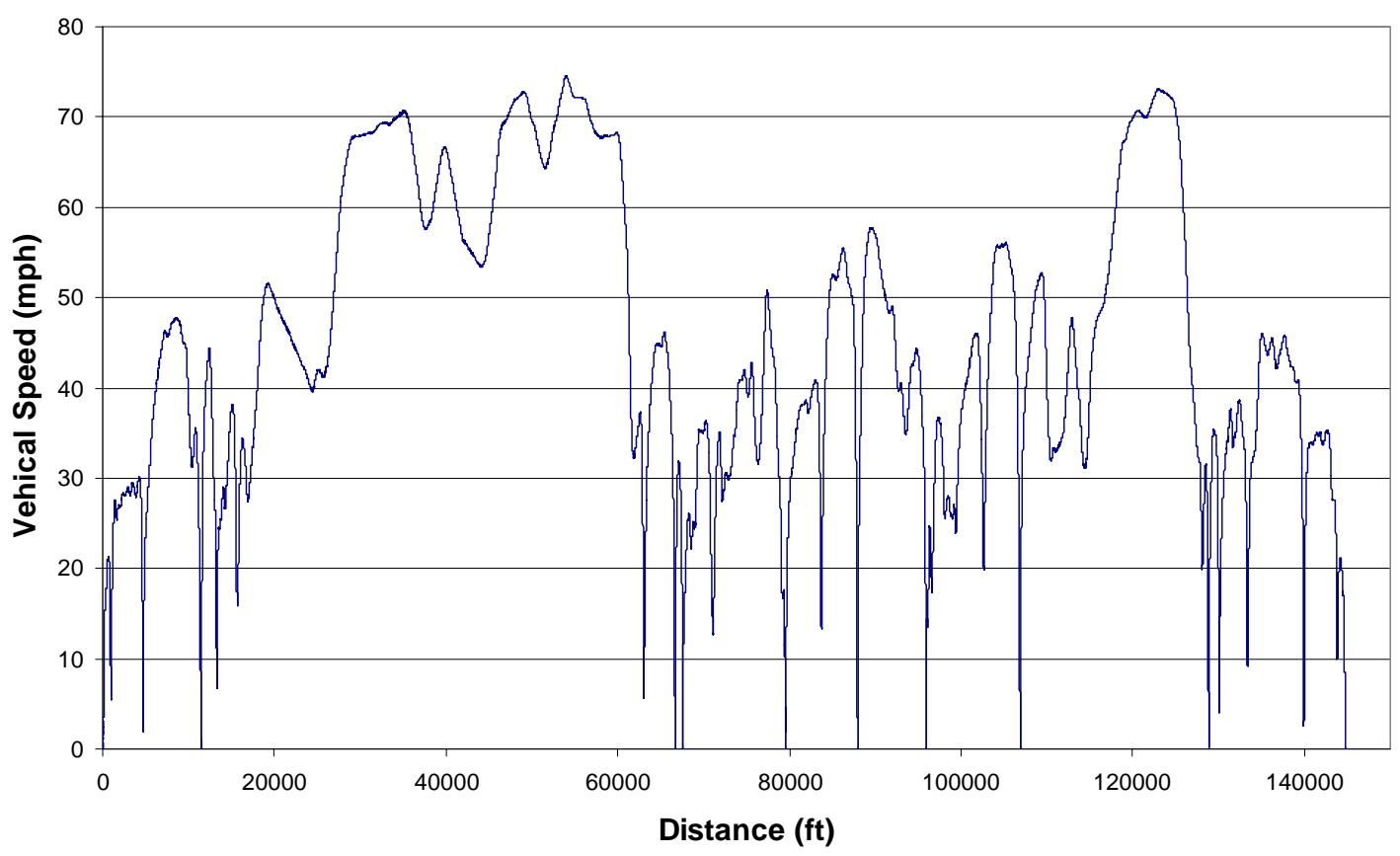

Figure 106: Test 6 / Full Load ECU Vehicle Speed

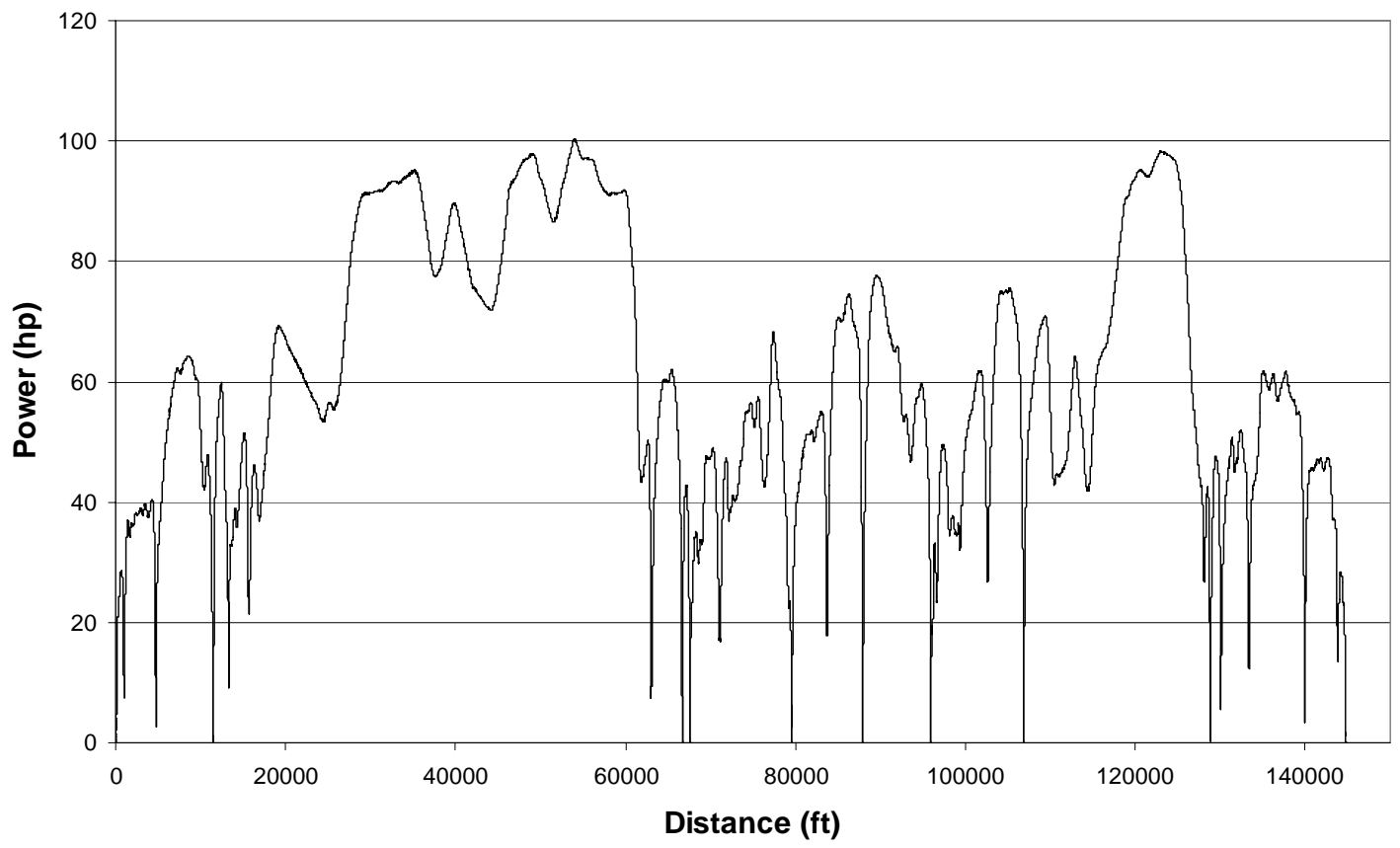

Figure 107: Test 6 / Full Load Rolling Power 


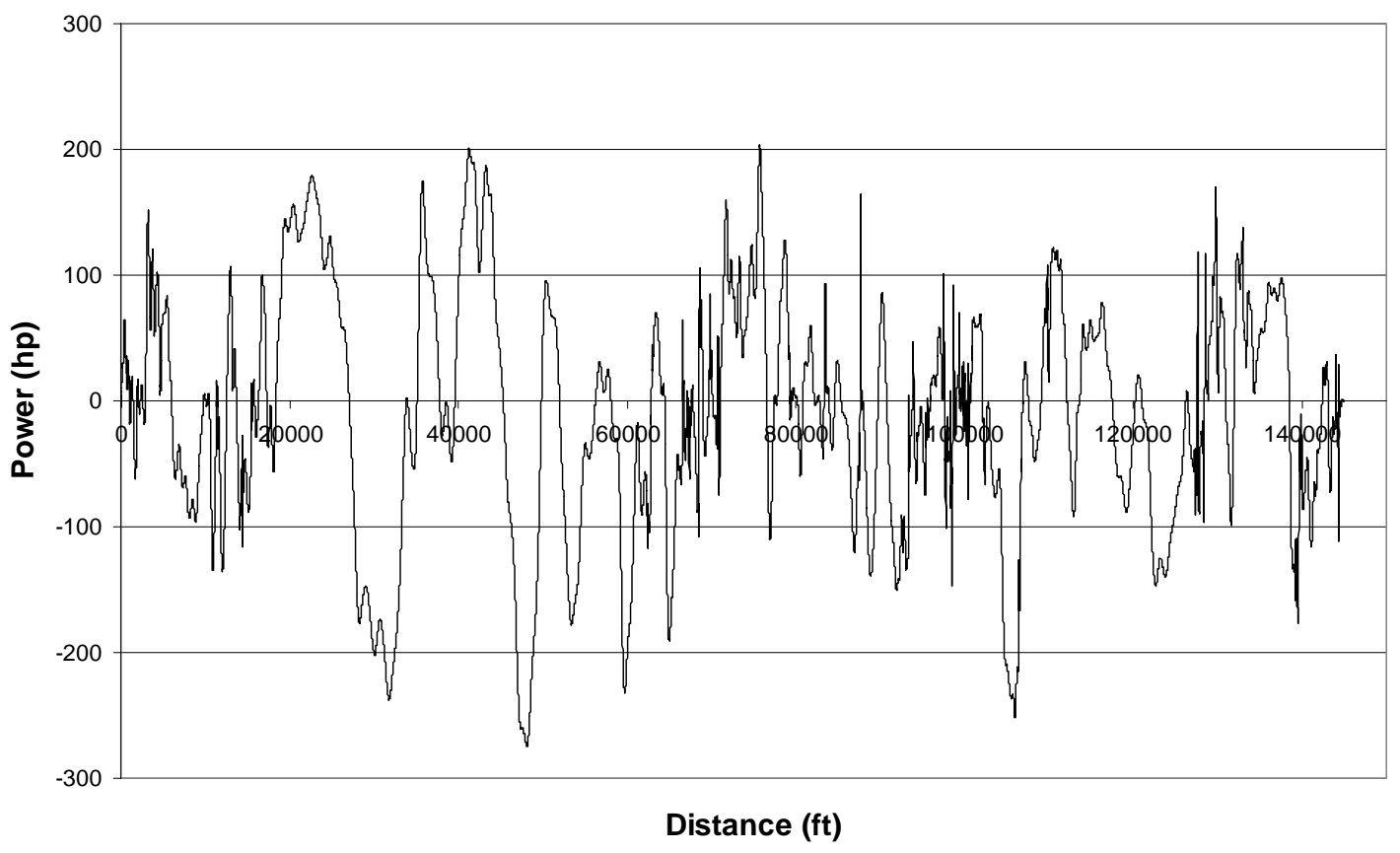

Figure 108: Test 6 / Full Load Climbing Power

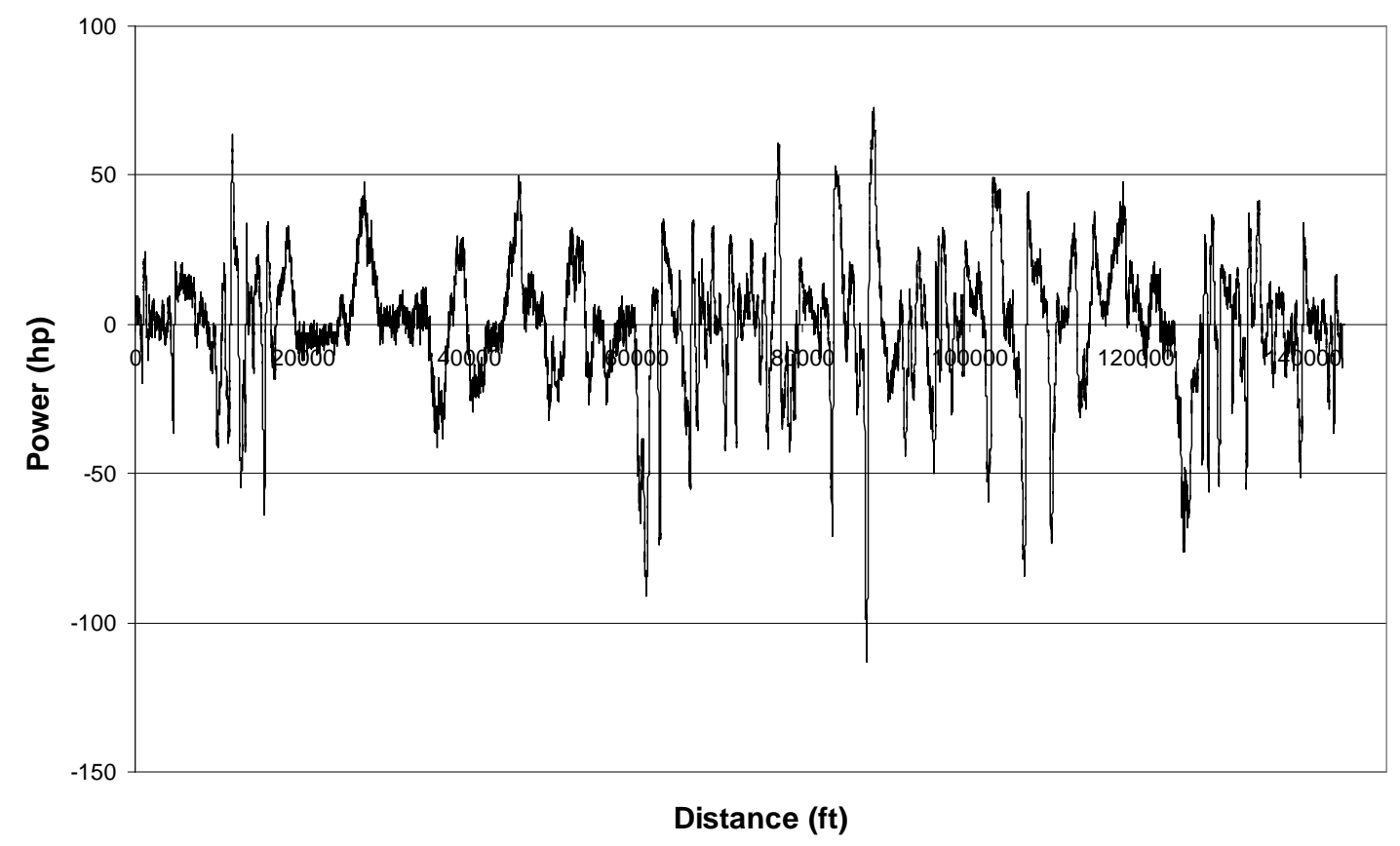

Figure 109: Test 6 / Full Load Acceleration Power 


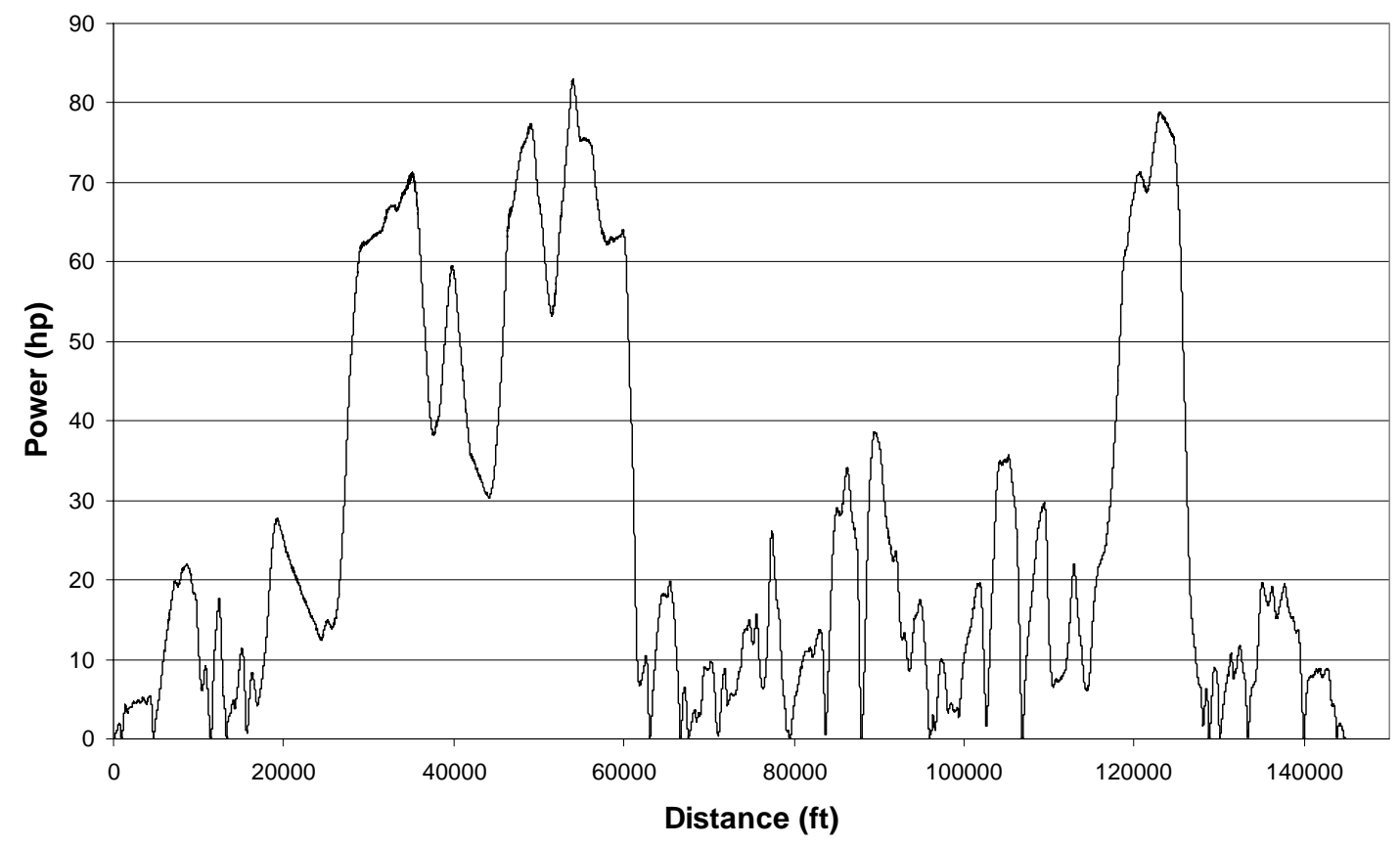

Figure 110: Test 6 / Full Load Aerodynamic Power

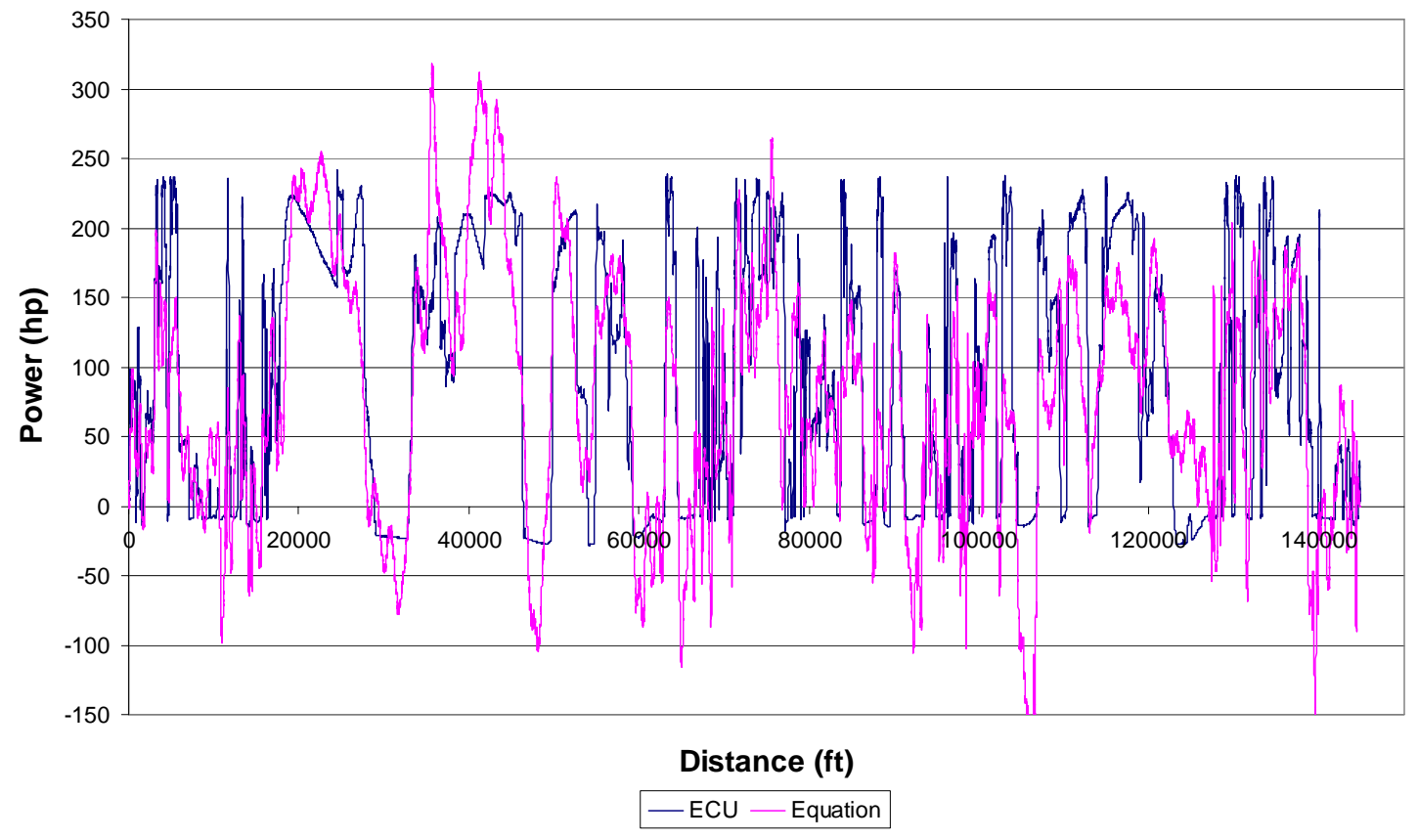

Figure 111: Test 6 / Full Load Power Comparison 